\title{
The transition from primary to secondary education
}

Citation for published version (APA):

van Rens, M. L. G. A. (2020). The transition from primary to secondary education: a study of the voices of children and teachers in the Netherlands. [Doctoral Thesis, Maastricht University]. Maastricht University. https://doi.org/10.26481/dis.20200904mr

Document status and date:

Published: 01/01/2020

DOI:

10.26481/dis.20200904mr

Document Version:

Publisher's PDF, also known as Version of record

\section{Please check the document version of this publication:}

- A submitted manuscript is the version of the article upon submission and before peer-review. There can be important differences between the submitted version and the official published version of record.

People interested in the research are advised to contact the author for the final version of the publication, or visit the DOI to the publisher's website.

- The final author version and the galley proof are versions of the publication after peer review.

- The final published version features the final layout of the paper including the volume, issue and page numbers.

Link to publication

\footnotetext{
General rights rights.

- You may freely distribute the URL identifying the publication in the public portal. please follow below link for the End User Agreement:

www.umlib.nl/taverne-license

Take down policy

If you believe that this document breaches copyright please contact us at:

repository@maastrichtuniversity.nl

providing details and we will investigate your claim.
}

Copyright and moral rights for the publications made accessible in the public portal are retained by the authors and/or other copyright owners and it is a condition of accessing publications that users recognise and abide by the legal requirements associated with these

- Users may download and print one copy of any publication from the public portal for the purpose of private study or research.

- You may not further distribute the material or use it for any profit-making activity or commercial gain

If the publication is distributed under the terms of Article $25 \mathrm{fa}$ of the Dutch Copyright Act, indicated by the "Taverne" license above, 
The transition from primary to secondary education:

A study of the voices of children and teachers in the Netherlands

Marlau van Rens 
(C) Marlau van Rens, Maastricht 2020.

All rights reserved. No part of this publication may be reproduced, stored or transmitted in any form or by any means without the prior written permission of the author.

ISBN: 978-90-830451-1-5

Cover design: Raadhuis voor creatieve communicatie, Alkmaar

This book is no $\mathbf{X V}$ of the TIER Research Series, a PhD thesis series published by TIER. 
The transition from primary to secondary education:

A study of the voices of children and teachers in the Netherlands

\author{
Dissertation \\ to obtain the degree of doctor \\ at Maastricht University \\ on the authority of the Rector Magnificus, \\ Prof. Dr. Rianne M. Letschert \\ in accordance with the decision of the Board of Deans \\ to be defended in public \\ on Friday 4 September 2020 at 10.00 hours \\ by \\ Maria Laura Gerarda Adèla van Rens
}




\section{Promotors}

Prof. dr. Wim Groot

Prof. dr. Henriëtte Maassen van den Brink (Universiteit van Amsterdam)

\section{Co- Promotor}

Dr. Carla Haelermans

\section{Assessment Committee}

Prof. dr. Kristof De Witte (Chair)

Prof. dr. Anique de Bruin

Prof. dr. Sjoerd Karsten (Universiteit van Amsterdam)

Prof. dr. Greetje van der Werf (Rijksuniversiteit Groningen)

Prof. dr. Inge de Wolf 


\section{List of abbreviations and frequently used terms}

CBS Centraal Bureau voor de Statistiek

An independent government agency charged with providing statistical information about Dutch society.

GT Grounded Theory

A systematic methodology in the social sciences involving the construction of theories through methodical gathering and analysis of data.

ITCT The Impending Transition to Secondary Perceived as Challenge and Threat

Questionnaire (Sirsch, 2003) to measure the challenges and threats of the transition in both school and social contexts.

ITS Instituut voor Toegepaste Sociologie

Institute of Applied Sociology

LAKS Het Landelijk Aktie Komitee Scholieren

The National Action Committee for Students, an organization of, for and by students.

SDT Self-Determination Theory

A macro theory of human motivation and personality that concerns people's inherent growth tendencies and innate psychological needs. SDT focuses on the degree to which an individual's behaviour is self-motivated and self-determined.

SEN Special Educational Needs

SES Socio-Economic Status 


\section{Contents}

List of abbreviations and frequently used terms..................................................... II

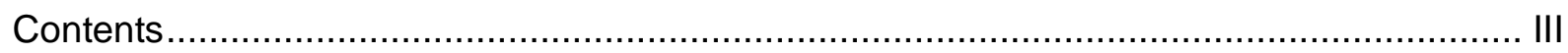

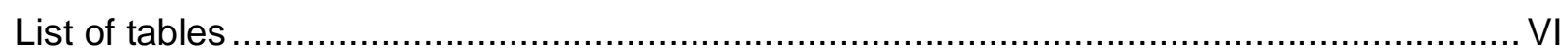

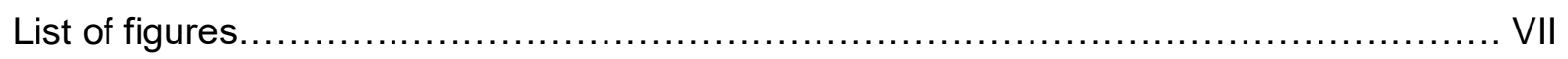

Chapter 1 General introduction......................................................................... 1

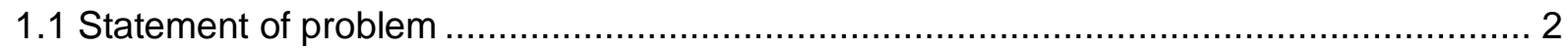

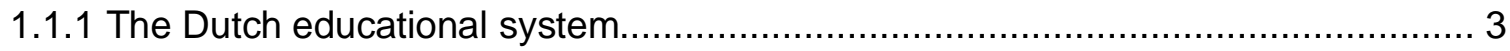

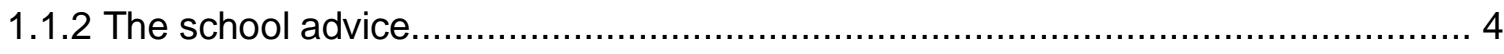

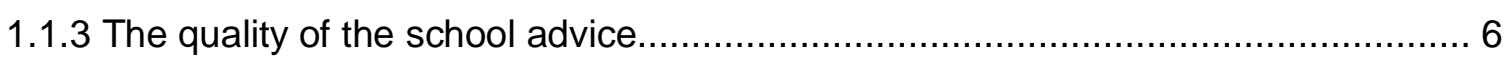

1.1.4 Skills required for a smooth transition ........................................................ 7

1.1.5 Communication and collaboration............................................................. 8

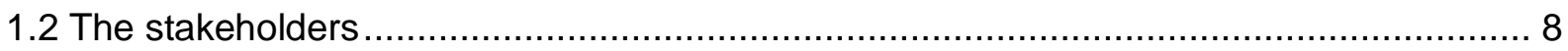

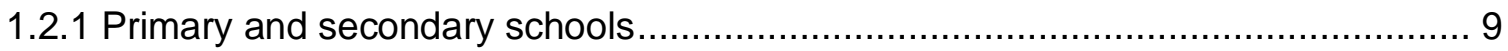

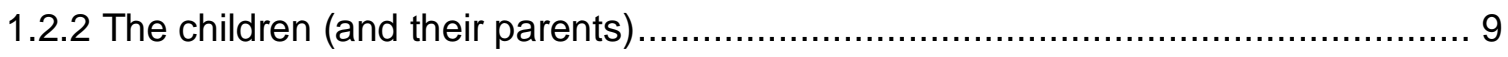

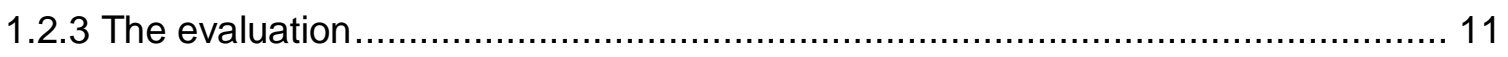

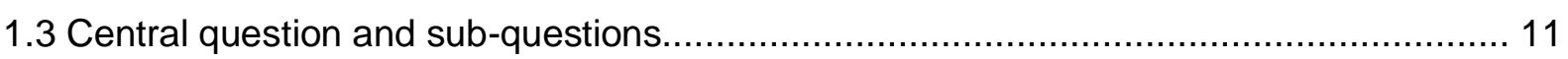

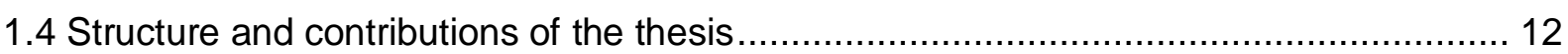

Chapter 2 Facilitating a successful transition to secondary school: (How) does it work? A

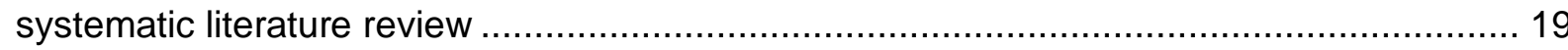

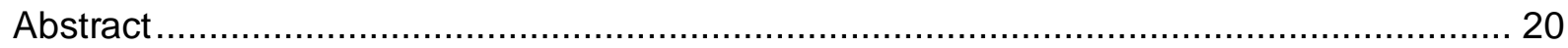

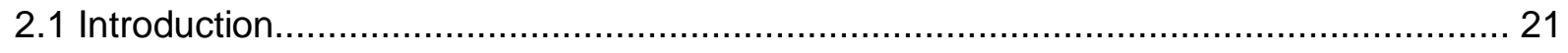

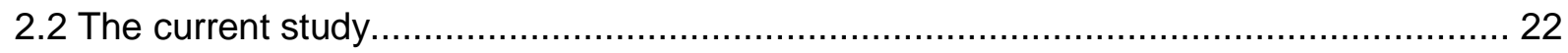

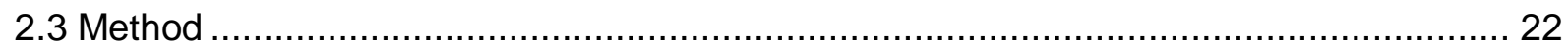

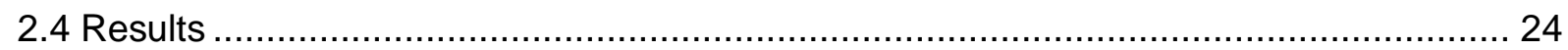

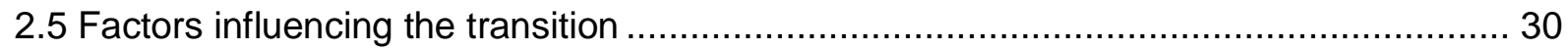

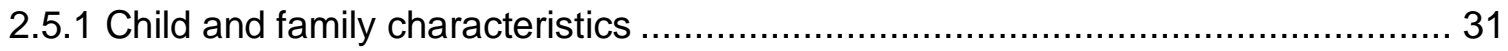

2.5.2 Preparing for a successful transition and support ......................................... 34

2.5.3 The relationship between primary and secondary school................................. 35

2.5.4. The formal and the informal context: school characteristics and peers ............... 36

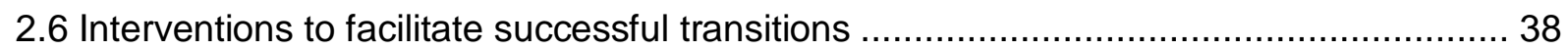

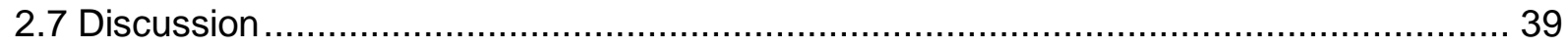

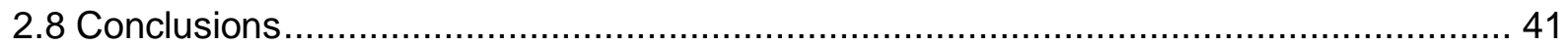


Chapter 3 Girls' and boys' perceptions of the transition from primary to secondary school. 45

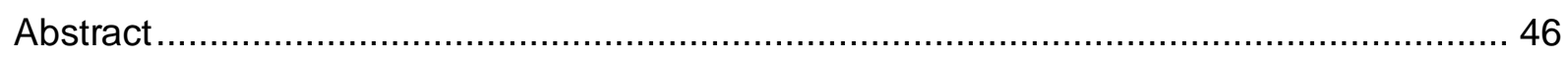

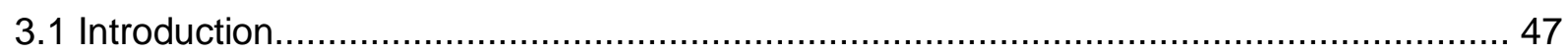

3.2 Literature review of children's expectations and experiences with the transition ........... 49

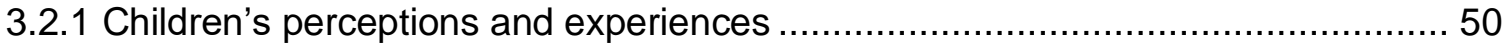

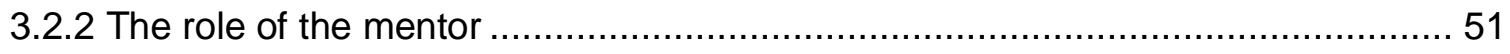

3.2.3 Differences in the formal and social contexts: making the transition with peers ... 52

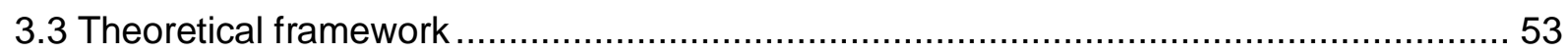

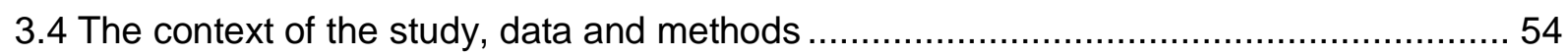

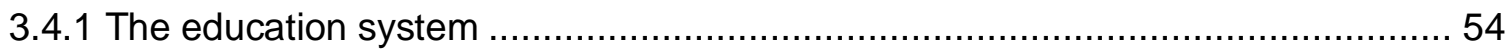

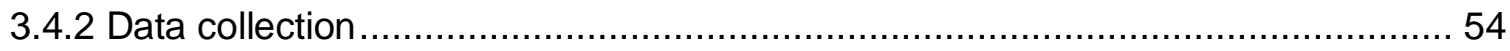

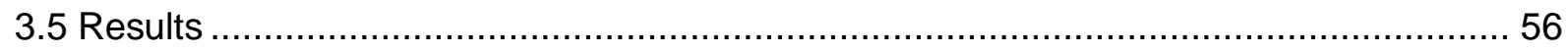

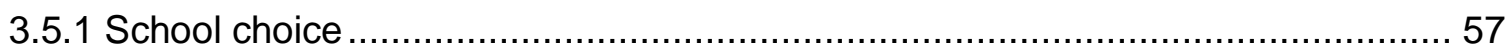

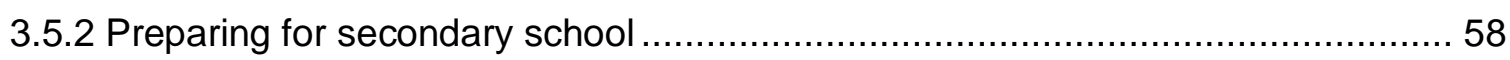

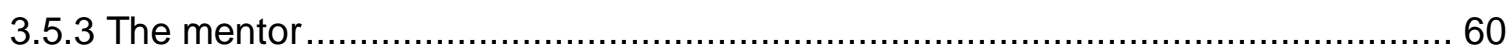

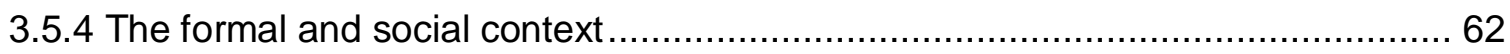

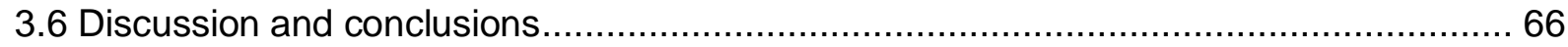

Chapter 4 (How) does information provided by children affect the transition

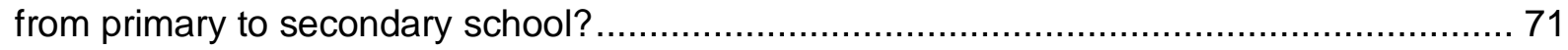

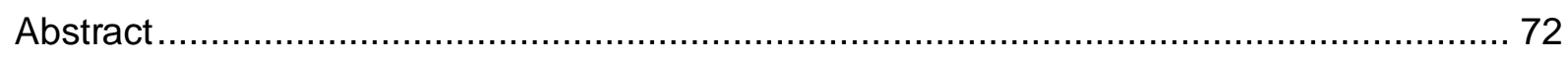

4.1 Introduction

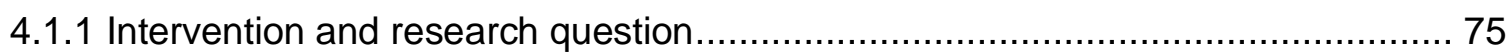

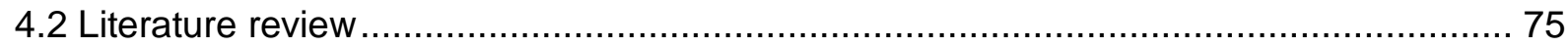

4.2.1 Individual differences in the quality of the transition from primary to secondary

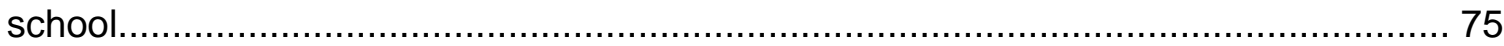

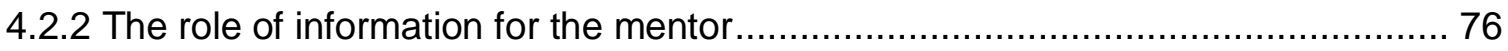

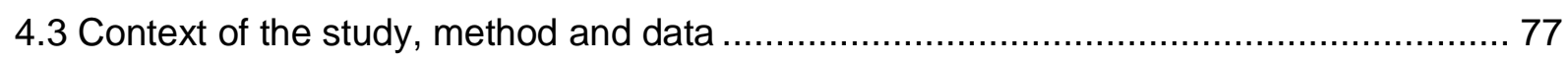

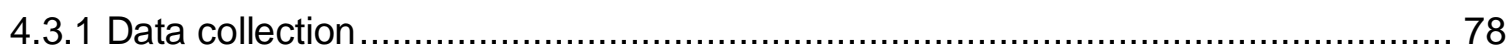

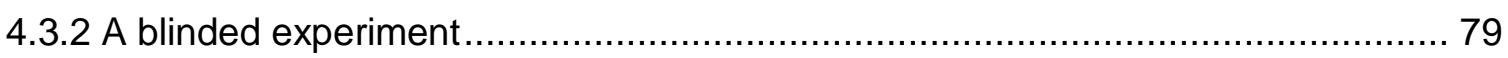

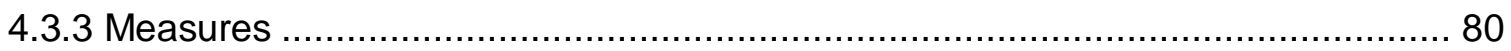

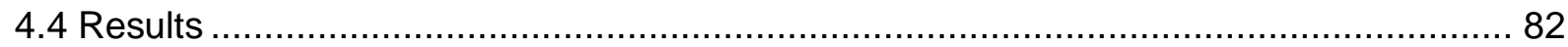

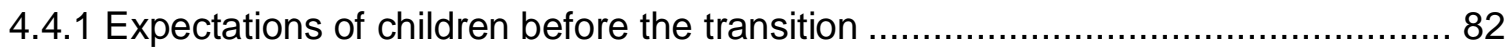

4.4.2 The social context: expectations about fear of and fun with peers ...................... 84

4.4.3 The school context: expectations about fear of and fun in schoolwork................. 85

4.4.4 The school context: expectations about fear and fun in the school context.......... 87

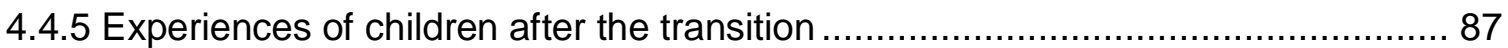


4.4.6 The social context: experiences with fear of and fun with peers........................ 88

4.4.7 The school context: fear of and fun with schoolwork......................................... 91

4.4.8 The school context: fear and fun in the school context ..................................... 92

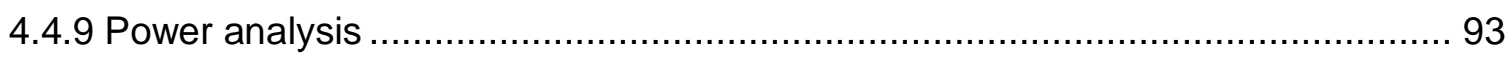

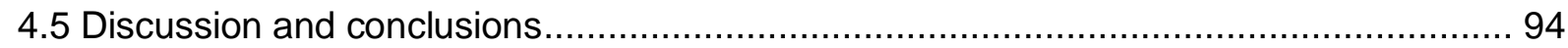

Chapter 5 Do mentors acquire information about pupils to improve the transition from primary to secondary education and how do they use this information? ..................................... 99

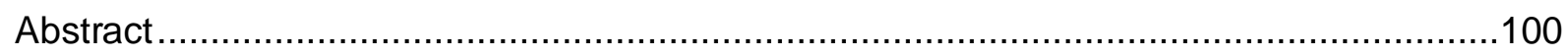

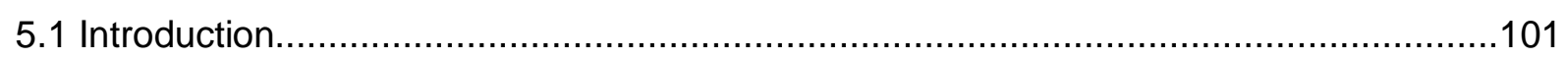

5.2 Literature review about support as perceived and experienced .................................103

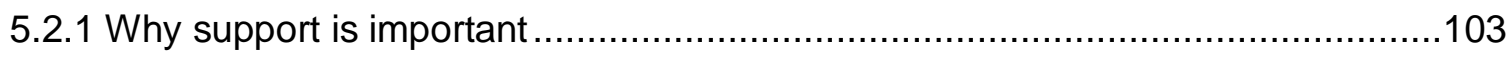

5.2.2 Providing support during the transition process .............................................. 104

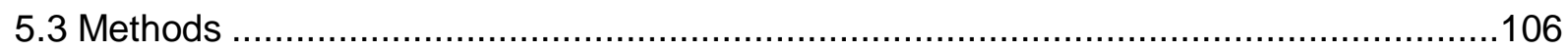

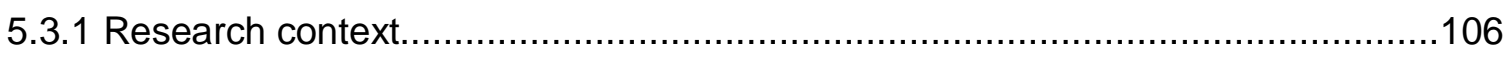

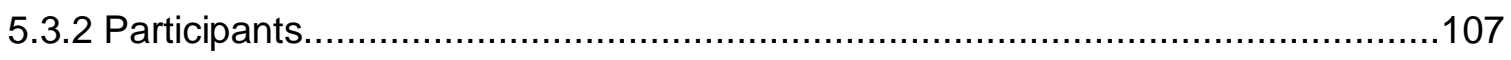

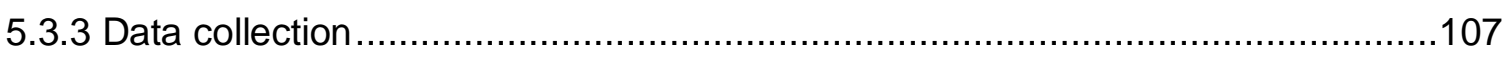

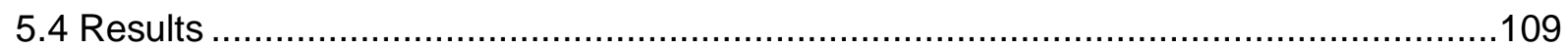

5.4.1 Information provided by the stakeholders before the transition to inform the mentor 109

5.4.2 Reliability, quality and usability of the pre-transition information 111

5.4.3 Information from the stakeholders after the transition to inform/support the mentor 112

5.4.4 Feedback to the stakeholders: awareness, and experiencing safety and success 115

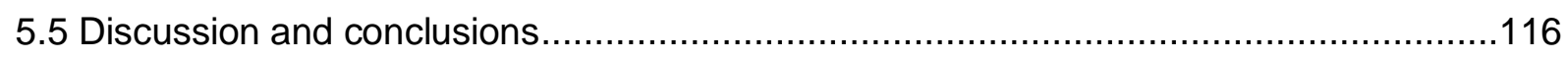

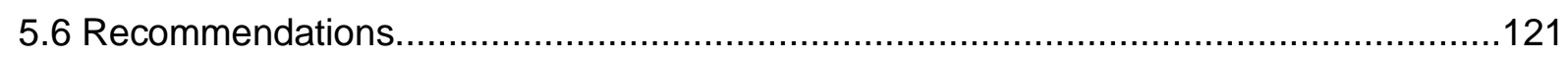

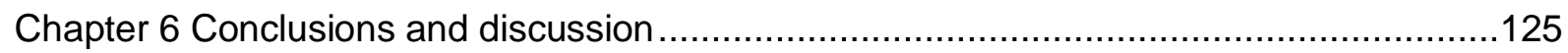

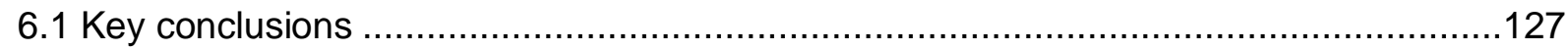

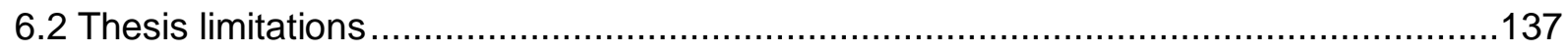

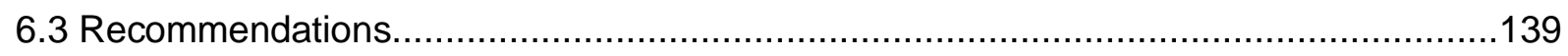

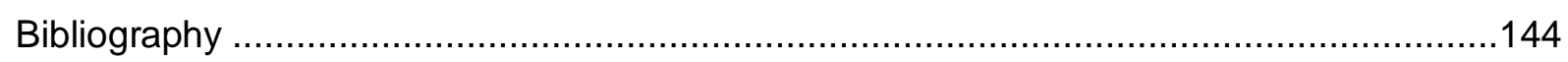

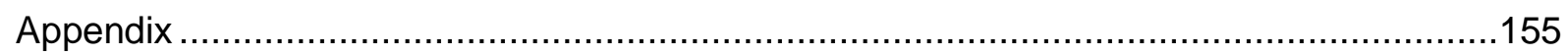

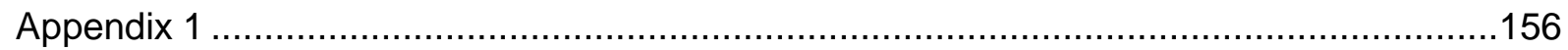

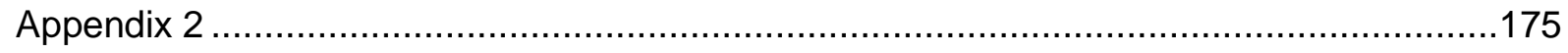

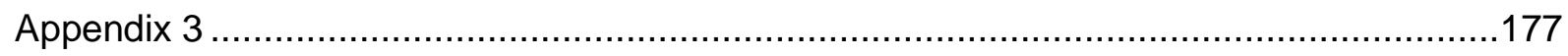

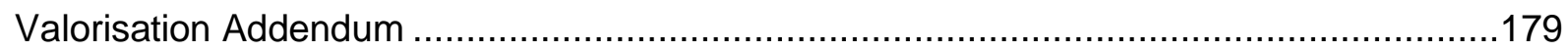




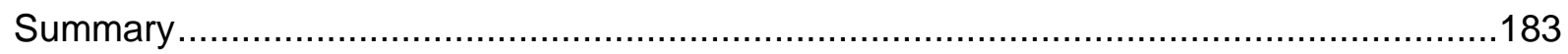

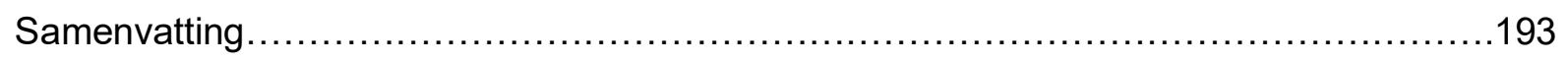

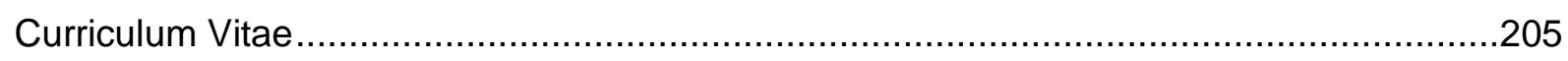

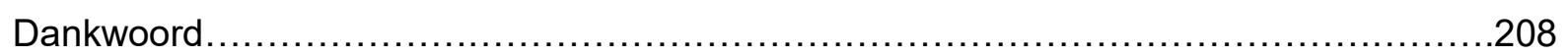

\section{List of tables}

Table 2.1: Literature on the transition from primary school to secondary school..............25

Table 3.1: The main reasons for school choice before and after the transition.................57

Table 3.2: Activities as a preparation for secondary school, before and after the transition..59

Table 3.3: Expectations about the mentor, before and after the transition.

Table 3.4: Threats and the challenges in the social and the school context, before and after the transition...

Table 4.1: The social context: fear of and fun with peers - pre-transition regression analyses.

Table 4.2 The school context: fear of and fun with schoolwork - pre-transition regression analyses.

Table 4.3: The school context: fear and fun in the school context - pre-transition regression analyses.

Table 4.4: The social context: fear of and fun with peers; regression analyses in 4 models post transition

Table 4.5: The school context: fear of and fun with schoolwork: regression analyses, 4 models - post-transition

Table 4.6: The school context: fun and fear in the school context; regression analyses, 4

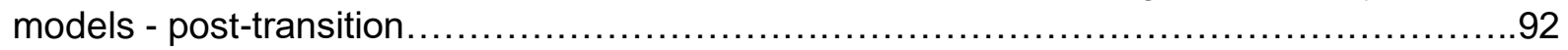

Table 4.7: Power calculated on results of T-tests of subscales post-transition. 94

Appendix 1

Table 3. I: Logistic regression: Does the sample loss cause a systematic bias on the second measurement? 156

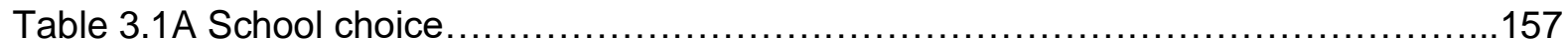

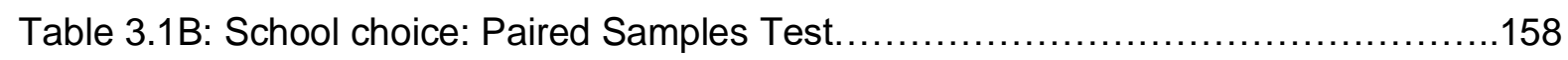

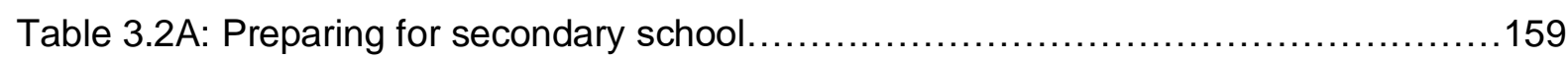

Table 3.2B: Preparing for secondary school Paired Samples Test........................160

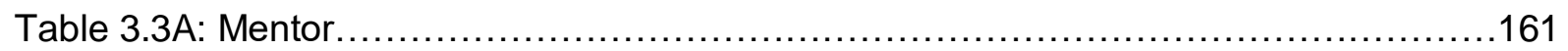

Table 3.3B: Mentor: Paired Samples Test..............................................

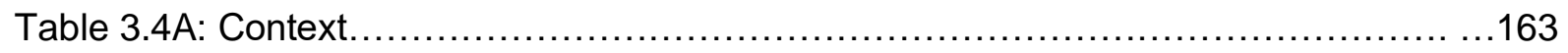

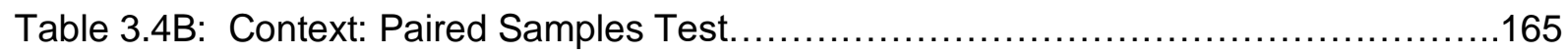




\section{Appendix 2}

Table 4.1: Composition research group: number of participants and percent response preand post-transition

Table 4.2: T-test observable characteristics intervention group- control group.

Table 4.3: mean scores control group and intervention group: T-test on subscales about the social and in the school context, pre- and post-transition

Appendix 3

Table 5.1: characteristics of interviewed mentors

\section{List of Figures}

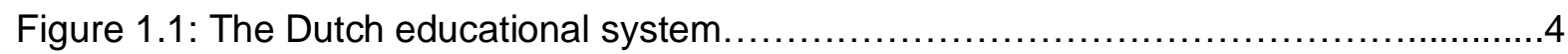

Figure 1.2: Timeline for grade 6 before the primary-secondary school transition..........5

Figure 1. 3: Level of students in Year 3 of secondary school compared to the final

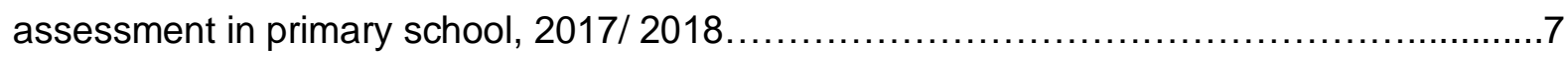

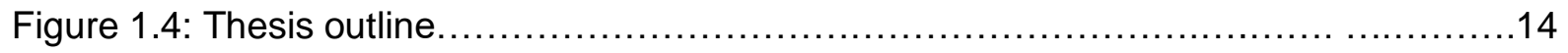

Figure 2.2: Stakeholders in the primary- secondary school transition......................30 
Chapter 1

General introduction 


\subsection{Statement of problem}

Each year approximately 180,000 children in the Netherlands make the transition from primary to secondary school. With good preparation and careful advice from the primary school, in principle all children should be able to make a smooth transition to secondary school to further develop their cognitive and non-cognitive knowledge and skills. Unfortunately, in practice this is not always the case.

In the Netherlands in 2010 , only $71 \%$ of the children felt that they were properly supervised in their choice. Two years later, in 2012, this had increased marginally to $73 \%$, but in 2014 satisfaction levels dropped back down to $71 \%$ again (source: The National Action Committee for Students, LAKS, an organization of, for and by students, available at https://www.onderwijsincijfers.nl/kengetallen/po/leerlingen-po/prestaties-schooladvies). This data indicates that nearly $30 \%$ of children are dissatisfied with the guidance they receive in preparation for secondary education. Research by Croes \& Terpstra (2017) at a Dutch lyceum showed that, on average, $52 \%$ of children experience the transition to secondary education as a major step in their lives. Despite its importance, the children felt that their primary school did not prepare them adequately, and the secondary school did not take sufficient measures to ensure that they could make the transition smoothly.

Forty percent of the complaints made by children and their parents concern preparation for and supervision of homework (Croes \& Terpstra, 2017). An English study concerning the opinions of children, parents, local authorities and schools about, among other things, what makes a transition successful, showed that up to $16 \%$ of children experience difficulties because they do not feel well prepared for secondary school (Evangelou, Taggart, Sylva, Melhuish, Sammons \& Siraj-Blatchford, 2008). Concerns about the amount of homework after the transition are also mentioned by Welsh children in a study by Powell, Smith, Jones \& Reakes (2006). They found that the amount of homework left some children feeling disaffected, which in turn led to disengagement (Powell et al., 2006).

The findings of Powell et al. (2006) and Evangelou et al. (2008) about the difficulties experienced by children in transition are not atypical for the Netherlands. National education systems may differ as to the age of transition and the extent to which an ability tracking system is used, but there are also many similarities in educational systems and the transition process. At some point in all countries, the outcome of the transition between primary and secondary education is influenced by the student, the school, and the educational environment (Humphrey \& Ainscow, 2006; Korpershoek, Beijer, Spithoff, Naaijer, Timmermans, van Rooijen, Vugteveen \& Opdenakker, 2016). Regardless of the age at which they make the transition and the educational system of which they are part, after transition all children must 
adapt to a new school and a different social environment. Evidence shows that this process causes most children to suffer reduced levels of achievement, albeit temporarily (Evangelou et al., 2008; McGee, Ward, Gibbons \& Harlow, 2004).

It is important for children to make a successful transition, because their future prospects in life and on the labor market rely strongly on the quality of their secondary education. A transition is considered successful when children are able to settle into their new school and become accustomed the routines, demonstrate an interest in school and schoolwork, and experience continuity in the curriculum. A healthy transition allows children to make new friendships readily and grow in self-esteem and confidence (Evangelou et al., 2008).

In other words, a child's experience of the transition from primary to secondary school can have long-term effects on his or her well-being, educational attainment and career choices (West, Sweeting \& Young, 2010). Recent years have witnessed increasing recognition in academia and educational practice of the risks that an unsatisfactory transition can pose to the development of a child's cognitive and non-cognitive knowledge and skills. Children who like school and their teachers, who have fewer retentions and who pay attention during classes, are less likely to drop out (De Witte \& Rogge, 2014). Thus, a successful transition is essential to their welfare.

\subsubsection{The Dutch educational system}

The education system in the Netherlands differs from that of some other countries because it is segmented and has the ability to start tracking at the relatively early age of 12 . The term tracking refers to the secondary school system that groups children according to their actual and perceived ability, IQ or achievement level in order to provide them with a standard of education that is appropriate to their needs and capabilities.

Figure 1.1 shows that the education system in the Netherlands is organized into three segments: primary education (special and standard), secondary education (special and standard) including secondary vocational education, and higher professional education and university. This thesis focuses on the transition from primary to secondary education. Children in the Netherlands tend to make this transition on average at the age of 12 . 


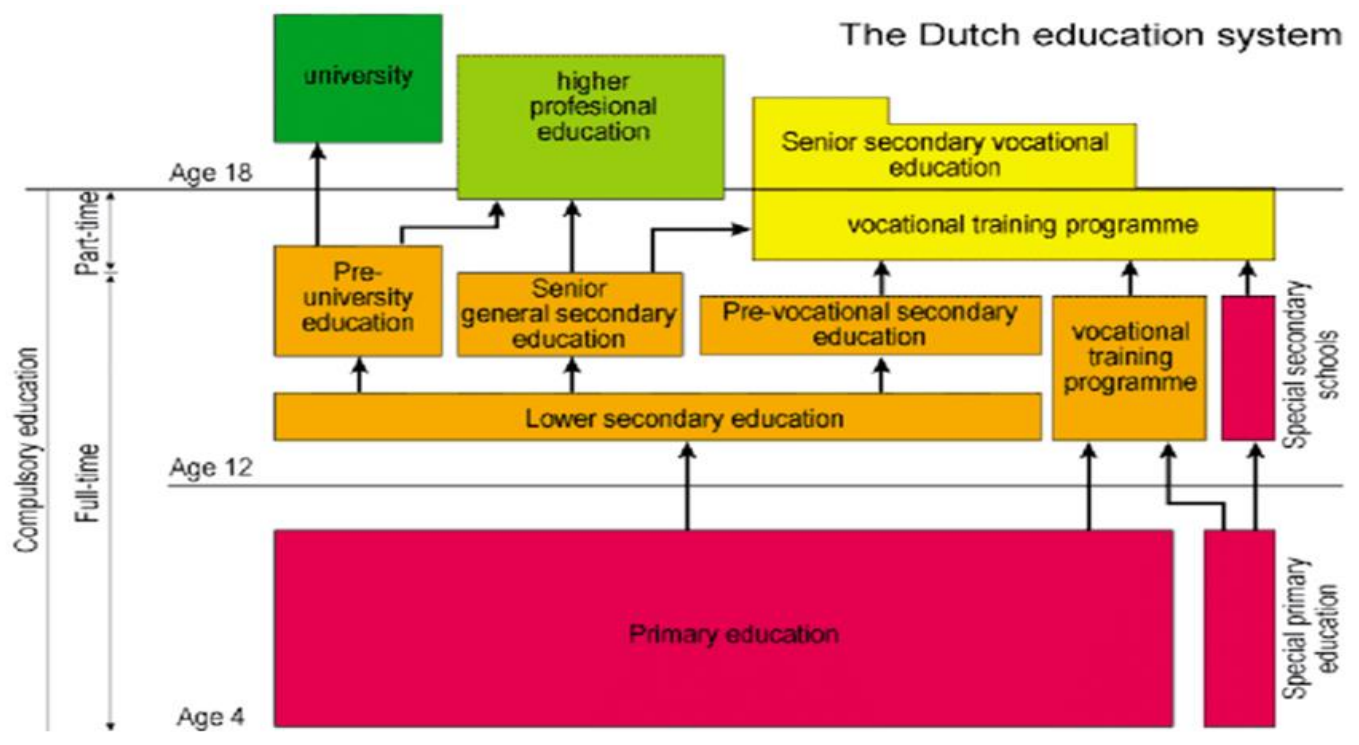

Figure 1.1: The Dutch education system (source:

https://www.onderwijsincijfers.nl/kengetallen/onderwijs-algemeen/nederlands-onderwijsstelsel)

As figure 1.1 shows, secondary education in the Netherlands is divided into three tracks: one to prepare children for vocational training (pre-vocational secondary education / VMBO), another to prepare children for university (pre-university education / VWO), and a middle track to prepare children to study at universities of applied sciences (higher general secondary education / HAVO). In addition to regular education, there is special secondary education (VSO) for children who need special educational assistance and a track called Praktijkonderwijs to prepare children through practical education for work.

\subsubsection{The school advice}

Before children in the Netherlands make the transition from primary to secondary education, a decision is made about the level at which they will enter secondary education. Since 2014/2015, the law requires that all primary school pupils in grade 6 must take a final test on their math and language proficiency. The administration of the final test takes place between 15 April and 15 May. Before the children take the final test, the primary school provides binding advice as to which type of secondary education best suits the child (Korpershoek et al., 2016).

The school advice is the guiding principle for admission to secondary education. The secondary school must place the student in a class that at least offers education at the level of the school advice. If, after taking the final test, the test score corresponds to a higher level of education than originally recommended, a primary school must reconsider its advice. Based on this review, the primary school may decide to adjust the school advice upwards, although this is not mandatory. Changing the school advice only happens in exceptional circumstances 
and only by mutual consultation between the teacher and the parents. If the school advice is not adjusted, the primary school must justify this.

The Institute of Applied Sociology, in Dutch called Instituut voor Toegepaste Sociologie (ITS) has issued some recommendations for the content of the school advice (Smeets, van Kuijk \& Driessen, 2014) and warns primary school teachers against under advice. This can occur if teachers include things in their school advice that might unintentionally hinder the chances of children, thereby giving a lower recommendation (under advice) than the child deserves based on his or her learning performance. The reading and math scores earned by children in grades 5 and 6 are considered helpful indicators, but multi-year information should also be included on each child's social-emotional development, covering non-cognitive skills such as work attitude and motivation. For children with specific educational needs, information about their disability and their need for specific guidance is required along with the school advice. A wellfounded school advice therefore not only provides information about the academic development of a child, but also gives insight into their social and emotional development. This is important, because children will confront not only a new learning environment in the secondary school, but also a new social environment (Smeets et al., 2014). Figure 1.2 shows in a flowchart of the activities in grade 6 related to the transition process.

\section{Januari}

-Open days secondary schools

\section{Before March 1}

-School advice primary school

\section{March- April}

- Formal registration at secondary school

- Overview of registered children

- Exchange children's data

-Warm transfer primary- secondary school

\section{April 15- May 15}

- Central final test at primary school

4 Weeks after central final test

-Announcement of test advice

- Reconsidering school advice

- Results of the final test to secondary school

-Admission notice in secondary education

\section{June- July}

-Introduction day(s) secondary school

Figure 1.2: Timeline for grade 6 before the primary-secondary school transition 


\subsubsection{The quality of the school advice}

For various reasons, the primary school advice cannot always guarantee a smooth transition to secondary education. Some children are vulnerable to a more difficult transition due to their background (e.g., lower socio-economic status, socio-ethnic origin) or individual characteristics (e.g., gender, behavioral or learning difficulties) (Anderson, Jacobs, Schramm \& Splittgerber, 2000; West et al., 2010; Van Rooijen, Korpershoek, Vugteveen, Timmermans \& Opdenakker, 2016). Adjustment problems (especially those experienced by vulnerable children) may stem from poor preparation for the transition, sometimes combined with little or no support during and/or after the transition. Such children may subsequently be unhappy, lose self-confidence and suffer a more negative self-image. These qualities can, in turn, impair school performance, perhaps ultimately causing the pupil to drop out of school (McGee et al., 2004).

In 2019, the Dutch Inspectorate of Education recognized that the school advice system has some biases, triggering widespread public debate about the system's objectivity. The chances of obtaining appropriate secondary school advice can depend on a child's background. Children with equivalent school achievement levels, but with less well-educated parents, are more likely to receive a school advice that "downgrades" them into a lower form of education, and are less likely to be "upgraded" into a higher level track, than their peers with bettereducated parents (De Staat van het Onderwijs, 2019). Furthermore, children in the Netherlands from families with a lower socio-economic status (SES) - as measured by their parents' jobs - are approximately $50 \%$ more likely to leave education prematurely than children from families with a higher SES (Alexander, Entwisle \& Kabbani, 2001; Traag \& Van der Velden, 2008).

There are also educational differences between boys and girls, which emerge mainly after the transition. At secondary school, boys are more likely than girls to be held back a year. Boys are also more likely to be "downgraded" to a lower track in secondary education and are "upgraded" less frequently than girls (De Staat van het Onderwijs 2019). Indeed, recent results from the Centraal Bureau voor de Statistiek (CBS), an independent government agency charged with providing statistical information about Dutch society, show that in 2017/2018, more girls than boys exceeded the expected school level (See Figure 1.3; CBS 2018, retrieved from: $\quad$ https://www.cbs.nl/en-gb/news/2018/50/more-girls-than-boys-exceeding-expectedschool-level). 


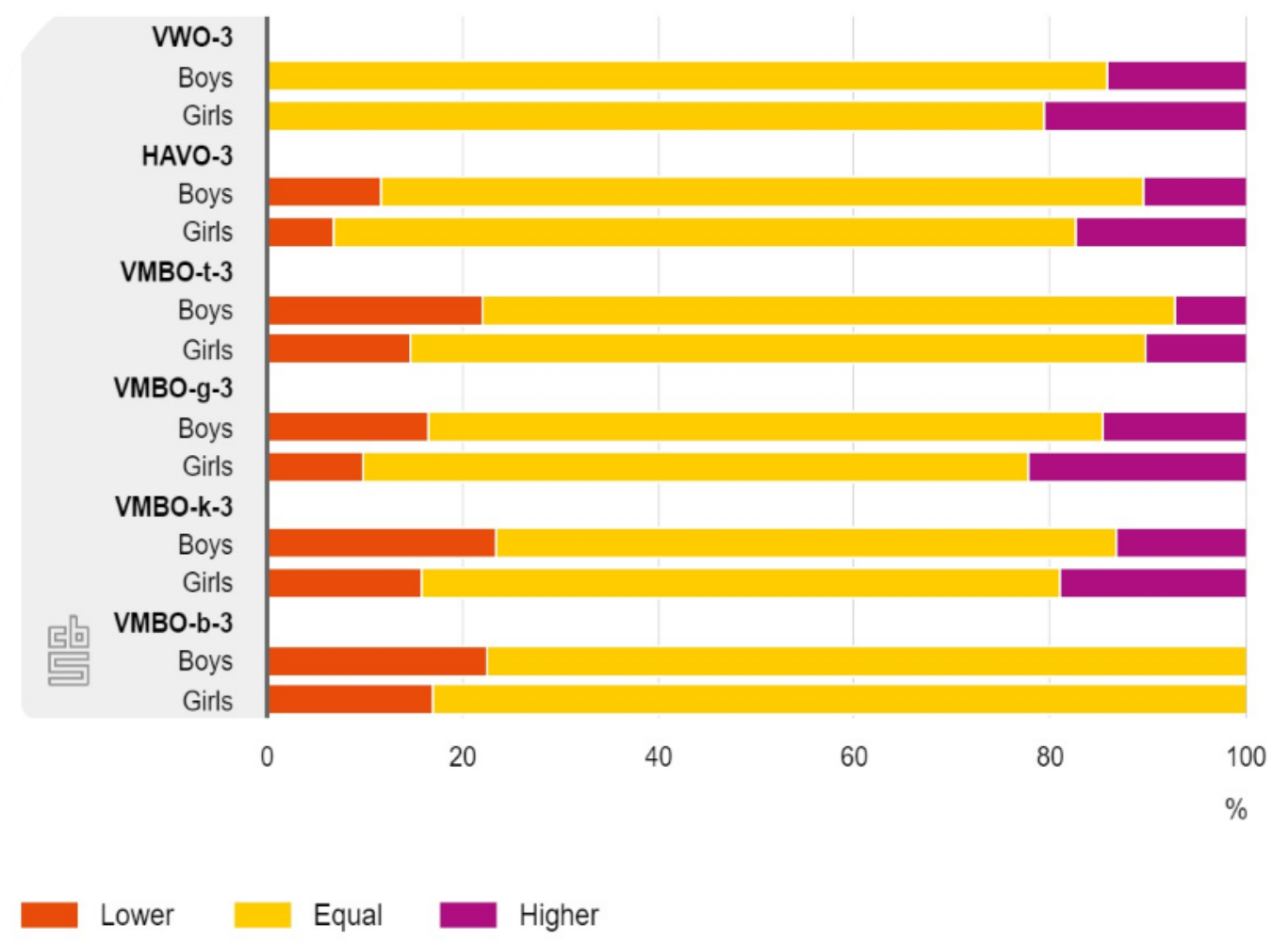

Figure 1.3: Level of students in Year 3 of secondary school compared to final assessment in primary school, 2017/2018. Students receiving VSO or practical education as recommended level are excluded (source: Centraal Bureau voor de Statistiek -CBS- 2019).

To summarize, the research shows that after three years in secondary school in the Netherlands, some children have upgraded to a higher level while others have downgraded to a lower level. In $2016,79.1 \%$ of both sexes were at the level of the primary school advice, $10.2 \%$ were downgraded to a lower level, and $10.1 \%$ were upgraded to a higher level. After being in secondary education for four years, one in eight children have repeated a class (Van Rooijen et al., 2016).

\subsubsection{Skills required for a smooth transition}

The quality of the school advice does not guarantee a proper transition for two reasons. Firstly, the school advice does not always adhere to the ITS instruction to take into account all the skills, cognitive and non-cognitive, that children need to make a successful transition. Therefore, the quality of the transition may depend on factors that are not necessarily all captured in the school advice, such as the extent to which an individual child is able to adapt to a new environment. Switching from a small, self-contained primary school to a large, more heterogeneous secondary school requires different social and academic skills (Poorthuis, 
2012; Hanewald, 2013). Secondly, there are personal qualities that may affect a child's ability to adapt to a new environment, regardless of the school, track (academic or vocational) or level of education, such as independence, motivation and perseverance. Compared to primary school, in secondary school the children are given more freedom and face greater challenges. They also are expected to be more self-sufficient.

Children therefore require a number of skills not always addressed in the school advice or measured by the final test, such as the ability to cope with the loss of old school friends, building new relationships with peers and teachers, and independently handling the academic demands of secondary school. In addition to the above-mentioned skills, children also have to deal with such issues as travelling further to get to school and longer school days. Their status among other students also changes at secondary school and the children must learn to adjust: they are no longer the oldest and tallest, but the youngest and smallest. This requires adaptability, and boys and girls may respond differently to these changes in a social context. Girls are at risk of decreasing self-esteem if social acceptance does not match expectations. Boys may be susceptible to a decline in academic achievement (Chung, Elias \& Schneider, 1998) and at higher risk of school problems such as repeating a class or dropping out of school altogether (CBS, 2010, retrieved from https://www.cbs.nl/en-gb/society/education).

\subsubsection{Communication and collaboration}

Problems in the transition also can arise due to poor communication or poor collaboration between the stakeholders in the transition process, that is, the children (with their parents), the primary school and the secondary school. The stakeholders do not play an equivalent role in the process nor do they have an equal vote. For example, although the Education Inspectorate recognizes the desirability of an active role for children in education, the children (and their parents) are rarely involved in drafting the binding primary school advice, and typical ${ }^{1}$ children often lack personal guidance and support in the transfer to secondary education (Amsing, et al., 2010). Collaboration by all stakeholders is not a common practice.

\subsection{The stakeholders}

Three parties all have an interest in a successful transition to secondary education: the children (and their parents), the primary education school and the secondary education school.

\footnotetext{
${ }^{1}$ We refer to children without disabilities as "typical" because they have the behaviour, intellectual ability and functional skills we would "typically" see in children of their age.
} 
Although they are related to each other, they all have their own interests, characteristics and possibilities for optimizing the transition. For children, it is important to develop in accordance with their abilities and capacities. Parents can help motivate them to commit to a particular school or to prevent underperformance. Experiences in the first year of secondary education can substantially influence a pupil's decision about whether or not to drop out (De Witte \& Rogge, 2014). Primary schools may advise what type of secondary school is best suited to a child, but the secondary schools decide whether they want to admit him or her. All schools are interested in a smooth transition, because this confirms their ability to properly anticipate the student's capacity to make the necessary changes (in the case of the primary school) and to adapt to the new circumstances (in the case of the secondary school) (Korpershoek et al., 2016).

Partnership can provide mutual benefits that are impossible to achieve otherwise (Mohr and Spekman, 1994). The literature shows, for example, that a healthy co-operation between school and parents promotes children's learning performance and, accordingly, their selfconfidence and well-being (Bakker, Denessen, Denessen \& Oolbekkink-Marchand, 2017; Desforges \& Abouchaar, 2003). For that reason, schools and teachers are urged to invest in building good relationships among themselves and with parents and children.

\subsubsection{Primary and secondary schools}

Primary and secondary schools are jointly responsible for a good transition. They share a common interest in ensuring that children find the most suitable place in secondary education. This shared responsibility is also known as "chain responsibility" or, in Dutch, ketenverantwoordelijkheid. Conflicting interests between these stakeholders can frustrate that outcome. The more referrals a primary school has to higher tracks in secondary education, the better its reputation and the more attractive it is to children and parents. This incentivizes primary schools to refer as many students as possible to the higher tracks. For secondary schools, on the other hand, an oversubscription to the higher tracks can expose them to increased risk of downgrading, class repetition and school drop-outs.

\subsubsection{The children (and their parents)}

From time to time, a primary school teacher might undertake to personally recommend a particular student to a secondary school. In this case, an oral or written guidance is communicated between two teachers (commonly, the sixth grade teacher at the primary school and the mentor at the secondary school). In Dutch, this is known as a warme overdracht or "warm transfer". Even when such a personal communication occurs in the transition process, the voices of the parents and children are often absent. This is particularly remarkable because 
of the great importance attached, both nationally and internationally (United Nations Convention, 1989), to involving children in the decision-making process about matters that concern them. It is widely believed that students should play an active role in their learning process, sharing joint responsibility with their teachers for a successful outcome (PO Raad, AVS \& VO Raad, 2011).

Article 12 of the United Nations Convention on the Rights of the Child states that in any judicial or administrative proceeding that affects them, children must be provided with an opportunity to be heard, either directly or indirectly through a representative or an appropriate body, in a manner consistent with the procedural rules of national law (UN 1989, retrieved from ttps://www.ohchr.org/EN/Professionallnterest/Pages/CRC.aspx). The question is: how do these rights manifest for children making the transition from primary to secondary school?

In the Netherlands, schools for secondary education invest in the role of the mentor to counter adaptation problems among first-year secondary school children. A mentor is a teacher who, in addition to teaching, also has a supervisory task with regard to his or her class. Teachers are vital to establishing the context in which the transition takes place, thereby ensuring that it proceeds smoothly. Indeed, previous research has shown that a healthy context has a stronger influence on the success of a transition than an individual student's characteristics or stage of development (Anderson et al. 2000). Schwarz et al. (2009) maintain that the teacher is the most important school-related factor influencing the ability to learn effectively.

It is not only teachers but also children who positively influence the learning process. Sellman (2009) found that children's involvement in decision-making can benefit learning performance in three ways. The first is motivation: the child becomes more involved in school, which improves motivation. The second is a better relationship between the child and the teacher. The teacher gains insight into the child's character, abilities and efforts and, based on this awareness, can adjust and improve his or her pedagogical efforts. The third way complements the second by encouraging feedback. Direct feedback from the child helps the teacher to improve specific teaching methods, thereby enhancing the particular child's learning experience and, consequently, the learning outcomes (Sellman, 2009).

It is apparent that children are able to make a valuable contribution to their own learning process, but what opportunities do they really have to contribute to the discussion about the transition to secondary school? Is there an opportunity for children to be engaged in a two-way conversation about the transition from their own perspective, and are they motivated to do so? Does participation of the child contribute to a better transition? Ashton (2008) found that sixthgrade children, including those with special educational needs, are willing and able to consider the transition process critically. Scant research has been done about children's participation 
as a stakeholder in the transition to secondary education and whether child participation can contribute in a meaningful way to improve the transition.

\subsubsection{The evaluation}

After the children are placed in secondary school and settle into the routine, it is important to evaluate the results of the transition process. Mentors of secondary schools should provide feedback to teachers of primary schools, and vice versa, about their experiences and expectations. What went well and what went wrong in the transition? What lessons have been learned and what can schools and teachers do to improve the transition even further in the next year?

Giving feedback and organizing an evaluation procedure is problematic for two reasons: secondary schools can only obtain information from the relevant primary schools about their former students with the consent of the parents. The second reason is that more than half of secondary schools receive pupils from more than 30 different primary schools. All of these primary schools have their own identity and autonomy, and their own policies with regard to their school advice and preparation for secondary education (Korpershoek et al., 2016).

As these multiple organizations and parties interact during the transition process, often coming from entirely different viewpoints, the transition is further complicated. In addition to the interests of all the stakeholders - that is, the children, their parents and the schools - a smooth transition to secondary education is also important from a policy point of view, as it contributes to better development of talent and helps to improve educational outcomes.

\subsection{Central question and sub-questions}

It is remarkable that, from the child's perspective, relatively little is known about the factors that determine a successful transition between primary and secondary education, and about what interventions can improve the transition. Scientific evidence is sparse about what works and what does not. Moreover, there is insufficient information from daily practice about the experiences and perspectives of children and teachers, and how they can contribute to a successful transition. Unfortunately, children rarely get to participate in research about the transition, and if they do, no weight is given to the way in which their opinions may affect the transition, or even to evaluating their opinions about the transition process. In response to this gap in our knowledge, this thesis contributes to understanding the factors that lead to a poor transition and to increasing the awareness of interventions that can improve it. 
With regard to the support and involvement of children in their education, including the transition to secondary school, the Education Inspectorate notes that although most schools in the Netherlands support and guide children correctly, only a minority actively involve children in setting goals concerning their learning process (Onderwijsverslag 2016/2017). Consequently, schools often deprive children of the chance of joint responsibility for their own learning process. This remarkable finding is not desirable, as the Inspectorate points out, because it is important to children to "own" their transition process. Ownership refers to the extent to which children invest in the topics they learn, the methods by which they learn, and the places where learning occurs (Fletcher, 2008).

Unfortunately, there is not much scientific evidence available about the degree of contribution by individual stakeholders to the transition to secondary school and what happens when they actively collaborate and communicate. Little is known about what happens when stakeholders mutually support each other in the transition process, adopt a joint approach and participate equally in the process. This research gap leads to the central question of this thesis:

\section{Can the transition from primary to secondary school be improved by better communication, collaboration, support and participation by teachers and children?}

This question raises a number of sub-questions that structure this thesis and correspond to the research questions in Chapters 2 to 5 . The sub-questions are:

- What is the effect on the transition from primary to secondary school if children are involved in the transition process?

- What do the children themselves expect and experience in the transition from primary to secondary school, and are there gender differences in their perceptions, expectations and experiences?

- What are children's concerns in the social and school context, and what are they looking forward to?

- How do mentors at secondary school acquire information about their future pupils: are they aided in acquiring this information and how do they use it?

\subsection{Structure and contributions of the thesis}

In response to the research gap identified, this thesis makes a scientific and societal contributions to improve the transition from primary to secondary education by including the perspectives of the children and the mentors of secondary school, particularly with a view to 
"giving children a voice". The aim of this thesis is to provide evidence, through quantitative and qualitative research, of the ways in which the input from these two groups of stakeholders children/parents and secondary school mentors - can enhance the transition.

Broadly speaking, each thesis chapter approaches the topic from a different angle. Firstly, the international literature is reviewed to obtain more insight into the existing evidence on the role of the stakeholders, especially the children, as active participants in the transition process. The next chapter presents the results of an experiment where children 's voices are "heard", in order to establish whether their concerns were indeed acknowledged and whether such recognition improves the quality of the transition. Mentors for grade seven in secondary education participated in this experiment and, for purposes of their own decision-making, were allowed to use the information provided by the children about themselves and how they felt about the transition. Last, but not least, we set out information collected from the mentors at a secondary school, because they are the professional "insiders" in the transition process. To make their opinions clear, they were interviewed in focus groups.

The data presented in this thesis are collected through a systematic literature search, selfreporting questionnaires, and through focus group interviews. The data are analyzed in different ways, using statistical techniques for the quantitative part and the principles of Grounded Theory ${ }^{2}$ for the qualitative part of the study.

\footnotetext{
${ }^{2}$ Grounded Theory (GT) is a systematic methodology in the social sciences involving the construction of theories through methodical gathering and analysis of data. This research methodology uses inductive reasoning, in contrast to the hypothetic-deductive model of the scientific method (source: Grounded theory - Wikipedia en. wikipedia.org > wiki > Grounded theory).
} 


\section{Part 1: Introduction}

Chapter 1

Introduction

Part 2: The role of the children

Chapter 3 Boys' and girls' perceptions of the transition
Chapter 2 Literature review on the transition to secondary school
Part 3: The role of the mentor

Part 4: Conclusions

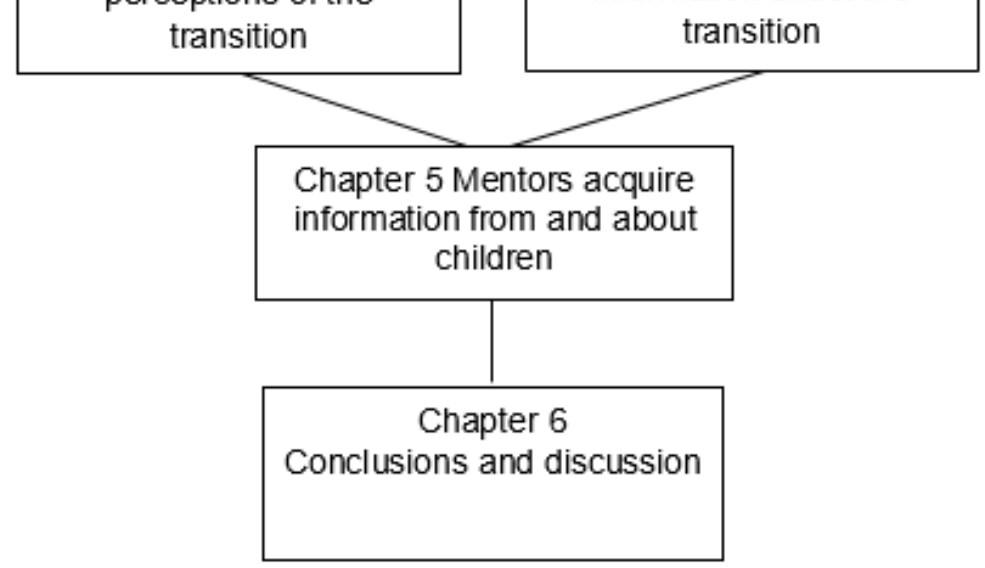

Figure 1.4: Thesis outline

Specifically, the thesis consists of six chapters, divided into four parts, as shown in figure 1.4. Part one, the introductory part of the thesis, consists of Chapters 1 and 2 . The systematic literature review in Chapter 2 provides evidence from the existing literature about the experiences and expectations of children making the transition. We also investigated the literature for the effects of interventions made to facilitate the transition, especially those that gave children a voice. In addition to the effects of the interventions, we also checked whether children were directly involved and, if so, how. The systematic literature review revealed the significance of a number of factors, including the relationships between all the stakeholders, the family background and personal characteristics of the children, sufficient preparation, and support. The review shows how these factors can make a positive contribution to interventions, leading to a successful transition. Despite recognition of the importance of these aspects to the transition, very few studies have been done from the perspective of the children themselves.

The results of the systematic literature review contribute to our scientific knowledge about the roles of the stakeholders, in particular those of the children and their parents in the transition 
process. The results are also important for schools, because they can help them to evaluate, refine, and improve existing interventions that aim to support pupils during this period. In addition, this evidence helps to identify the children who are most vulnerable to a poor transition. Consequently, the results of this study can help to ensure that interventions are directed and used where they are most needed (Robinson, 2014). We used the results of the systematic literature search to shape the research design as well as the intervention.

Part two of the thesis comprises Chapters 3 and 4. This part focuses on the consequences of an active role by children in the transition process and the effect of student feedback on the secondary school mentor's actions. The impact of this intervention may differ between boys and girls, as they have different expectations and needs in the transition to secondary school. The question we address in Chapter 3 is: Do girls and boys experience the transition differently?

Children are the experts about their experiences in the transition process, although teachers can support and assist them (Ellerbrock, Abbas \& DiCicco, 2014). The significance of such support is that children may come to expect the same encouragement and assistance from the mentor if and when they raise concerns. This leads to the following questions: Do children who inform their mentor about their needs and expectations for support make a better transition to secondary education? Does the effect of informing the mentor vary from one student population to another?

Some children settle into secondary school easily while others find the transition difficult. Chapter 3 contributes to both literature and pedagogical practice by providing insight into the expectations of children before and after they make the transition. This chapter also explores whether gender affects the way in which the transition is experienced. In the Netherlands, as in other countries, the academic performance of boys is, on average, poorer than that of girls, so that boys, as compared with girls, are more likely to be referred to a lower education track than that initially advised (Van Rooijen et al., 2016). Moreover, girls are more likely than boys to have positive attitudes to school and teachers (Rice et al., 2011) and, as a consequence, receive more support (Bokhorst, Sumter \& Westenberg, 2010). Awareness of the children's expectations and experiences might allow them to contribute significantly to a deeper understanding of such gender-based distinctions. This insight could then be used to further ease the transition from primary to secondary school.

Chapter 4 contains the results of a blinded experiment with the new mentor of grade seven at a secondary school. We experimented by providing him with information directly from the children about their experiences during the transition process from a prospective and retrospective point of view. In the blinded experiment, self-reporting questionnaires were used 
to investigate how the mentor responded to information provided by the children before they made the transition. We further analyzed the fun and fear factors that the children expected to experience at secondary school. The children themselves should be an important source of information in this regard, but there is little evidence in the literature about the role and importance of children informing the mentor about themselves. According to previous research, when teachers listen to children, it often occurs within the context of limited aspects of school life, primarily intended to improve the children's academic performance (Robinson, 2014). This chapter contributes to the literature by providing insight into the mentor's actions and furthering an understanding of what children anticipate and fear in the secondary school environment as compared to their actual experiences after the transition.

Part three is composed of Chapter 5, which is about the way mentors at secondary school acquire and use the information they need to guide and support children through the transition process. In the ideal situation, the teacher provides firm support and ensures that the children learn not only about the world around them, but also about their self-efficacy within it (Riley, 2009). Academic success is affected by the emotional aspects of learning and motivation (Reyes, Brackett, Rivers, White \& Salovey, 2012). In a warm and respectful classroom climate, characterized by emotionally supportive relationships between teachers and children, children are found to perform better because they are more emotionally engaged in the learning process (Reyes et al., 2012). Thus, Reyes et al. (2012) contend that the quality of the relationship between teachers and children is related to student engagement and academic performance.

As previously indicated, mentors are teachers who, in addition to teaching, also have a supervisory task with regard to his or her class. They are also responsible for passing on the information they receive through the transition process to the other teachers. All of these teachers need sufficient knowledge about their classes in order to connect well with the children. We therefore address the following research questions about the source, content and quality of the information that mentors receive: How do mentors at secondary school acquire information about their future pupils and are they provided with sufficient resources to improve the quality of the transition by using this information? We also analyze the process by which information about the children making the transition reaches the mentor and, in particular, if this information includes material from the children themselves. Finally, we explore whether the mentors actually use the information they receive, especially that provided by the pupils themselves, and if so, how. To obtain these findings, we designed focus groups to collect information, via qualitative interviews, from the mentors as "insiders". Before the focus interviews were conducted, the researcher followed a short training course to acquire the 
required skills. The data yielded by the qualitative interviews are analyzed according to the method of the Grounded Theory.

Finally, in part four, Chapter 6, the combined findings and overall conclusions of this thesis are presented. This chapter also offers some recommendations for future research. 


\section{Chapter 2}

\section{Facilitating a successful transition to secondary school: (How) does it work? A systematic literature review}

This chapter is based on: Van Rens, M., Haelermans, C., Groot, W. \& Maassen van den Brink, H. (2018). Facilitating a Successful Transition to Secondary School: (How) Does it Work? A Systematic Literature Review. Adolescent Research Review, 3 (1), 43-56. 


\section{Abstract}

For children, the transition from primary to secondary school is sometimes difficult. A problematic transition can have both short- and long-term consequences. Although information from children and their parents about what concerns them can contribute to a smooth transition, this information is rarely shared during the transfer to secondary school. This review examines 30 empirical studies on the effects of interventions to ease the transition process. These are interventions which, in contrast to the usual information about curriculum and test results, focus on what children report about the transition. Our findings suggest that, although their perspectives differ, positive relationships between the stakeholders in the transition process - schools, children and their parents - can help to improve the challenges presented by the transition. It shows the importance of involving all stakeholders in the transition process. However, there is a gap in exchanging information. Little evidence has been found of interventions that focus on partnership or cooperation between parents, children and schoolteachers. We conclude that children and their parents are not well-represented in the decision-making and in the interventions that provide information to the other stakeholders. There is a need for further research in this thesis on how children can be partners in the transition process and how they can inform other stakeholders. Researchers also must investigate how this information can be evaluated and what the consequences are for the collaboration between stakeholders in the transition. 


\subsection{Introduction}

Every year, after the summer break, many children around the world make the transition to secondary school. As has been argued in Chapter 1, this is not an uncomplicated step in a child's development, because the transition is accompanied by several changes in both the school environment and in the social context. Children not only have to get used to a larger building, different teachers and a larger number of peers. They also have to adapt to the ways of thinking and the way you have to behave in secondary school. These changes can have positive or negative effects on children's well-being. It has been shown that poorer school and peer transitions can have long-term negative consequences for mental health (Chung, Elias \& Schneider, 1998; Waters, Lester, Wenden \& Cross, 2012).

It is important that children can develop according to their abilities. A smooth transition from primary to secondary school contributes to this. Zeedijk, Gallacher, Henderson, Hope, Husband and Lindsay (2003) call the transition to secondary school one of the most difficult transitions in a pupil's educational career. Children frequently have mixed feelings about the transition. They look forward to secondary school but may also have reservations (Sirsch, 2003). Children look forward to having more freedom, more challenges, and making new friends. At the same time, they are concerned about being picked on and teased by older children, having to work harder, receiving lower grades and being lost in a larger, unfamiliar school (Lucey \& Reay, 2000). Success in navigating this transition may not only affect children's academic performance, but also their general sense of well-being and mental health (Waters et al., 2012; Zeedijk et al., 2003).

Both children and society benefit from students who use their talents and do not drop out of school because of underachievement. Unnecessary absenteeism, dropout, grade retention and run-off should be avoided as much as possible (Bosch, Konermann, de Wit, Rutten \& Amsing, 2008). Children who fail to make a successful transition frequently feel marginalized, unwelcome, and not respected or valued by others. This may initiate a disengagement process from school (Roderick, 1993 in: Anderson, Jacobs, Schramm \& Splittgerber, 2000), lead to poor academic achievement and school dropout (Waters et al., 2012) and contribute to conflicts between the child and the school (Roderick, 1993 in: Anderson, et al., 2000).

Since the United Nations Convention on the Rights of the Child (U.N.,1989) was introduced, the involvement of children in decision-making has been an area of growing interest. During the past 30 years, research about self-regulated learning has become popular in educational research and has been integrated into classroom practice to help children to become independent learners (Paris \& Paris, 2001). The aim of this chapter is to determine what the effect is of the involvement of children in the process to ease the transition to secondary school. 
Although a number of publications have analyzed children's perceptions on the transition to secondary school and have made recommendations based on the content of what children say (Ashton, 2008; Bru, Stornes, Munthe \& Thuen, 2010; Chedzoy \& Burden, 2005), little is known about the role of children as the owners of their learning process.

\subsection{The current study}

In this chapter, we review the literature on the characteristics and interventions that contributed to a smooth transition. The aim of this systematic literature review is to identify empirical studies focusing on the effects of interventions to ease the transition process between primary and secondary school, especially interventions which, in contrast to the usual information about curriculum and test results, "give children a voice". We distinguish three stakeholders involved in the transition: the children and their parents, primary schools, and secondary schools. We investigate whether children (and their parents) are involved as a partner in the transition process and if this involvement influences the transition.

Several indicators can be used to determine a successful transition. Evangelou, Taggart, Sylva, Melhuish, Pammons and Siraj-Blatchford (2008) define a successful transition as consisting of the following five underlying dimensions: 1. After a successful transition children have developed new friendships and improved their self-esteem and self-confidence; 2 . they are settled so well into school life that they cause no concern to their parents; 3 . interest in school and schoolwork has increased compared with primary school; 4. they are used to their new routines; and 5 . they and the school organization experience curriculum continuity. This definition links all stakeholders and their interests, and is therefore used for the purpose of this review.

The stakeholders, with their background characteristics, are the focus of this chapter. The chapter is structured as follows: First the factors that influence the transition are described. These are the child's and family's characteristics, the preparation and support at school, the school's characteristics, and peers. Then interventions that facilitate a successful transition are presented. After that, the chapter provides a discussion and conclusion.

\subsection{Method}

To find relevant literature about the involvement of children in the transition process, online databases ERIC (Education Research Information Center), PsychINDEX and SocINDEX were 
searched using the terms: transition primary secondary school; trans* primary secondary school ("indicates a wide card option, so trans* extracts transition, transfer, transitional, etc.). The keywords were paired with the keywords "child" AND perspectives; child" AND perceptions; child* AND concerns; child* AND experiences. Google Scholar was searched both for a free search and for a snowball search. The search of the databases identified 202 international studies. After reading, the abstracts of 57 international studies remained, of which 30 articles published between 1987 and 2011 were found to be relevant. Included were peerreviewed articles, written in Dutch, English or German, and relevant to the research theme. The main criteria for inclusion were that the study examined typically developing children ${ }^{3}$ making the transition to secondary school. Due to differences in school systems between different countries and ages that children make transitions, an age range of 11-13 was used. Studies were excluded if the children were outside that age range. Studies that focus on atypically developing children or focus on special groups, special themes or curriculum areas were also excluded. Small case studies, containing fewer than 10 children, were excluded as well. This yielded 30 international studies. The studies included various perspectives from parents and children, teachers and principals. They included a range of foci: aspects of the transition, children's background and personal characteristics (gender, adjustment, well-being and self-esteem, motivation) perceptions and expectations about support, preparedness, bullying, peer and teacher relationships and parental perceptions, involvement, choices and support. Most data were collected through questionnaires and interviews.

The reviewed literature is diverse. The sample sizes differed between $\mathrm{N}=10$ and $\mathrm{N}=7883$. Questionnaires and students' and teachers' reports were frequently used. Most studies were descriptive. Due to the diversity of the studies, it was possible to make a thorough review of the transition and a great many of the conceivable problems. Most studies were unable to demonstrate causal relationships or to provide solid evidence by an experimental design. Despite the different perspectives of the reviewed literature and the diverse assumptions of the researchers, there was agreement about the key aspects which influence a successful transition. Important aspects are:

1 The involvement of all stakeholders in the interventions and good communication between all stakeholders (Coffey, 2013; Green, 1997; Jindal-Snape \& Miller, 2008; Lester, Cross, Shaw \& Dooley, 2012a);

2 The formation of a supporting network (Topping, 2011);

\footnotetext{
3 "Typical," or "Typically Developing" is the most appropriate way to describe children who are not receiving special education services. "Normal" is frankly offensive since it implies that a special education child is "abnormal." It also implies that there is a single norm for children. Instead, it is preferred to refer to children without disabilities as "typical" because they have the behaviour, intellectual ability and functional skills we would "typically" see in children of their age.
} 
3 Priorities for preparedness for autonomy and relatedness (Gillison, Standage \& Skevington, 2008) and for making relationships at secondary school;

4 Issues related to safety and belonging (Ashton, 2008), awareness of gender differences (Chedzoy \& Burden, 2005; Chung et al., 1998) and children who are vulnerable to a poorer transition (Chung et al., 1998; Jindal-Snape \& Miller, 2008; Pratt \& George, 2005; Lester et al., 2012a; Pellegrini \& Long, 2002; Rudolph, Lambert, Clark \& Kurlakowsky, 2001).

\subsection{Results}

The transition to secondary school involves various stakeholders who have an interest in a successful transition. All stakeholders - the children and their parents, primary and secondary schools - have their own approaches to ease the transition. It was clear that the selected articles could be linked to the stakeholders and to their characteristics. Consequently, this classification is used to organise this review. We distinguish the factors that can contribute to a smooth transition and describe if and how they can lead to interventions to facilitate a successful transition.

An overview of the reviewed studies and their characteristics is presented in table 2.1. Table 2.1 shows, in alphabetical order per author(s), the theme and the main results of each study. The sample sizes and measures (the way in which the data were collected) are also indicated. 
Table 2.1: Literature on the transition from primary school to secondary school

\begin{tabular}{|c|c|c|c|c|}
\hline Author(s) \& Year & Sample & Themes & Measures & Main Results \\
\hline $\begin{array}{l}\text { Anderson, Jacobs, } \\
\text { Schramm \& Splittgerber } \\
(2000)\end{array}$ & Review & $\begin{array}{l}\text { The reasons that transitions are } \\
\text { difficult, the kinds of students } \\
\text { that have the greatest } \\
\text { difficulties and the process of } \\
\text { disengagement from school }\end{array}$ & & $\begin{array}{l}\text { Attention for students' } \\
\text { preparedness for transition, kinds } \\
\text { of support and recommendations } \\
\text { for facilitating successful } \\
\text { transitions. }\end{array}$ \\
\hline Ashton (2008) & $N=1673$ & $\begin{array}{l}\text { Children's perceptions of } \\
\text { transfer to high school }\end{array}$ & $\begin{array}{l}\text { Questionnaires, } \\
\text { discussion, } \\
\text { student } \\
\text { drawings \& } \\
\text { writings }\end{array}$ & $\begin{array}{l}\text { Children can be a very valuable } \\
\text { resource in improving transition. }\end{array}$ \\
\hline $\begin{array}{l}\text { Bru, Stornes, Munthe \& } \\
\text { Thuen }(2010)\end{array}$ & $N=7205$ & $\begin{array}{l}\text { The degree to which students' } \\
\text { perceptions of teacher support } \\
\text { are related to school type } \\
\text { (primary versus secondary) }\end{array}$ & Questionnaire & $\begin{array}{l}\text { A linear downwards tendency for } \\
\text { perceived teacher support with no } \\
\text { obvious abrupt change between } \\
\text { primary and secondary school. }\end{array}$ \\
\hline $\begin{array}{l}\text { Chedzoy \& Burden } \\
\text { (2005) }\end{array}$ & $\begin{array}{l}\text { Review } \\
\mathrm{N}=207\end{array}$ & $\begin{array}{l}\text { Review of the reactions of } \\
\text { students to transfer } \\
\text { Study: student expectations } \\
\text { about school ethos, academic } \\
\text { work, relationships, aspects of } \\
\text { personal development }\end{array}$ & Questionnaires & $\begin{array}{l}\text { The existence of myths, refutation } \\
\text { of those myths after a short time. } \\
\text { The need for careful consideration } \\
\text { of the most appropriate form of } \\
\text { learning experiences after } \\
\text { transition. }\end{array}$ \\
\hline $\begin{array}{l}\text { Chung, Elias \& } \\
\text { Schneider (1998) }\end{array}$ & $\mathrm{N}=99$ & $\begin{array}{l}\text { Changes in patterns of } \\
\text { individual adjustment during } \\
\text { transition }\end{array}$ & $\begin{array}{l}\text { Questionnaires } \\
\text { Students' and } \\
\text { teachers' } \\
\text { reports }\end{array}$ & $\begin{array}{l}\text { Three distinct patterns were } \\
\text { identified across genders. }\end{array}$ \\
\hline Coffey (2013) & $\begin{array}{l}\text { Six larger } \\
\text { secondary } \\
\text { schools }\end{array}$ & $\begin{array}{l}\text { The importance for schools to } \\
\text { focus on relationships during } \\
\text { transition }\end{array}$ & $\begin{array}{l}\text { Questionnaires } \\
\text { Interviews } \\
\text { (parents, } \\
\text { teachers and } \\
\text { students) }\end{array}$ & $\begin{array}{l}\text { Positive relationships between the } \\
\text { stakeholders can help to } \\
\text { ameliorate the challenges } \\
\text { presented by transition. }\end{array}$ \\
\hline $\begin{array}{l}\text { Driessen, Sleegers \& } \\
\text { Smit (2008) }\end{array}$ & $\begin{array}{l}\mathrm{N}=7883 \\
\text { (data from } \\
\text { PRIMA } \\
\text { study 2002) }\end{array}$ & $\begin{array}{l}\text { The influence of pupil } \\
\text { background characteristics, and } \\
\text { a number of class and school } \\
\text { characteristics on the transition } \\
\text { to secondary school in the } \\
\text { Netherlands }\end{array}$ & $\begin{array}{l}\text { School } \\
\text { administration, } \\
\text { tests, } \\
\text { questionnaires, } \\
\text { teacher and } \\
\text { school report }\end{array}$ & $\begin{array}{l}\text { Over-recommending not related to } \\
\text { ethnicity or cognitive level of the } \\
\text { class or type of community still } \\
\text { occurs. Performance weighs more } \\
\text { heavily than socio-ethnic } \\
\text { background. }\end{array}$ \\
\hline
\end{tabular}




\begin{tabular}{|c|c|c|c|c|}
\hline Author(s) \& Year & Sample & Themes & Measures & Main Results \\
\hline $\begin{array}{l}\text { Evangelou, Taggart, } \\
\text { Sylva, Melhuish, } \\
\text { Sammons \& Siraj- } \\
\text { Blatchford (2008) }\end{array}$ & $\begin{array}{l}\mathrm{N}=550 \\
\text { (children) } \\
\mathrm{N}=569 \\
\text { (parents) }\end{array}$ & $\begin{array}{l}\text { Transition practices, success } \\
\text { factors, support, experiences } \\
\text { and expectations of pupils and } \\
\text { parents } \\
\text { Background characteristics }\end{array}$ & $\begin{array}{l}\text { Interviews } \\
\text { Questionnaires } \\
\text { (parents, } \\
\text { children, } \\
\text { teachers and } \\
\text { local authorities) }\end{array}$ & $\begin{array}{l}\text { For successful transitions, social } \\
\text { adjustment, institutional adjustment } \\
\text { and curriculum interest and } \\
\text { continuity need to be taken in } \\
\text { account by planning transition } \\
\text { strategies. }\end{array}$ \\
\hline Green (1997) & $\begin{array}{l}\mathrm{N}=10 \\
\text { (students) } \\
\text { Their } \\
\text { parents \& } \\
\text { teachers }\end{array}$ & $\begin{array}{l}\text { The psychological and social } \\
\text { aspects of transition }\end{array}$ & $\begin{array}{l}\text { Interviews } \\
\text { (parents, } \\
\text { children and } \\
\text { teachers) } \\
\text { Observations } \\
\text { Document } \\
\text { review }\end{array}$ & $\begin{array}{l}\text { It is vital to facilitate transition. } \\
\text { There is a need for a challenging } \\
\text { curriculum and information } \\
\text { exchange between primary and } \\
\text { secondary teachers. }\end{array}$ \\
\hline $\begin{array}{l}\text { Gillison, Standage \& } \\
\text { Skevington (2008) }\end{array}$ & $\mathrm{N}=63$ & $\begin{array}{l}\text { Changes in quality of life and } \\
\text { student well-being immediately } \\
\text { after the transition to secondary } \\
\text { school }\end{array}$ & $\begin{array}{l}\text { Quality of life } \\
\text { questionnaire }\end{array}$ & $\begin{array}{l}\text { Support for the needs for } \\
\text { autonomy and relatedness would } \\
\text { enhance the quality of life of } \\
\text { students over the transition to } \\
\text { secondary school }\end{array}$ \\
\hline Hanewald (2013) & Review & $\begin{array}{l}\text { Literature review to identify and } \\
\text { describe how and why transition } \\
\text { is critical and to unpack it in } \\
\text { what ways it can be supported }\end{array}$ & & $\begin{array}{l}\text { Teacher educators need to } \\
\text { incorporate transition programs } \\
\text { and strategies so teachers can } \\
\text { deal with transition problems. }\end{array}$ \\
\hline $\begin{array}{l}\text { Jindal-Snape \& Miller } \\
\text { (2008) }\end{array}$ & Review & $\begin{array}{l}\text { Theoretical perspectives from } \\
\text { the literature on resilience and } \\
\text { self-esteem are employed to } \\
\text { examine key aspects of the } \\
\text { process of transition from the } \\
\text { perspective of the individual } \\
\text { child }\end{array}$ & & $\begin{array}{l}\text { In order to help vulnerable children } \\
\text { to cope with, and even benefit from } \\
\text { transition, we need to focus more } \\
\text { on the way social and personal } \\
\text { experiences are interpreted at this } \\
\text { time. }\end{array}$ \\
\hline Kakavoulis (1998) & $N=340$ & $\begin{array}{l}\text { Pupils' motives for school } \\
\text { learning at the end of primary } \\
\text { school. How are these motives } \\
\text { differentiated during their } \\
\text { transition to secondary school? } \\
\text { How are motives correlated to } \\
\text { gender, intelligence, } \\
\text { achievement, as well as to } \\
\text { socio-economic and } \\
\text { educational level of the pupils' } \\
\text { parents? }\end{array}$ & $\begin{array}{l}\text { Questionnaires } \\
\text { Academic } \\
\text { Motivation Self- } \\
\text { Rating Inventory }\end{array}$ & $\begin{array}{l}\text { Academic motivation increased } \\
\text { after transition. This was not } \\
\text { related to gender or socio- } \\
\text { economic status. Primary school } \\
\text { academic motivation was related to } \\
\text { school achievement and father's } \\
\text { occupation. }\end{array}$ \\
\hline
\end{tabular}




\begin{tabular}{|c|c|c|c|c|}
\hline Author(s) \& Year & Sample & Themes & Measures & Main Results \\
\hline $\begin{array}{l}\text { Lester, Cross, Shaw \& } \\
\text { Dooley }(2012 a)\end{array}$ & $\mathrm{N}=3459$ & $\begin{array}{l}\text { Examination of bully-victim } \\
\text { pathway during transition period }\end{array}$ & Questionnaires & $\begin{array}{l}\text { An association between support, } \\
\text { connectedness to school, pro- } \\
\text { victim attitudes, outcome } \\
\text { expectations and level of bullying } \\
\text { involvement. }\end{array}$ \\
\hline $\begin{array}{l}\text { Lester, Dooley, Cross \& } \\
\text { Shaw, (2012b) }\end{array}$ & $N=3459$ & $\begin{array}{l}\text { Relationships and gender } \\
\text { differences among adolescents } \\
\text { during transition process }\end{array}$ & $\begin{array}{l}\text { Self-completing } \\
\text { questionnaires } \\
\text { for times over } 3 \\
\text { years }\end{array}$ & $\begin{array}{l}\text { Depression in males is a precedent } \\
\text { and antecedent for victimisation, } \\
\text { and for females an antecedent } \\
\text { only, while anxiety is for both } \\
\text { genders a precedent and } \\
\text { antecedent. There is a need for } \\
\text { interventions. }\end{array}$ \\
\hline $\begin{array}{l}\text { Lester, Waters \& Cross } \\
\text { (2013) }\end{array}$ & $N=3459$ & $\begin{array}{l}\text { Association between feeling } \\
\text { connected \& mental health }\end{array}$ & Questionnaires & $\begin{array}{l}\text { Need for interventions to improve } \\
\text { social and mental health } \\
\text { outcomes. }\end{array}$ \\
\hline $\begin{array}{l}\text { McGee, Ward, Gibbons } \\
\text { \& Harlow (2004) }\end{array}$ & Review & $\begin{array}{l}\text { The relationship between } \\
\text { transition and academic } \\
\text { achievement, adjustment to } \\
\text { secondary school and impacts } \\
\text { on different groups of students }\end{array}$ & $\begin{array}{l}\text { Analyses of } \\
\text { literature and } \\
\text { key informants }\end{array}$ & $\begin{array}{l}\text { There are important gaps in } \\
\text { information about transition in the } \\
\text { New Zealand context and } \\
\text { particular issues need further } \\
\text { investigation. }\end{array}$ \\
\hline $\begin{array}{l}\text { Mellor \& Delamont } \\
\text { (2011) }\end{array}$ & $\begin{array}{l}\text { Cohort } \\
\text { project } \\
\text { ORACLE } \\
\text { and from a } \\
\text { recent } \\
\text { ethnographic } \\
\text { project }\end{array}$ & $\begin{array}{l}\text { Perceptions of children in 1977- } \\
1978 \text { and } 2003-2004 \text { are } \\
\text { compared, to explore whether } \\
\text { anxieties and anticipations have } \\
\text { changed }\end{array}$ & $\begin{array}{l}\text { Ethnographic } \\
\text { observations, } \\
\text { qualitative } \\
\text { interviews and } \\
\text { children's writing }\end{array}$ & $\begin{array}{l}\text { The core concerns of pupils facing } \\
\text { the transfer to secondary school } \\
\text { have continuities, especially in the } \\
\text { areas of friendship and sense of } \\
\text { independence. }\end{array}$ \\
\hline Nottelmann (1987) & $\mathrm{N}=445$ & $\begin{array}{l}\text { Exploration of the issue of } \\
\text { timing in school transition and } \\
\text { the effect on children's } \\
\text { competence and self-esteem. } \\
\text { Examination of the effect of } \\
\text { school transition in teacher } \\
\text { ratings }\end{array}$ & $\begin{array}{l}\text { Children's self- } \\
\text { reporting and } \\
\text { teacher ratings }\end{array}$ & $\begin{array}{l}\text { Entry into secondary school } \\
\text { represents a significant change } \\
\text { from elementary school, but most } \\
\text { children negotiate the transition } \\
\text { without undue difficulty. }\end{array}$ \\
\hline
\end{tabular}




\begin{tabular}{|c|c|c|c|c|}
\hline Author(s) \& Year & Sample & Themes & Measures & Main Results \\
\hline Pellegrini \& Long, (2002) & $\mathrm{N}=154$ & $\begin{array}{l}\text { Bullying and victimization during } \\
\text { transition from primary to } \\
\text { secondary school }\end{array}$ & $\begin{array}{l}\text { Self-reporting, } \\
\text { peer } \\
\text { nominations, } \\
\text { diary, direct } \\
\text { observations, } \\
\text { teacher } \\
\text { measures }\end{array}$ & $\begin{array}{l}\text { Bullying mediated dominance } \\
\text { status from primary to middle } \\
\text { school. Boys target each other, not } \\
\text { females, in aggressive bouts. } \\
\text { Contact with peers decreased with } \\
\text { the transition, and then increased. } \\
\text { Social affiliation as an inhibitor of } \\
\text { victimisation. }\end{array}$ \\
\hline Pratt \& George (2005) & $\mathrm{N}=30$ & $\begin{array}{l}\text { Students' concerns regarding } \\
\text { their attitudes to friendship } \\
\text { How the children negotiate their } \\
\text { new environment }\end{array}$ & $\begin{array}{l}\text { Semi-structured } \\
\text { interviews } \\
\text { Questionnaires }\end{array}$ & $\begin{array}{l}\text { Children's priorities (having a best } \\
\text { friend and belonging to a social } \\
\text { group) are different from those } \\
\text { advocated by schools (concerning } \\
\text { behaviour, curriculum, and } \\
\text { academic issues). }\end{array}$ \\
\hline $\begin{array}{l}\text { Riglin, Frederickson, } \\
\text { Shelton \& Rice (2013) }\end{array}$ & $\mathrm{N}=202$ & $\begin{array}{l}\text { The relationship between } \\
\text { psychological functioning at the } \\
\text { beginning of year } 7 \text { with } \\
\text { attainment at the end of year } 7\end{array}$ & $\begin{array}{l}\text { Self- and peer } \\
\text { reporting, } \\
\text { questionnaires }\end{array}$ & $\begin{array}{l}\text { Depressive symptoms, school } \\
\text { liking and conduct problems } \\
\text { predicted lower attainment. School } \\
\text { concerns predicted lower } \\
\text { attainment for boys, the effect of } \\
\text { depressive symptoms were } \\
\text { significantly stronger for boys. }\end{array}$ \\
\hline \multirow[t]{2}{*}{$\begin{array}{l}\text { Rudolph, Lambert, Clark } \\
\text { \& Kurlakowsky (2001) }\end{array}$} & $N=329$ & $\begin{array}{l}\text { The role of maladaptive self- } \\
\text { regulatory beliefs as } \\
\text { vulnerability factors for } \\
\text { academic and emotional } \\
\text { difficulties during transition }\end{array}$ & $\begin{array}{l}\text { Self-reporting } \\
\text { and teacher } \\
\text { questionnaires }\end{array}$ & $\begin{array}{l}\text { The transition experience was } \\
\text { found to interact with pre-existing } \\
\text { maladaptive self-regulatory beliefs } \\
\text { that formed the basis for } \\
\text { depressive vulnerability. }\end{array}$ \\
\hline & $\mathrm{N}=856$ & $\begin{array}{l}\text { Children were asked to } \\
\text { appraise the transition to }\end{array}$ & Questionnaires & $\begin{array}{l}\text { Personal factors seem to be } \\
\text { predictive for the perceived threat }\end{array}$ \\
\hline Sirsch (2003) & & $\begin{array}{l}\text { secondary school, which was } \\
\text { perceived as a challenge and a } \\
\text { threat }\end{array}$ & & $\begin{array}{l}\text { from the transition to secondary } \\
\text { school. Very few students perceive } \\
\text { the transition as both a low } \\
\text { challenge and a low threat. }\end{array}$ \\
\hline $\begin{array}{l}\text { Tobbell \& O’Donnell } \\
\text { (2013) }\end{array}$ & $\begin{array}{l}\mathrm{N}=35(6 \\
\text { focus } \\
\text { groups) }\end{array}$ & $\begin{array}{l}\text { The experiences of students in } \\
\text { their transition to secondary } \\
\text { school. The focus is on } \\
\text { relationships with their new } \\
\text { teachers. }\end{array}$ & $\begin{array}{l}\text { Observation } \\
\text { One-to-one and } \\
\text { focus group } \\
\text { interviews }\end{array}$ & $\begin{array}{l}\text { Attention must be paid to facilitate } \\
\text { the formation of interpersonal } \\
\text { relationships which can lead to } \\
\text { learning relationships. }\end{array}$ \\
\hline
\end{tabular}




\begin{tabular}{|c|c|c|c|c|}
\hline Author(s) \& Year & Sample & Themes & Measures & Main Results \\
\hline Topping (2011) & $\begin{array}{l}\mathrm{N}=30(5 \\
\text { focus } \\
\text { groups) } \\
\text { Review }\end{array}$ & $\begin{array}{l}\text { Teacher's perspective and } \\
\text { child's perspective }\end{array}$ & $\begin{array}{l}\text { Document } \\
\text { analyses }\end{array}$ & $\begin{array}{l}\text { Children were concerned with peer } \\
\text { relations, bullying, self-esteem and } \\
\text { external support networks. } \\
\text { Teachers were concerned with the } \\
\text { attainment dip. Some children are } \\
\text { more vulnerable to a poor } \\
\text { transition. }\end{array}$ \\
\hline $\begin{array}{l}\text { Vaz, Parsons, Falkmer, } \\
\text { Passmore \& Falkmer } \\
\text { (2014) }\end{array}$ & $\mathrm{N}=266$ & $\begin{array}{l}\text { Determination of the } \\
\text { contribution of personal } \\
\text { background and school } \\
\text { contextual factors on academic } \\
\text { competence and mental health } \\
\text { functioning }\end{array}$ & Questionnaires & $\begin{array}{l}\text { Personal background factors } \\
\text { accounted for the majority of the } \\
\text { variability in post-transitional } \\
\text { academic competence and mental } \\
\text { health functioning. The contribution } \\
\text { of school contextual factors was } \\
\text { relatively minor. }\end{array}$ \\
\hline $\begin{array}{l}\text { Waters, Lester, Wenden } \\
\& \text { Cross (2012) }\end{array}$ & $N=1500$ & $\begin{array}{l}\text { The impact of the transition } \\
\text { experience on adolescent social } \\
\text { and emotional health, both } \\
\text { immediately following transition, } \\
\text { and at the end of the first year } \\
\text { in the new school environment. }\end{array}$ & Questionnaires & $\begin{array}{l}31 \% \text { experienced a difficult/ } \\
\text { somewhat difficult transition and } \\
\text { experienced poorer social and } \\
\text { emotional health after the first } \\
\text { year. }\end{array}$ \\
\hline $\begin{array}{l}\text { West, Sweeting \& Young } \\
\text { (2010) }\end{array}$ & $\mathrm{N}=2000$ & $\begin{array}{l}\text { Pupils' experience of transition, } \\
\text { predictors of poorer transitions } \\
\text { and consequences for } \\
\text { educational attainment and } \\
\text { pupil well-being }\end{array}$ & $\begin{array}{l}\text { Surveys, self- } \\
\text { completing } \\
\text { questionnaires, } \\
\text { mini-interviews }\end{array}$ & $\begin{array}{l}\text { Respondents with lower ability and } \\
\text { lower self-esteem experienced } \\
\text { poorer school transitions; the } \\
\text { effects were seen within and } \\
\text { beyond secondary education. }\end{array}$ \\
\hline $\begin{array}{l}\text { Zeedijk, Gallacher, } \\
\text { Henderson, Hope, } \\
\text { Husband \& Lindsay } \\
\text { (2003) }\end{array}$ & $\mathrm{N}=472$ & $\begin{array}{l}\text { Pupils' and parent's concerns, } \\
\text { skills that were perceived to be } \\
\text { useful, aspects to which } \\
\text { children looked forward and } \\
\text { suggestions by which schools } \\
\text { could facilitate the transition. }\end{array}$ & $\begin{array}{l}\text { Questionnaire } \\
\text { (children, } \\
\text { parents and } \\
\text { teachers) }\end{array}$ & $\begin{array}{l}\text { Bullying was a major concern for } \\
\text { all groups, followed by fears of } \\
\text { getting lost, increased workload } \\
\text { and peer relationships, among } \\
\text { others. Teachers rarely identified } \\
\text { children's individual abilities, } \\
\text { focusing instead on institutional } \\
\text { initiatives that carry the risk of } \\
\text { creating a degree of helplessness. }\end{array}$ \\
\hline
\end{tabular}


The transition from primary to secondary school represents a significant challenge to the stakeholders who are involved in the process. The children, parents and teachers have to adapt to the new circumstances. While this process may be stressful, positive interrelationships can help to address many of the challenges (Coffey, 2013).

\subsection{Factors influencing the transition}

All stakeholders have their own approaches to smooth the transition, as is shown in figure 2.2. In this figure, we distinguish the three stakeholders, with their background characteristics, who influence the transition and hence the development of the child. For children, it is important that their development continues in accordance with their capabilities.

Schools have an interest in a smooth transition, because it demonstrates the capacity of the feeding/primary school to prepare children to realize their academic potential at secondary school, and the capacity of the receiving/secondary school to ensure the child's curriculum and attainment continuity.

The parents are positioned in the circle of the child, because they are inextricably linked with the child. They are the constant factor in all development stages of the child and are ultimately responsible for the education of the child and for the choices involved (Bosch et al, 2008).

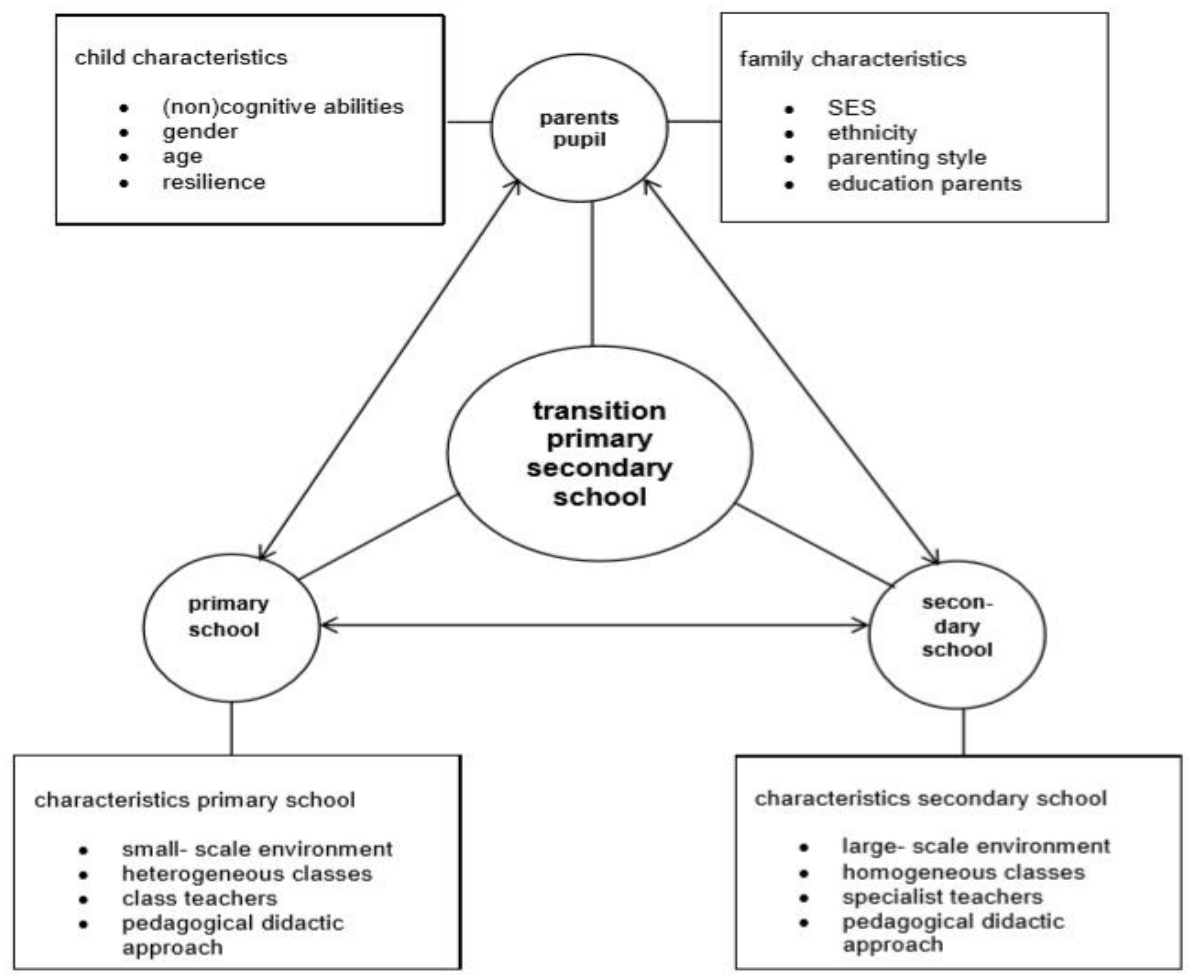

Figure 2.2: Stakeholders involved in the primary-secondary school transition 


\subsubsection{Child and family characteristics}

Adjustment difficulties to both school and peer social systems at the beginning of secondary school are related to the personal characteristics of the child (West, Sweeting and Young, 2010). Changing school, especially if the child moves to a secondary school with fewer children with a similar ethnical background, may have a negative impact on children's school career. Even children who are doing well in primary school can experience transition disruptions if their ethnic group is smaller at the secondary school (Benner \& Graham, 2009, in: Hanewald, 2013). The transition can pose specific problems and concerns for children from minority cultures and can make them vulnerable to a poor transition. Socio-economic factors, socio-ethnic factors/race, gender, prior problem behavior and low academic achievement can all have an impact on the transition to secondary school (Anderson et al., 2000).

The age factor does not seem to influence the transition process, but self-confidence and academic support do. McGee, Ward, Gibbons, \& Harlow (2004) found that, regardless of age, there appears to be evidence that the transition may lead to a decrease in academic attainment. This seems to be caused by the transition itself (McGee et al. 2004). Children who believe that they cannot exert much influence over their success in school and who experience little academic support report more school-related stress and become more depressed when they experience a transition into secondary school, but not when they remain in the same school (Rudolph et al., 2001).

Personal factors, such as socio-economic status (SES) and gender, particularly seem to be predictive factors for the perceived threat from the transition to secondary school (Sirsch, 2003). A lower SES may lead to lower achievement (Vaz, Parsons, Falkmer, Passmore \& Falkmer, 2014). Among children from low socio-economic households, $72 \%$ did not get used to the routines at secondary school and $58 \%$ did not settle in very well (Evangelou et al., 2008). Children from higher SES households had the highest score for academic competence while children from socially disadvantaged households had the lowest.

Gender differences are related to subject area. Girls perceive that close friend support and school support declines during the transition period, while boys self-report an increase in school problems during that period. School functioning during the transition period is a greater challenge for boys than for girls, while girls struggle to form new friendships with a new set of girls (Martinez, Aricak, Graves, Peters-Myszak \& Nellis, 2011 in: Hanewald, 2013). The majority of children moving to secondary school look forward to more freedom, new challenges, other subjects, different teachers and the opportunity to make new friends. Overall, 
girls make the transition more easily than boys and seem to be more settled after transition (Marston, 2008, in Hanewald, 2013).

School climate and school attachment as perceived by children themselves is correlated with misbehavior and aggressiveness. Violence and delinquency are related to negative perceptions of the school climate. Children's positive perceptions of the school climate and academic motivation are linked to teacher support (Hanewald, 2013). Familiarity with the new school makes the transition easier (Sirsch, 2003). Teachers and children have different perceptions of where problems lie (Topping, 2011). Children tend to think there is a problem with the delivery of the programs while teachers tend to think that the children bring the problems with them (McGee et al., 2004).

Children showing high levels of psychological distress prior to transition are at a greater risk than their peers for a stressful school transition (Chung et al., 1998; Riglin, Frederickson, Shelton \& Rice, 2013). Boys at risk tend to show adjustment problems (academic achievement and school behavior) whereas girls at risk show more generalized adaptive difficulties following the transition (Chung et al., 1998). Self-esteem is related to children's perceived social, physical and cognitive competence (Nottelmann, 1987).

Children with lower ability and lower self-esteem have more negative school transition experiences, which leads to lower levels of attainment and to higher levels of depression. Of all children, 3\%-5\% experienced depression and 3\%-6\% were anxious (Lester et al., 2012a). Anxious children experience peer victimization and thus poorer peer transition more frequently, which leads to lower self-esteem, more depression and anti-social behavior and therefore to a poor transition to secondary school (West et al., 2010). Of the children who were victimized, $12-21 \%$ experienced depression and $16-22 \%$, anxiety. Increased victimization at the end of primary school led to increased depression at the beginning of secondary school. Increased depression at the end of primary school leads to increased victimization for boys (Lester et al., 2012a).

Evangelou et al. (2008) found that children who experience a successful transition have developed friendships and boosted their self-esteem and confidence after moving to secondary school. These children received more help from their secondary school to settle in. Most of their primary school friends move with them to the same school and they have one or more older sibling(s) at the same school. They find that the older children at their school are friendly. Children are at risk of not expanding their friendships and boosting their self-esteem and confidence if they experience bullying while in secondary school. Problems with bullying are most acute among children with special education needs (SEN) (Vaz et al., 2014). Of 
those, $37 \%$ have problems with bullying, compared with $25 \%$ of the children without SEN (Evangelou et al., 2008).

Children from low or medium socio-economic status (SES) households are also vulnerable to a less smooth transition into school life if they experience bullying while at secondary school (Evangelou et al., 2008) and are less academically competent (Vaz et al., 2014). Three of every ten children have experienced bullying during their lives (Evangelou et al., 2008). Pellegrini and Long (2002) found disruptions in peer affiliations during transition to secondary school, peer victimization and increased use of aggression by boys, possibly to establish peer status. The factors of gender, prior problem behavior, low academic achievement, low SES and ethnicity are not independent of one another. They can be combined (and are) in many ways (Evangelou et al., 2008). Boys with a high level of psychological distress showed a significant decline in academic attainment and an increase in psychological distress, while girls showed a significant increase in only psychological distress (Chung et al., 1998).

Parental involvement can affect the transition process and the school achievement before and after the transition. It can be categorized into three dimensions: direct participation, academic encouragement and expectations for attainment (Chen \& Gregory, 2009, in: Hanewald, 2013). Children have a smooth transition from primary to secondary school if their parents remain a constant support, monitor their activities and intervene positively (Hanewald, 2013). Studies in the US have shown the importance of factors at home, such as the presence of books and a place to study, for a successful transition. Parental involvement is seen as important in the transition. Parents need to maintain rules, check on homework, discuss the schoolwork, and monitor their child's social life and academic progress (McGee et al., 2004). This affects children's school achievement. If parents and schools are not in line, parental support is less likely to be effective (McGee et al., 2004).

Family support is also linked to achievement after transition. Both school and family should create and keep an environment for reinforcing and renewing children's academic motivation (Kakavoulis, 1998). Children from lower SES households often lack parental support, including parental interest and participation in the school process, the extent to which they talk with their children about school, and the extent to which parents supplement the learning process with educational activities (Anderson et al., 2000).

Children living with both biological parents seem to perceive fewer concerns about the transition to secondary school than their peers from single-parent or blended families. It may be that intact families often have a higher quality of interaction that may prepare the children better for stressful events like the transition to secondary school (Duchesne, Ratelle, Poitras, \& Drouin, 2009 in: Hanewald, 2013). 


\subsubsection{Preparing for a successful transition and support}

In many school systems, in the final grade of primary school, children and their parents are advised which secondary school is the most suitable. In making this decision, three parties with desires or preferences are involved: the children, their parents and the teachers. The choice for a secondary school is determined by cognitive competences (performance, and test results), non-cognitive factors (attitudes, motivation, and interests) and the teacher's judgment (Driessen, Sleegers \& Smit, 2008).

Children must be prepared for a successful transition. Children who have the knowledge and skills to succeed at the next level (academic preparedness) and who are able to work by themselves and stay at the task (independence and industriousness) as well as children who conform to adult standards of behaviour and effort, and children who are able to cope with problems and difficulties, are more likely to be successful at the next school level (Simmons \& Blyth, 1987; Snow, Gilchrist, Schilling, Schinke \& Kelso, 1986; Timmins 1989; Ward et al., 1982 in: Anderson et al., 2000).

The literature shows that the environmental context has a stronger effect on the success or failure of a school transition than developmental characteristics (Anderson et al., 2000). The relative importance of the environmental context suggests the possibility that educators can contribute greatly to facilitating successful school transitions. However, few efforts have been made to do so (Anderson et al., 2000). One of the main features affecting a successful transition is whether children received enough help from their secondary school. Help can include procedures to help the children to adapt and to know their way around at secondary school. Schools can organize induction and taster days, and offer information support and assistance with lessons and homework to help children adapt (Evangelou et al., 2008).

During the transition, children pass through two types of discontinuities: organizational/formal (departmentalization) and social (fear of getting lost and being victimized) (Anderson et al., 2000). The greater the discontinuity the child perceives, the greater the support that is needed. To help vulnerable children cope with, and even benefit from, the period of transition, we need to focus more on the social and personal experiences at this time (Jindal-Snape \& Miller, 2008). There is a need for interventions to improve social and mental health outcomes (Lester, Waters \& Cross, 2013). Waters et al. (2012) suggest early detection of children who are vulnerable to a poor transition to enable support, tailored to their particular needs, to increase their connection to the new school environment and minimize the potential of long-term negative implications. Support can be informational, tangible, emotional and social. Regardless of the type of support, parents, peers and/or teachers can provide it (Anderson et al., 2000). 
There is a consensus in the literature that well-designed and implemented transition approaches can assist in the process of supporting students, their families and school staff (Hanewald, 2013). Most schools have developed systems to ease the transition process. Their emphasis is often on administrative and organizational procedures, in contrast with that of children and their parents, who are especially concerned with personal and social issues (Jindal-Snape \& Miller, 2008). Head teachers rarely pay attention to peer relationships or the importance of friendship during the transition process (Pratt \& George, 2005). The sensitivity of secondary school teachers to the children's psychosocial transfer and their awareness of the importance of social relations may well play a significant role in helping children (Chedzoy \& Burden, 2005). Attention should be paid to facilitating the formation of interpersonal relationships between children in the new school (Coffey, 2013; Tobbell \& O'Donnell, 2013).

An important aspect in the adjustment to a new school is the children's sense of belonging and their socio-emotional functioning (Cueto, Guerrero, Sugimaru \& Zevallos, 2010, in Hanewald, 2013). Children who feel supported by teachers are found to have a positive motivational orientation towards schoolwork and to experience positive social and emotional well-being (Bru et al., 2010). Teachers' ability to support students is a crucial element for better learning.

\subsubsection{The relationship between primary and secondary school}

Coffey (2013) found that positive relationships and good communication channels amongst and between the stakeholders before, during, and after transition are crucial to improving the transition (Coffey, 2013). For a smooth transition, the teacher plays a critical role (Coffey, 2013; Topping, 2011) and sharing information concerning the child is valuable to supporting transitions (Chedzoy \& Burden, 2005; Green, 1997). Nevertheless, the information shared between schools is usually generic information on the curriculum rather than information about individual children (Topping, 2011). Schools generally pay little attention to peer relationships or the importance of friendships (Pratt \& George, 2005). Information from primary to secondary school also needs to provide personal and social factors to make secondary schools alert to children who may be more vulnerable when they move (Jindal-Snape \& Miller, 2008). Although it is known that sharing information between primary and secondary school, focused on personal and social factors, smooths the transition, less is known about the results when children receive the opportunity to participate actively during the transition trajectory by sharing information with their secondary school teachers. In Chapters 3 and 4, we describe our study into the expectations and experiences of the children.

McGee et al. (2004) examined schools in New Zealand and found disappointingly few contacts between primary and secondary schools to manage the transition effectively. In schools where there was contact, it mainly concerned the transfer of information about students, familiarizing 
students and their parents with the secondary school, sharing facilities and teacher contacts about curriculum and teaching (McGee et al., 2004). One of the issues facing secondary school teachers is how much they want to know or should know about their students coming from primary school. Is it best to know very little so as to give children "a fresh start", or is it best to be well briefed on each student? In Chapter 5 , the views of seventeen mentor-teachers in the Netherlands about how they acquire, share and use information about the children in their class are discussed in more detail. Teachers at secondary school, faced with children from a variety of feeder schools, tended to start on the same level for all children regardless of previous achievement. This resulted in a loss of continuity in the curriculum because of the transition (Huggins \& Knight, 1997 in: McGee et al., 2004).

McGee et al. (2004) found that teachers' expectations often differ between primary and secondary school. Once at secondary school, the children experience the workload as lower than they had expected at primary school, including less homework. This raises the question of whether primary and secondary teachers understand each other's work and whether steps should be taken to ensure that they do (Green, 1997), because previous experience or achievement is often disregarded by secondary schools. This corresponds to the findings from Evangelou et al. (2008) that secondary schools do not appear to trust the data on children provided by primary schools.

\subsubsection{The formal and the informal context: school characteristics and peers}

There is no consensus about children's experiences with the transition. Generally, over the years, the literature shows that most children make the transition to secondary school without difficulty, but it can be stressful for some. For example, $85 \%$ of the children in a study by Nottelmann (1987) reported looking forward to secondary school, but $15 \%$ did not. The figures in a study by Coffey (2013) were close to those of Nottelmann: midway in the first term at secondary school, Coffey found that $88 \%$ of the children reported being settled, which means that $12 \%$ were not. In another study, Cedzoy and Burden (2005) found the percentage of happy anticipation to be as high as $92 \%$. In that study, by the end of the first term at secondary school, one in ten children reported that the transfer had not gone so well after all (Cedzoy \& Burden, 2005).

West et al. (2010) also found a significant number of children struggling to deal effectively with the start of secondary school. A quarter found the experience very difficult. In contrast to other studies (McGee et al., 2004), more concerns were expressed about the formal school system than the informal system of peer relations (West et al., 2010). McGee et al. (2004) found that continuity of peer group appears to be associated with continuity of achievement. Low 
achievers at primary school may do better with a new peer group at secondary school when they are influenced positively by their new peers (McGee et al., 2004).

Ashton (2008) and West et al. (2010), describe children's school and peer concerns as constituting two dimensions during the transition: the formal school system (size of school, different teachers, work volume) and the informal social peer system (different kids, older teenagers, bullying). Children can be successful in one area, but not in the other; and higher factor scores in the two dimensions represent poorer transitions.

Children in secondary schools often report a decrease in the sense of school belonging and perceived quality of school life. Even children who were victims of bullying at primary school, and who were already showing less connection with school, felt even more disconnected in secondary school (Lester et al., 2012a). Green (1997) found that all children at secondary school expressed concerns about making friends. Having friends is important for the security of walking into different rooms as well as deciding who to sit next to. When a child moves to secondary school with some known friends, knows older children at school or has siblings at the same school, some of the anxiety about making friends is alleviated (Green, 1997). This corresponds to the findings of Pratt and George (2005), who found that the continuity and development of peer group relations and friendships was the most important factor for children.

Having friends of your own is important because loyal, "real" friends are a protection against being bullied (Mellor \& Delamont, 2011). Mellor and Delamont distinguish rational anxieties (being separated from current friends, anxieties about the curriculum, the buildings and the range of different teachers) and irrational anxieties (myths or scary stories heard from older children). Friendship can serve as a social support. Green (1997) also reports that some children were concerned about being bullied by older students. Such fears were based on rumors spread by older students. In reality, such bullying did not occur (Green, 1997). In contrast to the findings of Green (1997), a large-scale survey in 40 countries revealed $10.7 \%$ of adolescents reporting involvement in bullying (as perpetrators), $12.6 \%$ as victimized and $3.6 \%$ as bully victims (Craig, Harel-Fisch, Fogel-Grinvald, Dostaler, Hetland \& Simons-Morten, 2009, in: Lester et al., 2012a). Behind the rational anxieties lies the children's culture with irrational fears, often spread by the stories of older students (Mellor \& Delamont, 2011). The children were particularly concerned about the way in which their behavior at secondary school was perceived by their peers. They did not want to be seen as "a nerd" but rather aimed to seen as being "cool" (Green, 1997). 


\subsection{Interventions to facilitate successful transitions}

To help children who are at risk of a poor transition, interventions that provide adequate information and social support activities, and that help with the formation of friendship networks, are crucial. They help children cope with the transition. Prior to the transition, at primary school, children need to be prepared for holding more responsibility for their learning. They need to learn to think about strategies for learning independently in a more challenging curriculum with clear goals for academic achievement like at secondary school (McGee et al., 2004). In Chapter 5, we will show that the class mentors of grade seven share this opinion, and in Chapters 3 and 4 , we examine the expectations and experiences of the children. When children enter secondary school, motivation increases significantly. Both school and family should assist in creating and maintaining a highly motivating environment for reinforcing and renewing children's academic motivation (Kakavoulis, 1998; in Chapter 5, we show that this is confirmed by the class mentors of grade seven).

According to Anderson et al. (2000), interventions to facilitate a successful transition have to be comprehensive and involve parents, and receiving schools have to make every effort to create a sense of community belonging (Anderson et al., 2000). Parents can contribute to a smooth transition by participating in their child's schooling. When they do so, the child should achieve at a higher level (Coffey, 2013). Pellegrini and Long (2002) suggest fostering relationships during the first year of middle school by organizing social and interest-specific events. Effective lines of communication need to be established between parents and the school so that both can work effectively together for the benefit of the children (Coffey, 2013). Green (1997) recommends an ongoing information exchange between primary and secondary teachers to facilitate the transition process and to reduce unnecessary discontinuity (Green, 1997).

Children struggling with the transition need support provided by multiple groups. Parents can provide support with respect to homework (Coffey, 2013; Jindal-Snape \& Miller, 2008; Kakavoulis, 1998; Pellegrini \& Long, 2002). Taking into account existing friendships, classifying the children in different freshman groups can also support children (Green, 1997). Teachers at secondary school who are more accessible to students facilitate successful transitions. Simply being available to students is a form of teacher support. Positive peer relationships promote adjustment to the new environment in the secondary school. In supporting these peer relationships, teachers can play an important role. Hamm, Farmer, Dadisman, Gravelle \& Murray, 2011, in Hanewald (2013) found that teachers who are more attuned to peer group affiliations promote more positive contexts and have students with 
improved views of their school's social climate and adjustment during the school transition period. Coffey (2013) noted that the teacher is the key person in helping the child settle.

Lester et al. (2012a) conclude that there is a need for transition programs with a focus on early targeted interventions to minimize health risks to children from bullying and to minimize the impact on the school environment. They suggest a critical time to implement bullying intervention programs (that address peer support, connectedness to school, pro-victim attitudes and negative outcome expectancies around perpetrating) is prior to the transition to, and within the first year of, secondary school (Lester et al., 2012a). Waters et al. (2012) suggest developing an intervention based on best practice guidelines, to help children to negotiate the transition.

Many school transition interventions have a single and relatively narrow focus. Essential components of a transition model are: developing a planning team, generating goals and identifying problems, developing a written transition plan, acquiring the support of all those involved in the transition process, and evaluating the process (Anderson et al., 2000). A focus on relationships and empathic school personnel can ensure that both child and parent concerns are acknowledged and accounted for when planning transition programs (Coffey, 2013). Topping found that having an external supporting network is crucial for a successful transition (Topping, 2011).

Some children are vulnerable to poor academic progression and disengagement during the first year of secondary school. Especially children with conduct problems and children who do not like school, as well as boys with depressive symptoms and school concerns, may need special support (Riglin et al., 2013). Prevention-oriented school psychologists need to understand different paths of adaption to the school transition in order to identify the characteristics of children at risk and provide them with early intervention services for their specific needs (Chung et al., 1998).

\subsection{Discussion}

The transition to secondary school, an important moment in the lives of children, is not always successful. Children's personal characteristics such as ability, self-esteem, depression and anxiety, and gender, as well as family characteristics, can lead to a poorer transition. They can influence the adjustment to the school systems and to the peer/social systems (West et al., 2010). 
The current review provides evidence about how children are involved in interventions to ease the transition and about the effect of those interventions on the transition process. In this review, we identified empirical descriptive studies focused on the effects of characteristics and interventions to ease the transition from primary to secondary school, especially interventions that give children a voice.

For the purpose of the study, we distinguished three stakeholders (children with their parents, and primary and secondary schools) involved in the transition process, who would benefit from a successful transition and can influence it by their background characteristics (Jindale-Snape \& Miller, 2008). Unfortunately, we found little evidence of educational partnership or cooperation between these stakeholders. Although educators can do a great deal to facilitate successful school transitions (Anderson et al., 2000), few efforts have been made to work together or to realize effective lines of communication. All stakeholders seem to approach the transition process from their own distinct perspective, and adjust interventions accordingly. The effectiveness of these efforts is rarely evaluated.

The influence on the transition process of school characteristics, such as differences between the primary and secondary school in the school environment and in pedagogical didactic approach, is barely investigated in the literature. The reviewed authors just give recommendations to facilitate successful transitions, suggestions for practice and targets for school interventions. Schools do not focus as much on their emotional climate as they do on academic requirements. This is particularly remarkable. Although the literature shows the need to help children to develop their social and personal skills and to enhance their self-esteem (Ashton, 2008; Coffey, 2013; Gillison et al., 2008; Zeedijk et al., 2003), there is a lack of proven effective interventions in this area.

Very close links between primary and secondary school teachers were found to be essential for successful transitions (Green, 1997; Jindale-Snape, \& Miller, 2008). These close links would make them aware of children who are vulnerable to a poor transition (Cedzoy \& Burden, 2005; Chung et al., 1998). In practice, this is not obvious. Teachers who prepare children for the transition or support them after the transition do not always have sufficient information about the children.

Family backgrounds, including cultural and socio-economic factors, can pose specific transition problems. Children from families in poverty, and from larger and less educated families, do worse than their peers, especially when they are younger than their classmates (Topping, 2011). Their parents, who can be a reliable source of information about their child, are less likely to be involved in school activities and to support the school (Topping, 2011). 
Little evidence is found of interventions that focus on partnership or cooperation between parents and schoolteachers during the transition process. There is agreement about the importance of support from external networks (Topping, 2011) such as extended family, neighbors or friends. In particular, support from the family is described as extremely important (Anderson et al., 2000; Coffey, 2013; Green, 1997; Jindale-Snape \& Miller, 2008; Lester et al., 2012a; Lester, Dooley, Cross \& Shaw, 2012b; McGee et al., 2004) but is often neglected by schools. Parents usually do not participate in the decisions about the transition.

The involvement of children in decision-making by giving them a voice has been an area of growing interest. In the literature on the transition to secondary school, the active role of the child remains somewhat under-explored, as few studies have focused on the perspective of the children. The absence of any direct consultation with the children involved in the transition process demonstrates the low priority given to this aspect of transfer. It is possible for secondary schools to learn from children by asking incoming students about their thoughts about the transition, and by asking students who have recently completed the transition about their experiences and what they can suggest to smooth the transition for other children. When teachers are able to explore teaching and learning through the eyes of the children, they might be able to develop strategies based on first-hand evidence.

The current study is not without limitations. The analyses of the literature indicate that, to gain insight into the active role of children during the transition, there is a need for further research. Issues such as whether children can be partners in the transition process, how they can inform their stakeholders in an effective way and how this information can be evaluated still have to be investigated. This is what we will do in Chapters 3 and 4 . What the consequences are for a successful transition and how the collaboration between stakeholders and educational practice at primary and secondary school can help children who are vulnerable or at risk of a poor transition also needs to be investigated. This will be the topic of Chapter 5 .

\subsection{Conclusions}

Exploring the literature on interventions to improve the transition to secondary school, especially on interventions that give the children a voice, the results of the present review underline the importance of positive relationships and good communication between all stakeholders to realization of a successful transition (Coffey 2013; Green 1997; Jindale-Snape \& Miller, 2008; Lester et al., 2012a). The findings also suggest that the children (and their parents) are under-represented both in the decision-making and in the interventions that provide information to the other stakeholders, the schools (McGee et al., 2004). To reduce risk 
factors for vulnerable children and their parents, the findings underscore the need for more social and personal interventions, such as interventions that promote the interpersonal relationships with peers and the sense of belonging at secondary school (Jindale-Snape \& Miller, 2008). Knowing that the environmental context influences a successful transition more than developmental characteristics can contribute to focusing interventions toward improving the transition (Anderson et al., 2000). Teachers especially have the opportunity to improve the transition by encouraging the children to participate in decision-making about their transition process. Unfortunately, little effort is still being made to do so.

This study not only provides empirical support for previous studies, but also contributes to increasing the awareness of policy makers, school leaders and educators of the importance of involving all stakeholders as equal partners in the interventions to improve the transition process. It also demonstrates the need for communication with children rather than about children. We hope that this will promote a more successful transition of young adolescents to secondary school.

Following the above findings, we investigate how the children themselves view the transition. In Chapter 3, the differences and similarities in perception between boys and girls are analyzed. In Chapter 4, we examine through a blinded experiment whether and how information from children can contribute to a better transition. 


\section{Chapter 3}

\section{Girls' and boys' perceptions of the transition from primary to secondary school}

This chapter is based on: Van Rens, M., Haelermans, C., Groot, W., \& Maassen van den Brink, H. (2019). Girls' and Boys' Perceptions of the Transition from Primary to Secondary School, Child Indicators Research, 12 (4), 1481-150. 


\begin{abstract}
This chapter explores the expectations and experiences of the transition from primary to secondary school using data from 98 Dutch primary education children: 45 boys and 53 girls. We focus on gender differences from the child's point of view about the ease of transition. The results show that before the transition, children are mostly worried about the continuity of relationships. Boys tend to think it is important to know someone at secondary school - a friend, older children, or a sibling - while girls are particularly interested in the challenges in the social environment (will my classmates like me?). After the transition, most children realize that they have underestimated the social-emotional impact. Many felt unprepared to handle the new social environment independently and needed external support to feel at home at their new school. Only three percent of all children (two percent of the boys and four percent of the girls) indicated that they were well equipped to make friends at their new school.
\end{abstract}




\subsection{Introduction}

In Chapter 2 of this thesis, we found that the quality of the transition may differ by gender. For example, boys with a high level of psychological distress showed a significant decline in academic achievement and an increase in psychological distress after the transition, while girls showed a significant increase in psychological distress (Chung, Elias, \& Schneider, 1998). Gender differences were also found in the way children acted during the transition period. Boys experienced an increase in school problems, while girls struggled to form new friendships (Martinez, Aricak, Graves, Peters-Myszak, \& Nellis, 2011). In this chapter, we further investigate the gender differences in the transition, as indicated by the children themselves. As described in Chapter 2, most studies about the experiences of children are descriptive. This study investigates the opinions of the children through an experimental study. Similarities between the experiences of boys and girls during the transition are also examined. The SelfDetermination Theory provides the underlying theoretical framework. According to the SelfDetermination Theory (SDT), the fulfilment of three basic psychological conditions competence, autonomy and relatedness - is essential to good personal development (Ryan \& Deci, 2000). If children's needs for these three are met, their natural curiosity and activity will be stimulated. This then leads to more intrinsic motivation and better personal development.

Every year worldwide, many children make the transition from primary to secondary school. This transition may be experienced differently by children in different countries. The study we describe in this chapter is limited to the experiences of children in the Netherlands, who make the transition from primary to secondary education at the age of twelve.

The transition from primary to secondary school is an important moment in a child's life and a major, and sometimes complicated, step in that child's development. As described in Chapter 2 , during a relatively short period of time, children experience many changes and challenges in their school and social environment. This can have both positive and negative effects on their cognitive, psycho-social and emotional development (Sirsch, 2003). Moving from a small, familiar primary school, where they feel safe, to a much larger, unfamiliar secondary school, where they feel repositioned as the youngest and smallest children, they have to cope with a new and different school culture (Pratt \& George, 2005). There is also much to look forward to, such as the prospect of having more freedom, making new friends and the opportunity to participate in extra-curricular activities (Coffey, 2013). 
The literature shows that prior to the transition, most children express some concerns and anxieties about the school system and the informal system of peers (Anderson, Jacobs, Schramm \& Splittgerber, 2000). There is less consistent evidence about the post-transition experiences, although there appears to be a general consensus that the worries children experience mostly disappear during the first year at secondary school (West, Sweeting \& Young, 2010).

After one semester in secondary school, children indicate that the social environment dominates their concerns (Pratt \& George, 2005). They find continuity and development of peer group relations and friendships more important than issues about the curriculum, because they worry more about being isolated or marginalised (Pratt \& George, 2005). Positive relationships can help them to address these challenges (Coffey, 2013), whereas personal and family characteristics can influence the process. Many authors have found gender differences in the coping behaviour of children at secondary school. Girls cope better than boys. Girls socialise more in groups of friends and are more attentive at school (McGee, Ward, Gibbons, \& Harlow, 2004), whereas boys socialise around sports activities and tend to be more disruptive than girls.

Previous research has suggested that children are competent to communicate valuable views that are worth taking into consideration (Mason \& Danby, 2011). Unfortunately, children seldom participate in research about the transition, and if they participate, no attention is paid to the effect of children's opinions on the transition. The aim of this chapter is to investigate the expectations and the experiences of children themselves. We analyse whether their experiences confirm the findings of the literature, which are reported by adults. We expect that children's vision about the transition process can bring new insights into the research of which adults might not have been aware and can challenge educators to make changes in their classrooms. This assumption is confirmed by Lundqvist (2014), who found that children's participation in research made it possible for them to contribute to policy and practice. Moreover, children's participation could also have a positive impact on their well-being and development (Lundqvist, 2014). We are interested in children's initial priorities and whether there are gender differences in the perceptions, expectations and experiences in the transition from primary to secondary education. For this, we use data on 98 children in the final year in primary education from 32 primary schools in the southeast of the Netherlands. Children's opinions are measured by two self-reporting questionnaires before and after the transition from primary school to secondary school (Appendix, Chapter 3, 3.2: Pre and post transition questionnaires). 
Each child's pre-transition expectations and perceptions were measured and compared with their perceived experiences eight weeks after the transition to secondary school. This allowed us to determine what information the children found to be important beforehand, and what aspects of this information should be taken into account by the new school or class mentor ${ }^{4}$ to help the children to become familiar with and accustomed to secondary school. By comparing the responses from the before and after questionnaires, we were able to analyse whether children over- or under-estimated the importance of certain aspects in the transition and obtain insight into what is really important to them. In a second step, this evaluation was done for boys and girls separately. The key themes in the questionnaires comprised the children's perceptions and experiences about school choice, preparing for secondary school, the role of the mentor, making the transition with peers, and differences in the context.

\subsection{Literature review of children's expectations and experiences with the transition}

Most studies on the transition to secondary school have been done relatively recently. Until the 1980s, research on this theme tended to be concerned with academic attainment and curricula demands (Pratt \& George, 2005). Since establishment of the United Nations Convention on the Rights of the Child (UN, 1989), which gives young people the right to express their views and to be taken seriously, the involvement of children in decision-making has been an area of growing interest. In several studies, children were considered to be competent enough to describe and share their experiences and perspectives. In doing so, children were able to bring new perspectives of which adults may not have previously been aware (Lundqvist, 2014). Despite this, in the scientific literature about the transition from primary to secondary school, children are still not considered as equal partners. The absence of any direct consultation with the children during the transition process and the fact that children are rarely asked for feedback demonstrates the low priority given to their voice (Pratt \& George, 2005; Chapter 2: Van Rens, Haelermans, Groot \& Maassen van den Brink, 2020). What we know about children's experiences and perceptions is largely based on empirical research among their parents or on research using self-completed questionnaires. Below we review the literature regarding girls' and boys' own perceptions and experiences, the role of the mentor, and the school and social contexts of the transition from primary to secondary education.

\footnotetext{
${ }^{4}$ In secondary school, each class has a mentor, usually one of the child's teachers, who is the key individual in the contact between 'their' pupils and the parents, teachers and classmates. In practice, mentors are responsible for addressing all of the adjustment problems that seventh graders might experience.
} 


\subsubsection{Children's perceptions and experiences}

All stakeholders in the transition process - children (and their parents), and the feeding and the receiving schools - agree about the importance of a successful transition. However, their perspectives with respect to the most important aspects of the transition process are quite different. While teachers focus on curriculum problems and school strategies in order to prevent an attainment dip, children and their parents concentrate on the social emotional aspects of secondary school life (Topping, 2011).

For the most part, the views of the children and their parents about the transition are similar (Zeedijk Gallacher, Henderson, Hope, Husband, \& Lindsay, 2003). According to Zeedijk et al. (2003), the similarity between the responses of parents and children suggests that parents are well informed about their children's expectations. At primary school, children themselves think that academic ability is important to manage the transition to secondary school, and they are concerned about social emotional matters. Once at secondary school, academic skills are rarely mentioned. Instead, children emphasize that time management, the ability to focus on a task, good behaviour and social skills are necessary. This suggests a mismatch between the fears and anxieties the children experience beforehand and the actual skills they need to address these fears and anxieties (Zeedijk et al., 2003).

From the children's perspective, the transition is complicated. They perceive it as both a challenge and a threat (Sirsch, 2003). Children look forward to making new friends and, at the same time, they are concerned about being picked on and teased by older children or getting lost in the larger building (Lucey \& Reay, 2000). They also worry about bullying, increased workload and peer relationships (Zeedijk et al., 2003). When peer relations from primary school can be continued at secondary school, it can function as a buffer and reduce stress (Topping, 2011).

Boys and girls may be differently affected by the transition. Girls report significantly more concerns than boys, but also express more positive attitudes towards school and teachers (Anderson et al., 2000; Rice, Frederickson, \& Seymour, 2011). Driessen \& Van Langen (2011) showed that there are no differences in cognitive competences between boys and girls. Boys have lower non-cognitive competences, such as working attitude and social behaviour (Driessen \& Van Langen, 2011). According to Chung et al. (1998), following the transition, boys demonstrate a significant decline in academic achievement, while girls do not suffer any significant change. However, girls experience more psychological distress than boys, assessed by physical symptoms, which may indicate that girls express the stressfulness of 
transition via internalisation (Chung et al., 1998). A more recent Dutch study found that girls' self-esteem reacts more to discrepancies between expected and experienced social acceptance than boys' self-esteem. Boys react more emotionally to grades and are more likely to experience decreased emotional school engagement than girls when they obtain low grades (Poorthuis, 2012).

Parents and teachers need to be aware of the experiences that children will encounter, in order to prepare them for the transition and to support them in their new school (Anderson et al., 2000). Some children, for example children with special educational needs, generally need and receive more support in comparison with typically developing children (Evangelou Taggart, Sylva, Melhuish, Sammons \& Siraj-Blatchford, 2008). Parents and teachers need to work together. Effective lines of communication between primary and secondary school are crucial (Coffey, 2013). However, schools and parents focus on different aspects in the transition process (Topping, 2011). In preparing children for secondary school, teachers and head teachers concentrate on long-term issues, such as behaviour, the curriculum and academic issues; they pay little attention to the importance of social relationships in the transition process, which is what children and parents find more important (Pratt \& George, 2005).

According to Zeedijk et al. (2003), teachers, especially at primary school, are focused on institutional initiatives and are less interested in developing children's coping skills. If children do not learn how to cope with stress themselves, they become dependent on organisational and external structures (Zeedijk et al., 2003). To help children to become independent learners, teachers should facilitate and support autonomy, competence and relatedness (Ryan \& Deci, 2000). This will also make them more able to accomplish a successful transition.

\subsubsection{The role of the mentor}

Anderson et al. (2000) found that the environmental context has a stronger effect on the school transition than developmental characteristics. This implies that educators are in a position to easily facilitate successful school transitions. In the Netherlands, the mentor is the educator designated to address adjustment problems of seventh graders, because the mentor has a central position among the children's contacts. Ryan and Deci (2000) confirmed that educators can promote achievement and well-being at school by supporting the three basic psychological needs of competences, autonomy and relatedness. We will return to this in the theoretical framework in section 3.3. However, when children experience excessive control, flawed challenges and lack of connectedness, this may result in a lack of initiative and responsibility as well as in distress and psychopathology (Ryan \& Deci, 2000). In Chapter 2, we explained 
that, although educators could help children to get involved in secondary school by developing a sense of belonging, few efforts have been made to do so and where efforts have been made, their effectiveness is seldom evaluated (Anderson et al., 2000). Secondary school teachers, especially mentors, are, for example, conflicted over whether it is better to be well-briefed about the children or to know very little about them in order to give them 'a fresh start' (McGee, Ward, Gibbons \& Harlow, 2004; Chapter 5 of this thesis). The former seems more important, because children who feel they get a lot of help from their secondary school to settle in, adapt and learn their way around school, are more likely to have a successful transition (Evangelou et al., 2008). Moreover, teachers have the opportunity to interpret and use information from children to change their pedagogical practice (Ferguson, Handreddy \& Draxton, 2011), and to aid children when they signal that they need help (McGee et al., 2004). Unfortunately, neither secondary school teachers nor mentors are likely to give higher levels of support. Having multiple teachers may make it more difficult to build personal relationships with all of them (Bokhorst, Sumter \& Westenberg, 2010). The literature shows that after the transition, boys' perceptions of support, including close friends and school support, are higher, while girls' perceptions of support are lower. On the other hand, boys' self-perceived school problems are greater after the transition (Martinez, Aricak, Graves, Peters-Myszak \& Nellis, 2011).

\subsubsection{Differences in the formal and social contexts: making the transition with peers}

After the transition, children experience organizational and social discontinuity. They are confronted with, among other things, changes in school size, teacher expectations and relations with teachers and peers. The greater the discontinuity, the greater the support needed (Anderson et al., 2000). The less children are prepared for secondary school, the more support they will need from parents, teachers and peers (Toping, 2011). However, primary schools prepare their pupils much more for school issues than for coping with a new social environment (West, Sweeting \& Young, 2010). In contrast, for children, transferring with existing friends is much more important than the structural arrangements of the school (Pratt \& George, 2005).

The transition to secondary school comes at a time that peer groups and friendships are very important to children. The transition can sever friendships when children move to a different school or class, or when they develop new interests and identities after the transition (Weller, 2007). At the end of primary school, children who have been classmates for years can become strangers (Pratt \& George, 2005). Peer relations are even more important for girls. As a result, they may find it more difficult to adjust to the disruption of friendship networks than boys (Anderson et al., 2000). Due to the new social circumstances at secondary school and the 
discrepancy between children's expected and perceived social acceptance, their level of selfesteem might change (Poorthuis, Thomaes, van Aken, Denissen \& Orobio de Castro, 2014).

A successful transition can be hindered by personal feelings or characteristics. Children will experience a poorer transition if they have been bullied, or worry about their ability to perform well or simply adjust to new teachers, or are apprehensive about whether they can make friends (Evangelou et al., 2008). The transition can be eased when the children already have friends at their new school (Evangelou, et al., 2008; West et al., 2010).

\subsection{Theoretical framework}

Making the transition to secondary school affects all children more or less (Anderson et al., 2000) and can affect children's academic performance as well as their sense of well-being and mental health (Bru, Stornes, Munthe \& Thuen, 2010; Chung et al., 1998; Waters, Lester, Wenden \& Cross, 2012). During the transition process, both motivation and academic performance decline (Bru et al., 2010; Waters et al., 2012; Zeedijk et al., 2003). Lower performance leads to decreased well-being and less motivation, which, in turn, causes even lower performance, and so forth, until the children risk ending up in a downward spiral. This could also initiate a disengagement process from school, poor academic attainment and even to school dropout (Anderson et al., 2000; Waters et al., 2012; Chapter 2 in this thesis).

To prevent the aforementioned negative consequences of the transition, it is important to enhance children's intrinsic motivation, self-regulation and well-being. Motivation is an important driver for tackling children's concerns and worries (Ryan \& Deci, 2000), positively influencing academic performance (Hattie \& Timperley, 2007) and providing a way to stop the downward spiral. This motivation is intrinsic in children's natural activity and curiosity and, according to the Self-Determination Theory (SDT), stem from three basic psychological needs: competence ( I can do it), autonomy (I can do it independently) and relatedness ( I am feeling connected with others and cared for). Fulfilment of these needs will lead to motivation and result in the experience of well-being and enjoyment (Ryan \& Deci, 2000).

SDT is the underlying theoretical framework for the present study. Active child participation, such as information exchange (Hart, 2008), is one way to meet children's need for competence, autonomy and relatedness. Involving children in the present research not only facilitates direct access (via questionnaires) to children's actual descriptions of their views, experiences and expectations, but also the ability to include these data in our research. 
Evidence has been found that children's participation in research has a positive impact on the children themselves (Lundqvist, 2014). Their self-confidence and social competence grows, they make new friends and learn to express their thoughts and discuss their ideas (Lundqvist, 2014). This indicates that child participation has positive effects on children's competence to act autonomously. They notice that their contribution is appreciated and are able to make new friends, which positively influences their sense of belonging.

\subsection{The context of the study, data and methods}

\subsubsection{The education system}

In Chapter 1, the structure of the educational system in the Netherlands was described in detail. In brief, the Dutch educational system has a hierarchical structure and is divided into three ability tracks. To ensure that children are well prepared prior to the transition, the primary school informs the children and their parents about secondary education and provides a school advice about which track best suits the children's abilities. Based on this advice, a suitable secondary school is chosen.

In secondary school, each class has a mentor, who is the key individual in the contact between 'their' pupils and the parents, teachers and classmates. The role of the mentor, who usually is one of the child's teachers, includes responsibility for the child adjusting safely to the secondary school's social and pedagogical environments. Pupils, parents and teachers will first turn to the mentor when problems arise, and in practice, mentors are responsible for addressing all of the adjustment problems that seventh graders might experience.

\subsubsection{Data collection}

The data for the current study were collected in two waves, via two identical, self-reporting questionnaires. The questionnaire was disseminated at all 110 primary schools (for both typical and special needs children) of a partnership in Venlo, a regional city in the southern part of the Netherlands. The first wave was collected in late June 2015. During the second measurement, the children were scattered in 14 different secondary schools. Therefore, the 270 pupils who participated in the first wave were contacted for the second wave at their home addresses in late October 2015, when they were about two months into secondary school. Both waves allowed for up to three reminders. Eventually, 98 pupils filled out the questionnaires twice, for which the parents' consent was obtained. The sample of 98 children consists of 45 boys and 
53 girls from 30 primary schools, including two schools for special education. The children had a mean age of almost 12 years at the time of the first interview.

To participate in the first wave of the survey, the eligible children were approached through their primary school. Those who received permission from their parents completed the first questionnaire at school. As a result, we only received information about the children who completed the questionnaire. Because schools are not allowed to share sensitive information we do not have data for the children who did not fill in the questionnaire. It is therefore not possible to perform an attrition analysis on the first -pre-transition- survey.

Whether the sample loss caused a systemic bias on the second measurement was checked by a logistic regression. The results of the test showed that, with one exception with significance at the $5 \%$ level, the children who did not complete the second questionnaire did not differ on the observable characteristics included in the logistic regression from the children who did participate in the follow-up questionnaire (Appendix 1, Chapter 3, Table 3.1). The exception concerns the children from special education. They were more likely to fill out the questionnaire in the second wave than the children in the mainstream schools.

Lack of control by the researchers in the process during the second measurement would explain the decrease in response rate. For the first measurement, the questionnaires were completed in class, under the supervision of the teacher. For the second measurement, the questionnaires were sent to the home email addresses, so supervision may have been lacking. Children from special education generally need and receive more support from their parents (Evangelou et al., 2008). Therefore, we expect that these parents were more likely to have encouraged their child to complete the questionnaire than the parents of children in the mainstream schools, leading to the significant difference in the percentage of children from special education schools in our sample.

The self-reporting questionnaire designed for the research was divided into two parts. The first part consisted of three themes: school choice, preparing for secondary school, and the role of the mentor. These themes were derived from the literature review described in Chapter 2. To gain insight into the SDT theory with respect to children's experiences, the three basic psychological needs - competence, autonomy and relatedness - were processed as follows in the questionnaire.

As shown in Chapter 2, the literature found the presence of old classmates, old friends from primary school or familiar children at secondary school to be very important for most children. The items that measure the need for the presence of familiar children at secondary school (Table 3.1) are associated with the need for relatedness. This also applies to the role of the 
mentor (Table 3.3). The mentor is charged with the task of taking care of the children's wellbeing and intervening if progress at school or a child's well-being is wanting. Table 3.2 reports the extent to which children feel competent and able to handle themselves autonomously in secondary school.

The second part of the questionnaire consists of questions about the challenges and threats that the children expect at secondary school. According to the SDT, challenges enhance intrinsic motivation while threats diminish it. Challenges, in contrast to threats, offer opportunities for self-direction and therefore impact on autonomy and competence. We used the questionnaire entitled "The Impending Transition to Secondary School Perceived as Challenge and Threat (ITCT)" (Sirsch, 2003), because it provides the possibility of measuring the perceived challenges and threats with regard to the transition. The questionnaire has been translated into Dutch and used extensively in the present investigation.

All themes were used to assess children's opinions and to identify their strengths, interests and areas of need during the transition process. The themes refer to the children's needs for competence, autonomy and relatedness. The full questionnaires are included in the appendix (Appendix, Chapter 3, 3.2: Pre and post transition questionnaires).

\subsection{Results}

Below we describe from both a prospective and retrospective viewpoint, per theme, the most important differences between the results of the first and the second wave of this study's questionnaires. Thereafter the results are summarised in terms of the SDT. The children answered the same questions before and eight weeks after the transition. The questionnaires were introduced twice in a different way: before the transition, the children were asked about their expectations, and after the transition, they were asked to look back on their experiences.

The results are presented in separate tables per theme. Tables 3.1 to 3.4 present the mean scores per wave, for the total sample, and for boys and girls separately. The extended tables, including standard deviations and T-statistics, can be found in Appendix 1 of Chapter 3, Tables 3.1A-3.4B. 


\subsubsection{School choice}

Because the choice of school is freely allowed in the Netherlands, parents and children compare schools before making a choice. Schools try to distinguish themselves by offering facilities, special classes, or pedagogical or learning pathways. Table 3.1 shows the descriptive statistics with the mean scores, T-tests and P-values (by gender and for the total sample), before and after the transition, on 12 items that are relevant to the school choice. In the questionnaire, the children chose the three items that are most important to them (without ranking). The maximum average score per item is 1 (1=highly important), the minimum average score is 0 ( 0 =highly unimportant).

Table 3.1: The main reasons for school choice before and after the transition (share of pupils per Item

\begin{tabular}{|c|c|c|c|c|c|c|c|c|c|c|}
\hline \multirow[b]{2}{*}{ What is important? } & \multicolumn{5}{|c|}{ Pre transition (first wave) } & \multicolumn{5}{|c|}{ Post transition (second wave) } \\
\hline & $\begin{array}{l}\text { Boys } \\
N=45\end{array}$ & $\begin{array}{l}\text { Girls } \\
N=53\end{array}$ & & & $\begin{array}{l}\text { Total } \\
N=98\end{array}$ & $\begin{array}{l}\text { Boys } \\
N=43\end{array}$ & $\begin{array}{l}\text { Girls } \\
N=52\end{array}$ & & & $\begin{array}{l}\text { Total } \\
N=95\end{array}$ \\
\hline & Mean & Mean & $\begin{array}{l}T- \\
\text { test }\end{array}$ & P-value & Mean & Mean & Mean & $\begin{array}{l}T- \\
\text { test }\end{array}$ & $P$-value & Mean \\
\hline The building & 0.22 & 0.32 & -1.09 & 0.28 & 0.28 & 0.28 & 0.23 & 0.53 & 0.59 & 0.25 \\
\hline The distance & 0.09 & 0.19 & -1.44 & 0.15 & 0.14 & 0.12 & 0.12 & 0.01 & 0.99 & 0.12 \\
\hline Classmates & 0.20 & 0.13 & 0.90 & 0.37 & 0.16 & 0.28 & 0.13 & 1.72 & 0.09 & 0.20 \\
\hline $\begin{array}{l}\text { Friends at the same } \\
\text { school }\end{array}$ & 0.27 & 0.23 & 0.46 & 0.65 & 0.24 & 0.30 & 0.31 & -0.06 & 0.96 & 0.31 \\
\hline $\begin{array}{l}\text { Special classes (sport- } \\
\text { dance-art-music) }\end{array}$ & 0.09 & 0.15 & -0.93 & 0.36 & 0.12 & 0.07 & 0.12 & -0.75 & 0.46 & 0.09 \\
\hline Billingual & 0.02 & 0.06 & -0.83 & 0.40 & 0.04 & 0.02 & 0.02 & 0.14 & 0.89 & 0.02 \\
\hline Small school & 0.16 & 0.04 & 1.94 & 0.06 & 0.09 & 0.09 & 0.04 & 1.04 & 0.30 & 0.06 \\
\hline Good guidance & 0.62 & 0.68 & -0.59 & 0.56 & 0.65 & 0.70 & 0.60 & 1.03 & 0.31 & 0.64 \\
\hline I know somebody & 0.51 & 0.47 & 0.39 & 0.70 & 0.49 & 0.33 & 0.50 & -1.73 & 0.09 & 0.42 \\
\hline $\begin{array}{l}\text { Bicycle with } \\
\text { classmates }\end{array}$ & 0.36 & 0.38 & -0.22 & 0.83 & 0.37 & 0.40 & 0.31 & 0.89 & 0.38 & 0.35 \\
\hline $\begin{array}{l}\text { Education for special } \\
\text { needs }\end{array}$ & 0.04 & 0.04 & 0.17 & 0.87 & 0.04 & 0.07 & 0.04 & 0.68 & 0.50 & 0.05 \\
\hline $\begin{array}{l}\text { Technasium/technical } \\
\text { education }\end{array}$ & 0.09 & 0.04 & -1.02 & 0.31 & 0.06 & 0.07 & 0.02 & 1.16 & 0.25 & 0.04 \\
\hline
\end{tabular}


The mean scores in Table 3.1 show that, before the transition, for $65 \%$ of the children, good guidance by the teachers at their new school is the most important issue when they consider a secondary school. For almost half of the children, it is important to know somebody at the new school. The children think it is important to go to the same school as their friends and classmates and to have someone to bicycle to school with. In fact, $5 \%$ of the children did not go to the same school as their classmate(s) and $10 \%$ did not have a friend at secondary school (not included in the table). Whether a school had facilities for bilingual teaching or for children with special educational needs were the least important considerations for all children. The differences between the scores of the boys and the girls are only minor.

After the transition, the mean scores of the children (Table 3.1) indicate that they attach more importance to classmates or friends going to the same school than they did before the transition. Once at secondary school, staying with their friends is more important than the children thought before. After the transition, boys report that the presence of old classmates is more important; and all children report higher mean scores on the item 'friends at the same school'. However, these differences are not statistically significant.

Summarized in terms of SDT, before the transition, nearly two-thirds of the children reported relatedness - in the sense of connectedness with the mentor and classmates - to be the most important consideration in their school choice. After the transition, the children did not change their minds. They appreciated the presence of friends even more.

\subsubsection{Preparing for secondary school}

Table 3.2 shows the mean scores, T-tests and P-values for ten items about the extent to which children are prepared for secondary school. The children indicated all items that are applicable. The maximum mean score per item is 1 (1=highly important), the minimum mean score is 0 (0=highly unimportant). 
Table 3.2: Activities as a preparation for secondary school, before and after the transition (share of pupils per item).

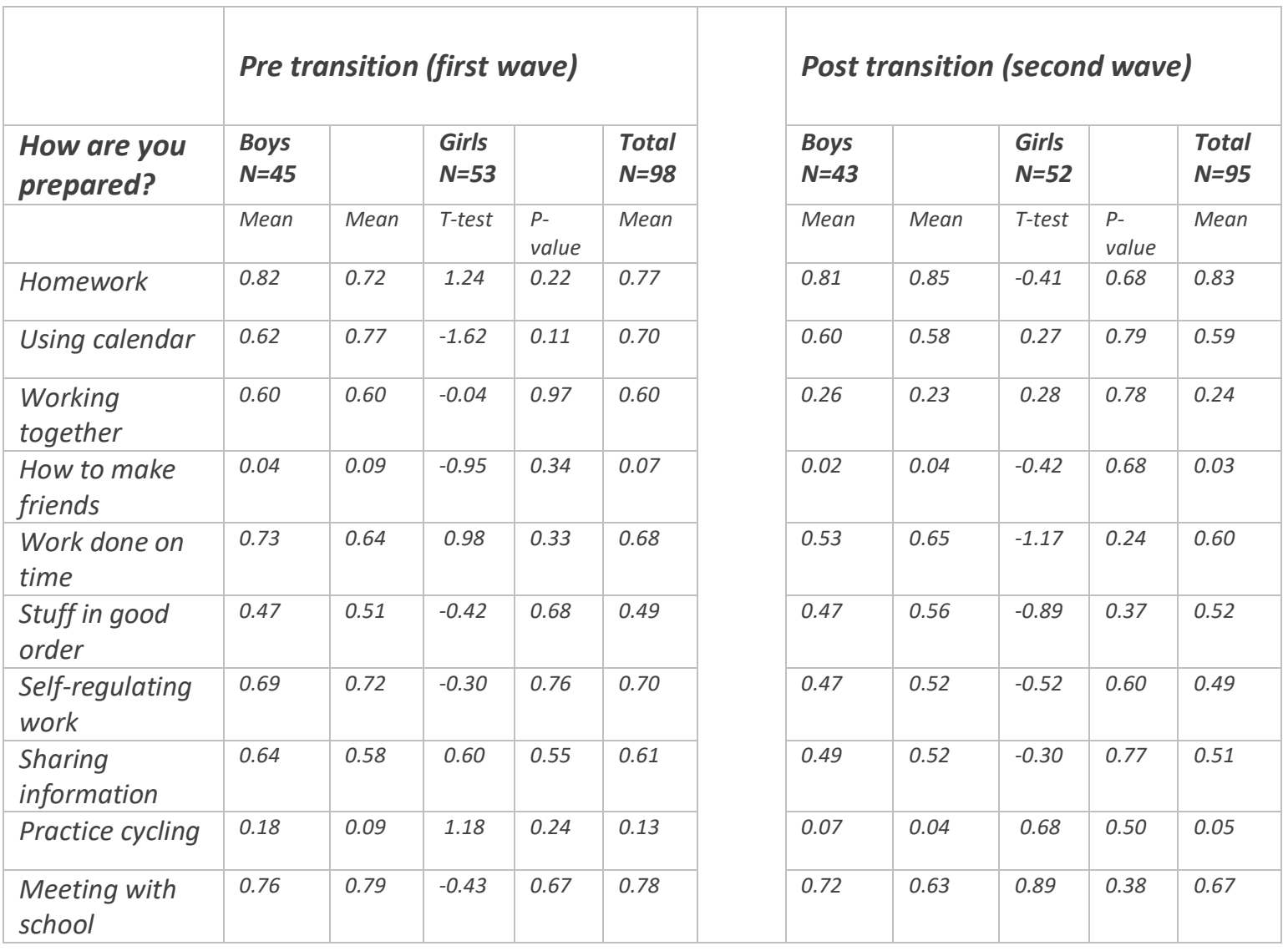

${ }^{*} \mathrm{p}<0.05 ;{ }^{* *} \mathrm{p}=<0.01 ;{ }^{* * *} \mathrm{p}=<0.001$

Table 3.2 shows that, in the preparation for secondary school, competence in such schoolrelated tasks as workload and demands receive the most attention at primary school. When children go to secondary school, not only does the school context change but also the informal peer context. Surprisingly, the changes in social environment (learning how to make friends) receives little attention according to the children. After the transition, the low mean score on this item even decreases. The difference between the first and the second wave is not significant.

Girls seem to feel more competent and better prepared for secondary school than boys. After the transition, they report being better prepared for their homework, doing their work in time, and having their materials in better order than they initially thought they would before the transition. After the transition, boys' scores on all items decrease. There are no significant differences between the mean results for boys and girls. 
When comparing the pre- and post-transition waves by a paired sample T-test (Appendix 1, Chapter 3, Table 3.2B), we do see significant differences. After the transition to secondary school, the scores on the items 'work together' $(p=0.00)$, 'work independently' $(p=0.00)$, 'information' ( $p=0.05)$, and 'practice cycling' $(p=0.03)$ decline significantly. When comparing the mean scores before and after the transition, paired by gender (Appendix 1, Table 3.2B: Preparing for secondary school), the data also show significant differences. For all children, the scores referred to competence and autonomy in the social context, 'work together' (girls $p=0.00$; boys $p=0.01$ ) and 'work independently' (girls $p=0.03$; boys $p=0.03$ ) significantly decline after the transition. For boys, the scores on 'information' about secondary school $(p=0.03)$, referring to competence in the school context, also decline significantly. After the transition, children feel less prepared to work together with schoolmates or to work independently. Boys afterwards feel that the information they received about secondary school was not as clear as they expected it to be before the transition.

In terms of SDT, children report that, both before and after the transition, they do not feel wellprepared to handle the autonomy; and they feel incompetent in the social context. While before the transition, the scores were already low, after the transition, they are significantly lower. All children seem to feel competent to perform their school tasks autonomously, although the boys afterwards report feeling significantly less well-informed about secondary school than they thought they were before the transition.

\subsubsection{The mentor}

Table 3.3 shows the mean scores for eight items about the mentor at secondary school. Children were asked to mark the three items they consider to be the most important. The maximum mean score per item is 1 (1=highly important), the minimum mean score is 0 (0=highly unimportant). 
Table 3.3: Expectations about the mentor, before and after the transition (mean of pupils who mentioned this)

\begin{tabular}{|c|c|c|c|c|c|c|c|c|c|c|}
\hline \multirow[b]{2}{*}{$\begin{array}{l}\text { I expect that my } \\
\text { mentor will }\end{array}$} & \multicolumn{5}{|c|}{ Pre transition (first wave) } & \multicolumn{5}{|c|}{ Post transition (second wave) } \\
\hline & $\begin{array}{l}\text { Boys } \\
N=45\end{array}$ & $\begin{array}{l}\text { Girls } \\
N=53\end{array}$ & & & $\begin{array}{l}\text { Total } \\
N=98\end{array}$ & $\begin{array}{l}\text { Boys } \\
N=42\end{array}$ & $\begin{array}{l}\text { Girls } \\
N=51\end{array}$ & & & $\begin{array}{l}\text { Total } \\
N=93\end{array}$ \\
\hline & Mean & Mean & $T$-test & P-value & Mean & Mean & Mean & $T$-test & P-value & Mean \\
\hline be nice & 0.69 & 0.51 & 1.82 & 0.07 & 0.59 & 0.52 & 0.53 & -0.05 & 0.96 & 0.53 \\
\hline be present & 0.51 & 0.64 & -1.30 & 0.20 & 0.58 & 0.52 & 0.55 & -024 & 0.81 & 0.54 \\
\hline $\begin{array}{l}\text { have a good } \\
\text { conversation }\end{array}$ & 0.42 & 0.77 & -3.72 & $0.00 * * *$ & 0.61 & 0.57 & 0.51 & 0.59 & 0.56 & 0.54 \\
\hline $\begin{array}{l}\text { have knowledge } \\
\text { of school }\end{array}$ & 0.16 & 0.06 & 1.56 & 0.12 & 0.10 & 0.12 & 0.06 & 1.00 & 0.32 & 0.09 \\
\hline talk with parents & 0.09 & 0.11 & -0.39 & 0.70 & 0.10 & 0.10 & 0.06 & 0.66 & 0.51 & 0.08 \\
\hline $\begin{array}{l}\text { solve our } \\
\text { problems }\end{array}$ & 0.40 & 0.36 & 0.42 & 0.68 & 0.38 & 0.40 & 0.53 & -1.19 & 0.24 & 0.47 \\
\hline $\begin{array}{l}\text { provide a good } \\
\text { atmosphere }\end{array}$ & 0.31 & 0.32 & -0.10 & 0.92 & 0.32 & 0.38 & 0.43 & -0.49 & 0.63 & 0.41 \\
\hline be our contact & 0.36 & 0.21 & 1.62 & 0.11 & 0.28 & 0.33 & 0.25 & 0.82 & 0.41 & 0.29 \\
\hline
\end{tabular}

${ }^{*} \mathrm{p}<0.05 ;{ }^{* *} \mathrm{p}=<0.01 ;{ }^{* * *} \mathrm{p}=<0.001$

Table 3.3 shows that three items referencing relatedness are greatly appreciated by both boys and girls. A mentor should especially be a nice person, who is accessible at school, and should be available for a good conversation. Boys' mean scores are, compared with girls, higher for 'will be nice', while girls score higher on the items 'have a good conversation' and 'will be present' at school. Girls score significantly higher on the item 'have a good conversation' than boys $(p=0.000)$.

Table 3.3 shows that, after the transition to secondary school, the children identify the same items as most important as before, although their priorities have shifted and their scores are more comparable between the sexes. There are no significant differences between boys and girls. However, when considered per wave (paired samples test, Appendix 1, Chapter 3, Table 3.3B), we do see significant differences with the items 'have a good conversation' $(p=0.00)$ and 'solve our problems' $(p=0.02)$ for the girls. Apparently, afterwards girls attach more importance to having their problems solved by the mentor than they assumed in advance. To have 'a good conversation with the mentor' becomes less important.

According to the SDT, a secure relational base is important for the expression of intrinsic motivation (Ryan \& Deci, 2000). Summarized in terms of SDT, with respect to their 
expectations of the mentor, girls as much as boys are pre-occupied by the need for relatedness to the mentor. A mentor should be nice, accessible and helpful. The priorities stated by the children before the transition did not change after the transition.

\subsubsection{The formal and social context}

Table 3.4 shows the mean scores for the 24 aspects of the transition that children are concerned about in the social and in the school context, as well as the aspects to which they are looking forward. The items are rated on a 4-point Likert-scale. The maximum average score per item is 4 (highly important), the minimum average score is 1 (highly unimportant).

Given the large number and the clear grouping of the items, the items are clustered through factor analysis into four subscales: 'fun at school', ' fun with peers', 'fear of school' and 'fear of peers'. To estimate the reliability, per subscale, Cronbach's alphas have been calculated. They are reported in Table 3.4. The subscales fun with peers ( $\alpha$ 0.841), fear of school $(\alpha 0.801)$ and fear of peers ( $\alpha 0.774)$ all have high reliabilities. However, the subscale fun at school $(\alpha 0.636)$ has lower reliability.

To measure the children's perception of the transition concerning well-being, the items are clustered into two subscales: 'challenges/fun' and 'threats/fear'. For both subscales, Cronbach's alphas are calculated. They are reported in Table 3.4. The subscales 'challenges/ fun' ( $\alpha$ 0.836) and 'threats/fear' ( $\alpha$ 0.826) both have high reliabilities. 
Table 3.4: Threats and the challenges in the social and the school context, before and after the transition; separately calculated and clustered per subscale (4-point Likert scale: $4=$ highly important, $1=$ not important)

\begin{tabular}{|c|c|c|c|c|c|c|c|c|c|c|}
\hline & \multicolumn{5}{|c|}{ Pre transition (first wave) } & \multicolumn{5}{|c|}{ Post transition (second wave) } \\
\hline & $\begin{array}{l}\text { Boys } \\
N=45\end{array}$ & $\begin{array}{l}\text { Girls } \\
N=53\end{array}$ & & & $\begin{array}{l}\text { Total } \\
N=98\end{array}$ & $\begin{array}{l}\text { Boys } \\
N=42\end{array}$ & $\begin{array}{l}\text { Girls } \\
N=51\end{array}$ & & & $\begin{array}{l}\text { Total } \\
N=93\end{array}$ \\
\hline & Mean & Mean & T-test & P-value & Mean & Mean & Mean & T-test & P-value & Mean \\
\hline \multicolumn{11}{|c|}{ Challenges in the school context: I am looking forward to my secondary school because } \\
\hline I can show what I have learned & 2.71 & 2.60 & 0.72 & 0.47 & 2.65 & 2.71 & 2.61 & 0.62 & 0.54 & 2.66 \\
\hline I will learn new things & 3.29 & 3.25 & 0.28 & 0.78 & 3.27 & 3.05 & 3.25 & -1.32 & 0.19 & 3.16 \\
\hline I am curious about new subjects & 2.95 & 3.15 & -1.24 & 0.22 & 3.06 & 2.95 & 2.80 & 0.85 & 0.40 & 2.87 \\
\hline I can show I perform well & 3.02 & 2.87 & 1.17 & 0.24 & 2.94 & 2.86 & 2.94 & -0.57 & 0.57 & 2.90 \\
\hline I will quickly know the way & 2.98 & 2.90 & 0.40 & 0.69 & 2.94 & 3.26 & 3.04 & 1.32 & 0.19 & 3.14 \\
\hline I like different classrooms & 2.74 & 2.92 & -1.01 & 0.32 & 2.84 & 2.79 & 2.78 & 0.01 & 0.99 & 2.78 \\
\hline SUBSCALE 'fun at school' $\alpha 0.636$ & 15.40 & 15.25 & & & 15.32 & 15.29 & 15.11 & & & 15.32 \\
\hline \multicolumn{11}{|c|}{ Challenges in the social context: I am looking forward } \\
\hline to meeting nice children & 3.10 & 3.31 & -1.50 & 0.14 & 3.21 & 3.12 & 3.20 & -0.58 & 0.56 & 3.16 \\
\hline $\begin{array}{l}\text { to having fun with the other } \\
\text { children }\end{array}$ & 3.17 & 3.37 & -1.46 & 0.15 & 3.28 & 3.15 & 3.22 & -0.51 & 0.61 & 3.19 \\
\hline to kids who will like me & 3.00 & 3.00 & 0.00 & 1.00 & 3.00 & 2.98 & 2.98 & -0.03 & 0.98 & 2.98 \\
\hline to knowing many nice children & 3.17 & 3.27 & -0.71 & 0.48 & 3.22 & 3.02 & 3.22 & -1.36 & 0.18 & 3.13 \\
\hline to getting into a nice group & 3.33 & 3.46 & -1.10 & 0.31 & 3.40 & 3.24 & 3.28 & -0.26 & 0.80 & 3.26 \\
\hline to the different teachers & 2.74 & 2.98 & -1.54 & 0.13 & 2.87 & 2.85 & 2.84 & 0.08 & 0.94 & 2.85 \\
\hline $\begin{array}{l}\text { SUBSCALE 'fun with peers' } \\
\alpha 0.841\end{array}$ & 16.21 & 16.90 & & & 16.59 & 15.98 & 16.37 & & & 16.19 \\
\hline $\begin{array}{l}\text { SUBSCALE challenges/fun' } \\
\alpha 0.836\end{array}$ & 36.19 & 37.07 & & & 36.68 & 35.90 & 36.18 & & & 36.05 \\
\hline
\end{tabular}




\begin{tabular}{|c|c|c|c|c|c|c|c|c|c|c|}
\hline & \multicolumn{5}{|c|}{ Pre transition (first wave) } & \multicolumn{5}{|c|}{ Post transition (second wave) } \\
\hline & $\begin{array}{l}\text { Boys } \\
N=45\end{array}$ & $\begin{array}{l}\text { Girls } \\
N=53\end{array}$ & & & $\begin{array}{l}\text { Total } \\
N=98\end{array}$ & $\begin{array}{l}\text { Boys } \\
N=42\end{array}$ & $\begin{array}{l}\text { Girls } \\
N=51\end{array}$ & & & $\begin{array}{l}\text { Total } \\
N=93\end{array}$ \\
\hline & Mean & Mean & $T$-test & P-value & Mean & Mean & Mean & T-test & $P$-value & Mean \\
\hline \multicolumn{11}{|c|}{ Threats in the school context: I am worried } \\
\hline I will not understand the lessons & 1.76 & 1.98 & -1.55 & 0.12 & 1.88 & 1.71 & 1.74 & -0.23 & 0.82 & 1.73 \\
\hline I cannot finish the schoolwork & 1.76 & 1.81 & -0.31 & 0.76 & 1.79 & 1.61 & 1.84 & -1.55 & 0.13 & 1.74 \\
\hline my planning will be bad & 1.90 & 1.88 & 0.13 & 0.90 & 1.89 & 1.56 & 1.74 & -1.12 & 0.27 & 1.66 \\
\hline about performing poorly & 1.52 & 1.65 & -0.90 & 0.37 & 1.60 & 1.56 & 1.68 & -0.72 & 0.47 & 1.63 \\
\hline about getting lost in the building & 1.57 & 1.88 & -1.74 & 0.09 & 1.74 & 1.22 & 1.26 & -0.40 & 0.69 & 1.24 \\
\hline I cannot find the classrooms & 1.64 & $2.10^{*}$ & -2.66 & $0.01^{* *}$ & 1.89 & 1.27 & 1.48 & -1.78 & 0.08 & 1.38 \\
\hline SUBSCALE 'fear of school' $\alpha 0.801$ & 8.79 & 9.56 & & & 9.21 & 7.86 & 8.50 & & & 8.21 \\
\hline \multicolumn{11}{|c|}{ Threats in the social context: I am worried } \\
\hline classmates will not like me & 1.49 & 1.65 & -1.11 & 0.27 & 1.58 & 1.32 & 1.44 & -1.06 & 0.29 & 1.38 \\
\hline I might not find nice friends & 1.26 & 1.29 & -0.31 & 0.76 & 1.27 & 1.15 & 1.34 & -1.96 & $0.05^{*}$ & 1.25 \\
\hline I won't find anybody in the breaks & 1.26 & 1.29 & -0.26 & 0.80 & 1.27 & 1.15 & 1.26 & -1.12 & 0.27 & 1.21 \\
\hline the children will bully me & 1.28 & 1.37 & -0.63 & 0.53 & 1.33 & 1.12 & 1.28 & -1.68 & 0.10 & 1.21 \\
\hline I might feel lonely & 1.21 & 1.40 & -1.59 & 0.12 & 1.32 & 1.12 & 1.20 & -0.92 & 0.36 & 1.16 \\
\hline $\begin{array}{l}\text { I will not become accustomed to } \\
\text { the teachers }\end{array}$ & 1.95 & 1.96 & -0.06 & 0.96 & 1.96 & 1.68 & 1.66 & 0.17 & 0.87 & 1.67 \\
\hline SUBSCALE 'fear of peers' $\alpha 0.774$ & 6.81 & 7.32 & & & 7.09 & 6.13 & 6.79 & & & 6.49 \\
\hline SUBSCALE 'threats/fear' $\alpha 0.826$ & 18.59 & 20.26 & & & 19.52 & 16.46 & 17.92 & & & 17.26 \\
\hline
\end{tabular}

${ }^{*} \mathrm{p}<0.05 ;{ }^{* *} \mathrm{p}=<0.01 ;{ }^{* * *} \mathrm{p}=<0.001$ 
The SDT links challenges and threats to intrinsic motivation. Challenges enhance the intrinsic motivation, because they offer opportunities for self-direction, and create feelings of autonomy and competence. Threats, on the other hand, diminish intrinsic motivation. In response to social environments, people experience differences in motivation and personal growth (Ryan \& Deci, 2000).

As the 'challenges' and 'threats' scores show in this study, both before and after the transition, children are positive about the challenges and only a little concerned about the threats during the transition process. After the transition, most scores decreased. Generally, afterwards, the children are less challenged and less concerned than they were before the transition. According to the SDT, diminished challenges may indicate a decrease of intrinsic motivation.

The mean scores on the four subscales show no significant differences between the scores of girls and boys both before and after the transition, although they do demonstrate different emphases. Girls are less likely than boys to look forward to the challenges at secondary school and have more fear about secondary school. The girls also have a higher mean score on the subscale of fear of peers than the boys. On the other hand, the girls expect to have more fun with their peers than the boys do. These findings are confirmed by the higher mean scores on the subscale 'challenges' by the girls and their lower mean scores on the subscale 'threats'.

Comparing the mean scores on the separate items by gender before the transition, we find that girls are significantly more worried than boys that they will not be able to find the classrooms (table 3.4, $\mathrm{p}=0.01$ ). Before the transition, the girls are more worried than the boys that their new classmates would not like them and that they might feel lonely, while the boys are more concerned about showing what they have learned and that they perform well. Boys are less curious about the new subjects or the new teachers. The scores on the first wave show that, as compared with girls, on the one hand boys do not look forward to their new classmates as much, but on the other hand, they are less worried about challenges in the social context. However, these differences are not statistically significant.

After the transition, the scores on most items decrease. Finding their way around the school is also no longer an issue for the children. All children become more afraid about performing poorly and girls become more concerned about finishing their schoolwork. After the transition, girls are significantly more worried than boys that they might not find friends (table 3.4, $p=0.05$ ). Compared with the first wave, the boys grow in their appreciation of being taught by different teachers in different classrooms with nice children. 
After the transition, as evidenced in the paired samples T-test, Table 3.4B (Appendix), all children are significantly less curious about the new subjects $(p=0.04)$, significantly less afraid that they will not find their classrooms $(p=0.00)$ or will get lost in the building $(p=0.00)$, and significantly less worried that they might feel lonely $(p=0.01)$. After the transition, the children are noticeably more accustomed to their teachers $(p=0.00)$ than they expected to be before the transition.

Besides similarities about getting lost in the building and finding the classrooms, we also see some significant differences by gender (Appendix 1, Chapter 3, Table 3.4, paired samples Ttest). After the transition, boys score significantly lower on bad planning ( $p=0.05)$, and girls become less curious about new subjects $(p=0.01)$, less worried that they will not understand the lessons $(p=0.02)$, less afraid that classmates will not like them $(p=0.01)$, and more accustomed to their teachers $(p=0.01)$.

\subsection{Discussion and conclusions}

The present study is based on the theoretical assumptions of the Self-Determination Theory (Ryan \& Deci, 2000). According to the SDT, fulfilment of the need for autonomy, competence and relatedness is essential for motivation and for everyone's optimal functioning, as well as for the social development and personal well-being. With active participation by children, we found a way to meet their need for competence, autonomy and relatedness during the transition process.

This study has investigated boys' and girls' perceptions and experiences about the transition to secondary school before and after the transition. It examined how children experience preparation for secondary school, and what their priorities are with respect to their school choice. Expectations about the mentor, and about the threats and challenges in the new social and school context, were also examined.

At the end of primary school, most children have a positive perception about the transition to secondary school. According to the children, the environmental context has the strongest effect on the school transition. This finding is confirmed by Anderson et al. (2000). The SDT is consistent with the perceptions that the children report. Ryan and Deci (2000) observed that social contexts in particular create differences in motivation and personal growth. The children are especially interested in the social environment, in contrast with the mostly school-related aspects for which they are prepared at primary school. That the children are mainly interested 
in the social environment is shown by their initial priorities when choosing a secondary school: good guidance by their future teachers, the opportunity to bicycle to secondary school with classmates, and making the transition with friends or children they know. Girls report more pretransition concerns about the school context and mixed feelings about the social context. Nevertheless, they are more optimistic about their future classmates than the boys. Before the transition, boys are more interested - in a competitive way - in the new things they will learn at secondary school, the possibility of showing what they already have learned at primary school, and the opportunity to prove that they can perform well.

All children expect their new mentor to be a nice person, who is present at secondary school when you need him or her, and competent and available for a good conversation with the pupils. Girls, significantly more than boys, appreciate having the opportunity to talk with their mentor. This is confirmed by the literature where girls are found to have more positive attitudes towards schools and teachers (Rice et al., 2011) and receive more support (Bokhorst et al., 2010). Nevertheless, the boys in our sample also scored high on this item as well.

In line with previous research (Anderson et al., 2000; Rice et al., 2011; West et al., 2010), after eight weeks at secondary school, most children have successfully coped with the transition and have found their way around school. The majority of the sample is less anxious and less worried about the challenges of the transition than before. As confirmed by Sirsch (2003), having friends at the same school becomes important for all children, especially after the transition. Once at secondary school, the children realise they have underestimated the importance of the social-emotional aspects on the transition and are not sufficiently prepared for making friends and cooperating with classmates. The latter aspect differs significantly from their expectations beforehand. In general, girls are still just as concerned as they were before the transition. Zeedijk et al. (2003) explain this as a mismatch between the fear children experience and the lack of skills they need to address this fear, i.e., a lack of social-emotional skills.

Overall, we conclude that children mostly focus on the social and emotional aspects, of the transition. These are the same aspects they had underestimated the importance of. They do not feel sufficiently prepared to cope successfully with the challenges presented by the social environment during the transition. Zeedijk et al. (2003) found that children whose coping skills are insufficient will depend on others. We also found that the lack of coping skills in the social environment made children dependent on support from their mentor, the key person in the transition process. This may explain why children emphasize the importance of good guidance 
at secondary school. Unfortunately for them, little support is provided by the teachers at secondary school (Martinez et al., 2011).

According to the SDT, social contexts are especially likely to cause differences between children's motivation and personal growth; and the children themselves agree with this. During the transition process, children are concerned about the social context, especially about the continuity of their peer group relations and friendships. Conditions that foster children's need for competence, autonomy and relatedness can contribute to the design of a social context that optimizes children's development, performance and well-being (Ryan \& Deci, 2000). All partners in the transition process can support these conditions.

Both primary and secondary schools can help children by taking into account children's perspectives in their preparation for secondary school and in their guidance at secondary school. Children, especially girls, should be taught how to cope with broken and new friendships. Empowering coping skills related to the social environment will make all children less dependent on external support and more competent to autonomously handle the new challenges before, during and after the transition process.

By being well-briefed and asking the children for feedback about their transition process, the mentor at secondary school can support the children who experience adjustment problems. To make them feel more competent and give them more autonomy, the mentor can use and evaluate the information from the children to improve pedagogical practice and keep the children motivated.

This study has some limitations. The relatively small sample size of this study may limit the ability to generalise the findings to other populations. The study is also limited due to the regionally bound location of the schools. A larger scale study, involving a broader range of schools, is recommended to further explore the results. 


\section{Chapter 4}

\section{(How) does information provided by children affect the transition from primary to secondary school?}

This chapter is based on: Van Rens, M., Groot, W. \& Haelermans, C. (2020). (How) does information provided by children affect the transition from primary to secondary school? Child Indicators Research, 13 (1), 105-130. 


\begin{abstract}
The transition from primary to secondary school comes with changes in both the social and the school contexts. This chapter focuses on assessing the concerns, expectations and experiences of 371 Dutch children making the transition. Data have been collected over the course of four years. The effect of providing such information to the mentor at secondary school was assessed through a blinded experiment. The results did not show that children who informed their mentor made a better transition. The intervention only had a small effect on the social context. Nevertheless, this chapter provides valuable and useful information for teachers and mentors on how children deal with, and think about, the transition. The results show that some children are more vulnerable to a poor transition, such as children at special education schools, anxious children, and, to a lesser extent, girls. This implies that teachers do need to be aware of the children's perspective in order to help them make a smooth transition.
\end{abstract}




\subsection{Introduction}

In Chapter 3, we concluded that successful school transitions can be facilitated by educators. Teachers at secondary school, especially mentors in grade seven, have the opportunity to interpret and use information from children to adjust their pedagogical practice (Ferguson, Handreddy \& Draxton, 2011), and to help children when they signal that help is needed (McGee, Ward, Gibbons \& Harlow, 2004). In Chapter 2, we found that children are able to share their feelings and expectations about their forthcoming transition to secondary school before they make the transition and about their experiences after the transition. In this chapter, we investigate the mentor's response to the information provided by children making the transition. Children's feelings and expectations about their forthcoming transition to secondary school before they made the transition, and their experiences after the transition, are also inspected.

In Chapter 1, we described the transition in the context of the educational system in the Netherlands. Every year, approximately 180,000 children make the transition from primary to secondary school. The majority of these children do this at the age of twelve (see Chapter 1 , and Chapter 2 of this thesis). Children have mixed feelings about the transition, because it is accompanied by, among other things, changes in the academic level, achievement requirements, and social environment (Sirsch, 2003). Although most children look forward to having more freedom, new challenges, and making new friends at secondary school (Sirsch, 2003), they also realize that the transition may disrupt their life and cause organizational and social discontinuity (Anderson, Jacobs, Schramm \& Splittgerber, 2000). For example, they are concerned about the larger school size, the greater number of older children, new teachers and new classmates, and about the unknown rules of behavior and teacher expectations at secondary school (Anderson et al. 2000).

The changes in school context include not just a larger school building and different school rules. At secondary school, the children also have to deal with multiple teachers (Anderson et al, 2000; Fredriksen \& Rhodes, 2004; Hanewald, 2013), who have different expectations of the children and set other requirements than the teacher at primary school. Therefore, during the transition period children experience a need for support at the same time that secondary school teachers expect them to be less dependent on their teachers and more capable of independent academic performance. In particular, children with learning difficulties and children from disadvantaged economic backgrounds are likely to be at risk of a poor transition. As described in Chapter 3, affective teacher/student relationships are especially relevant for 
these children to achieve a successful transition (see Chapter 3 of this thesis; Roorda, Koomen, Spilt \& Oort, 2011; Rice, Frederickson \& Seymour, 2011).

Teachers can help vulnerable children to cope with the transition process and even benefit from the transition when they focus on the way the children experience and interpret this change (Jindal-Snape \& Miller, 2008). Children vulnerable to a poor transition because of their home situation, and who see their mentor as a secondary attachment figure, are more engaged in school according to Van Ryzin (2010). During the transition to secondary school, attachment to the mentor plays a protective role for those children and they were able to be more successful at school in terms of academic achievement and adjustment (Van Ryzin, 2010).

Children deal with the transition in different ways. For some, the change is exciting and challenging, while others feel anxious and threatened by it (Topping, 2011). It is important for children to make a successful transition, because their academic performance, well-being and mental health can be affected - positively as well as negatively - in both the short- and longterm (Barber \& Olsen, 2004; Waters, Lester, Wenden \& Cross, 2012; Zeedijk, Gallacher, Henderson, Hope, Husband \& Lindsay, 2003). An unsuccessful transition could cause children to feel marginalized, unwelcome, worthless or disrespected by others at school. They may experience a sense of rejection by the mainstream community and school might become a place where these children do not want to be. This could lead to more frequent absenteeism, a decline in grades, and an increase in conflicts. Disengagement could follow and even ultimately result in the child leaving school (Anderson et al. 2000).

In a successful transition, the children adjust to the new social and school contexts. They make new and more friendships and report a greater confidence in secondary school. These children are considered to be well settled at secondary school and adjusted to the new routines. Whether children are motivated and interested in the curriculum and experience a sense of continuity are also indicators of a successful transition (Evangelou, Taggart, Sylva, Melhuish, Sammons \& Siraj-Blatchford, 2008).

Despite all the efforts by schools and parents to prepare children for secondary school, a smooth transition is not guaranteed for all children. The transition period involves stress and anxiety even for children who adjust well at secondary school (Rice et al., 2011). Aside from good preparation for the transition, whether a transition is considered a success, or even seen by the child as a challenge or threat, is likely to be influenced by the child's personal and environmental characteristics. Some children may simply be more vulnerable to school disengagement and adjustment problems (Rice et al., 2011). 
There are only a few studies on the transition that have focused on the perspective of the children themselves. Although it is considered important to include children's responses in research and the evaluation of educational settings, thus far conclusions appear to be based predominantly on reports about children, rather than on what children themselves say about their individual experiences (Lundqvist, 2014). In contrast to most previous literature, in the present chapter we focus on assessing children's concerns, expectations and experiences about changes caused by the transition in the school and social contexts. In particular, we look at the fun and fear factors that the children both expect and experience in the context of secondary school and its social environment.

\subsubsection{Intervention and research question}

This chapter presents the results of a study where the children's views have been collected, from a prospective as well as retrospective point of view. The information was collected through two self-reporting questionnaires, completed by four groups of children over the course of four consecutive years. This information was then shared with their future mentors at secondary school through a blinded experiment (the intervention). The question we were investigating was whether children making the transition, who have had the opportunity to inform their future mentor about their expectations, make a better transition than those who did not have that opportunity.

First, we explain how our study relates to previous research in the field and to the context of the study. Next, we describe the methods used and the data that were collected. Finally, the results of our study are presented and discussed.

\subsection{Literature review}

\subsubsection{Individual differences in the quality of the transition from primary to secondary school}

Obviously, there are many differences between primary and secondary school. Consequently, when changing schools children are faced with a disruption in both the formal school context and the informal (e.g., dealing with peers) (Green, 1997). Children realize that being successful in one context does not guarantee success in the other (Pratt \& George, 2005). Due to personal characteristics, individual children will respond differently to the transition with differing concerns. For children with less academic ability or self-esteem, the transition is often more troubled (Topping, 2011; West, Sweeting \& Young, 2010). Also, children who are anxious, feel 
less prepared for secondary school, or who have been victimized have worse peer transitions (West et al., 2010).

Gender and prior behavioral problems may also play a role in the transition process. Since peer relations are relatively more important for girls, they may find it commensurately more difficult to adjust to the disruption of friendship networks. However, girls express more positive attitudes than boys towards school and teachers, which can smooth their transition in the school context (Anderson et al., 2000; see this thesis Chapter 2 and Chapter 3 of this thesis). Children with behavioral problems tend to have conflicts and confrontations with peers and teachers, which increases the likelihood of an unsuccessful transition. Children from families with lower socio-economic status (SES) often lack sufficient parental support and interest in school events to enable them to make successful transitions. Furthermore, their parents participate less frequently in school activities, are less involved in the educational activities of their children, and may therefore be less aware of any problems in the transition (Anderson et al., 2000).

This suggests that the quality of the transition is related to individual characteristics (Sirsch, 2003). What one child may see as a great challenge could be experienced as a threat by another. Their educators, especially the teachers, should be able to teach children to cope with these challenges. Therefore, it is essential to include the children as partners in the transition process, actively taking into account their views on the transition and evaluating their involvement (Chapter 2 of this thesis).

\subsubsection{The role of information for the mentor}

One of the challenges of the transition is to form new relationships with the teachers, among others, in the new school (Tobbell \& O'Donnell, 2013). Teachers can play an important role in guiding and supporting children through the transition. As mentioned previously, positive relationships with teachers and the perception of adequate support may positively affect not only children's learning and their academic achievement, but also their psychological adjustment (Ellerbrock, Abbas \& DiCicco, 2014; Fredriksen \& Rhodes, 2004; Hopwood, Hay \& Dyment, 2016).

Every child has the right to be heard in matters affecting his or her life, including well-being and experiences in the educational setting (U.N. 1989, Article 12). Children's input can make a valuable contribution to understanding, from their perspective, how they experience their daily lives, including their school lives, and what is important for them (Mason \& Danby, 2011). Teachers, and especially class mentors, have the opportunity - and are the designated persons - to interpret and use children's information to change and improve their pedagogical 
practice (Ferguson et al., 2011). In this way, teachers can help children who signal that they need support (McGee et al., 2004)

While most schools emphasize the importance of administrative and organizational procedures, and teachers often are concerned with issues of attainment, children are found to be especially concerned with personal and social issues (Jindal-Snape \& Miller, 2008; Topping, 2011; Chapter 2 of this thesis; Anderson et al., 2000) found evidence that the environmental context has a stronger effect on the success or failure of the transition than developmental characteristics do. The present study investigates the suggestion (Anderson et al., 2000) that schools and educators can better contribute to a successful transition if they know what children find important. It is unclear whether class mentors at the new secondary school are aware of what individual children in their class are concerned about. And who can tell them better than the children themselves?

\subsection{Context of the study, method and data}

The data for this study were collected in the Netherlands, at the end of grade six in primary school and at the beginning of grade seven in secondary school. As explained in more detail in Chapter 1, secondary education in the Netherlands is divided into four tracks: practical education (PrO), preparation for intermediate vocational education (VMBO), upper-secondary education (HAVO) and preparation for academic education (VWO). About three to four percent of the children at secondary school have special educational needs (SEN). They require extra support in school to help them to develop successfully, and often go to a school for special needs education (VSO).

In grade six, the head teacher advises children and their parents which secondary school track would be the most suitable. Aside from the teachers' own judgement, this advice is based on children's cognitive competences and on non-cognitive factors that can contribute to a successful transition.

At secondary school, each class has a mentor, usually one of the children's teachers. The mentor is the key person in the contact between children, parents, classmates and other teachers. Besides his or her teaching task, the mentor is, more than the other teachers, responsible for and authorized to ensure a challenging pedagogical environment and a safe class climate. When problems arise, pupils, parents and teachers will first turn to the mentor, and in practice, mentors are responsible for addressing any adjustment problems seventh graders might experience. 


\subsubsection{Data collection}

The data collection for this study was conducted in two phases between 2012 and 2016 and includes a pre- and a post-transition data collection. In total, 678 children participated in the pre-transition data collection, of whom 371 children (54\%) also participated in the posttransition data collection. In Chapter 3, we described an explanation for the sample loss. Lack of control by the researchers on the process, during the second measurement, possibly explains the decrease in the response rate. For the first measurement, except for the questionnaires completed in 2015, the questionnaires are completed under the supervision of the teacher. For the second measurement the questionnaires were sent out via the children's home address. The supervision was absent.

The majority of the children came from primary schools belonging to the SWV PO31015 partnership in Venlo, a regional city in the southeast of the Netherlands. Some of them came from primary schools in the same region but outside the above-mentioned partnership of primary schools. Of the 94 feeding primary schools participating in the study, $22 \%$ were located in a town and $78 \%$ were in villages. In addition, primary school participants included three schools for special primary education for children who need extra support but do not qualify for special needs education (3\%), and five primary schools dedicated to or having a department for special educational needs $(5 \%)$. The children made the transition to 21 receiving secondary schools, which included two secondary schools for special needs education. The majority of the secondary schools were comprehensive schools, providing multiple types of secondary education. One school, as a 'single pitter', or eenpitter ${ }^{6}$ in Dutch, only offers VWO education. Of the secondary schools, $19 \%$ were located in a town and the rest, in a village.

All children filled out a questionnaire twice, for which their parents' consent was obtained. The children - 173 boys and 198 girls with a mean age of 12.5 years - completed both the prospective as well as the retrospective self-reporting questionnaires. They reported their feelings and expectations about their forthcoming transition to secondary school before they made the transition, and their experiences after the transition. Table 4.1 in Appendix 2, Chapter 4 , shows the composition of the research group, the response rate and the number of children per year and in total.

\footnotetext{
${ }^{5}$ SWV PO 3101 means: Primary Education Partnership North Limburg. The partnership consists of 103 primary schools, 7 schools for special primary education, and 6 schools for special education.

${ }^{6}$ An eenpitter is a school that has its own board, so it does not fall under one board with other schools. In the Netherlands, almost half of all school boards in primary education and about one-third of the school boards for secondary education are eenpitters.
} 
During the pre-transition data collection, between the months of May and August in the years 2012, 2013, 2015 and 2016, the children completed a prospective self-reporting questionnaire. The children were approached via their primary school, except for the children in the cohort of 2014, who were approached via their future secondary school.

The second, post-transition questionnaire was presented when all children were in grade seven, i.e., in the first year at secondary school. After their first term, in October, they completed the same questionnaire as before, but from a retrospective point of view, in relation to their experiences at secondary school. This made it possible to analyze whether the expectations before the transition matched the experiences afterwards, and whether the children in the intervention group reported a better transition than the children in the control group.

All the first-phase questionnaires were completed at school, except for the questionnaires completed in 2015, which were sent by email and completed at home. The other completed questionnaires were collected by the primary researcher through the school teachers. Children who participated in the pre-transition data collection were contacted directly, by regular mail or email, based on the contact information they provided during the first data collection.

\subsubsection{A blinded experiment}

A blinded experiment was used to investigate whether children who inform their future mentor of their expectations about the transition make a better transition than children who do not have that opportunity. For the purpose of this experiment, children who participated in the pretransition data collection were randomly assigned to a control group $(n=189 ; 51 \%)$ or an intervention group $(n=182 ; 49 \%)$. As described in Chapter 2 , the blinded experiment meant that the children were deliberately kept unaware of the group to which they were assigned, control or intervention, in order to prevent bias in the results. In the first week of the new school year, mentors of the children assigned to the intervention group received a copy of the questionnaire that 'their' children completed before they started at secondary school. Mentors of children from the control group did not receive this information.

We strived for an equal distribution in terms of the observable characteristics. Through an independent T-test (Table 4.2, Appendix 2, Chapter 4), the comparability of the control group and the intervention group was checked. We found no significant differences between the two groups on the observable characteristics gender, age, year of research and "warm transfer" to 
secondary school. ${ }^{7}$ The comparability of the control group and the intervention group was also checked through an independent T-test (Table 4.2 in Appendix 2, Chapter 4) on the items familiar people at school: familiar children, siblings, children from previous school, friends and the future mentor. We found no significant differences, implying that, with respect to these items, the control group and intervention group were indeed comparable.

The children knew that they were participating in a blinded experiment. They also realized that this implied that they would not know to which group they would be assigned and that it was possible that their class at secondary school could contain children from both the intervention group and the control group.

\subsubsection{Measures}

Previous research has demonstrated that transition problems are mostly caused by difficulties in the environment. As previously indicated, Anderson et al. (2000) identified the children's environment as having a strong effect on the success or failure of the transition. To measure the views of the children about secondary school, we used large parts of the questionnaire "The Impending Transition to Secondary School Perceived as Challenge and Threat (ITCT)" (Sirsch, 2003). The translated and customized self-reporting questionnaire allowed us to measure the challenges and threats for 24 aspects in both the school and social contexts with regard to the transition. Children were asked to report what they were looking forward to at their future school and with respect to their future peers. They were also asked to report what worried them in the future school context and about their future peers. Children were asked to rate their level of concern for each item on a 4-point Likert scale. The maximum score per item was 4 (highly important), the minimum, 1 (highly unimportant). The same questions were used twice, once before and once after the transition, in order to frame the items as expectations beforehand and as experiences afterwards.

Cluster analysis was performed to reduce the 24 items of the questionnaire to six subscales that could be divided into three themes (peers, schoolwork and the school context) and into two scales (fun and fear) for each theme. Two subscales - 'fun with peers', and 'fear of peers' - related to the social context. Four subscales - 'fun in schoolwork', 'fun in the school context', 'fear of schoolwork', 'fear in the school context' - related to the school context.

\footnotetext{
7 A "warm transfer", or warme overdracht in Dutch, occurs when a primary school teacher undertakes to personally recommend a particular student to a secondary school. In this case, an oral or written guidance is communicated between two teachers (commonly, the sixth grade teacher at the primary school and the mentor at the secondary school).
} 
Table 4.3 in Appendix 2, Chapter 4, shows the average scores (i.e., the average of all included items per scale) of the 6 subscales representing the challenges and threats that the children meet before and after they make the transition. The maximum score is 4 , the minimum score is 1. T-tests show that in the pre-transition scales, there are no statistically significant differences between the average scores on the subscales between the intervention group and the control group. However, the post-transition answers show a significant difference, at the $10 \%$ level $(p=0.076)$, between the intervention group and the control group on the item fear of peers. After transition, the children in the intervention group experienced less fear of peers than the children in the control group.

Before the transition, the highest average scores were on the subscales representing fun, indicating that children are especially looking forward to their new peers, but also to the school context and schoolwork. This also shows that children are not very concerned about the transition. After the transition, the average scores increased in the subscales representing fun, except in two instances, both in the intervention group: one in the subscale 'fun in schoolwork', where the scores remained the same; and one in the subscale 'fun in the school context', where the average score actually decreased by one point. The subscales representing fear show lower scores after the transition, except for the subscale 'fear of schoolwork' in the control group, where the scores remained the same.

To determine the reliability of each subscale, Cronbach's alphas were calculated. The pretransition Cronbach's alphas for the 4 subscales 'fun with peers' ( $\alpha$ : 0.855), 'fear of schoolwork' ( $\alpha$ : 0.799), 'fear in the school context' ( $\alpha: 0.866)$ and 'fear of peers' ( $\alpha: 0.876)$ all showed a high reliability. However, the subscales 'fun in the school context' ( $\alpha$ : 0.656) and 'fun in schoolwork' (a: 0.647 ) had a somewhat lower reliability.

For each subscale, we estimated three multiple regression models, shown in Tables 4.1-4.3. The dependent variables are the pre-transition scores on the six subscales. The explanatory variables used in the pre-transition regressions are intervention-control group, gender, age, secondary education and familiar people present at secondary school. The results of the pretransition regression analyses showed how the expectations of children before they made the transition to secondary school relate to background characteristics.

The post-transition Cronbach's alphas for the 5 subscales 'fun in the school context' ( $\alpha: 0.715)$, 'fun with peers' ( $\alpha$ : 0.883), 'fear of schoolwork' ( $\alpha$ : 0.808), 'fear in the school context' ( $\alpha$ : 0.797) and 'fear of peers' ( $\alpha$ : 0.877) all showed high reliability. However, the subscale 'fun in schoolwork' ( $\alpha$ : 0.636) had a somewhat lower reliability.

The results of the post-transition regression analyses displayed the associations between background characteristics and the experiences of children after they have made the transition. 
For each post-transition subscale, we conducted four multiple regression models (Tables 4.44.8). The regressions had the same structure in all three models. Model 1 shows the results of a simple regression representing the relation between the subscale and the intervention 'providing student information to the mentor at secondary school'. In the pre-transition regressions, the variables gender, age and school type are added to model 2 . Five variables about the presence of familiar people at secondary school are added to model 3 . In the posttransition regressions, we used the same variables but in a different order, because in model 2 we added the pre-transition measure of outcome. Below the results are described consecutively. The subscales 'fear' and 'fun' are described per theme and per model.

\subsection{Results}

\subsubsection{Expectations of children before the transition}

In Tables 4.1, 4.2 and 4.3, we present the results of the linear regression analysis of the expectations that children have about fear and fun in the social context and in the school context before they make the transition to secondary school. Each table presents the results of the positive (fun) and the negative (fear) subscales for the themes of peers (the social context), schoolwork, and school context. 
Table 4.1: The social context: fear of and fun with peers - pre-transition regression analyse

\begin{tabular}{|c|c|c|c|c|c|c|}
\hline \multirow[b]{2}{*}{ Peers } & \multicolumn{2}{|l|}{ Model 1} & \multicolumn{2}{|l|}{ Model 2} & \multicolumn{2}{|l|}{ Model 3} \\
\hline & fear & fun & fear & fun & fear & fun \\
\hline $\begin{array}{l}\text { Independent } \\
\text { variables }\end{array}$ & $\begin{array}{l}\text { coefficient } \\
(P \text {-value) }\end{array}$ & $\begin{array}{l}\text { coefficient } \\
\text { (P-value) }\end{array}$ & $\begin{array}{l}\text { coefficient } \\
\text { (P-value) }\end{array}$ & $\begin{array}{l}\text { coefficient } \\
\text { (P-value) }\end{array}$ & $\begin{array}{l}\text { coefficient } \\
(P \text {-value })\end{array}$ & $\begin{array}{l}\text { coefficient } \\
\text { (P-value) }\end{array}$ \\
\hline $\begin{array}{l}\text { Intervention - } \\
\text { control group }\end{array}$ & $\begin{array}{l}-0.062 \\
(0.292)\end{array}$ & $\begin{array}{l}0.077 \\
(0.208)\end{array}$ & $\begin{array}{l}-0.053 \\
(0.374)\end{array}$ & $\begin{array}{l}0.073 \\
(0.240)\end{array}$ & $\begin{array}{l}-0.064 \\
(0.279)\end{array}$ & $\begin{array}{l}0.081 \\
(0.195)\end{array}$ \\
\hline $\begin{array}{l}\text { Girl-boy } \\
\text { Age } \\
11\end{array}$ & & & $\begin{array}{l}-0.138 \\
(0.022 *) \\
-0.066 \\
(0.516)\end{array}$ & $\begin{array}{l}0.028 \\
(0.652) \\
\\
0.066 \\
(0.538)\end{array}$ & $\begin{array}{l}-0.112 \\
\left(0.064^{0}\right) \\
-0.061 \\
(0.546)\end{array}$ & $\begin{array}{l}0.025 \\
(0.694) \\
\\
0.070 \\
(0.518)\end{array}$ \\
\hline 12 & \multicolumn{6}{|c|}{ Reference category } \\
\hline $\begin{array}{l}13 \\
14\end{array}$ & & & $\begin{array}{l}-0.077 \\
(0.403) \\
1.182 \\
\left(0.034^{*}\right)\end{array}$ & $\begin{array}{l}0.060 \\
(0.526) \\
0.569 \\
(0.326)\end{array}$ & $\begin{array}{l}-0.097 \\
(0,293) \\
0.930 \\
(0.100)\end{array}$ & $\begin{array}{l}0.044 \\
(0.650) \\
0.817 \\
(0.169)\end{array}$ \\
\hline $\begin{array}{l}\text { School type } \\
\text { PrO-VMBO }\end{array}$ & \multicolumn{6}{|c|}{ Reference category } \\
\hline $\begin{array}{l}\text { VMBO-HAVO; } \\
\text { HAVO } \\
\text { HAVO-VWO; VWO } \\
\text { VSO }\end{array}$ & & & $\begin{array}{l}-0.118 \\
(0.248) \\
-0.063 \\
(0.345 \\
-0.004 \\
(0.984)\end{array}$ & $\begin{array}{l}0.219 \\
\left(0.042^{*}\right) \\
0.045 \\
(0.520) \\
0.136 \\
(0.494)\end{array}$ & $\begin{array}{l}-0.103 \\
(0.314) \\
-0.068 \\
(0.303) \\
-0.051 \\
(0.815)\end{array}$ & $\begin{array}{l}0.238 \\
(0.029 *) \\
0.035 \\
(0.619) \\
0.143 \\
(0.511)\end{array}$ \\
\hline $\begin{array}{l}\text { Present at school } \\
\text { Familiar children } \\
\text { Siblings } \\
\text { Children from } \\
\text { previous school } \\
\text { Friends } \\
\text { Mentor familiar }\end{array}$ & & & & & $\begin{array}{l}-0.033 \\
(0.751) \\
-0.013 \\
(0.851) \\
-0.0106 \\
(0.288) \\
0.247 \\
\left(0.007^{*}\right) \\
-0.011 \\
(0.861)\end{array}$ & $\begin{array}{l}0.056 \\
(0.605) \\
0.075 \\
(0.315) \\
-0.097 \\
(0.356) \\
0.113 \\
(0.243) \\
0.100 \\
(0.150)\end{array}$ \\
\hline $\begin{array}{l}\text { Constant } \\
\text { Observations } \\
R^{2} \\
R^{2} \text { adjusted }\end{array}$ & $\begin{array}{l}1.434 \\
N=349 \\
0.003 \\
0.000\end{array}$ & $\begin{array}{l}3.077 \\
N=351 \\
0.005 \\
0.002\end{array}$ & $\begin{array}{l}1.556 \\
N=345 \\
0.041 \\
0.018\end{array}$ & $\begin{array}{l}3.002 \\
N=346 \\
0.022 \\
-0.001\end{array}$ & $\begin{array}{l}1.889 \\
N=342 \\
0.085 \\
0.049\end{array}$ & $\begin{array}{l}2.855 \\
N=344 \\
0.037 \\
0.000\end{array}$ \\
\hline
\end{tabular}

Note: the tracks at secondary education are: practical education (PrO), preparation for intermediate vocational education (VMBO), upper-secondary education (HAVO) and preparation for academic education (VWO) 


\subsubsection{The social context: expectations about fear of and fun with peers}

Table 4.1 shows the results of the regression analyses about the expectations of the children before the transition with respect to fear of and fun with their future peers at secondary school. The results of model 1 revealed no significant differences between the expectations of the control group and the intervention group. This was expected: when the comparability of the control group and the intervention group was checked, we found no statistically significant differences in observable characteristics, which implies the composition of the control group and intervention group is comparable.

Models 2 and 3 show statistically significant differences between the expectations of girls and boys. Before the transition, girls expected to be less anxious in a significant degree about their future peers at secondary school (model 2, $p=0.022$; model $3, p=0.064$ ) than boys did. Model 2 also shows that, with respect to fear of peers, 14-year-old children differ statistically significantly (model $2, p=0.034$ ) from the reference group (the 12-year-olds). The 14-year-olds were more anxious in a significant degree about their future peers at secondary school. With respect to school type, models 2 and 3 show that, compared with the VMBO-PrO pupils in the reference group, the VMBO-HAVO and HAVO pupils expected to have statistically significantly more fun with their peers at secondary school (model 2, $p=0.042$; model $3, p=0.029$. In model 3 , surprisingly, we found that when children knew, before the transition, that friends from primary school would be attending the same secondary school, those children expected to experience statistically significant amounts of fear about their new peers (model $3, p=0.007$ ). 
Table 4.2: The school context: fear of and fun with schoolwork - pre-transition regression analyses

\begin{tabular}{|c|c|c|c|c|c|c|}
\hline \multirow[b]{2}{*}{ Schoolwork } & \multicolumn{2}{|l|}{ Model 1} & \multicolumn{2}{|l|}{ Model 2} & \multicolumn{2}{|l|}{ Model 3} \\
\hline & fear & fun & fear & fun & fear & fun \\
\hline $\begin{array}{l}\text { Independent } \\
\text { variables }\end{array}$ & $\begin{array}{l}\text { coefficient } \\
\text { (P-value) }\end{array}$ & $\begin{array}{l}\text { coefficient } \\
\text { (P-value) }\end{array}$ & $\begin{array}{l}\text { coefficient } \\
\text { (P-value) }\end{array}$ & $\begin{array}{l}\text { coefficient } \\
\text { (P-value) }\end{array}$ & $\begin{array}{l}\text { coefficient } \\
\text { (P-value) }\end{array}$ & $\begin{array}{l}\text { coefficient } \\
\text { (P-value) }\end{array}$ \\
\hline $\begin{array}{l}\text { Intervention - } \\
\text { control group }\end{array}$ & $\begin{array}{l}0.022 \\
(0.720)\end{array}$ & $\begin{array}{l}0.037 \\
(0.542)\end{array}$ & $\begin{array}{l}0.014 \\
(0.824)\end{array}$ & $\begin{array}{l}0.021 \\
(0.731)\end{array}$ & $\begin{array}{l}0.012 \\
(0.848)\end{array}$ & $\begin{array}{l}0.018 \\
(0.781)\end{array}$ \\
\hline $\begin{array}{l}\text { Girl-boy } \\
\text { Age } \\
11\end{array}$ & & & $\begin{array}{l}-0.018 \\
(0.777) \\
-0.024 \\
(0.822)\end{array}$ & $\begin{array}{l}0.017 \\
(0.784) \\
\\
0.004 \\
(0.971)\end{array}$ & $\begin{array}{l}-0.012 \\
(0.853) \\
\\
-0.030 \\
(0.785)\end{array}$ & $\begin{array}{l}0.021 \\
(0.748) \\
\\
0.010 \\
(0.927)\end{array}$ \\
\hline 12 & \multicolumn{6}{|c|}{ Reference category } \\
\hline $\begin{array}{l}13 \\
14\end{array}$ & & & $\begin{array}{l}0.009 \\
(0.926) \\
0.429 \\
(0.465)\end{array}$ & $\begin{array}{l}0.060 \\
(0.531) \\
-0.180 \\
(0.756)\end{array}$ & $\begin{array}{l}0.000 \\
(0.997) \\
0.492 \\
(0.417)\end{array}$ & $\begin{array}{l}0.055 \\
(0.572) \\
-0.103 \\
(0.864)\end{array}$ \\
\hline $\begin{array}{l}\text { School type } \\
\text { PrO-VMBO }\end{array}$ & \multicolumn{6}{|c|}{ Reference category } \\
\hline $\begin{array}{l}\text { VMBO-HAVO; } \\
\text { HAVO } \\
\text { HAVO-VWO; VWO } \\
\text { VSO }\end{array}$ & & & $\begin{array}{l}0.046 \\
(0.670) \\
-0.074 \\
(0.294) \\
0.031 \\
(0.883)\end{array}$ & $\begin{array}{l}0.135 \\
(0.203) \\
-0.017 \\
(0.806) \\
-0.040 \\
(0.842)\end{array}$ & $\begin{array}{l}0.054 \\
(0.625) \\
-0.092 \\
(0.198) \\
0.126 \\
(0.592)\end{array}$ & $\begin{array}{l}0.141 \\
(0.195) \\
-0.012 \\
(0.860) \\
-0.024 \\
(0.914)\end{array}$ \\
\hline $\begin{array}{l}\text { Present at school } \\
\text { Familiar children } \\
\text { Siblings } \\
\text { Children from } \\
\text { previous school } \\
\text { Friends } \\
\text { Mentor familiar }\end{array}$ & & & & & $\begin{array}{l}-0.057 \\
(0.620) \\
0.024 \\
(0.752) \\
-0.057 \\
(0.593) \\
0.037 \\
(0.707) \\
0.119 \\
\left(0.093^{\circ}\right)\end{array}$ & $\begin{array}{l}0.083 \\
(0.454) \\
-0.026 \\
(0.731) \\
-0.066 \\
(0.535) \\
0.042 \\
(0.666) \\
-0.053 \\
(0.445)\end{array}$ \\
\hline $\begin{array}{l}\text { Constant } \\
\text { Observations } \\
R^{2} \\
R^{2} \text { adjusted }\end{array}$ & $\begin{array}{l}1.797 \\
N=351 \\
0.000 \\
-0.002\end{array}$ & $\begin{array}{l}2.839 \\
N=350 \\
0.001 \\
-0.002\end{array}$ & $\begin{array}{l}1.839 \\
N=346 \\
0.008 \\
-0.015\end{array}$ & $\begin{array}{l}2.830 \\
N=345 \\
0.009 \\
-0.015\end{array}$ & $\begin{array}{l}1.827 \\
N=343 \\
0.020 \\
-0.019\end{array}$ & $\begin{array}{l}2.851 \\
N=343 \\
0.013 \\
-0.026\end{array}$ \\
\hline
\end{tabular}

${ }^{0} p \leq 0.10 ;{ }^{*} p \leq 0.05 ;{ }^{* *} p \leq 0.01 ;{ }^{* * *} p \leq 0.001$

Note: the tracks at secondary education are: practical education (PrO), preparation for intermediate vocational education (VMBO), upper-secondary education (HAVO) and preparation for academic education (VWO)

\subsubsection{The school context: expectations about fear of and fun in schoolwork}

Table 4.2 shows the results of the regression analyses about the pre-transition expectations of the children concerning schoolwork in secondary school. The variables of controlintervention group, gender, age and school type, which were added to models 1 and 2, do not 
affect expectations about fear or fun in schoolwork in a statistically significant way. Model 3 adds the variables of familiar children, siblings, children from previous school, friends and familiar mentor. Only the presence of a familiar mentor has a significant effect at the $10 \%$ level of fear of schoolwork (model $3, p=0.093$ ). The children expected that knowing their future mentor before the transition would lead to greater fear of schoolwork.

Table 4.3: The school context: fear and fun in the school context - pre-transition regression analyses

\begin{tabular}{|c|c|c|c|c|c|c|}
\hline \multirow[b]{2}{*}{ School context } & \multicolumn{2}{|l|}{ Model 1} & \multicolumn{2}{|l|}{ Model 2} & \multicolumn{2}{|l|}{ Model 3} \\
\hline & fear & fun & fear & fun & fear & fun \\
\hline $\begin{array}{l}\text { Independent } \\
\text { variables }\end{array}$ & $\begin{array}{l}\text { coefficient } \\
\text { (P-value) }\end{array}$ & $\begin{array}{l}\text { coefficient } \\
\text { (P-value) }\end{array}$ & $\begin{array}{l}\text { coefficient } \\
\text { (P-value) }\end{array}$ & $\begin{array}{l}\text { coefficient } \\
\text { (P-value) }\end{array}$ & $\begin{array}{l}\text { coefficient } \\
\text { (P-value) }\end{array}$ & $\begin{array}{l}\text { coefficient } \\
\text { (P-value) }\end{array}$ \\
\hline $\begin{array}{l}\text { Intervention - } \\
\text { control group }\end{array}$ & $\begin{array}{l}0.031 \\
(0.688)\end{array}$ & $\begin{array}{l}2.750 \\
\left(0.099^{\circ}\right)\end{array}$ & $\begin{array}{l}0.021 \\
(0.781)\end{array}$ & $\begin{array}{l}0.117 \\
(0.103)\end{array}$ & $\begin{array}{l}-0.004 \\
(0.959)\end{array}$ & $\begin{array}{l}0.122 \\
\left(0.096^{\circ}\right)\end{array}$ \\
\hline $\begin{array}{l}\text { Girl-boy } \\
\text { Age } \\
11\end{array}$ & & & $\begin{array}{l}0.079 \\
(0.311) \\
\\
-0.043 \\
(0.746)\end{array}$ & $\begin{array}{c}0.104 \\
(0.153) \\
\\
0.000 \\
(0.999)\end{array}$ & $\begin{array}{c}0.105 \\
(0.180) \\
\\
-0.059 \\
(0.657)\end{array}$ & $\begin{array}{c}0.109 \\
(0.144) \\
\\
-0.002 \\
(0.987)\end{array}$ \\
\hline 12 & Reference & ategory & & & & \\
\hline $\begin{array}{l}13 \\
14\end{array}$ & & & $\begin{array}{c}0.048 \\
(0.684) \\
0.201 \\
(0.780)\end{array}$ & $\begin{array}{c}0.063 \\
(0.566) \\
0.628 \\
(0.348)\end{array}$ & $\begin{array}{c}0.007 \\
(0.956) \\
0.339 \\
(0.643)\end{array}$ & $\begin{array}{l}0.048 \\
(0.667) \\
0.761 \\
(0.272)\end{array}$ \\
\hline $\begin{array}{l}\text { School type } \\
\text { PrO-VMBO }\end{array}$ & Reference & ategory & & & & \\
\hline $\begin{array}{l}\text { VMBO-HAVO; } \\
\text { HAVO } \\
\text { HAVO-VWO; VWO } \\
\text { VSO }\end{array}$ & & & $\begin{array}{l}-0.106 \\
(0.429) \\
-0.291 \\
\left(0.001^{* * *}\right) \\
-0.201 \\
(0.417)\end{array}$ & $\begin{array}{c}0.217 \\
\left(0.081^{\circ}\right) \\
0.144 \\
\left(0.075^{\circ}\right) \\
0.106 \\
(0.646)\end{array}$ & $\begin{array}{l}-0.048 \\
(0.721) \\
-0.313 \\
\left(0.000^{* * *}\right) \\
0.045 \\
(0.866)\end{array}$ & $\begin{array}{c}0.237 \\
\left(0.062^{\circ}\right) \\
0.135 \\
\left(0.097^{\circ}\right) \\
0.108 \\
(0.671)\end{array}$ \\
\hline $\begin{array}{l}\text { Present at school } \\
\text { Familiar children } \\
\text { Siblings } \\
\text { Children from } \\
\text { previous school } \\
\text { Friends } \\
\text { Mentor familiar }\end{array}$ & & & & & $\begin{array}{l}0.142 \\
(0.295) \\
-0.061 \\
(0.508) \\
-0.137 \\
(0.792) \\
-0.137 \\
(0.245) \\
0.234 \\
\left(0.006^{*}\right)\end{array}$ & $\begin{array}{l}0.035 \\
(0.784) \\
0.021 \\
(0.808) \\
-0.090 \\
(0.465) \\
0.029 \\
(0.797) \\
0.090 \\
(0.265)\end{array}$ \\
\hline $\begin{array}{l}\text { Constant } \\
\text { Observations } \\
R^{2} \\
R^{2} \text { adjusted }\end{array}$ & $\begin{array}{l}1.620 \\
N=353 \\
0.000 \\
-0.002\end{array}$ & $\begin{array}{l}2.750 \\
N=350 \\
0.008 \\
0.005\end{array}$ & $\begin{array}{l}1.719 \\
N=348 \\
0.044 \\
0.021\end{array}$ & $\begin{array}{l}2.601 \\
N=345 \\
0.031 \\
0.008\end{array}$ & $\begin{array}{l}1.590 \\
N=345 \\
0.078 \\
0.042\end{array}$ & $\begin{array}{l}2.554 \\
N=343 \\
0.038 \\
0.000\end{array}$ \\
\hline
\end{tabular}

${ }^{0} p \leq 0.10 ;{ }^{*} p \leq 0.05 ;{ }^{* *} p \leq 0.01 ;{ }^{* * *} p \leq 0.001$

Note: the tracks at secondary education are: practical education (PrO), preparation for intermediate vocational education (VMBO), upper-secondary education (HAVO) and preparation for academic education (VWO). 


\subsubsection{The school context: expectations about fear and fun in the school context}

Table 4.3 shows the results of the regression analyses about fear and fun in the school context, measured before the transition to secondary school. In model 1, there is a statistical difference at the $10 \%$ level between the expectations of the control and intervention groups for the item fun in the school context (model 1, $\mathrm{p}=0,099$ ). Before the transition, the children in the intervention group expected to experience more fun in the school context at secondary school than the children in the control group. Gender and age, added in model 2, do not significantly affect the expectations of the children about the school context. For the children in the school types VMBO-HAVO and HAVO, a significant effect was found at the $10 \%$ level with respect to fun with peers (model $2, p=0.081$; model $3, p=0.062$ ). Compared to the reference group, these children expected to experience more fun in the school context at secondary school. The children in the school types HAVO-VWO and VWO also expected, when compared to the reference group, significantly more fun in the school context at the $10 \%$ level (model 2, $\mathrm{p}=0.075$; model $3, \mathrm{p}=0.097$ ) as well as significantly less fear (model $2, p=0.001$; model 3 , $\mathrm{p}=0.000$ ). Model 3 shows that the children expected, before the transition, that if they already knew their future mentor, there would be a significant increase of fear in the school context (model 3, $\mathrm{p}=0.006$ ).

\subsubsection{Experiences of children after the transition}

Tables 4.4, 4.5 and 4.6 present the results of the linear regression analyses for fear and fun in the themes peers (the social context), schoolwork, and school context, as measured after the transition to secondary school. Each table shows the results of both the positive and negative subscales. 
Table 4.4: The social context: fear of and fun with peers; regression analyses in 4 models - post-transition

\begin{tabular}{|c|c|c|c|c|c|c|c|c|}
\hline \multirow[b]{2}{*}{ Peers } & \multicolumn{2}{|c|}{ Model 1} & \multicolumn{2}{|l|}{ Model 2} & \multicolumn{2}{|l|}{ Model 3} & \multicolumn{2}{|l|}{ Model 4} \\
\hline & fear & fun & fear & fun & fear & fun & fear & fun \\
\hline $\begin{array}{l}\text { Independent } \\
\text { variables }\end{array}$ & $\begin{array}{l}\text { coefficient } \\
\text { (P-value) }\end{array}$ & $\begin{array}{l}\text { coefficient } \\
(P \text {-value })\end{array}$ & $\begin{array}{l}\text { coefficient } \\
\text { (P-value) }\end{array}$ & $\begin{array}{l}\text { coefficient } \\
(P \text {-value })\end{array}$ & $\begin{array}{l}\text { coefficient } \\
(P \text {-value })\end{array}$ & $\begin{array}{l}\text { coefficient } \\
(P \text {-value })\end{array}$ & $\begin{array}{l}\text { coefficient } \\
(P \text {-value })\end{array}$ & $\begin{array}{l}\text { coefficient } \\
(P \text {-value })\end{array}$ \\
\hline $\begin{array}{l}\text { Intervention - } \\
\text { control group }\end{array}$ & $\begin{array}{l}-0.101 \\
\left(0.077^{\circ}\right)\end{array}$ & $\begin{array}{l}-0.054 \\
(0.416)\end{array}$ & $\begin{array}{l}-0.026 \\
(0.564)\end{array}$ & $\begin{array}{l}-0.101 \\
\left(0.096^{\circ}\right)\end{array}$ & $\begin{array}{l}-0.023 \\
(0.609)\end{array}$ & $\begin{array}{l}-0.104 \\
\left(0.089^{\circ}\right)\end{array}$ & $\begin{array}{l}-0.021 \\
(0.642)\end{array}$ & $\begin{array}{l}-0.112 \\
\left(0.072^{\circ}\right)\end{array}$ \\
\hline $\begin{array}{l}\text { Fear of peers } \\
\text { pre-transition }\end{array}$ & & & $\begin{array}{l}0.533 \\
(0.000 * * *)\end{array}$ & & $\begin{array}{l}0.527 \\
(0.000 * * *)\end{array}$ & & $\begin{array}{l}0.528 \\
(0.000 * * *)\end{array}$ & \\
\hline $\begin{array}{l}\text { Fun with peers } \\
\text { pre-transition }\end{array}$ & & & & $\begin{array}{l}0.450 \\
\left(0.000^{* * *}\right)\end{array}$ & & $\begin{array}{l}0.457 \\
\left(0.000^{* * *}\right)\end{array}$ & & $\begin{array}{l}0.458 \\
\left(0.000^{* * *}\right)\end{array}$ \\
\hline $\begin{array}{l}\text { Girl-boy } \\
\text { Age } \\
11\end{array}$ & & & & & $\begin{array}{l}0.011 \\
(0.810) \\
\\
-0.051 \\
(0.520)\end{array}$ & $\begin{array}{l}0.048 \\
(0.434) \\
\\
-0.045 \\
(0.665)\end{array}$ & $\begin{array}{l}0.016 \\
(0.736) \\
\\
-0.066 \\
(0.406)\end{array}$ & $\begin{array}{l}0.050 \\
(0.432) \\
\\
-0.048 \\
(0.650)\end{array}$ \\
\hline 12 & \multicolumn{8}{|c|}{ Reference category } \\
\hline $\begin{array}{l}13 \\
14\end{array}$ & & & & & $\begin{array}{c}0.095 \\
(0.184) \\
0.431 \\
(0.300)\end{array}$ & $\begin{array}{l}-0.049 \\
(0.608) \\
-1.162 \\
\left(0.035^{*}\right)\end{array}$ & $\begin{array}{c}0.080 \\
(0.273) \\
0.454 \\
(0.287)\end{array}$ & $\begin{array}{l}-0.068 \\
(0.489) \\
-1.171 \\
\left(0.041^{*}\right)\end{array}$ \\
\hline \multicolumn{9}{|c|}{$\begin{array}{l}\text { Secondary education } \\
\text { VMBO; PrO Reference }\end{array}$} \\
\hline $\begin{array}{l}\text { VMBO-HAVO; } \\
\text { HAVO } \\
\text { HAVO-VWO; VWO } \\
\text { VSO }\end{array}$ & & & & & $\begin{array}{c}-0.040 \\
(0.616) \\
0.009 \\
(0.865) \\
0.216 \\
(0.176)\end{array}$ & $\begin{array}{l}-0.125 \\
(0.245) \\
-0.073 \\
(0.288) \\
-0.289 \\
(0.127)\end{array}$ & $\begin{array}{l}-0.027 \\
(0.738) \\
-0.002 \\
(0.969) \\
0.284 \\
\left(0.086^{\circ}\right)\end{array}$ & $\begin{array}{l}-0.121 \\
(0.272) \\
-0.075 \\
(0.276) \\
-0.190 \\
(0.364)\end{array}$ \\
\hline $\begin{array}{l}\text { Present at school } \\
\text { Familiar children } \\
\text { Siblings } \\
\text { Children from } \\
\text { previous school } \\
\text { Friends } \\
\text { Mentor familiar }\end{array}$ & & & & & & & $\begin{array}{l}-0.027 \\
(0.736) \\
-0.018 \\
(0.738) \\
0.037 \\
(0.629) \\
-0.024 \\
(0.737) \\
0.123 \\
\left(0.017^{*}\right)\end{array}$ & $\begin{array}{l}-0.008 \\
(0942) \\
0.023 \\
(0.761) \\
0.015 \\
(0.884) \\
-0.029 \\
(0.766) \\
0.039 \\
(0.578)\end{array}$ \\
\hline $\begin{array}{l}\text { Constant } \\
\text { Observations } \\
R^{2} \\
R^{2} \text { adjusted }\end{array}$ & $\begin{array}{l}1.400 \\
N=348 \\
0.009 \\
0.006\end{array}$ & $\begin{array}{l}3.223 \\
N=344 \\
0.002 \\
-0.001\end{array}$ & $\begin{array}{l}0.602 \\
N=330 \\
0.348 \\
0.344\end{array}$ & $\begin{array}{l}1.848 \\
N=328 \\
0.184 \\
0.179\end{array}$ & $\begin{array}{l}0.588 \\
N=326 \\
0.360 \\
0.341\end{array}$ & $\begin{array}{l}1.870 \\
N=323 \\
0.202 \\
0.179\end{array}$ & $\begin{array}{l}0.521 \\
N=324 \\
0.372 \\
0.343\end{array}$ & $\begin{array}{l}1.856 \\
N=321 \\
0.205 \\
0.168\end{array}$ \\
\hline
\end{tabular}

${ }^{0} p \leq 0.10 ;{ }^{*} p \leq 0.05 ;{ }^{* *} p \leq 0.01 ;{ }^{* *} p \leq 0.001$

Note: the tracks at secondary education are: practical education (PrO), preparation for intermediate vocational education (VMBO), upper-secondary education (HAVO) and preparation for academic education (VWO).

\subsubsection{The social context: experiences with fear of and fun with peers}

Table 4.4 presents the results of linear regression analyses about fear of and fun with peers. The results for model 1 show a negative relationship between the intervention and fear of peers after the transition to secondary school, so that the children in the intervention group appeared 
as less fearful. This result in model 1 is statistically significant at the $10 \%$ level $(p=0.077)$. The post-transition results for fun with peers in model 1 are not significant, but models 2,3 and 4 show significant results for intervention at a 10\% level (model 2: $p=0,096$; model 3: $p=0.089$; model 4: $p=0.072$ ). Surprisingly, after the transition, there was a negative relationship with the intervention group in respect of having fun with their peers: children in the intervention group reported having less fun with their peers.

Models 2 to 4 add the independent variables of gender, age, school type, and familiar people at secondary school to the theme of fun with or fear of peers before the transition. The results of model 2 show a positive relationship before and after the transition. Children who were afraid of their peers before the transition experience more fear afterwards; and children who were looking forward to having fun with their peers experience more fun afterwards. Fear (or fun) before the transition seems to be a significant and reliable predictor for more fear or fun after the transition $(p=0.000)$. On average, a one-point higher score on the fun/fear variable prior to the transition translates into a half-point higher score on the post-transition variable.

With regard to gender, age or school type, model 3 shows that these variables do not have a statistically significant influence on the fear of or fun with peers, except in the case of 14-yearold children. After the transition, these children experienced significantly less fun (model 3 , $\mathrm{p}=0.035$ ) in comparison to their 12-year-old peers in the reference group. These findings regarding 14-year-olds remain in model 4 when we add the presence of familiar people at school: they still reported significantly less fun (model $4, p=0.041$ ) than their peers. After we control for the presence of familiar people, there is a difference between the children at a school for special educational needs (VSO) and typically developing children. The model shows a positive relationship between fear of peers and being at a SEN school. Fear of peers is significantly higher (at the $10 \%$ level) for special education needs children (model 4 , $\mathrm{p}=0.086)$.

In model 4, four variables are added concerning the presence of familiar people at secondary school. None of these variables are statistically significant to fun with peers, but familiarity of the mentor significantly influences fear of peers $(p=0.017)$. Surprisingly, we found that children who already knew their mentor were more fearful of their peers after the transition. 
Table 4.5: The school context: fear of and fun with schoolwork: regression analyses, 4 models - post-transition

\begin{tabular}{|c|c|c|c|c|c|c|c|c|}
\hline & \multicolumn{2}{|l|}{ Model 1} & \multicolumn{2}{|l|}{ Model 2} & \multicolumn{2}{|l|}{ Model 3} & \multicolumn{2}{|l|}{ Model 4} \\
\hline Schoolwork & fear & fun & fear & fun & fear & fun & fear & fun \\
\hline $\begin{array}{l}\text { Independent } \\
\text { variables }\end{array}$ & $\begin{array}{l}\text { coefficient } \\
(P \text {-value })\end{array}$ & $\begin{array}{l}\text { coefficient } \\
(P \text {-value })\end{array}$ & $\begin{array}{l}\text { coefficient } \\
(P \text {-value })\end{array}$ & $\begin{array}{l}\text { coefficient } \\
(P \text {-value })\end{array}$ & $\begin{array}{l}\text { coefficient } \\
(P \text {-value })\end{array}$ & $\begin{array}{l}\text { coefficient } \\
(P \text {-value })\end{array}$ & $\begin{array}{l}\text { coefficient } \\
(P \text {-value })\end{array}$ & $\begin{array}{l}\text { coefficient } \\
(P \text {-value })\end{array}$ \\
\hline $\begin{array}{l}\text { Intervention - } \\
\text { control group }\end{array}$ & $\begin{array}{l}-0.093 \\
(0.160)\end{array}$ & $\begin{array}{l}-0.020 \\
(0.756)\end{array}$ & $\begin{array}{l}-0.084 \\
(0.144)\end{array}$ & $\begin{array}{l}-0.038 \\
(0.520)\end{array}$ & $\begin{array}{l}-0.084 \\
(0.148)\end{array}$ & $\begin{array}{l}-0.055 \\
(0.352)\end{array}$ & $\begin{array}{l}-0.086 \\
(0.146)\end{array}$ & $\begin{array}{l}-0.042 \\
(0.477)\end{array}$ \\
\hline $\begin{array}{l}\text { Fear (pre- } \\
\text { transition) }\end{array}$ & & & $\begin{array}{l}0.557 \\
\left(0.000^{\star * *}\right)\end{array}$ & & $\begin{array}{l}0.555 \\
\left(0.000^{\star * *}\right)\end{array}$ & & $\begin{array}{l}0.557 \\
\left(0.000^{* * *}\right)\end{array}$ & \\
\hline $\begin{array}{l}\text { Fun (pre- } \\
\text { transition) }\end{array}$ & & & & $\begin{array}{l}0.491 \\
\left(0.000^{* * *}\right)\end{array}$ & & $\begin{array}{l}0.476 \\
\left(0.000^{* * *}\right)\end{array}$ & & $\begin{array}{l}0.487 \\
\left(0.000^{* * *}\right)\end{array}$ \\
\hline $\begin{array}{l}\text { Girl-boy } \\
\text { Age } \\
11\end{array}$ & & & & & $\begin{array}{l}0.131 \\
\left(0.027^{*}\right) \\
-0.112 \\
(0.273)\end{array}$ & $\begin{array}{l}0.020 \\
(0.732) \\
\\
0.078 \\
(0.438)\end{array}$ & $\begin{array}{l}0.135 \\
\left(0.026^{*}\right) \\
-0.119 \\
(0.253)\end{array}$ & $\begin{array}{l}0.027 \\
(0.654) \\
0.062 \\
(0.538)\end{array}$ \\
\hline 12 & \multicolumn{8}{|c|}{ Reference category } \\
\hline $\begin{array}{l}13 \\
14\end{array}$ & & & & & $\begin{array}{l}0.016 \\
(0.860) \\
-0.366 \\
(0.488)\end{array}$ & $\begin{array}{l}0.121 \\
(0.194) \\
-0.150 \\
(0.779)\end{array}$ & $\begin{array}{l}0.013 \\
(0.891) \\
-0.488 \\
(0.374)\end{array}$ & $\begin{array}{l}0.122 \\
(0.195) \\
0.003 \\
(0.996)\end{array}$ \\
\hline \multicolumn{9}{|c|}{$\begin{array}{l}\text { Secondary education } \\
\text { VMBO; PrO Reference }\end{array}$} \\
\hline $\begin{array}{l}\text { VMBO-HAVO; } \\
\text { HAVO } \\
\text { HAVO-VWO; } \\
\text { VWO } \\
\text { VSO }\end{array}$ & & & & & $\begin{array}{l}-0.037 \\
(0.717) \\
-0.015 \\
(0.821) \\
-0.086 \\
(0.676)\end{array}$ & $\begin{array}{l}0.102 \\
(0.322) \\
-0.023 \\
(0.733) \\
-0.107 \\
(0.560)\end{array}$ & $\begin{array}{l}-0.046 \\
(0.658) \\
-0.011 \\
(0.867) \\
-0.122 \\
(0.567)\end{array}$ & $\begin{array}{l}0.130 \\
(0.211) \\
-0.034 \\
(0.608) \\
-0.050 \\
(0.805)\end{array}$ \\
\hline $\begin{array}{l}\text { Present at } \\
\text { school } \\
\text { Familiar } \\
\text { children } \\
\text { Siblings } \\
\text { Children from } \\
\text { previous } \\
\text { school } \\
\text { Friends } \\
\text { Mentor familiar }\end{array}$ & & & & & & & $\begin{array}{l}-0.046 \\
(0.667) \\
-0.009 \\
(0.904) \\
0.064 \\
(0.520) \\
\\
-0.066 \\
(0.458) \\
-0.016 \\
(0.815)\end{array}$ & $\begin{array}{l}0.053 \\
(0.609) \\
-0.088 \\
(0.217) \\
-0.089 \\
(0.370) \\
\\
0.026 \\
(0.777) \\
0.134 \\
\left(0.045^{\star}\right)\end{array}$ \\
\hline $\begin{array}{l}\text { Constant } \\
\text { Observations } \\
R^{2} \\
R^{2} \text { adjusted }\end{array}$ & $\begin{array}{l}1.798 \\
N=348 \\
0.006 \\
0.003\end{array}$ & $\begin{array}{l}2.901 \\
N=349 \\
0.000 \\
-0.003\end{array}$ & $\begin{array}{l}0.779 \\
N=332 \\
0.284 \\
0.279\end{array}$ & $\begin{array}{l}1.501 \\
N=331 \\
0.214 \\
0,210\end{array}$ & $\begin{array}{l}0.737 \\
N=327 \\
0.295 \\
0.275\end{array}$ & $\begin{array}{l}1.526 \\
N=326 \\
0.229 \\
0.207\end{array}$ & $\begin{array}{l}0.786 \\
N=325 \\
0.296 \\
0.265\end{array}$ & $\begin{array}{l}1.427 \\
N=324 \\
0.254 \\
0.220\end{array}$ \\
\hline
\end{tabular}

${ }^{0} p \leq 0.10 ;{ }^{*} p \leq 0.05 ;{ }^{* *} p \leq 0.01 ;{ }^{* * *} p \leq 0.001$

Note: the tracks at secondary education are: practical education (PrO), preparation for intermediate vocational education (VMBO), upper-secondary education (HAVO) and preparation for academic education (VWO). 


\subsubsection{The school context: fear of and fun with schoolwork}

Table 4.5 presents the results of linear regression analyses on fear and fun with schoolwork. The results of model 1 are not significant. In none of the regressions did we find a statistically significant effect of the intervention on fear or fun with schoolwork.

The independent variables fear of schoolwork and fun with schoolwork of model 2 have a positive pre-transition relationship with the schoolwork experiences reported by the children afterwards. This means that children who are worried about schoolwork before they made the transition to secondary school will also be more anxious about it afterwards; and children who are looking forward to schoolwork in secondary school will also experience more fun with their schoolwork afterwards. Fear or fun with schoolwork before the transition seems to be a significantly reliable predictor for more fear or fun after the transition (Table 4.5, model 2, $p=0.000$ ). As was the case described above with peers, we found that a one-point increase in the perception of fun or fear with schoolwork before the transition increases the post-transition variables by approximately 0.5 of a point.

The independent variables of gender, age and school type added in model 3 yielded the following results. Compared to boys, girls after the transition scored statistically significantly higher on fear of schoolwork (model 3, $p=0.027$; model 4, $p=0.026$ ). Age and school type did not have a significant effect on either fear or fun with schoolwork. Finally, model 4 shows the influence of the presence of familiar people. Apparently, there are only a few significant relations between schoolwork and the presence of familiar children, siblings or friends, or of a familiar mentor at secondary school. The only significant result concerned children who knew the mentor before the transition: they experienced statistically significantly more fun in schoolwork after the transition (model $4, \mathrm{p}=0.045$ ). 
Table 4.6: The school context: fun and fear in the school context; regression analyses, 4 models - post-transition

\begin{tabular}{|c|c|c|c|c|c|c|c|c|}
\hline \multirow[b]{2}{*}{ School context } & \multicolumn{2}{|l|}{ Model 1} & \multicolumn{2}{|l|}{ Model 2} & \multicolumn{2}{|l|}{ Model 3} & \multicolumn{2}{|l|}{ Model 4} \\
\hline & fear & fun & fear & fun & fear & fun & fear & fun \\
\hline Independent variables & $\begin{array}{l}\text { coefficient } \\
\text { (P-value) }\end{array}$ & $\begin{array}{l}\text { coefficient } \\
\text { (P-value) }\end{array}$ & $\begin{array}{l}\text { coefficient } \\
\text { (P-value) }\end{array}$ & $\begin{array}{l}\text { coefficient } \\
\text { (P-value) }\end{array}$ & $\begin{array}{l}\text { coefficient } \\
\text { (P-value) }\end{array}$ & $\begin{array}{l}\text { coefficient } \\
\text { (P-value) }\end{array}$ & $\begin{array}{l}\text { coefficient } \\
\text { (P-value) }\end{array}$ & $\begin{array}{l}\text { coefficient } \\
\text { (P-value) }\end{array}$ \\
\hline $\begin{array}{l}\text { Intervention - } \\
\text { control group }\end{array}$ & $\begin{array}{l}-0.024 \\
(0.665)\end{array}$ & $\begin{array}{c}0.059 \\
(0.440)\end{array}$ & $\begin{array}{l}-0.025 \\
(0.645)\end{array}$ & $\begin{array}{l}-0.006 \\
(0.925)\end{array}$ & $\begin{array}{l}-0.017 \\
(0.757)\end{array}$ & $\begin{array}{l}-0.015 \\
(0.828)\end{array}$ & $\begin{array}{l}-0.020 \\
(0.718)\end{array}$ & $\begin{array}{l}-0.005 \\
(0.947)\end{array}$ \\
\hline $\begin{array}{l}\text { Fear in school context } \\
\text { (pre-transition) }\end{array}$ & & & $\begin{array}{l}0.242 \\
(0.000 * * *)\end{array}$ & & $\begin{array}{l}0.230 \\
(0.000 * * *)\end{array}$ & & $\begin{array}{l}0.224 \\
(0.000 * * *)\end{array}$ & \\
\hline $\begin{array}{l}\text { Fun in school context } \\
\text { (pre-transition) }\end{array}$ & & & & $\begin{array}{l}0.525 \\
\left(0.000^{* * *}\right)\end{array}$ & & $\begin{array}{l}0.528 \\
(0.000 * * *)\end{array}$ & & $\begin{array}{l}0.522 \\
\left(0.000^{* * *}\right)\end{array}$ \\
\hline $\begin{array}{l}\text { Girl-boy } \\
\text { Age } \\
11\end{array}$ & & & & & $\begin{array}{l}-0.060 \\
(0.273) \\
\\
0.067 \\
(0.481)\end{array}$ & $\begin{array}{l}-0.033 \\
(0.628) \\
0.086 \\
(0.458)\end{array}$ & $\begin{array}{l}-0.050 \\
(0.371) \\
0.067 \\
0.491\end{array}$ & $\begin{array}{l}-0.040 \\
(0.562) \\
\\
0.069 \\
(0.554)\end{array}$ \\
\hline \multicolumn{9}{|c|}{ Reference category } \\
\hline $\begin{array}{l}13 \\
14\end{array}$ & & & & & $\begin{array}{c}0.089 \\
(0.286) \\
0.579 \\
(0.239)\end{array}$ & $\begin{array}{l}0.123 \\
(0.243) \\
-0.395 \\
(0.519)\end{array}$ & $\begin{array}{l}0.085 \\
(0.325) \\
0.511 \\
(0.317)\end{array}$ & $\begin{array}{l}0.121 \\
(0.259) \\
-0.200 \\
(0.749)\end{array}$ \\
\hline \multicolumn{9}{|c|}{ Reference category } \\
\hline $\begin{array}{l}\text { VMBO-HAVO; HAVO } \\
\text { HAVO-VWO; VWO } \\
\text { VSO }\end{array}$ & & & & & $\begin{array}{l}-0.051 \\
(0.588) \\
-0.099 \\
(0.105) \\
-0.316 \\
\left(0.077^{\circ}\right)\end{array}$ & $\begin{array}{l}0.119 \\
(0.316) \\
0.019 \\
(0.806) \\
-0.226 \\
(0.309)\end{array}$ & $\begin{array}{l}-0.055 \\
(0.570) \\
-0.106 \\
(0.089) \\
-0.332 \\
\left(0.076^{\circ}\right)\end{array}$ & $\begin{array}{c}0.123 \\
(0.306) \\
-0.002 \\
(0.983) \\
0.022 \\
(0.928)\end{array}$ \\
\hline $\begin{array}{l}\text { Present at school } \\
\text { Familiar children } \\
\text { Siblings } \\
\text { Children from previous } \\
\text { school } \\
\text { Friends } \\
\text { Mentor familiar }\end{array}$ & & & & & & & $\begin{array}{l}-0.038 \\
(0.691) \\
-0.011 \\
(0.872) \\
-0.021 \\
(0.821) \\
-0.034 \\
(0.682) \\
0.002 \\
(0.978)\end{array}$ & $\begin{array}{l}-0.080 \\
(0.501) \\
-0.006 \\
(0.945) \\
-0.068 \\
(0.549) \\
0.180 \\
\left(0.084^{0}\right) \\
0.160 \\
\left(0.035^{*}\right)\end{array}$ \\
\hline $\begin{array}{l}\text { Constant } \\
\text { Observations } \\
R^{2} \\
R^{2} \text { adjusted }\end{array}$ & $\begin{array}{c}1.339 \\
N=349 \\
0.001 \\
-0.002\end{array}$ & $\begin{array}{l}2.801 \\
N=344 \\
0.002 \\
-0.001\end{array}$ & $\begin{array}{l}0.940 \\
N=335 \\
0.116 \\
0.111\end{array}$ & $\begin{array}{l}1.356 \\
N=328 \\
0.255 \\
0.250\end{array}$ & $\begin{array}{l}1.022 \\
N=330 \\
0.145 \\
0.121\end{array}$ & $\begin{array}{l}1.336 \\
N=323 \\
0.270 \\
0.249\end{array}$ & $\begin{array}{l}1.112 \\
N=328 \\
0.145 \\
0.107\end{array}$ & $\begin{array}{l}1.235 \\
N=321 \\
0.292 \\
0.259\end{array}$ \\
\hline
\end{tabular}

${ }^{0} p \leq 0.10 ;{ }^{*} p \leq 0.05 ;{ }^{* *} p \leq 0.01 ;{ }^{* * *} p \leq 0.001$

Note: the tracks at secondary education are: practical education (PrO), preparation for intermediate vocational education (VMBO), upper-secondary education (HAVO) and preparation for academic education (VWO).

\subsubsection{The school context: fear and fun in the school context}

Table 4.6 shows the results of linear regression analyses about fear and fun in the school context. The results of model 1 are not statistically significant, but the negative coefficients 
show that children in the intervention group experienced less fear in the school context and the positive coefficients show that they also experienced more fun in the school context than the children in the control group.

In model 2, the independent variables are added for pre-transition fear and fun in the school context. The findings showed a positive relationship between fear and fun in the school context before the transition and afterwards. This means that children who were already anxious about the school context before the transition tended to continue being anxious afterwards; and children who looked forward to the school context are likely to experience fun afterwards as well. The added variables are statistically and significantly reliable predictors for more fear or fun in the school context after the transition (model 2, $p=0.000$ ). Interestingly, a one-point higher score on fear in the school context increased the post-transition value of this variable by only 0.2 point, much less than the coefficients of the other pre-transition variables, which are all around 0.5 .

The independent variables for gender, age and school type that are added in model 3 show no significant effect, except for the children with special educational needs (VSO). These children reported, relative to the reference group, less fear in the school context after the transition. This relation is significant at the $10 \%$ level (model $3, p=0.077$; model $4, p=0.076$ ). With regard to gender, there are no significant differences between boys and girls. Looking at age, the results in model 3 also show no significant differences relative to the reference group.

Model 4 shows the influence of the presence of familiar people in the school context, by adding the independent variables for familiar children, siblings, children from previous school and familiarity with the mentor. The positive significant coefficient shows that children who were already familiar with the mentor reported statistically significantly more fun in the school context (model 4, $\mathrm{p}=0.035$ ). Also children who already had a friend at secondary school before the transition, reported, at the $10 \%$ level, having significantly more fun post-transition (model 4 : $\mathrm{p}=0.084)$.

\subsubsection{Power analysis}

To get insight into the reliability of the effect size, a power analyses was performed. For this, we calculated the standardized effect size using Cohen's $d$ with the post-transition results of the two tailed T-tests (Table 4.3 in Appendix 2, Chapter 4) on the post-transition subscales. The results of the Cohen's $d$ of the subscales show a small effect $(d \leq 0,2)$. Based on the results of the post-transition T-tests (Table 4.3, Appendix 2, Chapter 4) on the six subscales fun and fear of peers, in the school context and with schoolwork, the $\beta$ power (the probability of rejecting the null hypothesis when it should not be rejected) has been calculated (Table 4.7). 
Table 4.7: Power calculated on results of T-tests of subscales post-transition

\begin{tabular}{|l|c|}
\hline Subscale & Power $\boldsymbol{\alpha} \mathbf{0 . 0 5}$ \\
\hline Fun peers & 0.12 \\
\hline Fear peers & 0.42 \\
\hline Fun school context & 0.12 \\
\hline Fear school context & 0.07 \\
\hline Fun schoolwork & 0.06 \\
\hline Fear schoolwork & 0.33 \\
\hline
\end{tabular}

Table 4.7 shows that using an $\alpha$ of 0.05 , the results are: fun with peers: 0.12 ; fear of peers: 0.05 ; fun in the school context: 0.12 ; fear in the school context: 0.07 ; fun with schoolwork: 0.06 ; fear of schoolwork: 0.33. Because these values are all far less than 0.8, the achieved power is insufficient, and the probability is low that we would be able to detect any effects that might exist (Faul, Erdfelder, Lang \& Buchner, 2007).

\subsection{Discussion and conclusions}

The transition from primary to secondary school involves changes in both the school context and the social environment to which children must adapt, and educators can do a great deal to facilitate a successful transition. The results of previous research show that, unfortunately, few efforts are made to do so (Anderson et al. 2000).

We were interested in whether educators would be able to improve the support for children who are vulnerable to a poor transition if they were more aware of what the children needed. However, before they can enhance their support, educators need to better understand what, from the children's own perspective, can frustrate a successful transition. And who can provide this information better than the children themselves?

In this study, we used self-reporting questionnaires to investigate children's expectations before and experiences after the transition from primary to secondary school. The children's information was used not only to obtain insight into their experiences, but also to inform the future mentor at secondary school, under the assumption - to be confirmed through a blinded experiment - that children who can inform their mentor will make a better transition than children who cannot, because presumably mentors will use this information to ensure a smooth transition. 
Ultimately, after the intervention we found that mentors who received information provided by 'their' children scarcely seemed to consider it as useful in creating a safe, supportive pedagogical climate. The intervention only had a small effect on the social context at the $10 \%$ significance level $(p=0.077)$. Children in the intervention group experienced (at the $10 \%$ significant level) less fear of peers (Table 4.4, model 1), but, surprisingly, also less fun with their peers in the social context after transition at the $10 \%$ significant level (Table 4.4, model 2: $p=0.096$; model $3: p=0.089$; model $4: p=0.072$ ). The intervention had no significant effect at all on fear or fun in either schoolwork or school context. Consequently, we concluded that in most cases, the intervention generated no significant effect. Moreover, the post hoc control for statistical power showed a low power. This is reason to believe that we were correct in rejecting indications that our hypothesis may have been false. Overall the results of the intervention barely seem to affect the course of the transition process.

We had initially assumed that knowing the mentor in advance of the transition would help the children to feel more comfortable at secondary school. This assumption does not appear to have been borne out in practice. Initially, the children did not seem to associate the mentor with fun or fear in the social context. However, we did find that, before they make the transition, the children associated knowing the mentor more with fear in the school context (Table 4.2, model 3: $p=0.093$ ) and with schoolwork (Table 4.3, model 3: $p=0.006$ ). After the transition, they reported the opposite: knowing the mentor before the transition actually led to more fun with schoolwork (Table 4.5, model 4: $\mathrm{p}=0.045$ ) and in the school context (Table 4.6, model 4: $p=0.035$ ) and, surprisingly, to more fear in the social context (Table 4.4 , model $4: p=0.017$ ).

Based on the information provided by the children, we found three groups to be vulnerable to a poor transition, independent of the intervention. The first group, girls, stand out, because after the transition, they report significantly more fear than boys, especially of schoolwork (Table 4.5, model 3: $p=0,027$; Table 4.5, model 4: $p=0.026$ ). The negative impact of the transition on self-esteem also tends to be greater for girls than boys (Anderson et al., 2000).

The second vulnerable group are the children with SEN. In comparison to typically developing children, they show a mixed picture. These children were more worried than the others about the social context, especially about peers. After the transition, children with SEN suffered less fear in the school context significant at the 10\% level (Table 4.6, model 3: $p=0.077$; Table 4.6, model 4: $p=0.076$ ), but significantly higher fear of peers, at the $10 \%$ level (Table 4.4 , model 4 : $p=0.086)$. The literature confirms that children with special educational needs are more vulnerable to a poor transition than others (Anderson et al., 2000; Chedzoy \& Burden, 2005). Our findings seem to confirm this, which implies that intervention can indeed contribute to a smoother transition for children with SEN. 
A third group that stands out is formed by the children who are already anxious (or happy) before the transition. In the social context as well as in the school context, we found fear (and fun) to be significant reliable predictors $(p=0.000)$. Although the respective differences between the pre-transition scores and the post-transition scores for fear or fun became smaller, after the transition these children remained anxious (or happy). This finding illustrates the need to create opportunities, especially for vulnerable and anxious children, to share their opinions with teachers. It also shows the importance of protective support by teachers focused not only on attainment, but also on the social context.

Previous research has shown that social relationships with peers and familiarity with the future teachers can provide protection against a poor transition. Social relationships - in the sense of being known to teachers - may contribute to a sense of community at school (Tobbell, 2003). This implies that teachers can create a buffer against fear and stress. Surprisingly, our study seems to confirm these results only in terms of the school context and schoolwork, while they show the opposite for the social context. As described above, the children who knew their mentor before they made the transition expected more fear in the school context and with schoolwork. Afterwards, they reported more fun with their schoolwork and in the school context, but they were also significantly more anxious about relationships with peers than before the transition. In secondary school, pedagogical styles differ in comparison with primary school: teaching is more didactic and attainment is seen as more important. Perhaps it frightens children who already are anxious, to discover that teachers at secondary school are less likely to empower them to cope with stress and are more interested in the academic performance than in the emotional climate at school (Chedzoy \& Burden, 2005; Chung et al., 1998; Zeedijk et al., 2003).

The literature suggests that a positive transition is promoted by the friendliness of older children at secondary school, by having older siblings at secondary school, and by making the transition to the same secondary school with primary school friends (Evangelou et al. 2008). The results of our study confirmed that the social context can be helpful to compensate for or to reduce fear and increase fun in the social as well as in the school context. However, that did not apply in the presence of all familiar children. It seems counterintuitive that before the transition, children thought that having friends at secondary school would cause fear of peers in the social context. After the transition, the children indicated that the presence of friends no longer had an effect on the social context, but did provide a positive effect on fun in the school context.

Our findings demonstrate the need not only to be aware of the impact of the transition as experienced from the children's perspective, but also for teachers to adopt the children's 
perspective as part of the means for helping them. In this way, schools and teachers can benefit from information provided by children in combination with the information from adults. Children at special schools, anxious children, and, to a lesser extent, girls in general are found to be more vulnerable to a poor transition than others. The first two groups may struggle because they experience less fun in the social or school context; the last group, girls, because of their significantly increased fear of schoolwork. These children may benefit the most from the intervention.

This study had some limitations. The study was restricted to the experiences of children in the Netherlands, who generally make the transition from primary to secondary education at the age of twelve. This may limit the ability to generalize of the findings to other populations. The mentors have a non-committed role and remain free to decide for themselves whether and how they use the information provided not only by the children, but also all information that mentors receive about their class. This can lead to differences in approach. The study was also limited due to the regionally bound location of the schools and the insufficient power. A larger scale study is recommended to further explore the results. 


\section{Chapter 5}

Do mentors acquire information about pupils to improve the transition from primary to secondary education and how do they use this information?

This chapter is based on: Van Rens, M. \& Groot, W. (2019). (How) do mentors acquire and use information about pupils to improve the transition from primary to secondary school? Under review. 


\begin{abstract}
The transition from primary to secondary school is an important step for children and one that can affect the rest of their school careers and working lives. Mentors at secondary school are the persons designated to guide students carefully and successfully through the transition. To do this, mentors need to be supported by the other stakeholders: the children and their parents, and the teachers at primary school. In the study described in this chapter, 17 mentors were interviewed in focus groups, to investigate whether they have the opportunity to acquire the information they need to improve the transition, and if so, what they think about the quality, reliability and usefulness of that information. The results of the interviews showed that before as well as after the transition, mentors play an autonomous role in assessing the information they receive for usefulness and that they make personal appointments with the other stakeholders. The mentors felt that they were insufficiently aware of the experiences of teachers at primary school, and vice versa, which does not contribute to the quality of the overall school advice. Mentors were also dissatisfied with the educational report on the whole. Direct contact with primary education teachers before the transition, which is perceived as particularly valuable, often fails to occur due to a lack of time and, if there is a contact, there is often no time tto follow up in person after the transition.
\end{abstract}




\subsection{Introduction}

The conclusion in Chapter 4, that some children are more vulnerable to a poor transition than their peers, illustrates the need to create opportunities, especially for vulnerable and anxious children, to share their opinions with their teachers. It also shows the importance of protective support by teachers focused not only on achievement, but also on well-being.

Teachers play an important role in guiding and supporting children through the transition from primary to secondary school. Mentors at secondary school are designated to assist the children of 'their' class through the transition process. They are in a central position to provide the social, emotional and academic support children need to make a successful transition.

For teachers, the transition from primary to secondary school is an annual phenomenon. Every year, after the summer break, many children all over the world make this transition; and although school systems differ, the challenges and threats are broadly similar (Humphrey \& Ainscow, 2006). As described in Chapters 3 and 4, the transition initially causes most children to experience anxiety, stress and a decrease in motivation (Rice, Fredrickson \& Seymour, 2011; West, Sweeting \& Young, 2010), which, if left unchanged, may impair their socialemotional development (McGee, Ward, Gibbons \& Harlow, 2004; Topping, 2011) and undermine their academic achievement (Hanewald, 2013).

To support their personal and academic development and growth, it is important that children feel cared for by the people in their surroundings, including by teachers in the school environment (Noddings, 2005). Healthy interpersonal relationships are a prerequisite to rewarding learning relationships (Tobbell \& O'Donnell, 2013), and individual help and support by teachers is critical to making a meaningful contribution to students' adaptation to a new school (Rupsiene \& Kucinskiene, 2005).

When children make the transition to secondary school, new relationships need to be built with their new teachers (Tobbell \& O'Donnell, 2013). However, once at secondary school, children perceive that they receive less support from teachers (Tobbell \& O'Donnell, 2013). Teachers at primary school are able to spend more time with their class than teachers at secondary school and therefore have more opportunities than secondary school teachers to foster caring relationships on which to build academic confidence (Ellerbrock, Abbas \& DiCicco, 2014). In contrast to the children's' need for support, their relationships with secondary school teachers are less personal and more controlling (Ellerbrock et al., 2014). Therefore, as explained in Chapter 3, some children - especially girls - may experience difficulties in developing new social relationships; and boys, more often than girls, appear to experience a decline in positive school experiences (Tobbell \& O'Donnell, 2013). Moreover, contrary to their expectations 
before the transition, children experience fewer demands on their cognitive skills at secondary school (Hopwood, Hay \& Dyment, 2016). This seems to contradict expectations of secondary school teachers that children will have to learn to take more academic responsibility for their work. For example, in contrast to primary school teachers, secondary school teachers are less likely to accept late work or offer a second chance to children who do not meet the deadline (Ellerbrock et al., 2014).

The class mentor has an important role in the guidance of 'his/her' mentoring class during the transition period and can contribute to a smooth transition by assisting and supporting the children through the process. However, the mentors cannot take on such a task in a vacuum. The teachers themselves need support as well, especially in the form of time and resources sufficient to properly perform the role of mentor. They also need to be able to acquire the information necessary to determine how to adequately deal with the demands and desires of the children they are supervising (Hopwood et al., 2016).

Academic research about the transition, on the one hand, confirms that teachers play an important role in guiding and supporting children, but, on the other hand, pays little attention to the teachers' perspective about what is required to accomplish that important role. Based on the expectation that the teacher needs support to successfully guide the student through the transition process, in this study, we investigate how mentors at secondary school acquire information about their future pupils and whether they are provided with sufficient resources and time to use this information to improve the quality of the transition. This exploratory research was not intended to test a theoretical model, but to gain insight into the experiences and actions of the mentors. We were interested in determining if (and what) information about the children making the transition reaches the mentor and, in particular, if this information included statements from the children themselves. We wondered if and how mentors use the information they obtain, especially that provided by their pupils.

This chapter presents the results of a study into the views about the transition of 17 mentors of freshmen in secondary education in the Netherlands. Information from the mentors' perspective was collected via focus group discussions and is used to investigate whether mentors have had the opportunity to acquire information about the needs and expectations of their future pupils with respect to the transition, and how they use this information. First, we describe how our study relates to previous research and explain the context of the study. Next, we describe the methods that have been used and the data that have been collected. Finally, the results of our study are presented and discussed. 


\subsection{Literature review about support as perceived and experienced}

\subsubsection{Why support is important}

The transition from primary to secondary school creates a discontinuity in school location and in the social environment. Children may lose their school friends and feel insecure in the relationship with their new teachers. To ensure that the children adjust to their new secondary school environment and successfully meet the challenges that occur, support is important (Anderson, Jacobs, Schramm \& Splittgerber, 2000). The need for support is related to the children's preparedness for the transition and to continuity between the feeding and receiving schools. The greater the discontinuity and the lesser the preparation, the more support is needed. Support can be informational, tangible (by providing resources), emotional and social (having friends) (Anderson et al., 2000). Children struggling with the transition may need several types of support. Regardless of the type, support can be provided by all stakeholders in the transition process - parents, other children and teachers - and there is plenty of evidence of the importance of all types of support (Anderson et al., 2000).

Supportive teacher-student relationships can enhance children's motivation and engagement, promote social behavior, and improve academic attainment. These supportive relations are associated with lower levels of anger and depressive symptoms, as well as with enhanced adjustment and self-esteem. Less supportive teacher-student relationships can cause children to lose interest in learning (Van Ryzin, 2010).

To provide enough of this support at suitable levels, teachers themselves need to be supported as well, especially with information and tangible support (time and resources). Teachers, and class mentors in particular, have to give sufficient background information about the needs of the children in their future class (Hopwood et al., 2016). Help can be provided by the other stakeholders - the feeding primary schools, the parents and the children themselves - by sharing with the mentor at secondary school all the information they expect to be important for a successful transition.

It is noteworthy that the stakeholders may have different principles and interests. Their perspectives may differ from that of the mentor, but their information is not less valuable, because comprehensive information can lead to comprehensive support. According to Anderson et al. (2000), comprehensive transition programs involving all stakeholders in the transition process are the most promising for helping children to make a successful transition, particularly if those children are at risk of failing. Below we describe, based on the literature, how each stakeholder can provide support for the educators at secondary school and the way 
that teachers, especially mentors, have been shown by previous research to handle the stakeholders' support.

\subsubsection{Providing support during the transition process}

\section{- Primary school}

An important stakeholder and source of information is the feeding primary school. Because pre-transition factors may influence children's post-transition difficulties, primary schools provide the secondary school with background information about the children. One of the most important functions of providing this information is to reduce children's fears about their future secondary school. Their anxieties include, for example, being the youngest, bullying, discipline, new subjects and homework (Powell, Smith, Jones, \& Reakes, 2006). The information passed on by primary schools usually addresses other matters. In general, the secondary schools are apprised about such things as the children's academic performance and test results, their personal strengths and weaknesses, and their behavior.

Secondary schools generally accept children from multiple primary schools, not all of which provide information in the same way: it can differ in both content and detail. Sensitive information about children's background is usually provided verbally and needs to remain confidential (on a need-to-know basis) (Powell et al., 2006). Teachers, children and parents have different perspectives about what they believe are important issues in the transition. Parents and children are more concerned with personal and social issues, in the here and now, while teachers seem to be more preoccupied with institutional initiatives, such as delivering the curriculum. Teachers also take the long-term perspective, scrutinizing children's development over a longer trajectory (Tobbell \& O'Donnell, 2013). Surprisingly, teachers very rarely refer to personal skills and do not seem to value the development of children's own coping skills, for example, as they learn to cope with stress or take control over their lives and become less dependent on organizations and external structures (Zeedijk, Gallacher, Henderson, Hope, Husband \& Lindsay, 2003).

\section{- The children}

The second, and perhaps the most important, source of information is the children themselves. Children making the transition bring experiences and understandings from their former school to their new school, but these perceptions do not necessarily correspond to the new school environment. During the transition, the role of the children may change, but children do not necessarily appreciate this (Tobbell \& O'Donnell, 2013). 
Although children need support, they are also capable of informing their future mentor about their needs and expectations. For educators, including mentors, children's input can make a valuable contribution to understanding how children experience their school lives, and what is important to them (Mason \& Danby, 2011). In contrast to primary school, children at secondary school develop fewer close relationships with their peers and teachers, and may tend to conform more to group norms (Tobbell, 2003). At their new secondary school, children have to deal with multiple teachers. It may be difficult to build personal relationships with all of them. (Bokhorst, Sumter \& Westenberg, 2010).

Knowing that social relationships with teachers and peers can significantly contribute to a sense of community in the school environment leads one to expect that teachers will hear children's voices. Unfortunately, this is not always the case. Whatever the reason, not all teachers are able to meet the needs of children for support during the transition process, or have the time and space to talk with children about their needs or expectations. Hopwood et al. (2016) found in a recent Australian study that $42 \%$ of the secondary school teachers (and $60 \%$ of the primary school teachers) did nothing to prepare 'their' children. Only $28 \%$ of secondary school teachers talked with children about what to expect.

For many children, one of the biggest demands in the transition is building new peer relationships and making new friends (Topping, 2011). Feelings of vulnerability can be reduced if the children feel they are accepted as a part of the group (Coffey, 2013). Evangelou, Taggart, Sylva, Melhuish, Sammons \& Siraj-Blatchford (2008) found that support offered by secondary schools in terms of peer relationships - for example, in the perceived friendliness of other children or having children from their primary schools in their new classes - led to positive transition experiences. According to Evangelou et al. (2008), this aspect unfortunately receives relatively little attention from schools.

\section{- The parents}

Generally, the perceptions of parents and children do not differ much (Topping, 2011). As described previously, parents are mostly concerned about the social-emotional challenges that their children face in the here and now (Topping, 2011). The aspirations of the parents are not always matching to the aspirations and/or the cognitive capacities of the child (Korpershoek et al., 2016). A successful transition necessitates the involvement of parents: as parents and as role models, they are uniquely positioned to motivate their children on higher achievement. Communication between parents and teachers should enable them to work together to prevent transition problems or to intervene appropriately when problems do arise (Anderson et al., 2000). Therefore, schools should use the opportunity to engage parents in a partnership in the transition process, to help their children to develop positive bonds to home and school, a 
greater sense of personal potential and to construct a view of themselves in the social context (Elias, Patrikakou \& Weissberg, 2007).

\subsection{Methods}

\subsubsection{Research context}

In this chapter, we investigate if and how secondary school class mentors obtain and use information to support children through the transition process and the extent to which they are facilitated to do so.

Seventeen class mentors in grade seven, from four larger secondary schools located in the southeast of the Netherlands, participated in the study and were interviewed. Sixteen mentors were interviewed during four focus group discussions; one mentor was interviewed separately. Although the study was based on the experiences of these regional Dutch secondary schoolteachers, it provides insight that can be useful in other educational settings in the Netherlands and abroad. After all, despite the differences in school systems, children experience remarkably similar challenges and threats during the transition.

When they start at secondary school, most children are about 12 years old. Based on their capabilities and interests, and on the advice and test results from the elementary school, a choice is made by the children and their parents for one of the different tracks of secondary education. In the Netherlands, secondary education is divided into four tracks: practical education (PrO), preparation for intermediate vocational education (VMBO), upper-secondary education (HAVO) and preparation for academic education (VWO). Larger school communities often provide multiple tracks of secondary education.

As described in the previous chapters, this study is part of a larger project which followed 371 children in the southeast of the Netherlands, from the final term of primary school to the end of the first term of secondary school. Consequently, the geographical location of the secondary schools for the current study was the same as the sampling of the children's part of the project. Other selection criteria were that the schools had to be representative of the range of secondary education in the region and had to offer different tracks of secondary education and belong to different school boards.

The participating schools are members of school communities containing the three secondary school types VMBO, HAVO and VWO. The number of pupils in the schools varied between 1044 and 1954 pupils. All schools, except one, had a Roman Catholic signature. The schools belong to three different, large school boards; and one school is an eenpitter, which means 
that this school has its own school board (www.scholenopdekaart.nl). One of the schools (school 2) offers specialized education for children with special educational needs (SEN). This provides a bridge between primary education for children with special educational needs and secondary education. In order to be accepted into this school, the children must have a referral, which is issued by a regional alliance. To be considered for this referral, the children have to go through several observation periods and tests. If the intake level is found to be too high for a child, school 4 has made agreements with a school for practical education (PrO) to let their students enroll there.

\subsubsection{Participants}

After selecting the schools as described above, the grade 7 department manager in each secondary school was contacted. All department managers recruited at least four mentors from different school types to participate in the focus group discussion. Mentors were always subject teachers. The mentors were asked to participate in a focus group interview that would last at most 75 minutes. They differed in experience as teachers and as mentors. The focus groups were composed in accordance with the gender composition in secondary education in the Netherlands.

To ensure confidentiality, each teacher was allocated a letter which replaced their name. Table 5.1 (Appendix 3, Chapter 5, Table 5.1) shows the characteristics of the mentors from the four schools, who participated in the focus groups.

\subsubsection{Data collection}

We based the qualitative design of this study on Grounded Theory, as first described by Glaser and Strauss (1967) in their book entitled The Discovery of Grounded Theory: Strategies for Qualitative Research. Grounded Theory generates theories by creating different concepts from the data collected. These theories are generated from the context to which they will later be applied (Glaser \& Strauss, 1967). In this study, the data are generated in the school context.

The class mentors were interviewed in order to gain insight into their perspectives. The interviews were conducted at the secondary schools during the spring semester of 2019. The mentors were interviewed until saturation occurred and the interviews no longer provided any new information. Data were collected over the course of four consecutive weeks via four focus group interviews and one individual interview. To accommodate their schedules, the mentors were interviewed as a group, except for one person who, due to scheduling conflicts, was unable to participate in a focus group interview. The size of the focus groups varied between 
three to five people; and the interviews lasted from 45 to 90 minutes. With the consent of all participants, the interviews were audio recorded for later transcription and analysis.

Pursuant to Grounded Theory, we transcribed the interviews and applied a coding strategy to the transcribed data. As described below, we analyzed and categorized the data according to a constant comparative method and summarized them into themes via open, axial, and selective coding (Strauss, 1987).

We completely transcribed the audio recordings, using verbatim transcription. The transcripts were used to describe, summarize and interpret the opinions of the mentors. Similar and different findings were compared across interviews by generated codes, the so-called open coding, which includes repeated readings of the interviews, an in-depth, line-by-line analysis of the data, and coding data under various categories. Ultimately, we analyzed and combined the codes to develop themes. In Grounded Theory, this is called axial coding. In axial coding, the categories are linked together. As soon as the interviews no longer provided any new information because saturation had occurred, we stopped conducting any further, new interviews. In the final, selective coding, the linked categories resulted in a core category (Straus, 1987). To ensure the themes were an accurate and valid representation of the interviews during the coding process, we reread and reviewed the transcription several times.

The theme of the interviews was the information flow, as shared with the mentor at secondary school, about the children making the transition from primary to secondary school. This included information about the academic, as well as the social-emotional, development of the children, which was capable of being provided by the stakeholders in the transition process: primary school, secondary school, the children and their parents. The interviews yielded a large amount of initial data, which was coded in stages (open coding). By comparing the interviews, using axial coding, the information was merged and grouped into two types of information: information provided before the official start of the new school year on 1 August (pre-transition) and information provided after 1 August (post-transition). Both pre- and posttransition information have a central theme. The purpose of the pre-transition information is registering and placing a child at secondary school; the central theme is the placement of the children. The purpose of the post-transition information is providing (and keeping) children in a suitable place at secondary school where they can succeed in a safe educational environment. The central theme (selective coding) is the quality of the placement. The overarching theme is the reliability, quality and usability of the information. The themes are described from the perspective of the mentor. The outcome of having the information is that the mentor will be in a position to act autonomously, sometimes before but usually after the transition, to help guide children successfully through the transition process. 


\subsection{Results}

\subsubsection{Information provided by the stakeholders before the transition to inform the mentor}

According to the interviewed mentors, the phase prior to the transition proceeds in a similar way at all schools. The primary school advises children and their parents which education track is the most suitable. This advice is binding for eligibility for placement at secondary school, unless the outcome of the final test at primary school turns out to be higher than anticipated in the school advice. In that case, the advice can be adjusted upwards. Based on the primary school advice, parents register their child at the secondary school of their (and their child's) choice. At all secondary schools participating in our interviews, children were able to indicate with whom they wanted to be in their new class. Children generally like a class with children they know or with whom they are friendly. When they are reluctant to attend the same class as a familiar child, it often has to do with a history of bullying. As one of the mentors during the interviews indicated:

"And then at least they come to one or two names of children with whom they want to be in class and they can also indicate if they absolutely do not want to be in a class with someone. For example, with a history of bullying."

To the greatest extent possible, the wishes of the children are taken into account so that friendships do not have to be broken and bullying can be prevented. According to another mentor, and confirmed by her colleagues, a mentor has to be aware of:

"Bullying that happened at primary school. That's nice if you know that, then you can keep an eye on that."

As soon as the children are placed at a secondary school, the feeding and receiving schools start handling the administrative work, such as forwarding and receiving tracking documents, preparing the digital tracking system, and forming the classes. Most information is exchanged digitally.

At one secondary school, the teachers (as ambassadors) established direct contact with the teachers of all feeding primary schools to collect information about all placed children. $O$ explained:

"Most of us are ambassadors for a primary school. You are assigned to one, two, or sometimes more primary schools. There you have a conversation with the teacher of grade six, and you get information about the typical children. This information complements the information from the educational report, because an educational 
report says so little. In the individual conversation with a primary school grade six teacher, you get a little more insight into the children."

Retrieving the information orally allowed the mentors at this one secondary school to bypass the privacy law ${ }^{8}$ that prohibits written information from being transferred before 1 August (and only with the parents' consent). As a result, this secondary school was the only one in the interviews that already had a complete file on every child before the summer break.

At the other secondary schools, a so-called "warm transfer" often takes place. A warm transfer is a conversation between two teachers, usually the teacher of grade six at primary school and the mentor of secondary school, about a particular child. According to the mentors, the secondary school usually takes the initiative on this, although sometimes it is at the request of primary school. Forms of warm transfers mentioned by the mentors include telephone or email contact, "speed dating" (in this context, short conversations - often in the course of a single afternoon - about the future students from several different primary schools), direct contact discussing pupils who need extra attention, and direct contact discussing all children. The secondary school mentors regretted that not all primary schools responded to their invitation for a warm transfer to the secondary school.

Apart from the warm transfers and work by the mentor ambassadors, most mentors do little to actively collect information about their future class until the summer break. They usually receive a brief summary, made by an intermediary such as a team leader or a coordinator, with only the most urgent information about the children of their class. As expressed by $\mathrm{J}$ :

"Before the summer break, you will only know the very important things about your class, such as the information I received about a boy whose mother had died just before the introductory afternoon."

Following on this information, mentors may sometimes find it necessary to directly contact the parents or the former primary school teacher of the child. In that case, they would make a personal appointment.

Mentors do not generally meet or talk with individual children prior to the new school year, except sometimes when it concerns children with special educational needs. In the Netherlands, every child is supposed to attend a school that provides an education suited to their talents and capabilities. It is required by law that all schools offer an appropriate place to children who need extra assistance. About one in every five pupils needs extra assistance at

\footnotetext{
${ }^{8}$ Until 25 May 2018, all Members of the European Union (EU) had their own privacy laws. After 25 May 2018 , a single privacy law applied across the EU, instead of different national laws. Stronger rules on data protection are intended to give people more control over their personal data.
} 
primary school (Government of the Netherlands, https://www.government.nl/topics/primaryeducation/appropriate-education-at-primary-school). With this in mind, schools should expect to adapt their teaching to the individual child's development. At one of the four secondary schools participating in our study, the mentor had an individual meeting with each of the children who had extra assistance at primary school. One of the interviewed mentors indicated that it would be her preference, if she was given the time, to have a conversation with all the typical students before the transition.

Mentors meet their class for the first time as a group in June, before the summer break, on an introductory day or afternoon, generally designed and organized by the future mentors of the children of grade 7. Children with special educational needs, who enter the special educational facility, have a referral which is issued by a regional alliance, as described above. These children will have had several tests. As a result, the file of special educational needs children is complete before the transition. Those children also follow an introduction program which is more structured than the regular program.

\subsubsection{Reliability, quality and usability of the pre-transition information}

The information that mentors receive about their class prior to the transition includes the school advice, and sometimes a warm transfer - i.e., a meeting - with the grade six teacher. They also receive the transfer file (which is usually incomplete) containing the educational report and the results of the final central test that almost all children take at the end of grade six. There is no uniform school advice. Schools do not give the advice in the same way, and parents play a role in the development of this discrepancy. G explained:

"The general picture in society is that the VMBO is still the 'dregs' - I do not want to say it, but many parents see it that way, I think, because this is the way they speak in primary school: "Yes, my daughter or son goes to HAVO". Then that is seen as better than a VMBO student."

His colleague added:

"This year we had quite a few students from theoretical HAVO, who actually did not have the regular HAVO level and who were just fine VMBO-T students. But their parents really had a serious influence on the placement advice. So actually the primary school was more or less - forced is perhaps a little harsh word for it, but let's say exhorted - into giving them an advice for a level higher. So these children are actually working above their level and experiencing a very false start in secondary education." 
At another secondary school, the mentors also had reservations about the reliability of the school advice. They confessed that nowadays the lowest VMBO level is hardly ever advised. These children no longer seem to exist, according to the mentors, because there used to be four classes on the lowest level at their school and now there is only one class. The mentors admitted:

"We see that schools cannot give a completely unprejudiced school advice, because they are partly judged by it."

According to the mentors, the school advice level for the children who need extra support is often too high, because teachers at primary school do not take into account the environment in secondary education, which places a higher demand for children's independence. One mentor disclosed that in his regular class of nineteen children, twelve children required special care by a special teacher. The mentors were especially regretful that the attention these children demand is often at the expense of that which could otherwise be given to regular students.

Surprisingly, despite the careful placement policy of the regional alliance, even the advice of children with SEN is not always reliable. In particular, the advice by the teachers at the special primary education schools is often incorrect. The teachers at schools for special education do not take into account that regular education is not able to support the students in the same way as happens in special education, because they do not have the same resources. $\mathrm{H}$ said:

"The teachers in special education very quickly think that students have a high level, because they look at the children through a different lens than the one they should be using with children getting a VMBO-T / HAVO advice."

The mentors were all satisfied with the added value of the warm transfer and the quality of the data transferred by the primary school teachers during that consultation. They appreciated the direct contact with the grade six teacher at primary school as the most valuable contact and regretted that some primary schools have abolished this or do not respond to the invitation of secondary school for a warm transfer.

The quality of the transfer file varies per school and is usually incomplete. The completed file is only available after the start of the new school year on 1 August.

\subsubsection{Information from the stakeholders after the transition to inform/support the mentor}

On the one hand, mentors believe it is important to give children a fresh start at secondary school, so they do not believe it is always necessary to hear all the details of a child's past. On 
the other hand, the mentors aim to prevent false starts, so they actually want to know the things that are really important, to prevent adjustment problems at secondary school. $\mathrm{N}$ said:

"I think it is nice to meet the student with an open mind. Therefore, I don't want to know all the ins and outs. I think it's nice indeed to have the possibility of inquiring and making contact about situations if you get stuck in it."

F, a mentor at another secondary school, expressed something similar:

"I prefer not to be influenced so much in advance. I would rather be open and unbiased when I meet with a student for the first time, but if there are really urgent matters that you really need to know beforehand, then I would like to know."

The mentors were all in agreement that there was certain pre-transfer information they would like to know, such as notification about a difficult home situation, about certain disorders, or about a past history of bullying or suffering from bullying.

After the transition, it appears that some stakeholders are unwilling to provide information to the receiving school. Unfortunately, it is not always obvious that the 'really urgent matters' are known by the secondary school. As a result of the privacy law, documents are only provided if the parents give permission and only after 1 August, the official start of the new school year, and not before. Until then, essential information is mostly withheld. For example, notification about a disorder or a special approach is sometimes being not shared with the secondary school, because parents and/or primary schools want to prevent a child from being rejected at secondary school or because they believe the child deserves a fresh start or a second chance. $\mathrm{J}$ explained:

"I have had the experience where a parent had deliberately chosen not to pass on the diagnostic report of a child with autism to the secondary school, because she wanted her child to get a fresh start. Well, then you first run into many problems and finally the truth comes out. It appeared that there were indeed suggestions about how to deal with this child."

G added: "What we have noticed in recent years is that we receive students who all get a chance to prove themselves at a higher level than the school advice indicates." 
Mentors are facilitated by being allowed extra in-class hours (1-3 hours per week) and nonclass-specific hours (60-80 hours per year) to perform their mentoring tasks. The in-class hours are meant for performing tasks in the classroom or related to the classroom; the non-classspecific hours are for tasks outside of class. One secondary school clustered their available meeting hours and used them for a weekly team consultation. During this meeting, grade seven mentors concentrated on making an inventory of the problems they encountered, and on finding, implementing and evaluating a suitable solution for these problems together. All mentors complained that they did not have enough time to perform their mentoring tasks. However, they were all willing to accept the time-pressure, because they unanimously agreed that they found mentoring to be personally rewarding. F expressed the feeling of all of them:

"I really like being a mentor. I would rather be a mentor than not be one."

The most common ways that mentors receive information about the class or gain knowledge about the students are: orientation days, supporting students with special educational needs, a transition program, parent and child information sessions, parent-child talks or receiving information or feedback from the primary school. Secondary school mentors have an active autonomous role in designing and organizing the transition program, and in contacting and giving feedback to the other stakeholders (parents and primary school teachers) with regard to student information. To ensure a successful transition, the mentors all said they most appreciated the direct contact with the primary school grade six teachers, because that was the most valuable contact. Despite this, the interviewed mentors doubted whether grade six teachers at primary school were sufficiently aware of the educational practices in secondary education. $L$ voiced her misgivings:

"I think their view about us, how we do things here or do things differently, I think that the view is limited."

D confirmed this perspective:

"I worked in primary education myself for 26 years - until recently - and as primary school teacher, you cannot imagine teaching and mentoring in secondary education. It is a big difference."

Mentors also wondered whether primary school teachers were aware of how much they could contribute to preparing children for the transition process by helping them to develop the level 
of independence they needed to handle the demands of secondary education. In the experience of mentors at secondary school, there was quite a difference in the way children were prepared and supported before the transition. $L$ wondered about the lack of basic skills:

"If they all have to listen to something at the same time, it seems as if they can no longer do it or no longer learn it. Children sometimes look at you as if they are wondering: but why do we have to listen to you with 25 people at the same time?"

According to the mentors, the role of the parents is not limited to support during the transition process. Parents should also play a role in preparing children for a smooth transition.

I said that he does not think that learning skills, which are necessary to prepare children for secondary school, should only be linked to primary school; such skills are a matter for the entire process of education. $\mathrm{G}$ and $\mathrm{H}$ agreed.

I: "It just depends on what the parents have taught their children, whether they are able to take responsibility for their own actions or not. I cannot necessarily link that to primary school alone."

G: "What I notice is that the students are becoming more and more pampered and more outspoken. I notice that with parents, but also with students, and that there are indeed more students that you really have to steer towards social skills."

I: "And you also see here in the breaks, whole hordes of pupils sitting together at the table, who do not exchange a word...."

H: "No, not a word."

\subsubsection{Feedback to the stakeholders: awareness, and experiencing safety and success}

The mentors acknowledged the value and importance of improving the transition brought about by awareness of the practices used by the teachers at their feeding schools. All secondary schools provide some feedback about their experiences to the supplying school. The way they give feedback varies. Some mentors have personal contact with the primary school teacher; others give feedback via the person who represents them at the feeding primary school. One school initially invited all primary school teachers of grade six of their feeding schools for feedback. Unfortunately, to the regret of the mentors, this process has been stopped, because of a lack of time by the primary schools. 
The way in which secondary schools participating in this study provided feedback to the parents is comparable. Feedback was provided in the form of parent-child-mentor meetings that were prepared by the mentor with the children. The duration of the conferences varied per school, from 10 to 30 minutes. The purpose of the consultation was to clarify whether the child was enjoying school and developing, both at home and at school, as may be expected. The mentor plays an active role in the contacts with parents. According to the mentors, parents seldom take the initiative to share their experiences with the mentor, except when they have negative comments. Parents generally leave it to the mentor to contact them.

Independent of each other, all mentors interviewed agreed about the purpose of their efforts during the transition process. In collaboration with all stakeholders, they focused primarily on creating a safe educational environment with sufficient personal attention, so that all children could gain success in the experience. G expressed it as follows:

\footnotetext{
"I believe that a student who starts secondary education must gain success." H agreed: "Yes, absolutely."

G: "And what you very often see is, for example, the students who start in the VMBOT/ HAVO classes - we have this year, I think, about ten children who have been put on a lower track - all of whom had been receiving unsatisfactory marks, and now all of them are suddenly performing satisfactorily, suddenly showing what they can do."

H: "Yes."

G: "And who are much more enthusiastic in life and happier, more positive now."
}

\subsection{Discussion and conclusions}

The mentor plays an important role in guiding and supporting the children in his or her class through the transition from primary to secondary school and is in a central position to provide the social and academic support that the children need to make a successful transition (Hopwood et al., 2016). To enable the mentor to support the children, he or she needs support - at the very least, in the form of information about the children in the class - because appropriate teacher support leads to greater student success (Ganeson \& Ehrich, 2009). In this study, we examined, from the mentor's perspective through focus interviews, how mentors are fed information both before and after their class makes the transition from primary to secondary school, and how they are facilitated in time and resources. The mentor's actions in response to the information was also investigated. 
The mentors we interviewed were provided with information by the other stakeholders in the transition process: the parents and/or children, and the primary school of the children. To start with the information provided by the main stakeholders in the transition process, the children, we can be brief: with one exception - children with special educational needs - there is virtually no communication with the other stakeholders in the transition process. At some schools, children with special educational needs and their parents are invited to a personal interview before the transition in which the parents often speak for or about their child. Giving children a voice and active participation in the transition process is currently only introduced after the transition. That is a pity, because child participation could lead to more engagement and motivation for learning by children, and to feedback for teachers to improve their pedagogical practice (Ferguson, Handreddy \& Draxton, 2011).

In the literature, there is consensus that communication between primary and secondary school teachers is vital to improve the transition. Communication between schools can be improved by means of direct contact between teachers at the primary and secondary schools (Korpershoek et al., 2016; Topping, 2011; West et al., 2010). This was confirmed by the mentors in our study. Despite the problems and shortcomings, the mentors interviewed said that they were satisfied with the quality, reliability, and usability of the information they received through direct personal contact with the primary school teachers. In addition, information collected directly from the feeding school - for example, through ambassadors - was regularly evaluated and appeared to be the most complete and useful for allocating the student to the correct level. Mentors were less satisfied about aspects of the preparation for secondary school, the quality of the school advice, the comprehensiveness of the educational report made by the primary school, and the lack of time that the primary school teachers have to meet the mentor of the secondary school for a conversation or for feedback.

Because the transition does not start when the children start at secondary school, primary school teachers need to know how it works at secondary school, and vice versa, to prepare the children adequately (Hopwood et al., 2016). Unfortunately, according to the mentors in our study, this is rarely the case. The mentors noted that primary school teachers do not have a clear idea of secondary education, which then impacts on the preparation for secondary education at primary school. As an example, primary school teachers should prepare and help the children to work independently, because that is what they are expected to do in secondary education (Hopwood et al., 2016). Nevertheless, the mentors noted that, despite the fact that the children are becoming more assertive, unfortunately they are also more and more dependent on the help of the mentor to solve their social problems. The mentors at secondary school have to assist their students more and more to navigate their social skills. They blame 
this partly on the increasing use of social media, which tends to limit direct, personal communication between the children; and partly on a failure by some parents to raise their children with proper social skills and behavior.

The content of the educational report is incomplete at the moment the classes are formed, because the privacy law does not allow the files to be transferred before 1 August, the official start of the new school year. This may lead to strategic behavior with and abuse of the administrative process, as information which may have a negative impact on the placement is sometimes deliberately withheld from the secondary school. This is undoubtedly not the intention of the privacy law.

Not every school advice is as reliable as it should be. Some parents try to influence the school advice by withholding information about their child or trying to force to primary school to give an advice for a higher level, because they think their child deserves a chance at that level. Some primary schools systematically give an advice that is too high, because they cannot properly estimate what is asked of the children at secondary school, or because they think it is sad for a child to enter at the lowest level of secondary education. Instead of the successful transition desired, this may lead to frustration for the children, poor performance, and ultimately, to dropping down to a lower level.

Finally, it seems that teachers from grade six and mentors from grade seven lack the time to connect and meet with each other for a conversation before the transition or to provide feedback after the transition. They receive insufficient support to create and maintain the very contacts that they acknowledge as being the most valuable.

\section{Why a qualitative research design?}

Both qualitative and quantitative research methods were used in this dissertation to provide a more complete picture of the transition from primary to secondary school. The qualitative research design (described here, in Chapter 5) complements the results of the quantitative studies detailed in Chapters 2-4 by highlighting the perspective of the grade 7 mentors at secondary school during the transition process.

By examining the opinions, behavior and attitudes of the respondents, qualitative methods can generate knowledge that cannot be obtained by other, quantitative methods. According to Kelle (2006), method integration can provide mutual validation of data and findings, as well as produce a more coherent and complete picture of the investigated context, than a mono 
method can. Qualitative research aspires to give a more in-depth picture of all possible differences in opinion, attitudes and behavior that occur within a certain group. By using techniques such as interviews or focus group discussion, the findings of a qualitative study can be considered as representative (Dinklo, 2006).

\section{The participants and the focus group interviews}

To answer the research questions of whether, and how, mentors acquire and use information about children to improve the transition to secondary school, we interviewed 16 mentors from four secondary schools in four focus groups. ${ }^{9}$ This procedure was intended to guarantee firsthand involvement in, and understanding of, the patterns, structures and rules in the investigated context of the transition from primary to secondary school.

A focus group interview is a technique designed to collect information from a small group of 'insiders'. The process requires that they answer approximately five significant questions. The advantage of the qualitative method is that it answers important questions and generates many ideas, possibilities and initiatives in a relatively short period of time. Consensus and discussion with regard to the theme, as well as prevailing norms and values, readily become clear. However, managing a focus group interview can be difficult. There is a risk that the participants could influence each other or that one of the members of the group might dominate the discussion. (Evers, 2015; Fink, 2008). To overcome these potential handicaps, the focus group needs a trained and experienced interviewer. The investigator who conducted the interviews in our study was trained to lead focus group discussions and formulate the research questions. Furthermore, she was an experienced teacher and mentor in grade 7 herself, so that she was already familiar with the educational context at secondary school.

\section{Objectivity, reliability and validity in qualitative research}

To achieve the necessary objectivity, reliability and validity (Tilanus, 1997), we checked whether the research theme - 'the information transfer during the transition from primary to secondary education' - played a role among the mentors involved and the extent to which their views were consistent or different from each other. We asked the mentors to indicate whether they agreed with the content of the transcript and, if that was not the case, to make appropriate

\footnotetext{
9 'Focus groups' can be defined as: 'a group of employees who are brought together to discuss what they think about the organization and management of the company they work for.' (Retrieved 26-03-2020 from https://dictionary.cambridge.org/fr/dictionnaire/anglais/focus-group).
} 
adjustments. We also checked whether there was a relationship between the results of the interviews and the results found in the scientific literature.

According to Guba \& Lincoln (1994), the concepts of objectivity, reliability and validity are used differently in qualitative research than they are in quantitative. In qualitative research, validity becomes credibility and transferability, reliability becomes a thorough contextual description, and objectivity becomes inter-subjectivity. To increase the credibility of our study, the data were documented by recording the focus group interviews and transcribing all audio material. To ensure transparency, we clearly described our research method, the research context, the participants and the data collection.

Objectivity is a difficult concept to satisfy in qualitative research, because qualitative methods are often used to find out about individual, subjective perceptions. At best, one can strive for inter-subjectivity. This means that the respondents agree with the results of the survey and there is a kind of common truth. In addition, when analyzing the data, the researcher must take her own history and experience into account so as not to skew the results. We asked the respondents in our study to read the transcripts and indicate whether they thought the transcription was correct and whether they agreed with our interpretation of what had been said.

Thereafter, the data were analyzed - as is usually the case in qualitative research - by looking for and finding patterns in the responses of the mentors (i.e., the respondents). For this, we used the Grounded Theory method (GT), which aims at generating concepts that explain the way that people resolve their central concerns. The GT results do not constitute a report of statistically significant probabilities, but rather a set of probability statements about the relationship between concepts or an integrated set of conceptual hypotheses developed from empirical data (Glaser 1998). Consequently, validity in its traditional sense is not an issue in GT, which instead should be judged by fitness, relevance, workability, and modifiability (Glaser \& Strauss 1967; Glaser 1978; Glaser 1998).

\section{Results and conclusions in a broader perspective}

The secondary school mentors we interviewed, indicated how the transition from primary to secondary school could be improved. They mentioned aspects such as the warm transfer, preparing for the transition, knowledge of each other's educational practice, the school advice and involving children and parents actively in this advice. To assess the extent to which these findings are broadly supported - that is, concerning inter-subjectivity, credibility and transferability - we compared the conclusions of our respondents to the findings about the 
same themes by the Dutch Inspectorate of Education (Inspectie van het Onderwijs, 2018; De Staat van het Onderwijs, 2019).

The national investigations by the Inspectorate indicate that our results are not limited to the southeast of the Netherlands. The Inspectorate claims (De Staat van het Onderwijs 2019) that better cooperation between primary and secondary education would ensure that students end up in the right place. According to the Inspectorate, primary schools and primary school teachers often have their own ideas about guidance and support options for secondary schools, which they include in their advice. Sometimes children are only "informed" about the advice after he fact. The Inspectorate advises schools to learn how to handle pressure from parents to give a higher school advice or to place a child in a higher bridge class type. The results of this thesis confirm the perceptions of the Inspectorate.

In the final conclusions in Chapter 6, we will return to the findings of our investigation.

\subsection{Recommendations}

The comments of the mentors we interviewed were usually not about grades or test results, but concern the communication between primary and secondary school, the children's lack of skills to be prepared for secondary education, the role of the parents, and the absence of the children in the preliminary stage of the transition process. These comments resulted in the recommendations below.

According to the mentors, children play no direct role in the consultation during the pretransition project. There is talk about, and on behalf of the children, but not directly with the children. Of all those involved in the transition process, the child seems to be the least heard. That is surprising because the transition process is ultimately about the ongoing positive academic and social-emotional development of the child. The mentor is the designated person to help children settle into the new school. Therefore, it is important that a mentor understands and is able to respond to the issues about which the children are concerned. To do so, a mentor has to be informed by the children themselves. We argue that all children should have a personal conversation with their new mentor before they make the transition to secondary education.

The problems experienced between primary and secondary school with the school advice can only be tackled when all stakeholders work together well. To prevent unpleasant surprises for children, both primary and secondary schools need to agree and be transparent about what 
skills are required in secondary education, on what level, and about what skills are still missing. We recommend that the teachers communicate not only with other teachers, but also with the parents and the children in a more intensive collaboration to provide all stakeholders with feedback about their experiences after the transition. To make this possible, teachers on both sides of the transition need to be given adequate time to do so. Good practices that schools develop in the workplace should be evaluated and shared with other schools. Further study is recommended about the initiative where personal information is collected at the feeding school of each future student, in combination with feedback from the receiving school via personal contact during the course of the school year. This initiative seems to have the possibility of preventing placement problems and thereby resulting in fewer re-allocations of students in different tracks of secondary education.

Parents' support before, during and after the transition is a crucial tool for children to get used to the changing learning environment and learn to adapt to the pedagogical approach at secondary school. (Korpershoek et al., 2016). Anderson et al. (2000) maintains that family support is vital to improving the transition: children stand to benefit when schools and parents see eye-to-eye. Elias et al. (2007) agrees that both teachers and parents have an opportunity to support children to develop their social and emotional skills in the transition process. Elias et al. (2007) recommends that schools use suitable programs to train in these skills, and advises parents to help their children to cultivate conversational skills, to learn to deal with questions, and to develop listening skills along with courtesy and empathy for others. Unfortunately, the results of our study show that these recommendations have yet to be implemented. We would like to add the advice not only to provide, but also to evaluate the impact of the support of all stakeholders involved in the process, including the children. 
Chapter 6

Conclusions and discussion 
Children are the principal stakeholders in the transition from primary to secondary education, but they do not play a leading role in the process. Although there is evidence that children are willing and able to make a meaningful contribution to research on matters concerning themselves (Mason \& Danby, 2011), relatively little investigation has been made into the contribution children could make as equal partners in the transition process. The role of teachers in the transition - specifically that of mentors - also remains under-researched. This is equally remarkable, since they lead the daily supervision and contacts with parents and fellow teachers. In short, the perceptions and experiences of these key players, the children and the teachers, remain surprisingly uncharted over the course of the transition process.

The aim of this thesis was to reduce this gap in our knowledge by investigating whether and how children and their mentors can contribute to a smooth transition to secondary school. We expected that secondary education mentors, as daily supervisors, could play a crucial role in improving the transition by actively involving children as one of the partners. In order to fulfill their role properly, mentors must of course be adequately informed first, preferably by the children themselves, about the needs and expectations of their future students. This led to the central research question: Can the transition from primary to secondary school be improved by better communication, collaboration, support and participation by teachers and children?

The research question raised a number of sub-questions, which we investigated in Chapters 2 through 5 of this thesis. Through a systematic literature review (Chapter 2), we first investigated how children are involved in interventions to improve the transition and what the effects of those interventions are on the transition process. The expectations about secondary education that the children themselves had before going to secondary school were examined through self-reporting questionnaires (Chapters 3 and 4). In this way, we also collected data on the experiences of the children after their first period of eight weeks at secondary school. In a blinded experiment (Chapter 4), we investigated how the actions of secondary education mentors were affected when they received information from the children themselves. Finally, in Chapter 5, the mentors of grade seven at secondary school were interviewed and given an opportunity to express their feelings and thoughts about the information they received on their future class. They also shared what information they found to be important, how they acquired it, and how they used it in their school.

As a common thread in every chapter of this thesis, educational context emerged as important. However, the literature indicates that the environmental context, more than developmental characteristics of children, affects the success or failure of the transition process (Anderson, Jacobs, Schramm \& Splittgerber, 2000). This conclusion suggests that educators, especially teachers and parents, have an opportunity to contribute to a successful transition through 
positive relationships, good communication and very close links between primary and secondary school and the children and their parents (Coffey, 2013; Green, 1997; JindaleSnape \& Miller, 2008; Lester, Cross, Shaw \& Dooley, 2012a). The results of our study confirmed the significance of these factors.

However, in practice, cooperation between all stakeholders is not so easy to bring about. Opportunities to improve the transition process are missed for a variety of reasons. Although they indicate that cooperation and communication are important, educators do not always make the effort needed. Teachers, for example, could improve the transition by encouraging children to participate in the decision-making and by adopting the children's perspective in helping them (Chapter 4), but they seldom take that opportunity. Despite agreeing that children (and their parents) are under-represented both in decision-making and in the interventions that provide information to the other stakeholders, the schools do not readily collaborate with them (McGee, Ward, Gibbons \& Harlow, 2004). Our findings not only demonstrate the need for teachers to be aware of the impact of the transition as experienced from the children's perspective, but also to take this perspective as the starting point for helping them. In this way, schools and teachers could benefit from information provided by children, which, when combined with the information of adults, could serve to improve the transition (Chapter 5).

In this concluding chapter, the findings of the previous chapters are combined in a number of overarching statements that enable the discussion of the key conclusions, recommendations and limitations of our research. The key conclusions are organized around the five statements we describe below.

\subsection{Key conclusions}

- The transition from primary to secondary school is more than simply stopping at one school and starting again at another: it is a cross-school phenomenon

The transition from primary to secondary school is a cross-school phenomenon. This means that it is an ongoing process that starts in primary school and continues until the children have gotten used to the new school situation and firmly established their place as part of the new school community. According to the literature (Chapter 2), the transition should not be a sharp dividing line between primary and secondary education, but a smooth transition with continuous learning that contributes to the development of the children in accordance with their cognitive and non-cognitive abilities (Zeedijk, Gallacher, Henderson, Hope, Husband \& Lindsay, 2003). Because of its cross-school nature, the transition from primary to secondary education should be the joint responsibility of the teachers in both sets of schools. Chapters 2 
and 3 show that it is important that teachers, on both sides of the transition, work together to shape, implement and evaluate this process to ensure a smooth transition and continuity in the development of the children (Chedzoy \& Burden, 2005; Coffey, 2013; Green, 1997; Jindale-Snape \& Miller 2008; Lester et al., 2012a; Topping, 2011). However, in practice, this is not always the case (McGee et al., 2004; Anderson et al., 2000; Bokhorst, Sumter \& Westenberg, 2009). The cooperation is usually limited to the exchange of generic information on the curriculum rather than information about individual children (Topping, 2011).

When children make the transition (Chapters 2 and 5), they have experiences from primary education and expectations that do not necessarily correspond with the reality of secondary education (Tobbell \& O'Donnell, 2013; Powell, Smith, Jones \& Reakes, 2006). Unfortunately, primary education does not usually connect seamlessly with secondary education. For most children, it takes some time to get used to secondary education, because there is a world of difference between primary and secondary school. The small-scale primary school environment, where everyone knows each other and where each class has its own teacher, contrasts sharply with the often large, confusingly anonymous secondary school environment, which has a lot of unknown, often older, children and a lot of different subject teachers.

In addition to the school environment, the social environment at secondary school also differs from that of primary school. Children have to make new friendships, because old classmates do not necessarily attend the same school or are not in their class. They also need to develop relationships with their new teachers (Tobbell \& O'Donnell, 2013). As the youngest and smallest children at secondary school, they have a different status than they had in primary school, where they were the most senior children. As emphasized in the literature (Chapter 2), they must learn how to bridge the differences between primary and secondary school, how to handle the new rules, manners and customs of secondary education, how to behave, and what to do (or not to do).

Not only do all these differences between primary and secondary education illustrate how difficult it is to achieve continuity during the transition, they also show how important continuity is, because continuity reduces adjustment problems. As explained in Chapter 2, the more continuity the children experience, the less support they need (Anderson et al., 2000). That teachers on both sides of the transition support their students primarily from their own perspective, often without being aware of it, further contributes to the disruption of continuity. After all, the primary school teacher's perspective does not necessarily correspond with that of the secondary school teacher, or, for that matter, with that of the children. 


\section{- Good preparation in the $6^{\text {th }}$ grade of primary education does not guarantee a successful transfer to secondary education}

Scientists and teachers in primary and secondary education agree in the literature (Chapter 2) that, to make the transition a success, children must be well-prepared (Chedzoy \& Burden, 2005; Coffey, 2013; Green, 1997; Jindal-Snape \& Miller, 2008; McGee et al., 2004; Topping, 2011). Despite the fact that primary schools make an effort to prepare their children for it, the transition is not always successful for all children. As shown by our blinded study in Chapter 4 , the transition involves a period of stress and anxiety, even for children who adjust well at school (Rice, Frederickson \& Seymour, 2011).

To prepare the children properly for the transition, Chapter 3 demonstrates that primary school teachers need to be aware of the experiences the children will encounter (Anderson et al., 2000) and the expectations that are set upon them at secondary school. Often, teachers in primary education are not familiar enough with secondary school. As a result, their preparation does not always meet the requirements of secondary education (Chapter 5).

Even children who are well-prepared for secondary education do not always successfully adapt after the transition, for a number of reasons. Some of the reasons that we found in our study, as described in this thesis, include: the preparation does not meet expectations, personal and family characteristics, inappropriate school advice, improper parental involvement, no sense of belonging, and a lack of opportunity to evaluate and adjust the transition process. We will discuss each of these factors.

The preparation in primary education fails to meet the expectations of secondary education

In preparing their students for secondary school, our study (Chapter 3 ) indicates that primary school teachers frequently focus unilaterally on academic issues, such as the curriculum, and pay little attention to the importance of social relationships in the transition process (Pratt \& George, 2005). After the transition, the children not only need the knowledge and skills to succeed academically in secondary school, they also should be able to work independently and remain focused on their tasks. In addition, the findings of our study in Chapter 3 emphasize that children need the skills to cope with problems and difficulties in the school context (Anderson et al., 2000; Simmons \& Blyth, 1987; Snow, Gilchrist, Schilling, Schinke \& Kelso,1986; Timmins, 1989; Ward et al., 1982). The mentors we interviewed in the secondary schools expected their pupils to be able to perform a task independently and to handle the problems they encountered more or less adequately (Chapter 5). However, in practice, it appears that the children are not always capable of meeting those expectations, because they 
are not well-prepared to do so (Chapter 3). In particular, they are poorly prepared to cope with challenges in the social environment. Such poor preparation hinders successful transition in the short-term and good personal development over the long-term. The children themselves suffer from the additional burden of a lack of preparation (Chapter 3 ).

Personal and family characteristics of children may affect the success of the transition

Despite good preparation and the best of intentions, some children may, due to personal or family characteristics, be more vulnerable to a poorer transition than their peers. The literature study in Chapter 2 identifies a number of family characteristics that are risk factors for a poor transition, such as: a lower socio-economic status, ethnicity, and the parents' education level and parenting style (Evangelou, Taggart, Sylva, Melhuish, Sammons \& Siraj-Blatchford, 2008; Vaz, Parsons, Falkmer, Passmore \& Falkmer, 2014). In addition, individual characteristics can also make the transition more difficult for a child. Children with lower cognitive or socialemotional abilities, anxious children and children with lower self-esteem have a greater chance of experiencing a poorer transition (Chung, Elias \& Schneider, 1998; Nottelmann, 1987; Riglin, Frederickson, Shelton \& Rice, 2013).

In Chapter 4, data obtained from the children themselves confirmed that some children are more vulnerable to a poorer transition than their peers. This study identified three such vulnerable groups: girls, children with special educational needs (SEN), and children who indicated before the transition that they were anxious. Girls were especially susceptible to a poor transition, because after the transition they reported having more fear of schoolwork than boys have. Anderson et al. (2000) confirmed this finding. They also found that the transition had a more negative impact on the self-esteem of girls than of boys (Anderson et al., 2000).

Children with SEN constituted the second vulnerable group, because of the mixed picture they present going through the transition. In contrast to typically developing children, SEN children experience more anxiety after the transition, particularly fear of their peers. However, SEN children are also significantly less anxious about the school environment than their peers without SEN. The literature confirms that children with SEN are more vulnerable to a poor transition than others (Anderson et al., 2000; Chedzoy \& Burden, 2005).

The last group that stands out for its vulnerability consists of the children who are already anxious before they make the transition. They are likely to become even more anxious afterwards. In previous research (Chapter 2), it was found that children showing psychological distress prior to the transition are at greater risk than their peers to a stressful transition (Chung et al., 1998; Riglin et al., 2013). 
The school advice does not always reflect the capabilities of the child

In addition to a good preparation to ensure that children experience success, an adequate school advice is required. In Chapter 5 , secondary school mentors indicated that some children do not end up in the most suitable place. One of the reasons for this is that the primary school teacher wants to give them a 'second chance' by moving them into secondary education at a higher level than they might be able to handle based on their performance levels. Another reason for inadequate school advice, according to the mentors of grade seven (Chapter 5), concerns children from special education. Their teachers do not realize that secondary education does not have the resources needed to guide these children. Without the extra support they received in special education at primary school, these children often function at a lower level at secondary school and therefore experience a less successful transition and a less successful start to their school career.

Parents sometimes interfere with the school advice because they disagree with it

As disclosed in the literature (Chapter 2), parental involvement, before and after the transition, can affect both the transition process and school achievement (Chen \& Gregory, 2009 in: Hanewald, 2013). Both our study (Chapter 3) and other research (Chapter 2) support the notion that, to provide effective support, parents and school must be on the same page (McGee et al., 2004) and work together (Coffey, 2013). Unfortunately, as indicated in our blinded study (Chapter 4), the aspirations of the parents do not always match the aspirations or capacities of their children (Korpershoek, Beijer, Spithoff, Naaijer, Timmermans, van Rooijen, Vugteveen \& Opdenakker, 2016) or the primary school teacher's opinion about the capabilities of the children. The focus group interviews with secondary school mentors (Chapter 5 ) showed that some parents refuse to accept the school advice from the teacher at primary school. These parents usually want the school advice of their child to be adjusted upwards. According to the mentors at secondary school, if the parents succeed in obtaining the unwarranted upward adjustment, the child will frequently have problems in adjusting to the higher level and suffer from a negative impact on the transition, with all the attendant problems that can cause (Chapter 5).

Negative perceptions of the secondary school climate and inadequate school attachment

Personal feelings can affect the transition. Therefore, research emphasizes (Chapter 2) that an important aspect in the adjustment to secondary school is the social-emotional functioning and experiencing a sense of belonging (Cueto, Guerrero, Sugimaru \& Zevallos, 2010 in: Hanewald, 2013). For example, our study showed (Chapter 3) that children will struggle with 
the transition if they are worried about their performance or working with new teachers or making new friends and avoiding bullies (Evangelou et al., 2008). Negative perceptions of the school climate and an inadequate attachment to the school (Chapter 2), as perceived by the children themselves, are associated with aggressive and violent behavior and delinquency (Hanewald, 2013). According to Ryan and Deci (2000), and supported in our study (Chapter $3)$, lack of connectedness may trigger a commensurate lack of initiative and responsibility, ultimately culminating in distress and psychopathology.

The experiences of all stakeholders involved in the transition process are rarely shared or evaluated jointly

In the literature, few initiatives are found where teachers at primary and secondary school are able to work together regularly to achieve effective lines of communication to facilitate a successful transition. The primary and secondary schools each develop interventions from their own perspectives. Scientists have found (Chapter 2) that in preparing for secondary school, teachers at primary school focus on long-term issues, such as behavior, the curriculum and academic issues (Pratt \& George, 2005). The effectiveness of the school efforts is rarely evaluated (Anderson et al., 2000).

In educational practice, little has changed since the findings of Anderson et al. in 2000 (Chapter 5). Focus group interviews with secondary school mentors revealed that teachers of primary school and mentors of secondary school very rarely have sufficient time to contact each other - before or after the transition - for a conversation or to provide feedback.

\section{- It is difficult to properly prepare children for a good transition if teachers on both sides are unfamiliar with each other's perspectives and the nature of their work}

It goes without saying that secondary education brings many challenges, and teachers of primary education are partly responsible for preparing children to face as many of them as possible. To fulfill this responsibility, the teachers need to have an appreciation of the way in which secondary schools operate and how they differ from the primary school environment that the children have known (Hopwood, Hay \& Dyment, 2016). This finding was supported by the mentors in our focus study (Chapter 5 ). Conversely, teachers at secondary school need to understand the primary school environment and how children are being prepared to make the transition to secondary education. Unfortunately, research shows that none of this occurs (Chapter 2). Primary school teachers often have unrealistic notions about what is offered in the secondary school environment; and secondary school teachers fail to recognize the shortcomings of primary school before it is too late to protect the child from grief (McGee et 
al., 2004). Thus, a key question is: to what extent do teachers in primary and secondary education understand the nature of each other's work (Green 1997). Mutual misunderstandings can unintentionally cripple preparations for the transition.

In a study among children in England (Chapter 3), Evangelou et al. (2008) found that $16 \%$ experienced difficulties in the transition, because they did not feel well prepared for it. Primary and secondary school teachers' expectations are sometimes at odds with each other because they do not know each other's field of work sufficiently. Primary school teachers prepare children primarily for the academic challenges they think the children can expect in the new school situation (Zeedijk et al., 2003), but, as shown in our study (Chapter 3), they do not realize that secondary education demands many non-academic skills as well. For instance, children must be prepared to deal independently with challenges in both the new social context and the new school environment (Chapter 5).

The secondary school mentors interviewed in the focus groups confirmed the frustrations caused by insufficient understanding of each other's work and practices (Chapter 5). The mentors questioned whether the grade six teachers were aware of the educational practices and demands of secondary school, and of the importance of preparing children to learn and work independently. For instance, the mentors noticed that many students lacked certain basic non-cognitive skills, such as listening to instructions or waiting their turn. If the primary school teachers had realized the importance of these skills in secondary school, they might have made more of an effort to include them in the preparation for the transition (Chapter 5).

One of the mentors interviewed had no doubt as to how uninformed the teachers on both sides were as to the nature of each other's work, pedagogical and didactical practice, and expectations. This mentor had been a grade six teacher for 26 years before becoming a secondary school mentor, a position at which she had been working for three years when she participated in the focus group interview. According to this mentor, teachers on both sides of the transition know little to nothing at all about each other's school practice, nor do they have any knowledge of each other's pedagogical practice (Chapter 5 ).

Because primary school teachers are unfamiliar with the demands that secondary education places on children's skills, they can create mistaken expectations and even give inappropriate school advice. In Chapter 5, the mentors concluded that the school advice for the children from regular education was not always correct. More concerning, they also felt that the school advice for children with SEN - who are especially vulnerable to a poor transition (Chapter 4) was not always reliable. In particular, according to the mentors, the school advice by teachers at primary schools for special education is often incorrect, simply through ignorance about the level of guidance that secondary education can and cannot offer SEN children. 


\section{- Communication and information are important. Talking with children provides a different perspective than talking about - and without - children}

It has been said that a successful transition is built on a foundation of positive relationships and good communication between all stakeholders in the process (Coffey, 2013; Green 1997; Jindale-Snape \& Miller, 2008; Lester et al., 2012a). In practice, the lines of communication between the stakeholders do not always flow so smoothly. According to the mentors interviewed at secondary school, there was not enough cooperation between primary and secondary schools to be effective (Chapter 5$)$.

Mentors are the key persons in secondary education, designated to guide and support the children through the transition process. To do this properly, they need support themselves, primarily in the form of information about the children in their class. This information is provided by three stakeholders: the primary school, the parents, and the children themselves. Unfortunately, most communication takes place between the teachers of the primary and secondary schools; the parents and the children play only a small role, or are not involved at all in communications about the transition.

Direct involvement of the children themselves in communication and information is not only a precondition for a good transition, it is also a moral obligation of the stakeholders. Since the United Convention on the Rights of the Child was adopted in 1989, all children have the right to be heard and to express their views in matters affecting their lives (U.N., 1989, Article 12, https://www.unicef.org.uk/what-we-do/un-convention-child-rights/). However, children seldom get a chance to provide input about the transition they are about to undertake. Although research in the literature (Chapter 2) has urged the desirability of communication with the children, rather than about children, in practice, we found that the children were barely involved in the conversations between the grade six teacher and the grade seven mentor (Chapter 5). The children are not excluded because they are unable to give their opinion or because they think it is unimportant to talk with their future mentor. Mason \& Danby (2011) demonstrated that children are not only able to communicate their views (in Chapters 3 and 4), their ideas might even offer new insight that could be helpful for teachers to improve their daily pedagogical practice (Ferguson, Handreddy \& Draxton, 2011; Mason \& Danby, 2011). Furthermore, our study supports the idea (Chapter 3 ) that encouraging child participation could contribute to improvement in the children's well-being, personal development, and mental health (Bru, Stornes, Munthe \& Thuen, 2010; Chung et al., 1998; Lundqvist, 2014; Waters, Lester, Wenden \& Cross 2012), thereby facilitating a smooth transition (Chapter 2). 
In our study (Chapter 3), the children themselves indicated that they thought it was important to be able to talk with their mentor, and for the mentor be available for conversation with his class. Girls appreciated significantly more than boys the opportunity to talk with their mentor, although the boys also signaled that they found it to be worthwhile.

Unfortunately, not all teachers think that talking with the children is imperative. A recent Australian study (Hopwood et al., 2016) found that only $28 \%$ of secondary school teachers took the time to talk with the children about what to expect after the transition (Chapter 5).

This example demonstrates that the expectations, experiences and perspectives of children and teachers do not necessarily match. Indeed, as further evidence of the mismatch, children focus mostly on the social and emotional aspects of the transition, the aspects with which teachers at secondary education are least concerned (Chapter 4). Children's input can make a valuable contribution to understanding how they experience their school life and what is important to them (Mason \& Danby, 2011). Mentors agree that primary schools should teach children to work and behave more independently, and to take responsibility for their own learning process (Chapter 5). Involving children in matters that concern them may offer the best way to encourage children to be less dependent and more responsible than making such decisions for them in their absence.

\section{- The advantage of a fresh start does not always outweigh the disadvantage of a false start}

The children are generally a tabula rasa for the secondary school teachers. The underlying idea is that the children are given a chance to make a fresh start at secondary school, without any prejudices based on their past behavior at primary school. All adults in the transition process - the parents and the teachers from primary and secondary education - want to grant children an opportunity to make such a start in secondary education. However, when children make the transition to secondary education without the future school receiving any specific information about them, proper assessment is impossible.

The reasons for the fresh start are not always shared by the stakeholders; there may be hidden agendas. The motivations may, or may not, be selfless, or even in the best interest of the child. This can be the case, for example, when a child is unable to cope with the curriculum at secondary school because the school advice was too advanced, or when a child does not receive the guidance he or she needs from the secondary school because the parents have withheld essential information about their child's special educational needs. Thus, even with the best of intentions, a so-called fresh start can lead to a false start. 
Our findings (Chapter 3) agreed with McGee et al. (2004) that secondary school teachers themselves have conflicting opinions about whether it is better to be well-briefed and prepared for a child, or to know very little and approach the child with a completely open mind to give them the freshest of starts. The mentors in our focus groups reflected this conundrum (Chapter 5). They were convinced that every child deserved a fresh start in secondary education, and emphasized the importance of meeting each child with an open mind. However, they thought certain limitations to absolute objectivity were necessary. If there were serious problems in the past, such as disorders, bullying, or a difficult home situation, the mentors wanted to know as soon as possible. They felt that this was prerequisite to preventing the risk of problems arising or persisting too long before they were properly addressed. In all other cases, they preferred to refrain from delving into a child's file in advance, so that they could meet their new students completely free of any preconceived notions.

Primary school teachers (Chapter 5) like to provide children with a fresh start, because they believe that the children deserve an opportunity to show their best side in secondary education. They might argue that some children benefit from a new challenge. Consequently, some children may receive a higher school recommendation than they actually deserve, without their mentor being aware of it. In addition, primary schools have an interest in the promoting outflow at the highest possible level, to demonstrate what a good quality school they are. Mentors at secondary schools are strongly opposed to such an attitude, although, in their words, they "recognize that schools cannot give a completely unbiased school advice, because they are partly evaluated by it." (Chapter 5). However, such advice by the primary school often leads to stress and frustration among children, because they cannot handle the demands of the higher level, which sets them up for failure. The lack of correct information also frustrates the secondary school teachers, because they are unable to offer the proper guidance that the children need. According to the mentors interviewed, "these children are actually working above their level and experiencing a very false start in secondary education."

Sometimes the parents are the ones who obscure the child's start. For example, parents of a child with special educational needs may invoke the privacy law and refuse to give the primary school permission to reveal essential information about a disorder or the child's need for a special approach or counselling (Chapter 5). Those parents feared that if the truth were known, their child would be rejected by the secondary school or otherwise denied the new chance and fresh start they believed their child deserved. According to the focus group mentors, such measures are usually counterproductive for the child, because "then you first run into many problems and finally the truth comes out." Starting secondary school in the shadow of this false start is highly likely to create negative ramifications for everyone: the children, their parents, the mentors and the secondary school. The children fail to receive the guidance they need and 
suffer through the transition and in the school context. They could even disrupt the transition experience of other children. Mentors who are unable to provide the appropriate guidance, struggle to find a way to supervise the children properly. Frequently these children end up at a lower educational level or sometimes even have to leave the regular school for a school for special education. And the parents are left to witness the unhappiness of their child

\subsection{Thesis limitations}

Apart from the limitations we described for each study separately in the previous chapters, this thesis has some general limitations that we describe below.

\section{The composition of the sample}

The sample was drawn from a rural area and did not include children from urban areas. According to the School Inspectorate (Inspectie van het Onderwijs: Onderwijsverslag de Staat van het Onderwijs 2015-2016), there are major regional differences in the school advice provided by $6^{\text {th }}$ grade in the Netherlands. North Limburg, the region of our sample, is one of the regions in which a lower school advice is given more often in comparison to the test results. The location of the school in a city or village also affects the level of advice compared to the test results. Children in urban regions are more likely to receive a higher advice and less likely to receive a lower advice (Inspectie van het Onderwijs: Onderwijsverslag de Staat van het Onderwijs 2019). This means that the results of the study may, to some extent, be region specific.

\section{The sample size}

The number of participants in our study is relatively low. A power analysis showed that the sample has insufficient power to be able to detect any effects that might exist. Further study and data is required to extend the generalizability of the study and draw the right conclusions on a larger scale. Additionally, it would be advisable to incorporate children who are more representative of the entire population in the Netherlands, including more children from urban areas.

\section{Sample attrition}

A point for attention is the sample attrition in the quantitative part of the study that occurred after the second (post-transition) measurement, especially when the questionnaires were offered digitally. The questionnaires that were completed in class, under the supervision of the teacher, yielded the highest response. Also, approaching the teachers directly produced a 
greater response than approaching the teachers through their coordinator in the partnership. Furthermore, during the second measurement, the researchers were unable to control the process and provide sufficient guidance for completing the questionnaire online (the children sometimes had to restart the program up to four times before the data could be entered). This could at least partly explain the decrease in response rate.

\section{The instrument used}

The data supplied by the children participating in our study are based on self-reporting questionnaires. The disadvantage of using such questionnaires is that the motivation of the children to tick a certain answer is unknown, because children did not have to explain their answers. The input from the children, as well as the data of the focus group interviews with the mentors, are based on the subjective opinions of the respondents. Therefore, the data may contain potential sources of bias.

\section{The composition of the control- and intervention groups}

In this study children are randomly assigned to a control- and an intervention group. Consequently, children in both groups may have the same class mentor. This may lead to contamination issues that can affect the results of the study: when the mentor uses the information from the children in the intervention group, it could also affect the results of the children in the control group. Randomly assigning the mentors instead of the children could have prevented this. Matching (selecting pairs who are comparable one to another), was also considered but has drawbacks as well. Matching the children, may encounter problems. Causal inference become more problematic. Our research also shows that you cannot always predict how successful the transition will be and that the communication between primary and secondary education is not optimal. The success of the transition is likely to be determined by unobservables. In addition, some selection criteria may have a stigmatizing effect. Matching the mentors does not seem to add value compared to randomization either.

\section{The role of the mentor}

The mentors in our study had a non-committed role. They decided for themselves whether and how they used the information provided by the children (this applies to all information they receive about their class). This may lead to differences in approach.

\section{The teacher's perspective and the role of the parents}

In this thesis, the role of the teachers in the transition process is only described from the perspective of the secondary education mentors. Teachers in primary education were not interviewed. The study would be more objective and substantively stronger if the opinions of the grade six teachers were juxtaposed to those of the grade seven teachers. 
The role of parents during the transition was not investigated either. Because they know their child best, the parents are often the first to signal when things are not going well. To accurately complete the picture of the transition from the perspective of all stakeholders, and to validate our findings, further research is recommended into both the role of the grade six teachers and the role of the parents.

\section{Effects on children's school performance and school career}

In chapter 4, we have investigated the effect of information -provided by the child to the mentoron the transition. The effect of the intervention on the school performance and school career of the children was not investigated because information about children's school results is privacy sensitive information, only accessible with parental consent. We did not have that permission. We recommend further research, in which, in addition to the effect on school performance, the link with the SDT's assumptions is also examined. An additional advantage is that including the school results makes an alternative design possible: creating a second, comparison group of children who have not completed the questionnaires, to eliminate the bias and outside influence that could alter the results of the experiment.

\section{The generalizability of the findings}

This study was conducted into Dutch education. The Dutch education system differs in some respects from those in other countries. This applies, for example, to the school advice in primary education, to the early tracking at the age of 12 , and to the hierarchical structure of the system. Where solutions are found for problems specific to the Dutch system, the external validity of the study is limited.

\subsection{Recommendations}

Based on the results of the study described in this thesis, we formulated a number of recommendations to improve the transition from primary to secondary school. Each of these policy recommendations is a starting point for further research.

Concerning the children who are vulnerable to a poorer transition - children with special educational needs, anxious children, and girls (Chapter 4) - we advise teachers on both sides of the transition to discuss the guidance needs of children through personal contact. Depending on the help given at primary school, the secondary school mentor can decide whether specialized help is needed or whether there is need for a tailor-made program implemented by the teachers themselves. 
Both primary and secondary schools should be facilitated to become better acquainted with the nature of each other's work and working methods in order to better prepare children in primary education and ameliorate support in secondary education. Moreover, mutual contact and the knowledge of each other's expectations will give the teachers in primary education the opportunity to improve the quality of their school advice. Those teachers need to be aware of the basic skills, apart from cognitive skills, that secondary education requires of children, such as being able to deal autonomously with social situations (and thereby reducing dependence on the mentors' help in this respect).

Personal contact between mentors and teachers before children make the transition to secondary school (through direct, personal contact, or 'warm contact', as described Chapter 5) would help to ensure continuity in guidance and prevent a decline in learning performance. Furthermore, making time available for the mentors in secondary education to have personal contact with the teachers in primary education would increase the likelihood that mentors are aware of all the relevant details about the children in their future class.

Parents and children continue to be "missing" in consultations about the transition. We advise that they be involved as crucial partners in this process, because they can make valuable contributions to a smooth transition. In the personal discussions about the school advice that take place between the grade six teacher and each parent, the input of the parents and children could be a regular point of discussion.

Finally, we advise schools to share the successful initiatives ("best practices") that they have developed to improve the transition. Schools can learn from each other's experiences and adapt them to their own environment. For example, the initiative of one secondary school to cluster and use available meeting hours for team consultation might readily benefit other teams. During the bundled hours, these grade seven mentors were able to concentrate on making an inventory of the problems they encountered, and together work to find, implement and evaluate suitable solutions for these problems. A second example of such best practices is the initiative to divide all team members of grade seven across their feeding primary schools in order to gather information about all the future children through personal conversations with the children's grade six teachers. To promote continued benefit from such examples of best practices, we also advise schools to develop criteria for evaluating and adjusting their good practice initiatives.

Continuing on the topic of sharing best practices, the present research also revealed that three major groups involved in the transition - the government (including the Ministry of Education, the Inspectorate, and the politicians), the school system, and academia/scientists/researchers - are all working largely independently of each other to address the widespread concern about 
the quality of the transition from primary to secondary education. Researchers are investigating this phenomenon, whether their research is solicited or not, but the government, the administrators and the School Inspectorate will also sometimes instruct them to conduct research into the topic. Sadly, teachers rarely enjoy the benefit of this scientific research and the opportunity to read the results. This is partly because the researchers describe their findings in reports or in English-language papers in scientific journals to which teachers commonly have no access. Consequently, the recommendations from researchers to improve the transition do not reach the practice of teachers in the classroom. The lack of communication between these groups does their effort a great disservice and, more importantly, works to the detriment of the children. We recommend that steps be taken to ensure that outcomes and best practices are shared at all levels within school.

This research is limited to the experiences of the children and the teachers. It is striking that they experience and identify the same bottlenecks as the researchers and the policymakers. Independently of each other, these sources all indicate unequal opportunities for continuing the secondary education that best suits children's abilities. The children also indicate that they do not feel well-prepared for the social context at secondary school and the results from the literature review confirm this. According to the literature, there is a need for interventions to increase children's capacity to enter into social relationships with peers and teachers and to involve all stakeholders in the transition process. However, scientific research is mainly descriptive in nature. It offers an orientation on the course of the transition, but has little to say about the practical nature of the cause and effect of a poor transition and it offers few solutions.

The Appropriate Education Evaluation Report 2019 (Passend Onderwijs Evaluatie 2019, https://evaluatiepassendonderwijs.nl/) mentions the following four factors to improve the transition: involving parents early in the transition process, a good exchange of relevant data between primary and secondary education, a good school advice, and responding in educational practice to what is known about the student in the past. This is in line with the wishes of the focus group mentors reviewed in Chapter 5 . They were not satisfied with the reliability of the school advice or the content of the educational report, both of which are compiled by the primary school. In addition, they wanted more contact with the grade six teachers to exchange and share experiences. The mentors wanted more attention to be given to helping the children in grade six develop basic non-cognitive skills that would enable them to function independently in secondary education, particularly in the social environment.

The findings of this thesis show that close ties, positive relationships, and good communication between all stakeholders, including the input of children and teachers, are crucial for a successful transition. Perhaps policymakers should focus less on the need for advice and more 
on delivering the resources to facilitate the people who work to implement the most suitable solutions in practice. 


\section{Bibliography}

Alexander, K., Entwisle, D. \& Kabbani, N. (2001). The dropout process in life course perspective: early risk factors at home and school. Teachers College Record, 103, 760-822.

Amsing, M., Bosch, M., \& Rouweler, M. (2010). Tim gaat naar de brugklas. Hoe begeleidt u hem? Advies voor basisschool, voortgezet onderwijs en regionale samenwerkingsverbanden. 's-Hertogenbosch: KPC Groep.

Anderson, L. W., Jacobs, J., Schramm, S. \& Splittgerber, F. (2000). School transitions: beginning of the end or a new beginning? International Journal of Educational Research, 33, 325- 339 .

Ashton, R. (2008). Improving the transfer to secondary school: How every child's voice can matter. Support for Learning, 23(4), 176-182.

Bakker, J., Denessen, E., Denessen, M., Oolbekkink-Marchand, H. (2017). Leraren en ouderbetrokkenheid. Een reviewstudie naar de effectiviteit van ouderbetrokkenheid en de rol die leraren daarbij kunnen vervullen. Nijmegen: Behavioural Science Institute / Radbout Docenten Academie.

Barber, K. \& Olsen, J., (2004). Assessing the transition to middle and high school. Journal of Adolescence Research, 19(1), 3-30.

Benner, A. D., \& Graham, S. (2009). The transition to high school as a developmental process among multiethnic urban youth. Child Development, 80(2), 356- 476.

Bokhorst, C., Sumter, S. \& Westenberg, M. (2010). Social support from parents, friends, classmates, and teachers in children and adolescents aged 9 to 18 years: who is perceived most supportive? Social Development, 19(2), 417-426.

Bosch, M., Konermann, J., de Wit, C., Rutten, M. \& Amsing, M. (2008). Passende Overgang. Een verkenning naar de stand van zaken rond de overgang tussen primair en voortgezet onderwijs. 's Hertogenbosch: KPC Groep.

Bru, E., Stornes, T., Munthe, E. \& Thuen, E. (2010). Students' perceptions of teacher support across their transition from primary to secondary school. Scandinavian Journal of Educational Research, 54(6), 519- 533.

Cambridge Dictionary: Definition focus group. Retrieved: 26-03-2020.

https://dictionary.cambridge.org/fr/dictionnaire/anglais/focus-group. 
Centraal Bureau voor de Statistiek (2018). More girls than boys exceeding expected school level. Retrieved 26-03-2020: https://www.cbs.nl/en-gb/news/2018/50/more-girls-than-boysexceeding-expected-school-level.

Chedzoy, S. \& Burden, R. (2005). Making the move: Assessing student attitudes to primarysecondary school transfer. Research in Education, 74, 22-35.

Chen, W. B., \& Gregory, A. (2009). Parental involvement as a protective factor during the transition to high school. The Journal of Educational Research, 1003, 53-62.

Child Participation From Rights to Reality KidsRights. Retrieved 03-02-2020 from: https://resourcecentre.savethechildren.net/node/8717/pdf/kidsrights report child participation website.pdf.

Chung, H., Elias, M. \& Schneider, K. (1998) Patterns of individual adjustment changes during middle school transition. Journal of School Psychology, 36(1), 83-101.

Coffey, A. (2013) Relationships: The key to successful transition from primary to secondary school? Improving Schools, 16(3), 261-271.

Craig, W., Harel- Fisch, J., Fogel- Grinvald, H., Dostaler, S., Hetland, J., \& Simons- Morten, B. (2009). A cross- national profile of bullying and victimization among adolescents in 40 countries. International Journal of Public Health, 54, S216- S224.

Croes, M. \& Terpstra, J. (2017). Soepel van groep 8 naar de brugklas. Retrieved 14-11-2019 from: https://didactiefonline.nl/artikel/soepel-van-groep-8-naar-de-brugklas

Cueto, S., Guerrero, G, Sugimaru, C., \& Zevallos, A. M. (2010). Sense of belonging and transition to high schools in Peru. International Journal of Educational Development, 30, 277 287.

Desforges, C. \& Abouchaar, A. (2003). The impact of parental involvement, parental support and family education on pupil achievement and adjustment: A literature review. Research Report RR433, ISBN 1841859990.

De Witte, K. \& Rogge, N. (2014). Dropout from secondary education: All's well that begins well. TIER Working Paper Series, TIER WP 14/11. ISBN 9789400300774.

Dinklo, I. (2006). Fabels en feiten over kwalitatieve onderzoeksresultaten, Kwalon 32 (11) 2, 35-43.

Driessen, G., Sleegers, P. \& Smit, F. (2008). The transition from primary to secondary education: meritocracy and ethnicity. European Sociological Review, 26(4), 527- 542. 
Driessen, G. \& Van Langen, A. (2011). Staan de jongens in het primair en voortgezet onderwijs op achterstand? Pedagogische Studiën, 88, 323-328.

Duchesne, S., Ratelle, C. F., Poitras, S-C., \& Drouin, E. (2009). Early adolescent attachment to parents, emotional problems, and teacher-academic worries about the middle school transition. The Journal of Early Adolescence, 29(5), 743-766.

Elias, M., Patrikakou, E. \& Weissberg, R. (2007). A competence-based framework for parentschool-community partnerships in secondary schools. School Psychology International, 28(5), 540-554.

Ellerbrock, C., Abbas, B. \& DiCicco, M. (2014). Developmentally Responsive Teacher Practices Across the Middle-to-High-school Transition. Journal of Research in Education, 24(1), 17-37.

Evangelou, M., Taggart, B., Sylva, K., Melhuish, E., Sammons, P. \& Siraj- Blatchford, I. (2008). What makes a successful transition from primary to secondary school? London: Institute of Education, University of London.

Evers, J. (2015). Kwalitatief interviewen: kunst en kunde. Amsterdam, Nederland: Boom Lemma.

Faul, F., Erdfelder, E., Lang, A.-G., \& Buchner, A. (2007). G*Power 3: A flexible statistical power analysis program for the social, behavioral, and biomedical sciences. Behavior Research Methods, 39, 175-191.

Ferguson, D., Handreddy, A. \& Draxton, S. (2011). Giving pupils a voice as a strategy for improving teacher practice. London Review of Education, 9(1), 55-70.

Fink, A. (2008). Practicing research: discovering evidence that matters. Los Angeles, Californië: Sage.

Fletcher, A. (2008). The Architecture of Ownership. Educational Leadership, 66(3), 23-29.

Fredriksen, K., \& Rhodes, J. (2004). The role of teacher relationships in the lives of students. New Directions for Youth Development, 103, 45-54.

Ganeson, K. \& Ehrich, L. (2009). Transition into high school: A phenomenological study. Educational Philosophy and Theory, 41(1), 60-78.

Gillison, F., Standage M. \& Skevington, S. (2008). Changes in quality of life and psychological need satisfaction following the transition to secondary school. British Journal of Educational Psychology, 78(1), 149-162. 
Glaser, B. \& Strauss, A. (1967). The Discovery of Grounded Theory: Strategies for Qualitative Research. Chicago: Aldine Publishing Company.

Glaser BG. (1978). Theoretical Sensitivity: Advances in the methodology of Grounded Theory. Mill Valley, California: Sociology Press.

Glaser BG. (1998). Doing Grounded Theory - Issues and Discussions. Mill Valley, California: Sociology Press.

Government of the Netherlands, Appropriate education at primary school. Retrieved 29-012020 https://www.government.nl/topics/primary-education/appropriate-education-at-primaryschool.

Green, P. (1997). Moving from the world of the known to the unknown: The transition from primary to secondary school. Melbourne Studies in Education, 38(2), 67-83.

Guba, E. \& Lincoln, Y. (1994). Competing paradigms in qualitative research. In Handbook of qualitative research (105-117). California: Sage.

Hamm, J. V., Farmer, T. W., Dadisman, K., Gravelle, M. \& Murray, A. R. (2011). Teachers' attunement to students peer group affiliations as a source of improved student experiences of the school social-affective context following the middle school transition. Journal of Applied Developmental Psychology, 32, 267-277.

Hanewald, R. (2013). Transition between primary and secondary school: Why it is important and how it can be supported. Australian Journal of Teacher Education, 38(1), 62-74.

Hart R.A. (2008) Stepping Back from 'The Ladder': Reflections on a Model of Participatory Work with Children. In: Reid A., Jensen B.B., Nikel J., Simovska V. (eds) Participation and Learning. Dordrecht, Nederland: Springer.

Hattie, J. \& Timperley, H. (2007). The power of feedback. Review of Educational Research, 77(1), 81-112.

Hopwood, B., Hay, I. \& Dyment, J. (2016). The transition from primary to secondary school: Teachers' perspectives. Australian Educational Research, 43, 289-307.

Huggins, M., \& Knight, P. (1997). Curriculum continuity and transfer for primary to secondary school: The case of history. Educational Studies, 23(3), 333-348.

Humphrey, N., \& Ainscow, M. (2006). Transition club: Facilitating learning, participation and psychological adjustment during the transition to secondary school. European Journal of Psychology of Education, 21(3), 319-331. 
Inspectie van het onderwijs (2019). De staat van het Onderwijs: Onderwijsverslag 2019. Utrecht: Inspectie van het Onderwijs.

Inspectie van het onderwijs (2018). De staat van het Onderwijs: Onderwijsverslag 2016-2017. Utrecht: Inspectie van het Onderwijs.

Inspectie van het onderwijs (2017). De staat van het Onderwijs: Onderwijsverslag 2015-2016. Utrecht: Inspectie van het Onderwijs.

Inspectie van het Onderwijs. Ministerie van Onderwijs, Cultuur en Wetenschap (2018). Kansen(on)gelijkheid bij de overgangen PO-VO. Bevindingen en bevorderende en belemmerende factoren. Retrieved: 26-02-2020.

https://www.onderwijsinspectie.nl/documenten/rapporten/2018/06/13/onderzoeksverslagkansenongelijkheid-bij-de-overgangen-po-vo

Jindal-Snape, D. \& Miller, D. (2008). A challenge of living? Understanding the psycho-social processes of the child during primary-secondary transition through resilience and self-esteem theories. Educational Psychology Review, 20(3), 217-236.

Kakavoulis, A. (1998). Motives for school learning during transition from primary to secondary school. Early Child Development and Care, 145, 59-66.

Kelle, U. (2006). Combining qualitative and quantitative methods in research practice purposes and advantages. Qualitative research in Psychology 3, 293-311.

Korpershoek, H., Beijer, C., Spithoff, M., Naaijer, H., Timmermans, A., van Rooijen, M., Vugteveen, J. \& Opdenakker, M. (2016). Overgangen en aansluitingen in het onderwijs. Deelrapportage 1: reviewstudie naar de po-vo en de vmbo-mbo overgang. GION Onderwijs/ Onderzoek..

Lester, L., Cross, D., Shaw, T. \& Dooley, J. (2012a). Adolescent bully-victims: Social health and the transition to secondary school. Cambridge Journal of Education, 42(2), 213-233.

Lester, L., Dooley, J., Cross, D. \& Shaw, T. (2012b). Internalising symptoms: An antecedent or precedent in adolescent peer victimisation. Australian Journal of Guidance and Counselling, 22(2), 137-189.

Lester, L., Waters, S. \& Cross, D. (2013). The relationship between school connectedness and mental health during the transition to secondary school: A path analyses. Australian Journal of Guidance and Counselling, 23(2), 157-171.

Lucey, H. \& Raey, D. (2000). Identities in transition: anxiety and excitement in the move to secondary school. Oxford Review of Education, 26(2), 191-205. 
Lundqvist, J. (2014). A Review of Research in Educational Settings Involving Children's Responses. Child Indicators Research, 7, 751-768.

Marston, J. L. (2008). Perceptions of Students and Parents involved in Primary to Secondary School Transition Programs. Brisbane, QLD: Australian Association for Research in Education, International Education Research Conference, 30 November-4 December.

Martinez, R. S., Aricak, O. T., Graves, M. N., Peters-Myszak, J., \& Nellis, L. (2011). Changes in Perceived Social Support and Socioemotional Adjustment Across the Elementary to Junior High School Transition. Youth Adolescence, 40, 519-530.

Mason, J., \& Danby, S. (2011). Children as experts in their lives: Child inclusive research. Child Indicators Research, 4(2), 185-189.

McGee, C., Ward, R., Gibbons, J. \& Harlow, A. (2004). Transition to secondary school: a literature review. Hamilton, New Zealand: Waikato Institute for Research in Learning Curriculum, School of Education, University of Waikato.

Mellor, D. \& Delamont, S. (2011). Old anticipations, new anxieties? A contemporary perspective on primary to secondary transfer. Cambridge Journal of Education, 41(3), 331346.

Mohr; J. \& Spekman, R. (1994). Characteristics of partnership success: Partnership attributes, communication behavior, and conflict resolution techniques. Strategic Management Journal, 15(2), 135-152.

Noddings, N. (2005). Identifying and responding to needs in education. Cambridge Journal of Education, 35(2), 147-159, DOI: 10.1080/03057640500146757.

Nottelmann, E. (1987). Competence and self-esteem during transition from childhood to adolescence. Developmental Psychology, 23(3), 441- 450.

Onderwijs in Cijfers: Schooladvies en heroverweging schooladvies. Retrieved 26-03-2020 from: https://www.onderwijsincijfers.nl/kengetallen/po/leerlingen-po/prestaties-schooladvies.

Paris, S. G. \& Paris, A. H., (2001) Classroom Applications of Research on Self-Regulated Learning. Journal Educational Psychologist,_36(20), 89-101.

Pellegrini, A. \& Long, D. (2002). A longitudinal study of bullying, dominance and victimization during the transition from primary school through secondary school. British Journal of Developmental Psychology, 20(2), 259-280.

Poorthuis, A. (2012). Children in transition. Challenges and opportunities in adjusting to secondary school. Utrecht: Universiteit Utrecht. 
Poorthuis A., Thomaes, S., van Aken, M., Denissen, J. \& Orobio de Castro, B. (2014). Dashed hopes, dashed selves? A sociometer perspective on self-esteem change across the transition to secondary school. Social Development, 23(4), 770-783.

Powell, R., Smith, R., Jones, G. \& Reakes, A. (2006). Transition from primary to secondary school: Current arrangements and good practice in Wales, Final Report, National Foundation for Educational Research. https://www.nfer.ac.uk/media/2243/wtn01.pdf

Pratt, S. \& George, R. (2005). Transferring friendship: Girls' and boys' friendship in the transition from primary to secondary school. Children \& Society, 19(1), 16-26.

Reyes, M., Brackett, M., Rivers, S., White, M., \& Salovey, P. (2012). Classroom Emotional Climate, Student Engagement, and Academic Achievement. Journal of Educational Psychology, 5. Advance online publication DOI: 10.1037/a0027268.

Rice, F., Frederickson, N. \& Seymour, J. (2011). Assessing pupil concerns about transition to secondary school. British Journal of Educational Psychology, 81, 244-263.

Rice, F., Frederickson, N., Shelton, K., McManus, C., Riglin, L., \& Ng-Knight, T. Identifying factors that predict successful and difficult transitions to secondary school. Report, School Transition and Adjustment Research Study (STARS; www.ucl.ac.uk/stars), University College London.

\section{https://www.nuffieldfoundation.org/wp-content/uploads/2019/11/STARS report.pdf}

Riglin, L., Frederickson, N., Shelton, K. \& Rice, F. (2013). A longitudinal study of psychological functioning and academic attainment at the transition to secondary school. Journal of Adolescence, 36, 2007-2017.

Riley, P. (2009). An adult attachment perspective on the student-teacher relationship \& classroom management difficulties. Teaching and Teacher Education, 25, 626-635.

Robinson, C. (2014). Children, their voices and their experiences of school: What does the evidence tell us? Cambridge: Cambridge Primary Review Trust (CPR). Retrieved 29-01-2020: https://cprtrust.org.uk/wp-content/uploads/2014/12/FINAL-VERSION-Carol-Robinsonbriefing-with-header-Dec-20141.pdf

Roderick, M. (1993). The path of dropping out. Westport, CT: Auburn House.

Roorda, D., Koomen, H., Spilt, J. \& Oort, F., (2011). The influence of affective teacher-student relationships on students' school engagement and achievement: a meta-analytic approach. Review of Educational Research, 81, 493-529. Retrieved 29-01-2020 https://doi.org/10.3102/0034654311421793. 
Rudolph, K. D., Lambert, S. F., Clark, A. G. \& Kurlakowsky, K. D. (2001). Negotiating the transition to middle school: the role of self-regulatory processes. Child Development, 72(3), 929-946.

Rupsiene, L. \& Kucinskiene, R. (2005). Influence of teachers' behavior on students' adaption after school transition. Online submission https://www.semanticscholar.org/paper/Influenceof-Teachers'-Behaviour-on-Students'-after-Rup\%C5\%A1 ien\%C4\%97Ku\%C4\%8Dinskien\%C4\%97/ab967b2e9ade3243dad3267aaed4523e25b0338d SBN: N/A; ISSN: N/A. Retrieved 03-02-2020.

Ryan, R. \& Deci, E. (2000). Self-determination theory and the facilitation of intrinsic motivation, social development, and well-being. American Psychologist, 55(1), 68-78.

Schwarz, C., Reiser, B., Davis, E., Kenyon, L., Achér, A., Fortus, D., Shwartz, Y., Hug, B. \& Krajcik, J. (2009). Developing a Learning Progression for Scientific Modeling: Making Scientific Modeling Accessible and Meaningful for Learners. Journal of research in science teaching, 46(6), 632-654.

Sellman, E. (2009). Lessons learned: student voice at a school for pupils experiencing social, emotional and behavioural difficulties. Emotional and Behavioural Difficulties, 14(1), 33-48, DOI: $10.1080 / 13632750802655687$

Simmons, R. G., \& Blyth, D. A. (1987). Moving into adolescence: The impact of pubertal change and school context. Hawthorne, NY: Aldine de Gruyter.

Sirsch, U. (2003). The impending transition from primary to secondary school: Challenge or threat? International Journal of Behavioral Development, 27(5), 385-395.

Smeets, E., van Kuijk, J. \& Driessen, G. (2014). Handreiking bij het opstellen van het basisschooladvies. Nijmegen: ITS, Radboud Universiteit.

Snow, W. H., Gilchrist, L., Schilling, R. F., Schinke, S. P., \& Kelso, C. (1986). Preparing students for the junior high school. Journal of Early Adolescence, 6(2), 127-137.

Strauss, A., (1987). Qualitative Analysis for Social Scientists. New York, NY: Cambridge University Press.

Tilanus, C. (1997). Onderzoeksmethoden bij agogisch handelen. Utrecht, Nederland: SWP.

Timmins, M. C. (1989). Solid preparation for junior high. Perspectives for Teachers of the Hearing Impaired, 7, 2-5. 
Tobbell, J. (2003). Students' experiences of the transition from primary to secondary school. Educational and Child Psychology, 20(4), 4-14.

Tobbell, J. \& O'Donnell, V., (2013). The formation of interpersonal and learning relationships in the transition from primary to secondary school: Students, teachers and school context. International Journal of Educational Research, 59, 11-23.

Topping, K., (2011). Primary-secondary transition: Differences between teachers' and children's perceptions. Improving Schools, 14(3), 268-285.

Traag, T., \& Van der Velden, R. (2008). Early school-leaving in the Netherlands. The role of student-, family- and school factors for early school-leaving in lower secondary education. Maastricht: Research Centre for Education and the Labour Market.

United Nations (1989). Convention on the Rights of the Child. Retrieved: 03-02-2020 https://www.ohchr.org/en/professionalinterest/pages/crc.aspx .

United Nations on the Rights of the Child (1989) UN General Assembly Resolution 44/25. Retrieved 03-02-2020 from https://www.unicef.org.uk/what-we-do/un-convention-child-rights/

Van der Want A., den Brok, P., Beijaard, D., Brekelmans, M., Claessens, L. \& Pennings H. (2015). Teachers' interpersonal role identity. Scandinavian Journal of Educational Research, 59(4), 24-442.

Van Rens, M., Haelermans, C., Groot, W. \& Maassen van den Brink, H. (2018). Facilitating a Successful Transition to Secondary School: (How) Does it Work? A Systematic Literature Review. Adolescent Research Review, 3(1), 43-56.

Van Rens, M., Haelermans, C., Groot, W., \& Maassen van den Brink, H. (2019). Girls' and Boys' Perceptions of the Transition from Primary to Secondary School. Child Indicators Research,12(4), 1481-1506.

Van Rens, M., Groot, W. \& Haelermans, C. (2020). (How) does information provided by children affect the transition from primary to secondary school? Child Indicators Research, 13(1),105-130. https://doi.org/10.1007/s12187-019-09646-2.

Van Rens, M. \& Groot, W. (2019). (How) do mentors acquire and use information about pupils to improve the transition from primary to secondary school? Pending publication 2020.

Van Rooijen, M., Korpershoek, H., Vugteveen, J., Timmermans, A. \& Opdenakker, M. (2016). Overgangen en aansluitingen in het onderwijs. Deelrapportage 2: empirische studie naar de cognitieve en niet-cognitieve ontwikkeling van leerlingen rondom de po-vo overgang. GION Onderwijs/Onderzoek Projectnummer: NRO-ProBO 405-14-402. 
Van Ryzin, M., (2010). Secondary school advisors as mentors and secondary attachment figures. Journal of community psychology, 38(2), 131-154.

Vaz, S., Parsons, R., Falkmer, T., Passmore, A. \& Falkmer, M. (2014). The impact of personal background and school contextual factors on academic competence and mental health functioning across the primary-secondary school transition. PLos one, 9, (3), e89874. doi: 10.1371/journal.phone.0089874.

Ward, B. A., Mergendoller, J. R., Tikunoff, W. J., Rounds, T. S., Mitman, A. L., \& Dadey, G. J. (1982). Junior high school transition study, Executive summary, vol. VII. San Francisco: Far West Laboratory for Educational Research and Development.

Waters, S., Lester, L., Wenden, E. \& Cross, D., (2012). A theoretical grounded exploration of the social and emotional outcomes of transition to secondary school. Australian Journal of Guidance and Counselling, 22(2), 190-205.

Weller, S. (2007). Sticking with your mates? Children's friendship trajectories during the transition from primary to secondary school. Children and Society, 21(5), 339-351.

West, P., Sweeting, H. \& Young, R. (2010). Transition matters: pupils' experiences of the primary-secondary school transition in the West of Scotland and consequences for well-being and attainment (2010). Research Articles in Education, 25(1), 21-50.

Zeedijk, M. S., Gallacher, J., Henderson, M., Hope, G., Husband, B. \& Lindsay, K. (2003). Negotiating the transition from primary to secondary school. Perceptions of pupils, parents and teachers. School Psychology International, 24(1), 67-79. 
Appendix 


\section{Appendix 1}

\section{Chapter 3: Logistic regression}

Table 3. I: Logistic regression: Does the sample loss cause a systematic bias on the second measurement?

\begin{tabular}{|l|l|c|c|}
\hline \multirow{3}{*}{} & & $p$ & $B$ \\
\cline { 2 - 4 } & Gender & 0.155 & -0.348 \\
\hline \multirow{2}{*}{ Primary school type } & Age & 0.408 & -0.206 \\
\hline \multirow{2}{*}{ Secondary school type } & SBO (special education) & 0.046 & 1.409 \\
\hline \multirow{3}{*}{} & VMBO & 0.112 & -0.820 \\
\hline & HAVO & 0.431 & -0.434 \\
\cline { 2 - 4 } & VWO & 0.475 & -0.379 \\
\hline & PrO & 0.272 & 1.396 \\
\hline & Constant & 0.588 & 1.647 \\
\hline
\end{tabular}

${ }^{*} p<0.05 ;{ }^{* *} p<0.01 ; * * *<0.001$ 


\section{Chapter 3: Extended tables including standard deviations and t-statistics}

\section{Table 3.1A School choice}

\begin{tabular}{|c|c|c|c|c|c|c|c|c|c|c|c|c|c|c|}
\hline & & \multicolumn{5}{|c|}{ First wave } & \multicolumn{4}{|c|}{ Second wave } & \multicolumn{4}{|c|}{ Wave 2-1 } \\
\hline \multicolumn{2}{|l|}{ SCHOOL CHOICE } & \multirow[b]{2}{*}{$N=98$} & \multirow[t]{2}{*}{ Mean } & \multirow[t]{2}{*}{$S D$} & \multirow{2}{*}{$\begin{array}{l}T- \\
\text { test }\end{array}$} & \multirow{2}{*}{$\begin{array}{l}P \text { - } \\
\text { value }\end{array}$} & \multirow[t]{2}{*}{ Mean } & \multirow[t]{2}{*}{$S D$} & \multirow{2}{*}{$\begin{array}{l}T- \\
\text { test }\end{array}$} & \multirow{2}{*}{$\begin{array}{l}P \text { - } \\
\text { value }\end{array}$} & \multirow[t]{2}{*}{ Mean } & \multirow[t]{2}{*}{$S D$} & \multirow{2}{*}{$\begin{array}{l}T- \\
\text { test }\end{array}$} & \multirow{2}{*}{$\begin{array}{l}P \text { - } \\
\text { value }\end{array}$} \\
\hline What is important? & & & & & & & & & & & & & & \\
\hline \multirow[t]{2}{*}{ The building } & Boy & $N=45$ & 0.22 & 0.42 & -1.09 & 0.28 & 0.28 & 0.45 & 0.53 & 0.59 & 0.07 & 0.46 & 1.87 & 0.07 \\
\hline & Girl & $N=53$ & 0.32 & 0.47 & & & 0.23 & 0.43 & & & -0.10 & 0.41 & & \\
\hline \multirow[t]{2}{*}{ The distance } & Boy & & 0.09 & 0.29 & -1.44 & 0.15 & 0.12 & 0.32 & 0.01 & 0.99 & 0.02 & 0.34 & 1.22 & 0.22 \\
\hline & Girl & & 0.19 & 0.40 & & & 0.12 & 0.32 & & & -0.08 & 0.44 & & \\
\hline \multirow[t]{2}{*}{ Classmates } & Boy & & 0.20 & 0.41 & 0.90 & 0.37 & 0.28 & 0.45 & 1.72 & 0.09 & 0.07 & 0.55 & 0.68 & 0.50 \\
\hline & Girl & & 0.13 & 0.34 & & & 0.13 & 0.35 & & & 0.00 & 0.44 & & \\
\hline \multirow[t]{2}{*}{ Friends at the same school } & Boy & & 0.27 & 0.45 & 0.46 & 0.65 & 0.30 & 0.47 & -0.06 & 0.96 & 0.02 & 0.56 & -0.53 & 0.60 \\
\hline & Girl & & 0.23 & 0.42 & & & 0.31 & 0.47 & & & 0.08 & 0.44 & & \\
\hline \multirow{2}{*}{$\begin{array}{l}\text { Special classes (sport-dance-art- } \\
\text { music) }\end{array}$} & Boy & & 0.09 & 0.29 & -0.93 & 0.36 & 0.07 & 0.26 & -0.75 & 0.46 & -0.02 & 0.15 & 0.32 & 0.75 \\
\hline & Girl & & 0.15 & 0.36 & & & 0.12 & 0.32 & & & -0.04 & 0.2 & & \\
\hline \multirow[t]{2}{*}{ Bilingual } & Boy & & 0.02 & 0.15 & -0.85 & 0.40 & 0.02 & 0.15 & 0.14 & 0.89 & 0.00 & 0.00 & 1.43 & 0.16 \\
\hline & Girl & & 0.06 & 0.23 & & & 0.02 & 0.14 & & & -0.04 & 0.19 & & \\
\hline \multirow[t]{2}{*}{ Small school } & Boy & & 0.16 & 0.37 & 1.94 & 0.06 & 0.09 & 0.29 & 1.04 & 0.30 & -0.05 & 0.21 & -1.10 & 0.27 \\
\hline & Girl & & 0.04 & 0.19 & & & 0.04 & 0.19 & & & 0.00 & 0.20 & & \\
\hline \multirow[t]{2}{*}{ Good guidance } & Boy & & 0.62 & 0.49 & -0.59 & 0.56 & 0.70 & 0.47 & 1.03 & 0.31 & 0.09 & 0.53 & 1.42 & 0.16 \\
\hline & Girl & & 0.68 & 0.47 & & & 0.60 & 0.50 & & & -0.08 & 0.62 & & \\
\hline \multirow[t]{2}{*}{ I know somebody } & Boy & & 0.51 & 0.51 & 0.39 & 0.70 & 0.33 & 0.47 & -1.73 & 0.09 & -0.16 & 0.69 & -1.37 & 0.18 \\
\hline & Girl & & 0.47 & 0.50 & & & 0.50 & 0.51 & & & 0.02 & 0.61 & & \\
\hline \multirow[t]{2}{*}{ I bicycle with classmates } & Boy & & 0.36 & 0.48 & -0.22 & 0.83 & 0.40 & 0.50 & 0.89 & 0.38 & 0.02 & 0.60 & 0.85 & 0.40 \\
\hline & Girl & & 0.38 & 0.49 & & & 0.31 & 0.47 & & & -0.08 & 0.55 & & \\
\hline \multirow[t]{2}{*}{ Education for special needs } & Boy & & 0.04 & 0.21 & 0.17 & 0.87 & 0.07 & 0.26 & 0.68 & 0.50 & 0.02 & 0.27 & 0.08 & 0.94 \\
\hline & Girl & & 0.04 & 0.19 & & & 0.04 & 0.19 & & & 0.02 & 0.24 & & \\
\hline 'Technasium'/ technical education & Boy & & 0.09 & 0.29 & 1.02 & 0.32 & 0.07 & 0.26 & 1.16 & 0.25 & -0.02 & 0.27 & -0.10 & 0.93 \\
\hline & Girl & & 0.04 & 0.19 & & & 0.02 & 0.14 & & & -0.02 & 0.14 & & \\
\hline
\end{tabular}

${ }^{*} p<0.05 ; * * p<0.01 ; * * * p<0.001$ 
Table 3.1B: School choice: Paired Samples Test: Total group first wave second wave; boys wave 1-2; girls wave 1- 2

\begin{tabular}{|c|c|c|c|c|c|c|c|c|c|c|c|c|c|c|c|c|c|}
\hline \multirow{2}{*}{\multicolumn{2}{|c|}{$\begin{array}{l}\text { SCHOOL CHOICE } \\
\text { What is important? }\end{array}$}} & \multicolumn{4}{|c|}{ Total: wave 1-wave 2} & & \multicolumn{5}{|c|}{ Boys: wave 1-2 } & & \multicolumn{5}{|c|}{ Girls wave 1-2 } \\
\hline & & \multirow{2}{*}{$\begin{array}{l}\text { Mean } \\
\text { total } \\
\quad 0.02\end{array}$} & \multicolumn{2}{|c|}{$\begin{array}{ll}\text { SD } & T- \\
& \text { test }\end{array}$} & \multirow{2}{*}{$\begin{array}{r}P \text {-value } \\
0.64\end{array}$} & \multirow{2}{*}{ Boy } & \multirow[b]{2}{*}{ Pair 1} & \multirow{2}{*}{\begin{tabular}{|c|}
$\begin{array}{l}\text { Mean } \\
\text { boys }\end{array}$ \\
-0.07
\end{tabular}} & \multirow{2}{*}{$\begin{array}{l}S D \\
0.46\end{array}$} & \multirow{2}{*}{$\begin{array}{l}T- \\
\text { test } \\
-1.00\end{array}$} & \multirow{2}{*}{$\begin{array}{r}\text { P-value } \\
0.32\end{array}$} & \multirow[t]{2}{*}{ Girl } & \multicolumn{2}{|r|}{$\begin{array}{l}\text { Mean } \\
\text { girls }\end{array}$} & \multirow{2}{*}{$\begin{array}{l}S D \\
0.41\end{array}$} & \multirow{2}{*}{$\begin{array}{l}T- \\
\text { test } \\
1.70\end{array}$} & \multirow{2}{*}{$\begin{array}{r}P \text {-value } \\
0.10\end{array}$} \\
\hline Pair 1 & The building & & 0.44 & 0.47 & & & & & & & & & Pair 1 & 0.10 & & & \\
\hline Pair 2 & The distance & 0.03 & 0.40 & 0.77 & 0.44 & & Pair 2 & -0.02 & 0.34 & -0.44 & 0.66 & & Pair 2 & 0.08 & 0.44 & 1.27 & 0.21 \\
\hline Pair 3 & Classmates & -0.03 & 0.49 & -0.62 & 0.53 & & Pair 3 & -0.07 & 0.55 & -0.83 & 0.41 & & Pair 3 & 0.00 & 0.44 & 0.00 & 1.00 \\
\hline Pair 4 & Friends at the same school & -0.05 & 0.49 & -1.04 & 0.30 & & Pair 4 & -0.02 & 0.56 & -0.27 & 0.79 & & Pair 4 & -0.08 & 0.44 & -1.27 & 0.21 \\
\hline Pair 5 & $\begin{array}{l}\text { Special classes (sport-dance- } \\
\text { art-music) }\end{array}$ & 0.03 & 0.23 & 1.35 & 0.18 & & Pair 5 & 0.02 & 0.15 & 1.00 & 0.32 & & Pair 5 & 0.04 & 0.28 & 1.00 & 0.32 \\
\hline Pair 6 & Bilingual & 0.02 & 0.14 & 1.42 & 0.16 & & Pair 6 & & & & & & Pair 6 & & & & \\
\hline Pair 7 & Small school & 0.02 & 0.21 & 1.00 & 0.32 & & Pair 7 & 0.05 & 0.21 & 1.43 & 0.16 & & Pair 7 & 0.00 & 0.20 & 0.00 & 1.00 \\
\hline Pair 8 & Good guidance & 0.00 & 0.58 & 0.00 & 1.00 & & Pair 8 & -0.09 & 0.53 & -1.16 & 0.25 & & Pair 8 & 0.08 & 0.62 & 0.89 & 0.38 \\
\hline Pair 9 & I know somebody & 0.06 & 0.65 & 0.95 & 0.35 & & Pair 9 & 0.16 & 0.69 & 1.55 & 0.13 & & Pair 9 & -0.02 & 0.61 & -0.23 & 0.82 \\
\hline Pair 10 & I bicycle with classmates & 0.03 & 0.57 & 0.54 & 0.59 & & Pair 10 & -0.02 & 0.60 & -0.26 & 0.80 & & Pair 10 & 0.08 & 0.56 & 1.00 & 0.32 \\
\hline Pair 11 & Education for special needs & -0.02 & 0.25 & -0.82 & 0.42 & & Pair 11 & -0.02 & 0.27 & -0.57 & 0.57 & & Pair 11 & -0.02 & 0.24 & -0.57 & 0.57 \\
\hline Pair 12 & $\begin{array}{l}\text { 'Technasium'/ Technical } \\
\text { education }\end{array}$ & 0.02 & 0.21 & 1.00 & 0.32 & & Pair 12 & 0.02 & 0.27 & 0.57 & 0.57 & & Pair 12 & 0.02 & 0.14 & 1.00 & 0.32 \\
\hline
\end{tabular}


Table 3.2A: Preparing for secondary school

\begin{tabular}{|c|c|c|c|c|c|c|c|c|c|c|c|c|c|c|}
\hline & & & First & vave & & & Secon & wav & & & Wave & $2-1$ & & \\
\hline $\begin{array}{l}\text { PREPARING FO } \\
\text { SECONDARY SC } \\
\text { How are you pre }\end{array}$ & $\begin{array}{l}\text { oOL } \\
\text { red? }\end{array}$ & $N=98$ & Mean & $S D$ & $T$-test & $\begin{array}{l}P- \\
\text { value }\end{array}$ & Mean & $S D$ & $T$-test & $\begin{array}{l}P \text { - } \\
\text { value }\end{array}$ & Mean & $S D$ & T-test & $\begin{array}{l}P \text { - } \\
\text { value }\end{array}$ \\
\hline Homework & Boy & $N=45$ & 0.82 & 0.39 & 1.24 & 0.22 & 0.81 & 0.39 & -0.41 & 0.68 & -0.02 & 0.51 & -1.48 & 0.14 \\
\hline & Girl & $N=53$ & 0.72 & 0.46 & & & 0.85 & 0.36 & & & 0.13 & 0.53 & & \\
\hline Using calendar & Boy & & 0.62 & 0.49 & -1.62 & 0.11 & 0.60 & 0.50 & 0.27 & 0.79 & 0.00 & 0.76 & 1.36 & 0.18 \\
\hline & Girl & & 0.77 & 0.42 & & & 0.58 & 0.50 & & & -0.19 & 0.63 & & \\
\hline Work together & Boy & & 0.60 & 0.50 & -0.04 & 0.97 & 0.26 & 0.44 & 0.28 & 0.78 & -0.37 & 0.66 & -0.05 & 0.96 \\
\hline & Girl & & 0.60 & 0.49 & & & 0.23 & 0.43 & & & -0.37 & 0.56 & & \\
\hline How to make & Boy & & 0.04 & 0.21 & -0.95 & 0.34 & 0.02 & 0.15 & -0.42 & 0.68 & -0.02 & 0.27 & 0.52 & 0.61 \\
\hline & Girl & & 0.09 & 0.30 & & & 0.04 & 0.19 & & & -0.06 & 0.37 & & \\
\hline Work done on & Boy & & 0.73 & 0.45 & 0.98 & 0.33 & 0.53 & 0.51 & -1.17 & 0.24 & -0.19 & 0.73 & -1.47 & 0.15 \\
\hline & Girl & & 0.64 & 0.48 & & & 0.65 & 0.48 & & & 0.02 & 0.61 & & \\
\hline Stuff in good & Boy & & 0.47 & 0.51 & -0.42 & 0.68 & 0.47 & 0.51 & -0.89 & 0.37 & 0.00 & 0.65 & -0.45 & 0.66 \\
\hline & Girl & & 0.51 & 0.51 & & & 0.56 & 0.50 & & & 0.06 & 0.61 & & \\
\hline Self-regulating & Boy & & 0.69 & 0.47 & -0.30 & 0.76 & 0.47 & 0.51 & -0.52 & 0.60 & -0.23 & 0.68 & -0.30 & 0.77 \\
\hline work & Girl & & 0.72 & 0.46 & & & 0.52 & 0.51 & & & -0.19 & 0.63 & & \\
\hline Sharing & Boy & & 0.64 & 0.48 & 0.60 & 0.55 & 0.49 & 0.51 & -0.30 & 0.77 & -0.19 & 0.55 & -0.85 & 0.40 \\
\hline information & Girl & & 0.58 & 0.50 & & & 0.52 & 0.51 & & & -0.08 & 0.68 & & \\
\hline Practice cycling & Boy & & 0.18 & 0.39 & 1.18 & 0.24 & 0.07 & 0.26 & 0.67 & 0.50 & -0.12 & 0.39 & -0.75 & 0.45 \\
\hline & Girl & & 0.09 & 0.30 & & & 0.04 & 0.19 & & & -0.06 & 0.37 & & \\
\hline Meeting with & Boy & & 0.76 & 0.44 & -0.43 & 0.67 & 0.72 & 0.45 & 0.89 & 0.38 & -0.05 & 0.62 & 0.88 & 0.38 \\
\hline & Girl & & 0.79 & 0.41 & & & 0.63 & 0.49 & & & -0.15 & 0.57 & & \\
\hline
\end{tabular}

${ }^{*} p<0.05 ; * * p<0.01 ; * * * p<0.001$ 
Table 3.2B: Preparing for secondary school Paired Samples Test: Total group first wave second wave; boys wave 1-2; girls wave 1- 2

\section{Paired Samples Test: Total group wave1- 2; boys wave 1-2; girls wave 1- 2}

\begin{tabular}{|c|c|c|c|c|c|c|c|c|c|c|c|c|c|c|c|c|c|}
\hline \multicolumn{18}{|c|}{ PREPARING FOR SECONDARY SCHOOL } \\
\hline \multicolumn{2}{|c|}{ How are you prepared? } & \multirow{2}{*}{$\begin{array}{l}\begin{array}{l}\text { Mean } \\
\text { total }\end{array} \\
-0.06\end{array}$} & \multirow{2}{*}{$\begin{array}{l}S D \\
0.52\end{array}$} & \multirow{2}{*}{$\begin{array}{l}\text { T-test } \\
-1.18\end{array}$} & \multirow{2}{*}{$\begin{array}{l}P \text {-value } \\
0.24\end{array}$} & \multirow[b]{2}{*}{ Boy } & \multirow[b]{2}{*}{ Pair 1} & \multirow{2}{*}{$\begin{array}{l}\begin{array}{l}\text { Mean } \\
\text { boys }\end{array} \\
0.02\end{array}$} & \multirow{2}{*}{$\begin{array}{l}S D \\
0.51\end{array}$} & \multirow{2}{*}{$\begin{array}{r}T \text {-test } \\
0.30\end{array}$} & \multirow{2}{*}{$\begin{array}{l}\text { P-value } \\
0.77\end{array}$} & \multirow[b]{2}{*}{ Girl } & \multirow[b]{2}{*}{ Pair 1} & \multirow{2}{*}{$\begin{array}{l}\text { Mean } \\
\text { girls } \\
-0.14\end{array}$} & \multirow{2}{*}{$\begin{array}{l}S D \\
0.53\end{array}$} & \multirow{2}{*}{$\begin{array}{l}\text { T-test } \\
-1.85\end{array}$} & \multirow{2}{*}{$\begin{array}{l}\text { P-value } \\
0.07\end{array}$} \\
\hline Pair 1 & Homework & & & & & & & & & & & & & & & & \\
\hline Pair 2 & Using callendar & 0.11 & 0.69 & 1.48 & 0.14 & & Pair 2 & 0.00 & 0.76 & 0.00 & 1.00 & & Pair 2 & 0.19 & 0.63 & 2.21 & $0.03^{*}$ \\
\hline Pair 3 & Work together & 0.37 & 0.60 & 5.96 & $0.00 * * *$ & & Pair 3 & 0.37 & 0.66 & 3.72 & $0.00^{* * *}$ & & Pair 3 & 0.37 & 0.56 & 4.70 & $0.00 * * *$ \\
\hline Pair 4 & How to make friends & 0.04 & 0.32 & 1.27 & 0.21 & & Pair 4 & 0.02 & 0.27 & 0.57 & 0.57 & & Pair 4 & 0.06 & 0.37 & 1.14 & 0.26 \\
\hline Pair 5 & Work done on time & 0.07 & 0.67 & 1.07 & 0.29 & & Pair 5 & 0.19 & 0.73 & 1.67 & 0.10 & & Pair 5 & -0.02 & 0.61 & -0.23 & 0.82 \\
\hline Pair 6 & Stuff in good order & -0.03 & 0.63 & -0.49 & 0.62 & & Pair 6 & 0.00 & 0.66 & 0.00 & 1.00 & & Pair 6 & -0.06 & 0.61 & -0.69 & 0.50 \\
\hline Pair 7 & Self-regulating work & 0.21 & 0.65 & 3.15 & $0.00 * * *$ & & Pair 7 & 0.23 & 0.68 & 2.23 & $0.03 *$ & & Pair 7 & 0.19 & 0.63 & 2.21 & $0.03^{*}$ \\
\hline Pair 8 & Sharing information & 0.13 & 0.62 & 1.98 & $005 *$ & & Pair 8 & 0.19 & 0.55 & 2.24 & $0.03^{*}$ & & Pair 8 & 0.08 & 0.68 & 0.81 & 0.42 \\
\hline Pair 9 & Practice cycling & 0.08 & 0.38 & 2.18 & $0.03 *$ & & Pair 9 & 0.12 & 0.39 & 1.95 & 0.06 & & Pair 9 & 0.06 & 0.37 & 1.14 & 0.26 \\
\hline Pair 10 & Meeting with school & 0.11 & 0.59 & 1.73 & 0.09 & & Pair 10 & 0.05 & 0.62 & 0.50 & 0.62 & & Pair 10 & 0.15 & 0.57 & 1.94 & 0.06 \\
\hline
\end{tabular}

${ }^{*} p<0.05 ;{ }^{* *} p<0.01 ; * * * p<0.001$ 
Table 3.3A: Mentor

\begin{tabular}{|c|c|c|c|c|c|c|c|c|c|c|c|c|c|c|}
\hline \multicolumn{7}{|c|}{ First wave } & \multicolumn{4}{|c|}{ Second wave } & \multicolumn{4}{|c|}{ Wave 2-1 } \\
\hline \multicolumn{2}{|l|}{ MENTOR } & & & & & & & & & & & & & \\
\hline \multicolumn{2}{|l|}{ What do you expect? } & $N=98$ & Miean & $S D$ & $T$-test & P-value & IVIean & $S D$ & $T$-test & P-value & Mean & $S D$ & $T$-test & P-value \\
\hline \multirow[t]{2}{*}{ Will be nice } & Boy & $N=45$ & 0.69 & 0.47 & 1.82 & 0.07 & 0.52 & 0.51 & -0.05 & 0.96 & -0.17 & 0.62 & -1.54 & 0.13 \\
\hline & Girl & $N=53$ & 0.51 & 0.51 & & & 0.53 & 0.50 & & & 0.02 & 0.55 & & \\
\hline \multirow[t]{2}{*}{ Will be present } & Boy & & 0.51 & 0.51 & -1.30 & 0.20 & 0.52 & 0.51 & -0.24 & 0.81 & 0.02 & 0.72 & 0.87 & 0.39 \\
\hline & Girl & & 0.64 & 0.48 & & & 0.55 & 0.50 & & & -0.10 & 0.64 & & \\
\hline \multirow[t]{2}{*}{ Will have a good conversation } & Boy & & 0.42 & 0.50 & -3.72 & $0.00 * * *$ & 0.57 & 0.50 & 0.59 & 0.56 & 0.12 & 0.77 & 2.64 & $0.01 * *$ \\
\hline & Girl & & 0.77 & 0.42 & & & 0.51 & 0.51 & & & -0.25 & 0.59 & & \\
\hline \multirow[t]{2}{*}{ Will have knowledge of school } & Boy & & 0.16 & 0.37 & 1.56 & 0.12 & 0.12 & 0.33 & 1.00 & 0.32 & -0.05 & 0.54 & -0.52 & 0.61 \\
\hline & Girl & & 0.06 & 0.23 & & & 0.06 & 0.24 & & & 0.00 & 0.28 & & \\
\hline \multirow[t]{2}{*}{ Will talk with parents } & Boy & & 0.09 & 0.29 & -0.39 & 0.70 & 0.10 & 0.30 & 0.66 & 0.51 & 0.05 & 0.38 & 1.37 & 0.18 \\
\hline & Girl & & 0.11 & 0.32 & & & 0.06 & 0.24 & & & -0.06 & 0.37 & & \\
\hline \multirow[t]{2}{*}{ Will solve our problems } & Boy & & 0.40 & 0.50 & 0.42 & 0.68 & 0.40 & 0.50 & -1.19 & 0.24 & 0.00 & 0.70 & -1.50 & 0.14 \\
\hline & Girl & & 0.36 & 0.48 & & & 0.53 & 0.50 & & & 0.20 & 0.57 & & \\
\hline \multirow[t]{2}{*}{ Will provide a good atmosphere } & Boy & & 0.31 & 0.47 & -0.10 & 0.92 & 0.38 & 0.49 & -0.49 & 0.63 & 0.07 & 0.71 & -0.19 & 0.85 \\
\hline & Girl & & 0.32 & 0.47 & & & 0.43 & 0.50 & & & 0.10 & 0.64 & & \\
\hline \multirow[t]{2}{*}{ Will be our contact } & Boy & & 0.36 & 0.48 & 1.62 & 0.11 & 0.33 & 0.48 & 0.82 & 0.41 & -0.02 & 0.68 & -0.48 & 0.64 \\
\hline & Girl & & 0.21 & 0.41 & & & 0.25 & 0.44 & & & 0.04 & 0.60 & & \\
\hline
\end{tabular}

${ }^{*} p<0.05 ;{ }^{* *} p<0.01 ;{ }^{* * *} p<0.001$ 


\section{Table 3.3B: Mentor}

\section{Paired Samples Test: Total group wave 1- wave 2; boys wave 1-2; girls wave 1- 2}

\section{MENTOR}

\begin{tabular}{|c|c|c|c|c|c|c|c|c|c|c|c|c|c|c|c|c|c|}
\hline \multicolumn{2}{|c|}{ What do you expect? } & \multirow{2}{*}{$\begin{array}{c}\text { Mean } \\
\text { Total } \\
0.07\end{array}$} & \multirow{2}{*}{$\begin{array}{l}S D \\
0.59\end{array}$} & \multirow{2}{*}{$\begin{array}{r}T \text {-test } \\
1.06\end{array}$} & \multirow{2}{*}{$\begin{array}{r}P \text {-value } \\
0.29\end{array}$} & \multirow{2}{*}{$\begin{array}{l}\text { gender } \\
\text { Boy }\end{array}$} & \multirow[b]{2}{*}{ Pair 1} & \multirow{2}{*}{$\begin{array}{c}\text { Mean } \\
\text { Boys } \\
0.17\end{array}$} & \multirow{2}{*}{$\begin{array}{l}S D \\
0.62\end{array}$} & \multirow{2}{*}{$\begin{array}{r}T \text {-test } \\
1.74\end{array}$} & \multirow{2}{*}{$\begin{array}{r}P \text {-value } \\
0.09\end{array}$} & \multirow{2}{*}{$\begin{array}{l}\text { gender } \\
\text { Girl }\end{array}$} & \multirow[b]{2}{*}{ Pair 1} & \multirow{2}{*}{$\begin{array}{l}\text { Mean } \\
\text { Girls } \\
-0.02\end{array}$} & \multirow{2}{*}{$\begin{array}{l}S D \\
0.55\end{array}$} & \multirow{2}{*}{$\begin{array}{l}T \text {-test } \\
-0.26\end{array}$} & \multirow{2}{*}{$\begin{array}{l}P \text {-value } \\
0.80\end{array}$} \\
\hline Pair 1 & Will be nice & & & & & & & & & & & & & & & & \\
\hline Pair 2 & Will be present & 0.04 & 0.67 & 0.62 & 0.54 & & Pair 2 & -0.02 & 0.72 & -0.22 & 0.83 & & Pair 2 & 0.10 & 0.64 & 1.09 & 0.28 \\
\hline Pair 3 & Will have a good conversation & 0.09 & 0.70 & 1.18 & 0.24 & & Pair 3 & -0.12 & 0.77 & -1.00 & 0.32 & & Pair 3 & 0.26 & 0.60 & 3.06 & $0.00^{* * *}$ \\
\hline Pair 4 & Will have knowledge of school & 0.02 & 0.42 & 0.50 & 0.62 & & Pair 4 & 0.05 & 0.54 & 0.57 & 0.57 & & Pair 4 & 0.00 & 0.28 & 0.00 & 1.00 \\
\hline Pair 5 & Will talk with parents & 0.01 & 0.38 & 0.28 & 0.78 & & Pair 5 & -0.05 & 0.38 & -0.81 & 0.42 & & Pair 5 & 0.06 & 0.37 & 1.14 & 0.26 \\
\hline Pair 6 & Will solve our problems & -0.11 & 0.63 & -1.64 & 0.11 & & Pair 6 & 0.00 & 0.70 & 0.00 & 1.00 & & Pair 6 & -0.20 & 0.57 & -2.47 & $0.02 *$ \\
\hline Pair 7 & Will provide a good atmosphere & -0.09 & 0.67 & -1.24 & 0.22 & & Pair 7 & -0.07 & 0.71 & -0.65 & 0.52 & & Pair 7 & -0.10 & 0.64 & -1.09 & 0.28 \\
\hline Pair 8 & Will be our contact & -0.01 & 0.63 & -0.16 & 0.87 & & Pair 8 & 0.02 & 0.68 & 0.23 & 0.82 & & Pair 8 & -0.04 & 0.60 & -0.47 & 0.64 \\
\hline
\end{tabular}

${ }^{*} p<0.05 ;{ }^{* *} p<0.01 ; * * * p<0.001$ 


\section{Table 3.4A: Context}

$\begin{array}{lll}\text { First wave } & \text { Second wave } & \text { Wave 2-1 }\end{array}$

\begin{tabular}{|c|c|c|c|c|c|c|c|c|c|c|c|c|c|c|}
\hline \multicolumn{2}{|l|}{ CONTEXT } & $N$ & Mean & $S D$ & $T$-test & P-value & Mean & $S D$ & T-test & P-value & Mean & $S D$ & T-test & P-value \\
\hline \multirow{2}{*}{$\begin{array}{l}\text { I can show what I have } \\
\text { learned }\end{array}$} & Boy & 42 & 2.71 & 0.71 & & & 2.71 & 0.74 & & & -0.05 & 1.02 & & \\
\hline & Girl & 52 & 2.60 & 0.85 & 0.72 & 0.47 & 2.61 & 0.92 & 0.62 & 0.54 & 0.02 & 0.96 & -0.34 & 0.74 \\
\hline \multirow[t]{2}{*}{ I will learn new things } & Boy & & 3.29 & 0.55 & & & 3.05 & 0.83 & & & -0.26 & 0.91 & & \\
\hline & Girll & & 3.25 & 0.65 & 0.28 & 0.78 & 3.25 & 0.69 & -1.32 & 0.19 & 0.00 & 0.76 & -1.42 & 0.16 \\
\hline \multirow{2}{*}{$\begin{array}{l}\text { I am curious about new } \\
\text { subjects }\end{array}$} & Boy & & 2.95 & 0.83 & & & 2.95 & 0.83 & & & -0.03 & 0.90 & & \\
\hline & Girl & & 3.15 & 0.75 & -1.24 & 0.22 & 2.80 & 0.85 & 0.85 & 0.40 & -0.32 & 0.82 & 1.61 & 0.11 \\
\hline \multirow{2}{*}{$\begin{array}{l}\text { I can show I perform } \\
\text { well }\end{array}$} & Boy & & 3.02 & 0.60 & & & 2.86 & 0.72 & & & -0.26 & 0.91 & & \\
\hline & Girl & & 2.87 & 0.69 & 1.17 & 0.24 & 2.94 & 0.71 & -0.57 & 0.57 & 0.10 & 0.84 & -1.92 & 0.06 \\
\hline \multirow{2}{*}{$\begin{array}{l}\text { I will quickly know the } \\
\text { way }\end{array}$} & Boy & & 2.98 & 0.84 & & & 3.26 & 0.77 & & & 0.26 & 0.97 & & \\
\hline & Girl & & 2.90 & 0.89 & 0.40 & 0.69 & 3.04 & 0.85 & 1.32 & 0.19 & 0.16 & 1.02 & 0.45 & 0.65 \\
\hline \multirow{2}{*}{$\begin{array}{l}\text { I like different } \\
\text { classrooms }\end{array}$} & Boy & & 2.74 & 0.80 & & & 2.79 & 0.93 & & & 0.00 & 0.76 & & \\
\hline & Girl & & 2.92 & 0.95 & -1.01 & 0.32 & 2.78 & 0.83 & 0.01 & 0.99 & -0.12 & 1.08 & 0.61 & 0.54 \\
\hline \multirow{2}{*}{$\begin{array}{l}\text { To meeting nice } \\
\text { children }\end{array}$} & Boy & & 3.10 & 0.69 & & & 3.12 & 0.64 & & & 0.00 & 0.70 & & \\
\hline & Girl & & 3.31 & 0.67 & -1.50 & 0.14 & 3.20 & 0.64 & -0.58 & 0.56 & -0.06 & 0.75 & 0.39 & 0.70 \\
\hline \multirow{2}{*}{$\begin{array}{l}\text { To having fun with the } \\
\text { other kids }\end{array}$} & Boy & & 3.17 & 0.62 & & & 3.15 & 0.69 & & & -0.05 & 0.73 & & \\
\hline & Girl & & 3.37 & 0.69 & -1.46 & 0.15 & 3.22 & 0.68 & -0.51 & 0.61 & -0.10 & 0.85 & 0.29 & 0.78 \\
\hline \multirow[t]{2}{*}{ Kids who will like me } & Boy & & 3.00 & 0.70 & & & 2.98 & 0.69 & & & 0.00 & 0.81 & & \\
\hline & Girl & & 3.00 & 0.71 & 0.00 & 1.00 & 2.98 & 0.82 & -0.03 & 0.98 & 0.02 & 0.97 & -0.11 & 0.92 \\
\hline \multirow{2}{*}{$\begin{array}{l}\text { To knowing many nice } \\
\text { children }\end{array}$} & Boy & & 3.17 & 0.76 & & & 3.02 & 0.69 & & & -0.11 & 0.89 & & \\
\hline & Girl & & 3.27 & 0.63 & -0.71 & 0.48 & 3.22 & 0.68 & -1.36 & 0.18 & -0.04 & 0.76 & -0.36 & 0.72 \\
\hline \multirow{2}{*}{$\begin{array}{l}\text { To getting into a nice } \\
\text { group }\end{array}$} & Boy & & 3.33 & 0.65 & & & 3.24 & 0.66 & & & -0.11 & 0.86 & & \\
\hline & Girl & & 3.46 & 0.58 & -1.01 & 0.31 & 3.28 & 0.67 & -0.26 & 0.80 & -0.18 & 0.78 & 0.44 & 0.66 \\
\hline \multirow{2}{*}{$\begin{array}{l}\text { To the different } \\
\text { teachers }\end{array}$} & Boy & & 2.74 & 0.73 & & & 2.85 & 0.82 & & & 0.16 & 0.79 & & \\
\hline & Girl & & 2.98 & 0.78 & -1.54 & 0.13 & 2.84 & 0.82 & 0.08 & 0.94 & -0.12 & 0.78 & 1.65 & 0.10 \\
\hline \multirow{2}{*}{$\begin{array}{l}\text { I will not understand } \\
\text { the lessons }\end{array}$} & Boy & & 1.76 & 0.48 & & & 1.71 & 0.72 & & & 0.03 & 0.72 & & \\
\hline & Girl & & 1.98 & 0.80 & -1.55 & 0.12 & 1.74 & 0.66 & -0.23 & 0.82 & -0.27 & 0.76 & 1.82 & 0.07 \\
\hline
\end{tabular}


Table 3.4A: Context -continued-

\begin{tabular}{|c|c|c|c|c|c|c|c|c|c|c|c|c|c|c|}
\hline & & \multicolumn{4}{|c|}{ First wave } & \multicolumn{5}{|c|}{ Second wave } & \multicolumn{4}{|c|}{ Wave 2-1 } \\
\hline \multicolumn{2}{|l|}{ CONTEXT } & $N$ & Mean & $S D$ & $T$-test & P-value & Mean & $S D$ & $T$-test & P-value & Mean & $S D$ & $T$-test & P-value \\
\hline \multirow{2}{*}{$\begin{array}{l}\text { I cannot finish the } \\
\text { schoolwork }\end{array}$} & Boy & 42 & 1.76 & 0.58 & & & 1.61 & 0.67 & & & -0.08 & 0.85 & & \\
\hline & Girl & 52 & 1.81 & 0.79 & -0.31 & 0.76 & 1.84 & 0.74 & -1.55 & 0.13 & 0.04 & 0.89 & 0.64 & 0.53 \\
\hline \multirow{2}{*}{$\begin{array}{l}\text { My planning will be } \\
\text { bad }\end{array}$} & Boy & & 1.90 & 0.69 & & & 1.56 & 0.63 & & & -0.26 & 0.79 & & \\
\hline & Girl & & 1.88 & 0.83 & 0.13 & 0.90 & 1.74 & 0.85 & -1.12 & 0.27 & -0.10 & 1.05 & 0.79 & 0.43 \\
\hline \multirow{2}{*}{$\begin{array}{l}\text { About performing } \\
\text { poorly }\end{array}$} & Boy & & 1.52 & 0.55 & & & 1.56 & 0.78 & & & 0.05 & 0.87 & & \\
\hline & Girl & & 1.65 & 0.79 & -0.90 & 0.37 & 1.68 & 0.79 & -0.72 & 0.47 & 0.04 & 0.96 & 0.06 & 0.95 \\
\hline \multirow{2}{*}{$\begin{array}{l}\text { About getting lost in } \\
\text { the building }\end{array}$} & Boy & & 1.57 & 0.70 & & & 1.22 & 0.42 & & & -0.37 & 0.82 & & \\
\hline & Girl & & 1.88 & 0.98 & -1.74 & 0.09 & 1.26 & 0.53 & -0.40 & 0.69 & -0.65 & 1.03 & 1.39 & 0.17 \\
\hline \multirow{2}{*}{$\begin{array}{l}\text { I cannot find } \\
\text { classrooms }\end{array}$} & Boy & & 1.64 & 0.69 & & & 1.27 & 0.45 & & & -0.39 & 0.75 & & \\
\hline & Girl & & 2.10 & 0.91 & -2.66 & $0.01 * *$ & 1.48 & 0.68 & -1.78 & 0.08 & -0.61 & 1.04 & 1.09 & 0.28 \\
\hline \multirow{2}{*}{$\begin{array}{l}\text { Classmates will not like } \\
\text { me }\end{array}$} & Boy & & 1.49 & 0.86 & & & 1.32 & 0.61 & & & -0.05 & 0.86 & & \\
\hline & Girl & & 1.65 & 0.59 & -1.11 & 0.27 & 1.44 & 0.50 & -106 & 0.29 & -0.22 & 0.59 & 1.12 & 0.27 \\
\hline \multirow{2}{*}{$\begin{array}{l}\text { I might not find nice } \\
\text { friends }\end{array}$} & Boy & & 1.26 & 0.58 & & & 1.15 & 0.42 & & & -0.08 & 0.53 & & \\
\hline & Girl & & 1.29 & 0.46 & -0.31 & 0.76 & 1.34 & 0.52 & -1.96 & $0.05^{*}$ & 0.04 & 0.54 & -1.02 & 0.31 \\
\hline \multirow{2}{*}{$\begin{array}{l}\text { I won't find anybody in } \\
\text { the breaks }\end{array}$} & Boy & & 1.26 & 0.66 & & & 1.15 & 0.53 & & & -0.05 & 0.76 & & \\
\hline & Girl & & 1.29 & 0.57 & -0.26 & 0.80 & 1.26 & 0.44 & -1.12 & 0.27 & -0.02 & 0.63 & -0.21 & 0.84 \\
\hline \multirow{2}{*}{$\begin{array}{l}\text { The children will bully } \\
\text { me }\end{array}$} & Boy & & 1.28 & 0.70 & & & 1.12 & 0.40 & & & -0.08 & 0.66 & & \\
\hline & Girl & & 1.37 & 0.63 & -0.63 & 0.53 & 1.28 & 0.50 & -1.68 & 0.10 & -0.10 & 0.59 & 0.19 & 0.85 \\
\hline \multirow[t]{2}{*}{ I might feel lonely } & Boy & & 1.21 & 0.56 & & & 1.12 & 0.40 & & & -0.05 & 0.46 & & \\
\hline & Girl & & 1.40 & 0.63 & -1.59 & 0.12 & 1.20 & 0.40 & -0.92 & 0.36 & -0.20 & 0.54 & 1.44 & 0.15 \\
\hline \multirow{2}{*}{$\begin{array}{l}\text { I will not become } \\
\text { accustomed to the } \\
\text { teachers }\end{array}$} & Boy & & 1.95 & 0.72 & & & 1.68 & 0.69 & & & -0.26 & 0.94 & & \\
\hline & Girl & & 1.96 & 0.66 & -0.06 & 0.96 & 1.66 & 0.63 & 0.17 & 0.87 & -0.31 & 0.77 & 0.27 & 0.79 \\
\hline
\end{tabular}

${ }^{*} p<0.05 ;{ }^{* *} p<0.01 ;{ }^{* * *} p<0.001$ 


\section{Table 3.4B: CONTEXT}

\section{Paired Samples Test: Total group (all children) measure 1- 2; boys measure 1-2; girls measure 1-measure 2}

\section{CONTEXT}

\begin{tabular}{|c|c|c|c|c|c|c|c|c|c|c|c|c|c|c|c|c|c|}
\hline total & & mean & $S D$ & $T$-test & $P$-value & gender & & mean & $S D$ & $T$-test & $P$-value & gender & & mean & $S D$ & $T$-test & $P$-value \\
\hline Pair 1 & $\begin{array}{l}\text { I can show what I } \\
\text { have learned }\end{array}$ & 0.01 & 0.98 & 0.11 & 0.91 & Boy & Pair 1 & 0.05 & 1.03 & 0.31 & 0.76 & Girl & Pair 1 & -0.02 & 0.96 & -0.15 & 0.88 \\
\hline Pair 2 & $\begin{array}{l}\text { I will learn new } \\
\text { things }\end{array}$ & 0.11 & 0.83 & 1.27 & 0.21 & & Pair 2 & 0.26 & 0.91 & 1.76 & 0.09 & & Pair 2 & 0.00 & 0.76 & 0.00 & 1.00 \\
\hline Pair 3 & $\begin{array}{l}\text { I am curious about } \\
\text { new subjects }\end{array}$ & 0.19 & 0.86 & 2.09 & $0.04 *$ & & Pair 3 & 0.03 & 0.90 & 0.18 & 0.86 & & Pair 3 & 0.32 & 0.82 & 2.76 & $0.01 *$ \\
\hline Pair 4 & $\begin{array}{l}\text { I can show I perform } \\
\text { well }\end{array}$ & 0.06 & 0.88 & 0.60 & 0.55 & & Pair 4 & 0.26 & 0.91 & 1.76 & 0.09 & & Pair 4 & -0.10 & 0.84 & -0.84 & 0.40 \\
\hline Pair 5 & $\begin{array}{l}\text { I will quickly know } \\
\text { the way }\end{array}$ & -0.20 & 0.99 & -1.93 & 0.06 & & Pair 5 & -0.26 & 0.97 & -1.66 & 0.11 & & Pair 5 & -0.16 & 1.02 & -1.11 & 0.27 \\
\hline Pair 6 & $\begin{array}{l}\text { I like different } \\
\text { classrooms }\end{array}$ & 0.07 & 0.95 & 0.67 & 0.51 & & Pair 6 & 0.00 & 0.76 & 0.00 & 1.00 & & Pair 6 & 0.12 & 1.08 & 0.79 & 0.44 \\
\hline Pair 7 & $\begin{array}{l}\text { To meeting nice } \\
\text { children }\end{array}$ & 0.03 & 0.72 & 0.45 & 0.66 & & Pair 7 & 0.00 & 0.70 & 0.00 & 1.00 & & Pair 7 & 0.06 & 0.75 & 0.57 & 0.57 \\
\hline Pair 8 & $\begin{array}{l}\text { To having fun with } \\
\text { the other children }\end{array}$ & 0.08 & 0.80 & 0.94 & 0.35 & & Pair 8 & 0.05 & 0.73 & 0.44 & 0.66 & & Pair 8 & 0.10 & 0.85 & 0.84 & 0.40 \\
\hline Pair 9 & $\begin{array}{l}\text { To kids who will like } \\
\text { me }\end{array}$ & -0.01 & 0.90 & -0.12 & 0.91 & & Pair 9 & 0.00 & 0.81 & 0.00 & 1.00 & & Pair 9 & -0.02 & 0.97 & -0.15 & 0.88 \\
\hline Pair 10 & $\begin{array}{l}\text { To knowing many } \\
\text { nice children }\end{array}$ & 0.07 & 0.82 & 0.79 & 0.43 & & Pair 10 & 0.11 & 0.89 & 0.73 & 0.47 & & Pair 10 & 0.04 & 0.76 & 0.38 & 0.71 \\
\hline Pair 11 & $\begin{array}{l}\text { To getting into a nice } \\
\text { group }\end{array}$ & 0.15 & 0.82 & 1.71 & 0.09 & & Pair 11 & 0.11 & 0.86 & 0.75 & 0.46 & & Pair 11 & 0.18 & 0.78 & 1.64 & 0.11 \\
\hline Pair 12 & $\begin{array}{l}\text { Tot the different } \\
\text { teachers }\end{array}$ & 0.00 & 0.79 & 0.00 & 1.00 & & Pair 12 & -0.16 & 0.79 & -1.23 & 0.23 & & Pair 12 & 0.12 & 0.78 & 1.10 & 0.28 \\
\hline
\end{tabular}


Table 3.4B -continued- Paired Samples Test: Total group (all children) measure 1- 2; boys measure 1-2; girls measure 1-measure 2

\section{CONTEXT}

\begin{tabular}{|c|c|c|c|c|c|c|c|c|c|c|c|c|c|c|c|c|c|}
\hline Total & & mean & $S D$ & $T$-test & $P$-value & gender & & mean & $S D$ & $T$-test & $P$-value & gender & & mean & $S D$ & $T$-test & $P$-value \\
\hline Pair 13 & $\begin{array}{l}\text { I will not understand } \\
\text { the lessons }\end{array}$ & 0.14 & 0.75 & 1.72 & 0.09 & Boy & Pair 13 & -0.03 & 0.72 & -0.23 & 0.82 & Girl & Pair 13 & 0.27 & 0.76 & 2.45 & $0.02 *$ \\
\hline Pair 14 & $\begin{array}{l}\text { I cannot finish the } \\
\text { schoolwork }\end{array}$ & 0.01 & 0.87 & 0.12 & 0.90 & & Pair 14 & 0.08 & 0.85 & 0.57 & 0.57 & & Pair 14 & -0.04 & 0.89 & -0.32 & 0.75 \\
\hline Pair 15 & $\begin{array}{l}\text { My planning will be } \\
\text { bad }\end{array}$ & 0.17 & 0.94 & 1.71 & 0.09 & & Pair 15 & 0.26 & 0.80 & 2.04 & $0.05^{*}$ & & Pair 15 & 0.10 & 1.05 & 0.68 & 0.50 \\
\hline Pair 16 & $\begin{array}{l}\text { About performing } \\
\text { poorly }\end{array}$ & -0.05 & 0.91 & -0.47 & 0.64 & & Pair 16 & -0.05 & 0.87 & -0.37 & 0.71 & & Pair 16 & -0.04 & 0.96 & -0.30 & 0.77 \\
\hline Pair 17 & $\begin{array}{l}\text { About getting lost in } \\
\text { the building }\end{array}$ & 0.53 & 0.95 & 5.19 & 0.00 & & Pair 17 & 0.37 & 0.82 & 2.77 & $0.01^{* *}$ & & Pair 17 & 0.65 & 1.03 & 4.43 & $0.00^{* * *}$ \\
\hline Pair 18 & $\begin{array}{l}\text { I cannot find } \\
\text { classrooms }\end{array}$ & 0.52 & 0.93 & 5.21 & $0.00 * * *$ & & Pair 18 & 0.40 & 0.76 & 3.22 & $0.00 * * *$ & & Pair 18 & 0.61 & 1.04 & 4.13 & $0.00 * * *$ \\
\hline Pair 19 & $\begin{array}{l}\text { Classmates will not } \\
\text { like me }\end{array}$ & 0.15 & 0.72 & 1.93 & 0.06 & & Pair 19 & 0.05 & 0.86 & 0.37 & 0.71 & & Pair 19 & 0.22 & 0.59 & 2.68 & $0.01 * *$ \\
\hline Pair 20 & $\begin{array}{l}\text { I might not find nice } \\
\text { friends }\end{array}$ & 0.01 & 0.54 & 0.20 & 0.84 & & Pair 20 & 0.08 & 0.53 & 0.90 & 0.37 & & Pair 20 & -0.04 & 0.54 & -0.53 & 0.60 \\
\hline Pair 21 & $\begin{array}{l}\text { I won't find anybody } \\
\text { in the breaks }\end{array}$ & 0.03 & 0.69 & 0.47 & 0.64 & & Pair 21 & 0.05 & 0.76 & 0.42 & 0.68 & & Pair 21 & 0.02 & 0.63 & 0.23 & 0.82 \\
\hline Pair 22 & $\begin{array}{l}\text { The children will bully } \\
\text { me }\end{array}$ & 0.09 & 0.62 & 1.38 & 0.17 & & Pair 22 & 0.08 & 0.66 & 0.72 & 0.47 & & Pair 22 & 0.10 & 0.59 & 1.22 & 0.23 \\
\hline Pair 23 & I might feel lonely & 0.14 & 0.51 & 2.52 & $0.01 * *$ & & Pair 23 & 0.05 & 0.46 & 0.70 & 0.49 & & Pair 23 & 0.20 & 0.54 & 2.65 & $0.01 * *$ \\
\hline Pair 24 & $\begin{array}{l}\text { I will not become } \\
\text { accustomed to the } \\
\text { teachers }\end{array}$ & 0.28 & 0.84 & 3.16 & $0.00 * * *$ & & Pair 24 & 0.26 & 0.94 & 1.71 & 0.10 & & Pair 24 & 0.31 & 0.77 & 2.79 & $0.01 * *$ \\
\hline
\end{tabular}

$* p<0.05 ;{ }^{* *} p<0.01 ;{ }^{* *} p<0.001$ 


\section{Chapter 3}

3.2: Pre and post transition questionnaires

\section{Vragenlijst overgang basisschool- voortgezet onderwijs}

\begin{tabular}{|c|c|}
\hline $\begin{array}{l}\text { Voornaam en } \\
\text { achternaam leerling }\end{array}$ & .....leeftijd......jongen/ meisje \\
\hline Naam basisschool & 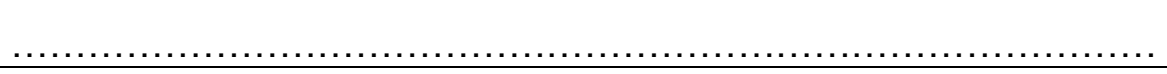 \\
\hline $\begin{array}{l}\text { Naam leerkracht(en) } \\
\text { groep } 8\end{array}$ & \\
\hline
\end{tabular}

\section{De nieuwe school}

Hoe heet jouw nieuwe school?

Mijn nieuwe school heet.

\section{Naar welke schoolsoort ga jij?}

Kruis aan.

Ga je naar het VMBO? Vul de richting in.

\begin{tabular}{|c|c|c|}
\hline o praktijkschool & $\begin{array}{ll}\circ & \mathrm{VMBO} \\
& \text { richting } \ldots \ldots \ldots \ldots \ldots \ldots\end{array}$ & o VMBO-T/ HAVO \\
\hline ○ HAVO & o $\mathrm{HAVO} / \mathrm{VWO}$ & o VWO \\
\hline
\end{tabular}

\section{Belangrijk voor de nieuwe school}

Kruis 3 dingen aan

\begin{tabular}{|c|c|c|c|}
\hline 0 & Het gebouw & 0 & Dat het een kleine school is \\
\hline 0 & Hoe ver je moet fietsen & 0 & Dat er goede begeleiding is \\
\hline 0 & Dat er kinderen uit mijn klas heengaan & O & Dat ik er al iemand ken \\
\hline O & Dat er vrienden/ vriendinnen heengaan & $\mathrm{O}$ & Dat ik samen kan fietsen met anderen \\
\hline 0 & Topklassen (sport- dans-kunst-muziek) & 0 & Dat het speciaal onderwijs is \\
\hline 0 & Tweetalig onderwijs & o & Het technasium/ de techniekroute \\
\hline
\end{tabular}

- lets anders:

Hoe ben je voorbereid op de nieuwe school?

Kruis aan

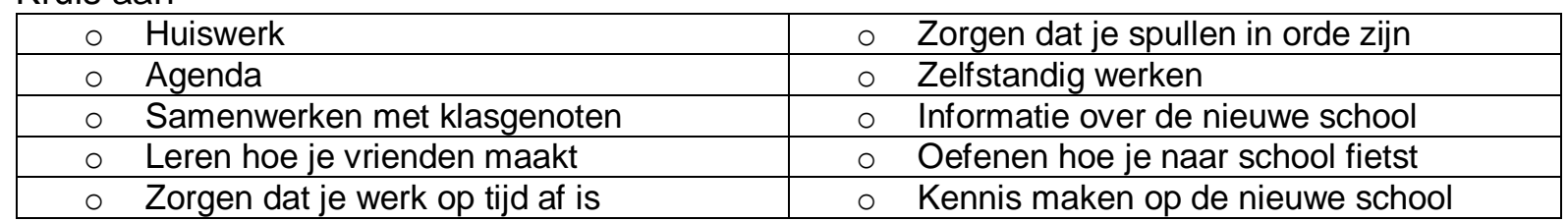

- lets anders 
Hoe maakte je kennis met je nieuwe school?

Kruis aan

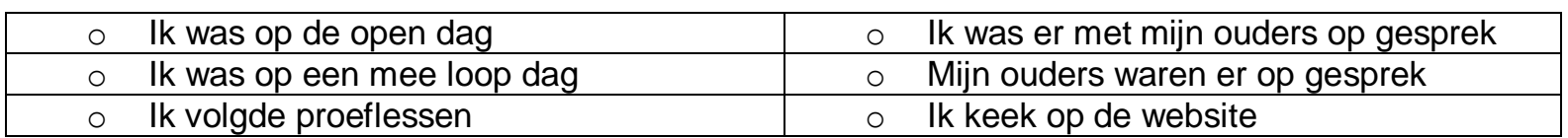

- lets anders:

Heb je al kennis gemaakt met je nieuwe mentor en je nieuwe klas?

Kruis aan

○ Ja, met de mentor en met de klas

\begin{tabular}{|l|ll|}
\hline$\circ$ Nee & $\circ \quad$ Alleen met de mentor \\
\hline
\end{tabular}

Kruis aan

\begin{tabular}{|l|l|l|}
\hline & ja & nee \\
\hline Zit een broer of zus op je nieuwe school? & & \\
\hline Ken je kinderen op je nieuwe school? & & \\
\hline Gaan er meer kinderen uit je klas naar jouw middelbare school? & & \\
\hline Gaan er vrienden of vriendinnen naar jouw middelbare school? & & \\
\hline Weet je wie jouw mentor wordt op de nieuwe school? & & \\
\hline
\end{tabular}

Wat verwacht jij van jouw mentor?

Kruis de 3 belangrijkste dingen aan

\begin{tabular}{|c|c|}
\hline$\circ$ Is aardig & $\circ$ Praat met de ouders \\
\hline$\circ$ Is er als je hem nodig hebt & $\circ$ Lost problemen in de klas op \\
\hline$\circ$ Ik kan goed met hem praten & $\circ \quad$ Zorgt voor een goede sfeer \\
\hline$\circ$ Leert ons de school kennen & $\circ \quad$ Is ons aanspreekpunt \\
\hline
\end{tabular}

- lets anders:

Stel jezelf kort voor aan je nieuwe mentor

Schrijf iets op over jezelf. 
Kruis één antwoord per regel aan

\begin{tabular}{|c|c|c|c|c|}
\hline \multicolumn{5}{|l|}{ Ik verheug me op de nieuwe school: } \\
\hline & nooit & 'n beetje & vaak & $\begin{array}{l}\text { heel } \\
\text { vaak }\end{array}$ \\
\hline - Ik ga laten zien wat ik al heb geleerd & & & & \\
\hline - $\quad$ Ik ga er nieuwe dingen leren & & & & \\
\hline - $\quad$ Ik ben benieuwd naar de nieuwe vakken & & & & \\
\hline - $\quad$ lk denk dat ik goed mee kan komen & & & & \\
\hline - $\quad$ Ik denk dat ik er snel de weg weet & & & & \\
\hline - $\quad$ lk vind het leuk dat ik in verschillende lokalen les heb & & & & \\
\hline
\end{tabular}

\begin{tabular}{|c|c|c|c|c|}
\hline \multicolumn{5}{|l|}{ Ik verheug me op de nieuwe school: } \\
\hline & nooit & 'n beetje & vaak & $\begin{array}{l}\text { heel } \\
\text { vaak }\end{array}$ \\
\hline - $\quad$ Ik kan daar met leuke kinderen omg & & & & \\
\hline - $\quad$ De kinderen zullen mij aardig vinden & & & & \\
\hline - $\quad$ Ik kan veel plezier maken met de kin & & & & \\
\hline - $\quad$ Ik zal veel kinderen leren kennen & & & & \\
\hline - $\quad$ lk kom in een leuke klas & & & & \\
\hline - $\quad$ Ik krijg les van verschillende leraren & & & & \\
\hline
\end{tabular}


Kruis één antwoord per regel aan

\begin{tabular}{|c|l|l|l|l|}
\hline Ik maak me zorgen dat: & nooit & 'n beetje & vaak & $\begin{array}{l}\text { heel } \\
\text { vaak }\end{array}$ \\
\hline$-\quad$ Ik de lessen niet zal snappen & & & & \\
\hline$-\quad$ Ik het schoolwerk niet af krijg & & & & \\
\hline$-\quad$ Ik het werk slecht kan plannen & & & & \\
\hline$-\quad$ Ik slechter ga presteren & & & & \\
\hline$-\quad$ Ik de weg kwijtraak in het gebouw & & & & \\
\hline$-\quad$ Ik de leslokalen niet kan vinden & & & & \\
\hline
\end{tabular}

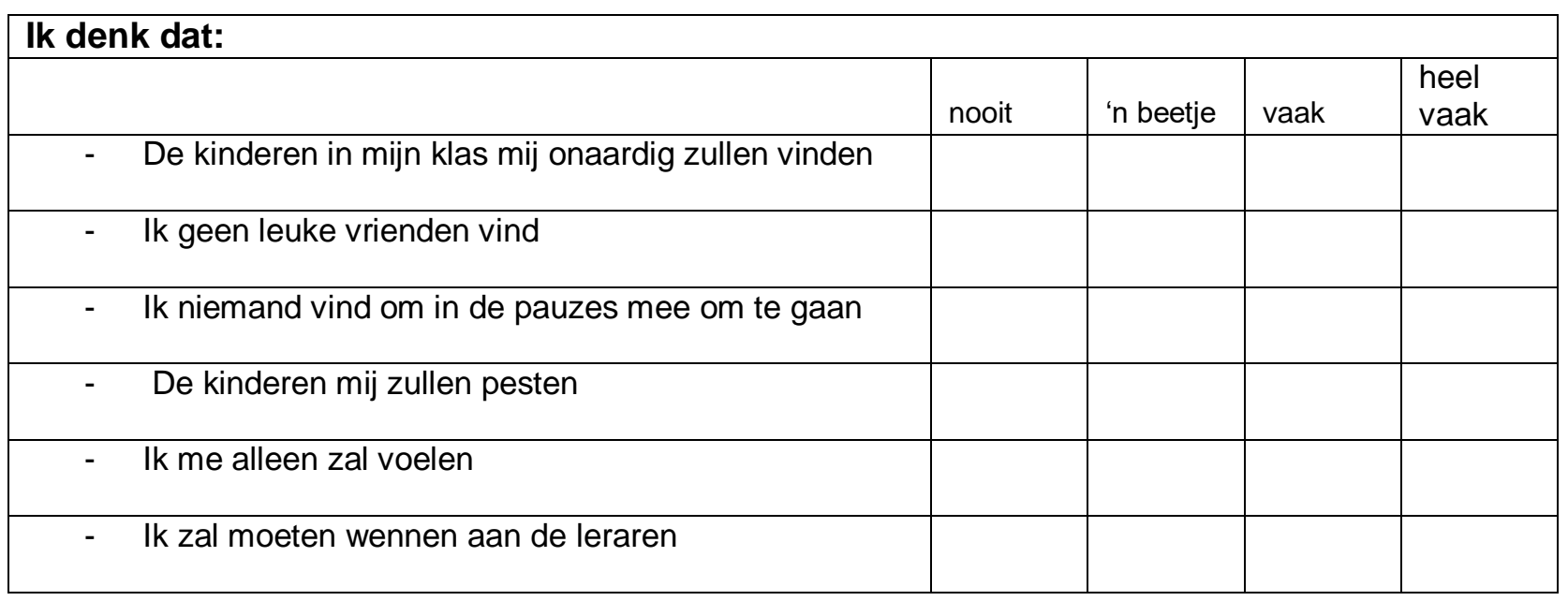

Dank je wel voor het invullen.

Wij vinden het fijn dat je ons hebt geholpen. 


\section{Vragenlijst terugblik overgang basisschool- voortgezet onderwijs}

\begin{tabular}{|c|c|}
\hline $\begin{array}{l}\text { Voornaam en } \\
\text { achternaam leerling }\end{array}$ & 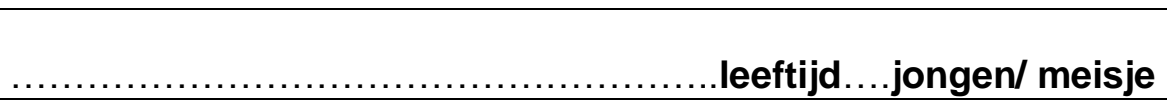 \\
\hline Klas & \\
\hline Naam mentor(en) & \\
\hline
\end{tabular}

Dit schooljaar ga je voor het eerst naar de middelbare school. Daar willen wij je graag wat over vragen.

Naar welke school ga jij?

Mijn middelbare school heet.

Vind je deze school achteraf een goede keuze?

\begin{tabular}{|c|c|}
\hline$\circ \mathrm{Ja}$ & $0 \mathrm{Nee}$ \\
\hline
\end{tabular}

Vinden je ouders deze school achteraf een goede keuze?

\begin{tabular}{|l|l|l}
\hline$\circ \mathrm{Ja}$ & $\circ \mathrm{Nee}$ \\
\hline
\end{tabular}

Leg dit uit

Naar welke schoolsoort ga jij?

Kruis jouw schoolsoort aan. Vul, als je naar het VMBO gaat, ook jouw richting in.

\begin{tabular}{|c|c|c|}
\hline $\begin{array}{l}\text { VMBO } \\
\text { richting.. }\end{array}$ & & VMBO-T/ HAVO \\
\hline HAVO/ VWO & & VWO \\
\hline
\end{tabular}

Welke dingen vind jij achteraf belangrijk bij de keuze voor een nieuwe school? Kruis niet meer dan 3 dingen aan die jij belangrijk vindt

\begin{tabular}{|c|r|rl|}
\hline$\circ$ & Het gebouw & $\circ$ & Dat het een kleine school is \\
\hline$\circ$ & Hoe ver je moet fietsen & $\circ$ & Dat er goede begeleiding is \\
\hline$\circ$ & Dat er kinderen uit mijn klas heengaan & $\circ$ & Dat ik er al iemand ken \\
\hline$\circ$ & Dat er vrienden/ vriendinnen heengaan & $\circ$ & Dat ik samen kan fietsen met anderen \\
\hline$\circ$ & Topklassen (sport- dans-kunst-muziek) & $\circ$ & Dat het speciaal onderwijs is \\
\hline$\circ$ & Tweetalig onderwijs & $\circ$ & Het technasium/ de techniekroute \\
\hline
\end{tabular}

- lets anders:

Wat vind je belangrijk ter voorbereiding op de overstap naar de nieuwe school? Kruis de 3 belangrijkste dingen aan

\begin{tabular}{|c|r|rl|}
\hline$\circ$ & Huiswerk leren plannen (en maken) & $\circ$ & Leren zorgen dat je spullen in orde zijn \\
\hline$\circ$ & Agenda leren gebruiken & $\circ$ & Zelfstandig leren werken \\
\hline$\circ$ & Samenwerken met klasgenoten & $\circ$ & Informatie over de nieuwe school \\
\hline$\circ$ & Leren hoe je vrienden maakt & $\circ$ & Oefenen hoe je naar school fietst \\
\hline$\circ$ & Er voor zorgen dat je werk op tijd af is & $\circ$ & Kennis maken op de nieuwe school \\
\hline
\end{tabular}

- lets anders: 
Heb je, voor de zomervakantie, al kennis gemaakt met je mentor en je nieuwe klas? Kruis één antwoord aan

- Ja, met de mentor en met de klas

$\circ \quad \mathrm{Nee}$

- Alleen met de mentor

Kruis één antwoord per vraag aan

\begin{tabular}{|l|l|l|}
\hline & ja & nee \\
\hline Was er een introductieprogramma op school? & & \\
\hline Ken je al nieuwe kinderen op school? & & \\
\hline Heb je al nieuwe vrienden of vriendinnen gemaakt op school? & & \\
\hline Weet je de weg al in het schoolgebouw? & & \\
\hline Ken je de schoolregels en afspraken al? & & \\
\hline Ben je al gewend aan de leraren? & & \\
\hline
\end{tabular}

Wat vind jij van jouw mentor?

Kruis de 3 belangrijkste dingen aan

\begin{tabular}{|c|c|cl|}
\hline$\circ$ & Hij/ zij is aardig & $\circ$ & Hij/ zij praat met de ouders \\
\hline$\circ$ & Hij/zij is er als je hem/haar nodig hebt & $\circ$ & Hij/ zij lost problemen in de klas op \\
\hline$\circ$ & Ik kan goed met hem/haar praten & $\circ$ & Hij/ zij zorgt voor een goede sfeer \\
\hline$\circ$ & Hij/ zij heeft ons de school leren kennen & $\circ$ & Hij/ zij is ons aanspreekpunt \\
\hline
\end{tabular}

- lets anders:

Hoe kan de mentor ervoor zorgen dat je je snel thuis voelt op school? (Bijvoorbeeld een kennismakingsgesprek houden, een activiteit organiseren met de klas, of iets heel anders...) Schrijf kort op:

- Wat doet de mentor?

- Wat zou de mentor moeten doen? 
Kruis één antwoord per regel aan

\begin{tabular}{|c|c|c|c|c|}
\hline \multicolumn{5}{|l|}{ Als ik aan mijn nieuwe school denk verheug ik me want: } \\
\hline & nooit & 'n beetje & vaak & $\begin{array}{l}\text { heel } \\
\text { vaak }\end{array}$ \\
\hline - $\quad$ Ik ga laten zien wat ik al heb geleerd & & & & \\
\hline - $\quad$ Ik ga er nieuwe dingen leren & & & & \\
\hline - $\quad$ Ik ben benieuwd naar de nieuwe vakken & & & & \\
\hline - $\quad$ lk denk dat ik goed mee kan komen & & & & \\
\hline $\begin{array}{ll}- & \text { Ik denk dat ik snel de weg weet in school }\end{array}$ & & & & \\
\hline - $\quad$ lk vind het leuk dat ik in verschillende lokalen les heb & & & & \\
\hline
\end{tabular}

\begin{tabular}{|c|c|c|c|c|}
\hline \multicolumn{5}{|c|}{ Ik verheug me op mijn nieuwe school omdat: } \\
\hline & nooit & ' $n$ beetje & vaak & $\begin{array}{l}\text { heel } \\
\text { vaak }\end{array}$ \\
\hline - $\quad$ Ik daar met leuke kinderen kan omga & & & & \\
\hline - $\quad$ De kinderen mij aardig zullen vinden & & & & \\
\hline - $\quad$ Ik veel plezier kan maken met de kin & & & & \\
\hline - $\quad$ Ik veel kinderen zal leren kennen & & & & \\
\hline - $\quad$ lk in een leuke klas kom & & & & \\
\hline - $\quad$ Ik les krijg van verschillende leraren & & & & \\
\hline
\end{tabular}


Kruis één antwoord per regel aan

\begin{tabular}{|c|c|c|c|c|}
\hline \multicolumn{5}{|c|}{ Als ik aan mijn nieuwe school denk ben ik bang dat: } \\
\hline & nooit & 'n beetje & vaak & $\begin{array}{l}\text { heel } \\
\text { vaak }\end{array}$ \\
\hline - $\quad$ Ik de lessen niet zal snappen & & & & \\
\hline - $\quad$ Ik het schoolwerk niet af krijg & & & & \\
\hline - $\quad$ Ik het werk slecht kan plannen & & & & \\
\hline - $\quad$ Ik slechter ga presteren & & & & \\
\hline - $\quad$ Ik de weg kwijtraak in het gebou & & & & \\
\hline - $\quad$ Ik de leslokalen niet kan vinden & & & & \\
\hline
\end{tabular}

\begin{tabular}{|c|c|c|c|c|}
\hline \multicolumn{5}{|c|}{ Ik maak me zorgen over de nieuwe school, ik denk dat: } \\
\hline & nooit & 'n beetje & vaak & $\begin{array}{l}\text { heel } \\
\text { vaak }\end{array}$ \\
\hline De kinderen in mijn klas mij onaardig $z$ & & & & \\
\hline - lk geen leuke vrienden vind & & & & \\
\hline - $\quad$ Ik niemand vind om in de pauzes mee & & & & \\
\hline - $\quad$ De kinderen mij zullen pesten & & & & \\
\hline - $\quad$ Ik me alleen zal voelen & & & & \\
\hline - $\quad$ Ik zal moeten wennen aan de leraren & & & & \\
\hline
\end{tabular}

Dank je wel voor het invullen van deze vragenlijst.

Wij vinden het fijn dat je ons wilt helpen. 


\section{Appendix 2}

\section{Chapter 4}

Table 4.1: Composition research group: number of participants and percent response pre- and post-transition

\begin{tabular}{|l|c|c|c|}
\hline Surveyed & N pre transition & N post transition & \%response \\
\hline 2012 & 64 & 53 & $83 \%$ \\
\hline 2014 & 224 & 162 & $72 \%$ \\
\hline 2015 & 246 & 98 & $40 \%$ \\
\hline 2016 & 153 & 58 & $38 \%$ \\
\hline Total & 687 & 371 & $54 \%$ \\
\hline
\end{tabular}

Table 4.2: T-test observable characteristics intervention group- control group

\begin{tabular}{|c|c|c|c|c|c|c|c|c|}
\hline \multirow[b]{2}{*}{ Characteristics } & \multicolumn{3}{|c|}{ Intervention group } & \multicolumn{3}{|c|}{ Control group } & \multirow[b]{2}{*}{ difference } & \multirow[b]{2}{*}{$P$-value } \\
\hline & $N$ & mean & $S D$ & $N$ & mean & $S D$ & & \\
\hline Gender & 182 & 0.53 & 0.500 & 187 & 0.53 & 0.500 & 367 & 0.367 \\
\hline Age & 182 & 12,4 & 0.519 & 182 & 12,5 & 0.490 & 362 & 0.756 \\
\hline $\begin{array}{l}\text { 'Warm transfer' / } \\
\text { No 'warm transfer }\end{array}$ & 182 & 0.03 & 0.179 & 187 & 0.03 & 0.177 & 0.67 & 0.962 \\
\hline $\begin{array}{l}\text { Year research } \\
\text { conducted }\end{array}$ & 182 & 2014.0 & 1.176 & 187 & 2014.7 & 1.180 & 0.810 & $0.029^{*}$ \\
\hline Familiar children & 181 & 0.89 & 0.314 & 182 & 0.88 & 0.320 & 0.005 & 0.883 \\
\hline Siblings & 181 & 0.23 & 0.423 & 183 & 0.24 & 0.426 & -0.004 & 0.925 \\
\hline $\begin{array}{l}\text { Children from } \\
\text { previous school }\end{array}$ & 181 & 0.86 & 0.352 & 180 & 0.87 & 0.341 & -0.010 & 0.777 \\
\hline Friends & 181 & 0.80 & 0.404 & 181 & 0.84 & 0.368 & -0.044 & 0.277 \\
\hline Mentor familiar & 180 & 0.68 & 0.469 & 181 & 0.65 & 0.478 & 0.026 & 0.606 \\
\hline
\end{tabular}

${ }^{0} p \leq 0.1 ;{ }^{*} p \leq 0.05 ;{ }^{* *} p \leq 0.01 ;{ }^{* * *} p \leq 0.001$ 
Table 4.3: mean scores control group and intervention group: T-test subscales social and school context, pre- and post-transition

\begin{tabular}{|c|c|c|c|c|c|c|c|c|c|c|c|c|}
\hline \multirow[b]{3}{*}{ Subscale } & \multicolumn{4}{|c|}{ Intervention group } & \multicolumn{4}{|c|}{ Control group } & & & & \\
\hline & \multicolumn{2}{|l|}{ mean } & \multicolumn{2}{|l|}{$S D$} & \multicolumn{2}{|l|}{ mean } & \multicolumn{2}{|l|}{$S D$} & \multicolumn{2}{|c|}{ difference } & \multicolumn{2}{|l|}{$P$-value } \\
\hline & $\begin{array}{l}\text { Pre } \\
\text { transition }\end{array}$ & $\begin{array}{l}\text { Post } \\
\text { transition }\end{array}$ & $\begin{array}{l}\text { Pre } \\
\text { transition }\end{array}$ & $\begin{array}{l}\text { Post } \\
\text { transition }\end{array}$ & $\begin{array}{l}\text { Pre } \\
\text { transition }\end{array}$ & $\begin{array}{l}\text { Post } \\
\text { transition }\end{array}$ & $\begin{array}{l}\text { Pre } \\
\text { transition }\end{array}$ & $\begin{array}{l}\text { Post } \\
\text { transition }\end{array}$ & $\begin{array}{l}\text { Pre } \\
\text { transition }\end{array}$ & $\begin{array}{l}\text { Post } \\
\text { transition }\end{array}$ & $\begin{array}{l}\text { Pre } \\
\text { transition }\end{array}$ & $\begin{array}{l}\text { Post } \\
\text { transition }\end{array}$ \\
\hline Fun with peers & 3.15 & 3.17 & 0.56 & 0.60 & 3.08 & 3.22 & 0.59 & 0.62 & -0.08 & 0.05 & 0.208 & 0.416 \\
\hline Fear of peers & 1.37 & 1.30 & 0.51 & 0.45 & 1.43 & 1.40 & 0.60 & 0.60 & 0.06 & 0.10 & 0.298 & $0.076^{\circ}$ \\
\hline $\begin{array}{l}\text { Fun school } \\
\text { context }\end{array}$ & 2.87 & 2.86 & 0.66 & 0.68 & 2.75 & 2.80 & 0.66 & 0.73 & -0.12 & -0.06 & $0.099^{\circ}$ & 0.440 \\
\hline $\begin{array}{l}\text { Fear school } \\
\text { context }\end{array}$ & 1.65 & 1.32 & 0.71 & 0.49 & 1.62 & 1.34 & 0.74 & 0.54 & -0.03 & 0.02 & 0.688 & 0.665 \\
\hline Fun schoolwork & 2.88 & 2.88 & 0.58 & 0.59 & 2.84 & 2.90 & 0.56 & 0.62 & -0.04 & 0.02 & 0.542 & 0.756 \\
\hline Fear schoolwork & 1.82 & 1.70 & 0.58 & 0.56 & 1.80 & 1.80 & 0.57 & 0.67 & -0.02 & 0.09 & 0.720 & 0.160 \\
\hline
\end{tabular}

${ }^{0} \mathrm{p} \leq 0.1 ;{ }^{*} \mathrm{p} \leq 0.05 ;{ }^{* *} \mathrm{p} \leq 0.01 ;{ }^{* * *} \mathrm{p} \leq 0.001$

Note: The 6 subscales may be composed of a different number of items which makes their mean scores not comparable. Therefore, each subscale is converted to a new variable at which the mean is dived by the number of items the subscale consists. After that, with the new calculated subscales, a t-test yielded the above score. 


\section{Appendix 3}

\section{Chapter 5}

Table 5.1: characteristics of interviewed mentors

\begin{tabular}{|c|c|c|c|c|c|c|c|}
\hline $\begin{array}{l}M=\text { Male } \\
F=\text { Female }\end{array}$ & School & Teacher & $\begin{array}{l}\text { Years } \\
\text { teacher }\end{array}$ & $\begin{array}{l}\text { Years } \\
\text { mentor }\end{array}$ & Subject & Mentor class & Class size \\
\hline$M$ & 1 & $A$ & 41 & 40 & $\begin{array}{l}\text { German } \\
\text { language } \\
\text { Math }\end{array}$ & MAVO/HAVO & 29 \\
\hline$F$ & 1 & $B$ & 27 & 27 & $\begin{array}{l}\text { English } \\
\text { Language }\end{array}$ & HAVO/VWO & 22 \\
\hline$F$ & 1 & $C$ & 3 & 1 & Math & MAVO/HAVO & 28 \\
\hline$F$ & 1 & $D$ & 30 & 3 & $\begin{array}{l}\text { Dutch } \\
\text { language }\end{array}$ & Gymnasium & 26 \\
\hline$F$ & 1 & $E$ & 19 & 12 & Geography & MAVO/HAVO & 27 \\
\hline$F$ & 2 & $F$ & 5 & 4 & $\begin{array}{l}\text { English } \\
\text { Language }\end{array}$ & $V M B O$ & 18 \\
\hline$M$ & 2 & $G$ & 5 & 4 & Economy & VMBO & 26 \\
\hline$F$ & 2 & $H$ & 13 & 11 & $\begin{array}{l}\text { Dutch } \\
\text { Language }\end{array}$ & VMBO (SEN) & 18 \\
\hline$M$ & 2 & I & 8 & 6 & History & HAVO/VWO & 26 \\
\hline$F$ & 3 & $J$ & 29 & 27 & $\begin{array}{l}\text { Dutch } \\
\text { language }\end{array}$ & VWO & 31 \\
\hline$F$ & 3 & $K$ & 28 & 28 & Music & VMBO-T/ HAVO & 32 \\
\hline$M$ & 3 & $L$ & 26 & 26 & Gymnastics & $V M B O$ & 31 \\
\hline$F$ & 3 & $M$ & 5 & 4 & $\begin{array}{l}\text { English } \\
\text { language }\end{array}$ & $V M B O$ & 31 \\
\hline$F$ & 4 & $N$ & 13 & 13 & $\begin{array}{l}\text { Dutch } \\
\text { language }\end{array}$ & HAVO & 22 \\
\hline$F$ & 4 & 0 & 17 & 17 & Math & $V M B O$ & 15 \\
\hline$F$ & 4 & $P$ & 14 & 14 & $\begin{array}{l}\text { Biology } \\
\text { Gymnastics }\end{array}$ & $V M B O$ & 17 \\
\hline$F$ & 4 & $Q$ & 15 & 15 & $\begin{array}{l}\text { Dutch } \\
\text { language }\end{array}$ & VMBO & 22 \\
\hline
\end{tabular}

Note: the tracks at secondary education are: practical education (PrO), preparation for intermediate vocational education (VMBO), upper-secondary education (HAVO) and preparation for academic education (VWO; gymnasium). 


\section{Valorisation Addendum}




\section{Valorisation Addendum}

\section{The innovative aspect of the thesis}

It is not self-evident that science and social practice are aware of each other's findings and recommendations. In my thesis: 'The transition from primary to secondary education: $A$ study of the voices of children and teachers in the Netherlands' I bridge the gap in the exchange of knowledge between science and the pedagogical practice to stimulate dissemination from within schools by involving children and teachers directly in the research. The approach to start from the role of the child and to analyze the interaction with the other stakeholders makes it possible to find ways to improve the transition process from primary to secondary education.

That the educational practice, for various reasons, does not always meet science is one of the results of my study. The results demonstrate on the one hand, that teachers in primary education often do not have access to scientific knowledge. It is sometimes difficult for teachers to assess scientific knowledge because of the lack of access to scientific libraries. The outcomes of scientific research are often described in scientific English, and therefore difficult to read plus, in addition most of the scientific educational knowledge is not relevant to practice. This reduces the chances to disseminate the results within the professional field.

On the other hand, the results of my study demonstrate the added value of communication with children -rather than about children- to promote a more successful transition and to increase the awareness of policy makers, school leaders and educators of the importance of involving all stakeholders as equal partners in the interventions to improve the transition process from primary to secondary schools.

\section{Target groups}

The transition from primary to secondary school is a cross-school process. The supplying primary school and the receiving secondary school are jointly responsible for the successful progress of this process. In Dutch we call this 'ketenverantwoordelijkheid'.

Aside from the schools, the main target groups for which the results of my thesis have added value are the children who make the transition to secondary school, and their mentors at secondary school. My research contributes to both the scientific literature and the pedagogical practice by providing insight into the expectations of children before and after they make the transition. It explores among others to what extent gender has an effect on experiencing the transition (Chapter 3). Awareness of the children's expectations and experiences might allow 
teachers to contribute significantly to a deeper understanding of -among others- genderbased- distinctions. The results of my study show that before the transition, the children were particularly interested in the social environment at secondary school. Girls experienced more pre-transition concerns about the school context and mixed feelings about the social context, but were more optimistic about their future classmates than boys. Boys were more interested - in a competitive way -in the possibility of showing off what they had already learned and the chance to show that they could perform well. More than boys, girls appreciated having the opportunity to talk with the mentor. All children expected their mentor to be a nice person, available for a good conversation.

After eight weeks at secondary school, most children in our sample had found their way around their new school. At this point, having friends became important for all children. The children realized that they initially have underestimated the importance of the social-emotional aspects on the transition and that they were not sufficiently prepared to cope successfully with the social-environmental challenges of transition. This insight could then be used by primary and secondary schools to further ease the transition from primary to secondary school.

To give teachers insight in the children's expectations, in Chapter 4 the fun and fear factors that the children expected to experience at secondary school are analyzed. In the academic literature little information is found about the role, importance and results of involving children in the mentoring process. My research results can contribute to the knowledge about this rather under researched but important topic. Chapter 5 contributes to the literature by providing insight into the mentor's actions, furthering our understanding of what children anticipate and fear in the secondary school environment as compared to their actual experiences after the transition.

\section{Social (and economic) relevance}

The results of this thesis can, in addition to the scientific relevance, be used to improve the transition from primary to secondary education by including the perspectives of the children and the secondary school mentors of grade seven, particularly with a view to "giving children a voice". The thesis provides evidence of the ways in which the input from these stakeholders can enhance the transition.

The results of the systematic literature review, in addition to their scientific relevance, can help schools to evaluate, refine, and improve existing interventions to support pupils during the transition process. Furthermore, this evidence helps to identify the children who are most 
vulnerable to a poor transition. Consequently, the results of the literature study can help to ensure that interventions are directed and used where they are most needed.

The qualitative research contributes to more goal-oriented and systematic work on educational improvements because the study provides insight into the wishes and views of mentors on the current state of affairs during the transition from primary to secondary education.

The results of my study can also contribute to school development: by giving feedback and by stimulating a dialogue that leads to the implementation of educational innovation. This dialogue leads to substantive conversations between teachers and policy makers and therefore increases professionalization. 
Summary 


\section{Summary}

It is important for children to make a smooth, successful transition from primary education to secondary education. Problems with this transition can affect their school careers, in both the short- and long-term, potentially leading to a downward spiral of underperformance, reduced motivation, and perhaps eventually to class repetition, outflow or early school-leaving. The transition also affects children's general sense of well-being and mental health (Korpershoek, Beijer, Spithoff, Naaijer, Timmermans, Van Rooijen, Vugteveen \& Opdenakker, 2016; Waters, Lester, Wenden \& Cross, 2012; Zeedijk, Gallacher, Henderson, Hope, Husband \& Lindsay, 2003).

Different parties are interested in and contribute to a successful transition. First and foremost, the children themselves benefit from a successful transition. It is important that their cognitive and non-cognitive development continues smoothly after the transition and does not stagnate due to adjustment problems. In addition to the children, the schools involved in the transition process also have an interest in a successful transition. A successful transition confirms the primary school's capacity to anticipate what is necessary to prepare children for the transition, and the secondary school's ability to help children adapt to their new circumstances. Finally, society as a whole is interested in a successful transition. Under-utilization of talents, class repetition, or 'dropping out' - due to motivation problems, absenteeism or premature failure and unnecessary outflow impose costs on society. These costs can, and must be, prevented (Bosch, Konermann, De Wit, Rutten \& Amsing, 2008).

Whether children experience a transition as successful depends on the extent to which the feeding primary school connects with the receiving secondary school. After a successful transition, the children can become well-settled in the secondary school, growing accustomed to the new routines and the school organisation. In a good transition, the children are able to develop new friendships, establish an interest in school and schoolwork, and experience curriculum continuity (Evangelou, Taggart, Sylva, Melhuish, Sammons \& Siraj-Blatchford, 2008). In principle, it should be possible for all typical ${ }^{10}$ children to make a smooth transition, but in practice, this is not always the case. Obstacles to a good transition can occur, for example, when a child's cognitive or non- cognitive skills do not adequately match the level required in secondary education or when the child does not receive good guidance from the

\footnotetext{
${ }^{10}$ We refer to children without disabilities as "typical" because they have the behaviour, intellectual ability and functional skills we would "typically" see in children of their age.
} 
primary school to make a successful transition for example, when the 'warm' transfer is missing (Korpershoek et al., 2016).

Notwithstanding all the research into the transition from various angles, one perspective is notably absent: that of the children themselves. Children are the main characters in the transition process, but their expectations, experiences and opinions, as expressed by themselves, play only a minor role in research. Similarly, little attention has been given in the research to the experiences and opinions of the teachers (the mentors at secondary school), who guide the children during the transition process. This thesis contributes to the knowledge about the perceptions of the children who make the transition to secondary school and about the experiences of their mentors at secondary school.

\section{A systematic literature review}

To obtain relevant evidence about the involvement of children in the transition process, in Chapter 2, we systematically reviewed the empirical literature. The aim of this systematic review was to identify characteristics and interventions that improve the transition, especially by 'giving children a voice'.

We distinguished three stakeholders involved in the transition process: the children (and their parents), the primary school, and the secondary school. All three adapt to the new circumstances in their own way and have their own approach to ease the transition process. In the literature, we found little evidence of educational partnership or cooperation between the stakeholders. Although the desirability of close links between primary and secondary school teachers, and of effective communication between all stakeholders, should be obvious (Coffey, 2013; Green, 1997; Jindal-Snape \& Miller, 2008; Lester, Cross, Shaw \& Doole, 2012a), in practice, this is not the case. Close links between the stakeholders would serve to raise awareness of children who are vulnerable to a poor transition (Chedzoy \& Burden, 2005; Chung, Elias \& Schneider, 1998), but the teachers who prepare children for the transition or support them afterwards, do not always have sufficient information about the children's background or, if they have the information, they have insufficient time and resources to share that information.

Children's personal characteristics, such as their capabilities, self-esteem, mental state (e.g., depression or anxiety), gender, and family characteristics can make them vulnerable to a poor transition (Rice, Frederickson \& Seymour, 2011). Family background, including cultural and socio-economic factors, can increase the risk of specific transition problems. Children from families in poverty, or from larger or less educated families, do worse than their peers. Their 
parents are less likely to be involved in school activities and to support the school (Anderson et al., 2000; Topping, 2011).

The literature has scant information on children's opinions and experiences with the transition, as only few studies have focused on their perspective. In principle, it should be easy for secondary schools to learn from children by asking them about their thoughts and experiences with the transition. If teachers were able to further develop teaching and learning through the eyes of children, they would be able to develop strategies and improve their pedagogical practice based on first-hand evidence.

\section{Children's visions: gender differences}

In Chapter 3, we investigated the children's view of the transition process. We were interested in children's priorities and whether there were gender differences in their perceptions, expectations and experiences with the transition. For the purpose of the study, we used data collected in two waves, through two identical self-reporting questionnaires filled out by 98 children. The children answered the same questions before and six weeks after the transition, in other words, from a prospective as well as a retrospective viewpoint. The key themes in the questionnaires were: school choice, preparing for secondary school, the role of the mentor, making the transition with peers, and differences in the school context.

The study was based on the theoretical assumptions of Self-Determination Theory (SDT, Ryan \& Deci, 2000). To prevent negative consequences from the transition, it is important to boost children's intrinsic motivation, self-regulation and well-being. The SDT distinguishes three basic psychological needs: competence ( I can do it), autonomy (I can do I independently) and relatedness (I am feeling connected with others and cared for). Fulfilment of these needs reinforces motivation and produces well-being and enjoyment (Ryan \& Deci, 2000). In the present study, the children were able to actively participate, in the form of providing information. This contributed to the children's need for autonomy, competence and relatedness (Hart, 2008) and had a positive impact on their self-confidence and on their social competences.

The results of our study show that before the transition, the children were particularly interested in the social environment at secondary school. Their priorities when choosing a secondary school included good guidance by their future teachers and making the transition with friends or children they knew. Girls experienced more pre-transition concerns about the school context and mixed feelings about the social context, but were more optimistic about their future classmates than boys were. Boys were more interested - in a competitive way - in the new things they would learn, the possibility of showing off what they had already learned and the 
chance to show that they could perform well. More than boys, girls appreciated having the opportunity to talk with the mentor. However, the boys in our sample scored high on this item as well. All children expected their mentor to be a nice person, present whenever needed, competent, and available for a good conversation.

After eight weeks at secondary school, most children in our sample had found their way around their new school. At this point, having friends became important for all children. The children realised that they initially have underestimated the importance of the social-emotional aspects on the transition and that they were not sufficiently prepared to cope successfully with the social-environmental challenges of transition. In terms of the SDT, the lack of coping skills in the social environment left the children less capable of autonomously handling challenges in the social-emotional context and more dependent on support from their mentor. This may have consequences for the children's demands for guidance by their mentor, and may explain the desire, previously observed in the children, for mentors to be readily and constantly available.

\section{Fun and fear in the school environment and in the social context}

There are many differences between primary and secondary education. During the transition, children have to deal with these changed circumstances in both the school context and the social context (Green, 1997). They have to form new relationships with their peers as well as with their new teachers at secondary school (Tobbell \& O'Donnell, 2013). Teachers can play an important role in guiding and supporting children through the transition. Positive relationships with teachers and an environment of encouragement can be constructive for children's learning, their academic achievement, and their overall well-being (Ellerbrock, Abbas \& DiCicco, 2014).

Children's input can make a valuable contribution to understanding how they experience their school lives, and teachers - especially class mentors - are in a position to interpret and use this information to improve their pedagogical practice (Ferguson, Handreddy \& Draxton, 2011) as well as smooth the transition. In Chapter 4 , we investigated whether children who are vulnerable to a poor transition would fare better if their mentor were more aware of what the children themselves thought they needed.

To provide such information to the mentors, we investigated the concerns, expectations, and experiences of 371 children through a self-reporting pre- and post-transition questionnaire. We looked at the fun and fear factors that the children expected before the transition and experienced after the transition in the school context and social context. To measure the challenges and threats of the transition from 24 aspects in both school and social contexts, we 
used the translated and customized self-reporting questionnaire entitled "The Impending Transition to Secondary School Perceived as Challenge and Threat” (ITCT) (Sirsch, 2003).

In addition, a blinded experiment was conducted with secondary school mentors to establish the impact of making that information available during the transition. For the purpose of this experiment, the children who participated in the pre-transition data collection were randomly assigned to a control group $(n=189)$ or an intervention group $(n=182)$. Mentors of the children assigned to the intervention group received a copy of the pre-transition questionnaire that 'their' children had completed. Mentors of the children in the control group did not receive this information. Assuming that mentors would use the information to create a smooth transition, we expected the children in the intervention group to make a better transition than the children in the control group.

In fact, we found that mentors barely used the information provided by the children. The intervention had only a small effect on the social context at the $10 \%$ significance level. The children whose mentor had received information (the intervention group) experienced less fear of peers after the transition than the children in the control group, whose mentor had not received any information. Surprisingly, the intervention group also experienced less fun with peers in the social context after the transition. The intervention had no significant effect on fear or fun with schoolwork, or on fear or fun in the school context. Moreover, the post hoc estimation of statistical power showed that, because of the low statistical power - the sample was too small-, it was reasonable to believe that we correctly rejected our hypothesis may have been false. Overall, the results of the intervention barely seemed to affect the course of the transition process.

Based on the information provided by the children, we identified three groups vulnerable to a poor transition. The first group, girls, stood out because after the transition, they reported significantly more fear than boys, especially with schoolwork.

The second vulnerable group comprised children with special educational needs (SEN). In comparison to typically developing children, they presented a mixed picture. These children were more worried than their peers about the social context. After the transition, children with SEN suffered less fear in the school context, which was significant at the $10 \%$ level, but their fear of peers in the social context was significantly higher at the $10 \%$ level.

The third vulnerable group consisted of children who were already anxious before the transition. In the social context and the school context, we found fear (and fun) to be significant reliable predictors. Although the differences between the pre-transition scores and the posttransition scores for fear or fun, respectively, became smaller, after the transition these children remained anxious. This finding illustrates the need to create opportunities, especially for 
vulnerable and anxious children, to share their opinions with their teachers. It also demonstrates the need for teachers not only to be aware of the impact of the transition on children, but also benefit of using the children's perspective to provide pertinent help.

\section{Supporting the mentor}

Appropriate teacher support leads to greater student success (Ganeson \& Ehrich, 2009). To enable mentors to properly support the children, they need to have some support of their own, usually in the form of information about the children in their class. In Chapter 5 , we set out the results from four focus group interviews and one individual interview of 17 grade seven mentors from four secondary schools. Our goal was to determine if and how mentors are fed intelligence about their class, both before and after the children make the transition to secondary school. We also investigated the mentors' actions as a result of the information they received, and if and how mentors are facilitated to take action.

According to the mentors, the children played no direct role in the consultation process before the transition. Various stakeholders talk about the children, and decisions are made on their behalf, but there is no direct communication with them. Until the summer break, most mentors in our study did little to actively collect information themselves. Usually, they received a brief summary with only the most urgent information about the children in their new class. The mentors agreed that communication between primary and secondary school teachers is vital to improving the transition (Korpershoek et al., 2016; Topping, 2011; West, Sweeting \& Young, 2010). They were satisfied with the quality, reliability and usefulness of the information they received directly through personal contact with the primary school teachers (the so-called warm transfer $\left.{ }^{11}\right)$. The mentors were less satisfied about the preparation given children for secondary school, the quality of the school advice, and the comprehensiveness of the educational report they received from primary school. They were also frustrated by the number of primary school teachers who were not given the time or space to meet with the mentors for a conversation or feedback to improve or evaluate the transition.

The school advice is not always based purely on the abilities of the children. Some schools recommend too high a level, because of insufficient awareness of the requirements of secondary education or because the primary school educator thinks it would be a shame for a child to enrol at a lower level. Parents sometimes interfere as well, because they think their

\footnotetext{
${ }^{11} \mathrm{~A}$ "warm transfer", or warme overdracht in Dutch, occurs when a primary school teacher undertakes to personally recommend a particular student to a secondary school. In this case, an oral or written guidance is communicated between two teachers (commonly, the sixth grade teacher at the primary school and the mentor at the secondary school).
} 
child deserves a chance to attend classes at a higher level. The parents might insist that important information be withheld and, under European privacy legislation, schools are prohibited from provide information about children without the consent of parents.

The interviewed mentors questioned whether grade six teachers were sufficiently aware of the educational practices in secondary education. They wondered if, when preparing children for the transition, primary school teachers appreciated the level of independence that children needed to handle the demands of secondary education. Despite the fact that children are more outspoken, mentors noted that they suffered from a lack of social skills, leaving them more dependent on receiving help to resolve their social or emotional problems. The mentors urged parents to play a more significant role in helping their children to develop social and emotional skills. This is not just a task for school, but for all educators, including parents.

To address the above-mentioned problems, all stakeholders should work together. Such cooperation could be greatly improved if parents and children were welcomed to participate in the transition process as equal partners.

\section{Conclusions}

The key conclusions of the literature review and the empirical studies led to the formulation of five statements, which are briefly summarized below.

The transition is a cross-school phenomenon; it is an ongoing process that starts at primary school and continues until the children become accustomed to their secondary school and are settled into the school community. Primary education does not usually connect seamlessly with secondary education. The children have to learn how to bridge the differences between primary and secondary school, how to adapt to the new rules, manners and customs of secondary education, how to behave, and what to do or not to do.

Because of its cross-school nature, teachers on both sides of the transition should work together to ensure a smooth transition and continuity in the development of the children (Anderson et al., 2000). In practice, cooperation is usually limited to the exchange of generic information on the curriculum, rather than information about individual children (Topping, 2011).

The prerequisite to a successful transition is good preparation at primary school, which meets the expectations of secondary school. Mentors expect that children who enter secondary education will have acquired a certain degree of independence. Unfortunately, this is at odds with daily practice, because the children appear to be dependent on having at least some help 
and guidance from their secondary school teachers, especially in the social context. Primary school teachers do not seem to realize the high demands that secondary education places on the autonomy and coping skills of children. Therefore, they do not pay sufficient attention to it during the preparation for secondary education.

In addition to poor preparation, we found that children may experience a less successful transition for other reasons. These include: personal and family characteristics, inappropriate school advice, improper parental involvement, no sense of belonging at secondary school, and a lack of possibilities to evaluate and adjust the transition process.

The expectations, experiences and perspectives of children and teachers do not necessarily have to match. Therefore, children's input can make a valuable contribution to understanding how they experience their school life and what is important to them (Mason \& Danby, 2011). If mentors were to involve children in matters that concerned them, and discuss them together with the children, the mentors might be able to find a way to help children become less dependent and more responsible. Furthermore, child participation could positively influence children's well-being, their development, and their mental health (Bru, Stornes, Munthe \& Thuen, 2010; Chung et al., 1998; Lundqvist, 2014; Waters et al., 2012), and thereby contribute to a smooth transition.

Secondary school teachers are conflicted whether it is better to be well-briefed or to know very little about the children and give them a fresh start (McGee, Ward, Gibbons \& Harlow, 2004). Ultimately, the mentors interviewed said that they preferred to give children the chance of a fresh start, albeit under certain conditions: they wanted to be informed about serious problems, such as disorders, bullying, or a difficult home situation. Although some parents may be reluctant to share such information, the absence of this sort of crucial information can cause children to have a false start in their new school. Those children might receive a higher school advice than they are able to handle, without their mentor being aware of it. When children cannot receive the guidance they are entitled to expect, they are unlikely to experience success in the transition from primary school to secondary school, which may lead to a false start. 
Samenvatting 


\section{Samenvatting}

Het is belangrijk dat de transitie van kinderen van het basisonderwijs naar voortgezet onderwijs soepel en succesvol verloopt. Problemen ten gevolge van deze transitie kunnen, zowel op korte als op lange termijn, een effect hebben op de schoolloopbaan van kinderen. Een slechte transitie kan leiden tot een negatieve spiraal van onderpresteren, minder motivatie en zelfs tot zitten blijven, uitstroom en- /of voortijdig schoolverlaten. De transitie heeft ook invloed op het welzijn en op de geestelijke gezondheid van kinderen (Korpershoek, Beijer, Spithoff, Naaijer, Timmermans, Van Rooijen, Vugteveen \& Opdenakker, 2016; Waters, Lester, Wenden \& Cross, 2012; Zeedijk, Gallacher, Henderson, Hope, Husband \& Lindsay, 2003).

Verschillende partijen zijn geïnteresseerd in en dragen bij aan een succesvolle transitie. In de eerste plaats hebben de kinderen er zelf baat bij. Het is belangrijk dat hun -cognitieve en nietcognitieve- ontwikkeling doorloopt en niet stagneert vanwege aanpassingsproblemen na de transitie. Ook de scholen die bij het proces betrokken zijn hebben belang bij een succesvolle transitie. Een succesvolle transitie zegt iets over de anticiperende capaciteiten (de voorbereiding) van de basisschool en over het adaptieve vermogen van de middelbare school. Ten slotte is de samenleving geïnteresseerd in een succesvolle transitie. Onderbenutting van talenten, 'uitval' - vanwege motivatieproblemen, verzuim of voortijdig falen - en onnodige uitstroom, brengen maatschappelijke kosten met zich mee die kunnen en moeten worden voorkomen (Bosch, Konermann, De Wit, Rutten \& Amsing, 2008).

Of kinderen een overgang als succesvol ervaren, hangt af van de mate waarin de basisschool van herkomst, samenwerkt met de middelbare school die de kinderen aanneemt. $\mathrm{Na}$ een succesvolle transitie voelen de kinderen zich thuis op de middelbare school en zijn ze gewend aan de nieuwe routines en aan de schoolorganisatie. Ze hebben vriendschappen gesloten, zijn geïnteresseerd in school en in het schoolwerk en ervaren continuïteit in het curriculum (doorlopende leerlijnen) (Evangelou, Taggart, Sylva, Melhuish, Sammons \& Siraj-Blatchford, 2008). In principe moet het voor reguliere kinderen mogelijk zijn om een soepele overgang te maken, maar in de praktijk is dit niet altijd het geval. Obstakels voor een goede overgang kunnen zich bijvoorbeeld voordoen wanneer de cognitieve of niet-cognitieve vaardigheden van een kind niet voldoende overeenkomen met het niveau dat vereist is in het voortgezet onderwijs of omdat de informatieoverdracht -over de kinderen door de basisschool aan de nieuwe school- onvoldoende is om de overgang met succes te kunnen maken, bijvoorbeeld wanneer een 'warme' overdracht ontbreekt (Korpershoek et al. 2016). 
$\mathrm{Er}$ is vanuit verschillende invalshoeken onderzoek gedaan naar de transitie van het basisonderwijs naar het voortgezet onderwijs. Desondanks is er weinig bekend over de bijdrage die de kinderen gedurende dit proces kunnen leveren aan het verstrekken van informatie over zichzelf. Als de hoofdpersonen in het transitieproces spelen de kinderen met hun verwachtingen, ervaringen en meningen, zoals ze die zelf formuleren, veelal slechts een ondergeschikte rol in onderzoek. Er is ook weinig onderzoek gedaan naar de ervaringen en meningen van de leerkrachten (de mentoren op de middelbare school) die de kinderen begeleiden tijdens het overgangsproces. Dit proefschrift draagt bij aan de kennis over de perceptie van de kinderen die de transitie maken naar de middelbare school en over de ervaringen van hun mentoren op de middelbare school.

\section{Een systematisch literatuuroverzicht}

In hoofdstuk twee onderzoeken we de wetenschappelijke literatuur systematisch naar relevant bewijs over de directe betrokkenheid van kinderen bij het transitieproces. Het doel van deze systematische review was vooral om aanknopingspunten en interventies te vinden die 'de kinderen een stem geven' en daardoor een bijdrage leveren aan een betere overgang.

We onderscheiden drie stakeholders die betrokken zijn bij het transitieproces: de kinderen en hun ouders, de basisschool en de middelbare school. Alle drie passen zij zich op hun eigen manier aan, aan de nieuwe omstandigheden en hebben ze hun eigen aanpak om het transitieproces te versoepelen. In de literatuur hebben we weinig bewijs gevonden van educatief partnerschap of van samenwerking tussen de stakeholders onderling. Hoewel zeer nauwe banden tussen leraren in het basis- en voortgezet onderwijs en communicatie tussen alle belanghebbenden essentieel zijn voor een succesvolle overgang (Coffey 2013; Green 1997; Jindal-Snape \& Miller 2008; Lester, Cross, Shaw \& Doole, 2012a) is dit in de praktijk niet zo vanzelfsprekend. Nauwe banden tussen de belanghebbenden kunnen hen bewust maken van kinderen die kwetsbaar zijn voor een slechte overgang (Chedzoy \& Burden 2005; Chung, Elias \& Schneider, 1998) maar de leraren die de kinderen voorbereiden op de overgang of hen na de overgang ondersteunen, hebben niet altijd voldoende informatie over de achtergrond van de kinderen, of beschikken over onvoldoende tijd en middelen om die informatie te delen.

Door persoonlijke factoren, zoals: capaciteiten, zelfrespect, depressie en angst, geslacht en door gezinskenmerken kunnen kinderen kwetsbaar zijn voor een slechte overgang (Rice, Frederickson \& Seymour, 2011). Familieachtergronden, inclusief culturele en sociaaleconomische factoren, kunnen specifieke overgangsproblemen veroorzaken. Kinderen uit arme en grote gezinnen en kinderen van laagopgeleide ouders 'doen het slechter' dan hun 
leeftijdsgenoten. De ouders van deze kinderen zijn minder vaak betrokken bij schoolactiviteiten en ondersteunen de school minder (Anderson et al. 2000; Topping 2011).

In de literatuur blijft de actieve rol van de kinderen tijdens de overgang naar het voortgezet onderwijs enigszins onderbelicht, omdat slechts enkele onderzoeken zijn gericht op het perspectief van de kinderen. Middelbare scholen kunnen wellicht van kinderen leren door kinderen te vragen wat hun gedachten over en ervaringen met de overgang zijn. Wanneer zij door de ogen van kinderen naar het onderwijs en naar het leren kijken, dan zijn leraren in de gelegenheid om strategieën ontwikkelen die gebaseerd zijn op bewijs uit de eerste hand en die hun pedagogische praktijk kunnen verbeteren.

\section{De visie van kinderen: verschillen tussen jongens en meisjes}

In hoofdstuk drie hebben we de visie van de kinderen op het transitieproces onderzocht. We waren geïnteresseerd in de prioriteiten die de kinderen stelden en of jongens en meisjes verschillende percepties, verwachtingen en ervaringen hadden met betrekking tot de overgang. Via een voor- en een nameting zijn gegevens verzameld voor het onderzoek. Twee identieke vragenlijsten werden door 98 kinderen ingevuld. De kinderen beantwoordden dezelfde vragen vóór de overgang en zes weken na de overgang, zowel vanuit een prospectief als vanuit een retrospectief oogpunt. De hoofdthema's in de vragenlijsten waren: schoolkeuze, voorbereiding op de middelbare school, de rol van de mentor, de overgang met leeftijdgenoten en verschillen in de context.

De studie is gebaseerd op de Zelfdeterminatietheorie (SDT; Ryan \& Deci, 2000). Om negatieve gevolgen van de overgang te voorkomen, is het belangrijk om de intrinsieke motivatie, de zelfregulatie en het welzijn van kinderen te verbeteren. De SDT onderscheidt drie psychologische basisbehoeften: competentie (ik kan het), autonomie (ik kan het zelfstandig doen) en verbondenheid (ik voel me verbonden, men geeft om mij). Vervulling van deze behoeften zal volgens de SDT leiden tot motivatie en tot welbevinden en plezier (Ryan \& Deci, 2000).

Aan dit onderzoek namen de kinderen actief deel door informatie te verstrekken. Dit is een manier om tegemoet te komen aan de behoefte van kinderen aan autonomie, competentie en verbondenheid (Hart, 2008) en dit kan een positieve invloed hebben op het zelfvertrouwen en op de sociale competenties.

De resultaten van ons onderzoek tonen aan dat de kinderen vóór de overgang vooral geïnteresseerd waren in de sociale omgeving op de middelbare school. Hun prioriteiten bij het kiezen van een middelbare school waren: een goede begeleiding door hun toekomstige 
leraren en de overgang samen kunnen maken met vrienden of kinderen die ze kennen. Meisjes maakten zich voor de transitie meer zorgen over de schoolcontext en hadden gemengde gevoelens over de sociale context, maar ze waren optimistischer over hun toekomstige klasgenoten dan jongens. Jongens waren, op een competitieve manier, meer geïnteresseerd in de nieuwe dingen die ze gingen leren, in laten zien wat ze al hadden geleerd en laten zien dat ze goed konden presteren. Meer dan de jongens waardeerden meisjes de mogelijkheid om met de mentor te praten. De jongens in onze steekproef scoorden echter ook hoog op dit item. Alle kinderen verwachtten dat hun mentor aardig is, aanwezig wanneer je hem of haar nodig hebt, competent en beschikbaar voor een goed gesprek.

$\mathrm{Na}$ acht weken op de middelbare school hadden de meeste kinderen in onze steekproef hun weg gevonden op school. Vrienden hebben was belangrijk voor alle kinderen. De kinderen beseften dat ze in eerste instantie het belang van de sociaal-emotionele aspecten bij de overgang hadden onderschat en dat ze niet voldoende waren voorbereid om de sociale en emotionele uitdagingen tijdens de overgang succesvol aan te gaan. Volgen de SDT maakt het gebrek aan vaardigheden om zelfstandig om te kunnen gaan met de sociale omgeving de kinderen afhankelijk van de steun van hun mentor en minder competent om uitdagingen in de sociale emotionele context zelfstandig aan te gaan. Dit kan gevolgen hebben voor de begeleiding door hun mentor en kan de eerder waargenomen behoefte aan mentor-nabijheid verklaren.

\section{Plezier en angst in de schoolomgeving en in de sociale context}

Er zijn veel verschillen tussen primair en voortgezet onderwijs. Tijdens de overgang hebben de kinderen te maken met veranderingen in zowel de school- als in de sociale context (Green 1997). Ze moeten nieuwe relaties aangaan met hun leeftijdsgenoten en ook met de leraren op de middelbare school (Tobbell en O'Donnell, 2013). Leraren kunnen een belangrijke rol spelen bij het begeleiden en ondersteunen van kinderen tijdens de overgang. Positieve relaties met leerkrachten en adequate ondersteuning kunnen een positief effect hebben op het leren van kinderen, zowel op hun academische prestaties als op hun welzijn (Ellerbrock, Abbas \& DiCicco, 2014).

De inbreng van kinderen kan een waardevolle bijdrage leveren om te begrijpen hoe ze hun schoolleven ervaren en leraren - met name klassenmentoren - hebben de mogelijkheid om deze informatie te interpreteren en te gebruiken om hun pedagogische praktijk te verbeteren (Ferguson, Handreddy \& Draxton, 2011) en daarmee de overgang te vergemakkelijken. In hoofdstuk 4 hebben we onderzocht of kinderen die kwetsbaar zijn voor een slechte transitie 
een betere transitie maken wanneer hun mentor zich er beter van bewust is wat de kinderen denken dat ze nodig hebben.

We onderzochten de zorgen, verwachtingen en ervaringen van 371 kinderen via een vragenlijst die de kinderen voor en na de transitie invulden en gebruikten deze informatie om de mentor te informeren We keken naar het plezier en de angst van de kinderen in de schoolcontext en in de sociale context. Om uitdagingen en bedreigingen van 24 aspecten met betrekking tot de transitie in zowel de school- als in de sociale context te meten, is de vragenlijst 'The Impending Transition to Secondary Perceived as Challenge and Threat' (ITCT, Sirsch, 2003) vertaald en aangepast. Daarnaast werd er een blind experiment uitgevoerd om vast te stellen of informatie van de kinderen voor de mentor effect had op de overgang. Voor dit experiment werden kinderen die voor de transitie de vragenlijst hadden ingevuld willekeurig toegewezen aan een controlegroep $(n=189)$ of aan een interventiegroep $(n=182)$. Mentoren van de kinderen die waren toegewezen aan de interventiegroep ontvingen een kopie van de vragenlijst die 'hun' kinderen voor de transitie hadden ingevuld. Mentoren van kinderen in de controlegroep ontvingen deze informatie niet. Ervan uitgaande dat mentoren de informatie gebruikten om een soepele overgang te creëren, verwachtten we dat de kinderen in de interventiegroep een betere overgang zouden maken dan de kinderen in de controlegroep.

We ontdekten dat mentoren de door de kinderen verstrekte informatie nauwelijks gebruikten. De interventie had slechts een klein effect op de sociale context op het significantieniveau van $10 \%$. Kinderen waarvan de mentor informatie had ontvangen - de interventiegroep - hadden na de overgang minder angst voor leeftijdgenoten dan de kinderen in de controlegroep. Verrassend genoeg ervoeren ze ook minder plezier met leeftijdsgenoten. De interventie had geen significant effect op angst of plezier in schoolwerk, noch op angst of plezier in de schoolcontext. Bovendien bleek uit de post-hoc controle voor statistische power dat, vanwege de lage statistische power, er een kans is dat we onze hypothese ten onrechte verwerpen. Over het algemeen leken de resultaten van de interventie het verloop van het overgangsproces nauwelijks te beïnvloeden.

Op basis van de informatie van de kinderen identificeerden we drie groepen kinderen die kwetsbaar kunnen zijn voor een slechte overgang. De eerste groep, de meisjes, viel op omdat ze na de overgang aanzienlijk meer angst rapporteerden, vooral voor schoolwerk, dan de jongens. De tweede kwetsbare groep is de groep kinderen met speciale onderwijsbehoeften (SEN). In vergelijking met kinderen zonder SEN vertonen ze een gemengd beeld. Deze kinderen maakten zich, meer dan hun leeftijdsgenoten, zorgen over de sociale context, vooral over leeftijdsgenoten. $\mathrm{Na}$ de overgang was de angst voor de schoolcontext significant lager voor kinderen met SEN, op het niveau van $10 \%$, maar was de angst voor leeftijdsgenoten 
aanzienlijk hoger op het niveau van $10 \%$. Een derde groep die opvalt zijn kinderen die al angstig zijn voor de overgang. Zowel in de sociale context als in de schoolcontext vonden we angst (en plezier) belangrijke betrouwbare voorspellers. Hoewel de verschillen tussen de scores voor en na de overgang voor respectievelijk angst (of plezier) kleiner zijn geworden, bleven deze kinderen na de overgang angstig. Deze bevindingen tonen aan dat het nodig is om kwetsbare en angstige kinderen de kans te geven om hun mening met hun leraren te delen en dat leraren zich niet alleen bewust dienen te zijn van de impact van de overgang op kinderen, maar ook van het feit dat het kennisnemen van het perspectief van de kinderen, een voorwaarde is om hen te kunnen helpen.

\section{Ondersteuning van de mentor}

Passende ondersteuning door leraren leidt tot betere prestaties bij leerlingen (Ganeson \& Ehrich 2009). Om de mentoren in staat te stellen de kinderen te ondersteunen, hebben zij zelf steun nodig, meestal in de vorm van informatie over de kinderen in hun klas. In hoofdstuk 5 onderzochten we, via 4 focus- interviews en 1 individueel interview, of en hoe 17 brugklasmentoren van 4 middelbare scholen, werden gevoed met informatie over de leerlingen in hun klas, zowel voor als nadat de kinderen de transitie naar de middelbare school hadden gemaakt. We onderzochten of en hoe mentoren werden gefaciliteerd om actie te ondernemen en welke acties er door de mentoren, op basis van de informatie die ze hadden ontvangen, zijn ondernomen.

Volgens de mentoren spelen de kinderen voordat de transitie plaatsvindt geen directe rol in het overleg. Er wordt alleen over kinderen gesproken en er worden beslissingen genomen namens kinderen, maar er is geen rechtstreeks contact met hen. Tot de zomervakantie verzamelden de meeste mentoren uit ons onderzoek nauwelijks actief zelf informatie. Meestal ontvingen ze een korte samenvatting met de meest dringende informatie over de kinderen van hun nieuwe klas.

De mentoren zijn het erover eens dat communicatie tussen leraren in het basis- en voortgezet onderwijs van vitaal belang is om de overgang te verbeteren (Korpershoek et al. 2016; Topping 2011; West, Sweeting \& Young, 2010). Ze zijn tevreden over de kwaliteit, betrouwbaarheid en bruikbaarheid van de informatie die ze ontvangen via direct persoonlijk contact met de leraren in het basisonderwijs, de zogenaamde 'warme overdracht'. Mentoren zijn minder tevreden over de manier waarop de leerlingen worden voorbereid op de middelbare school, over de kwaliteit van het schooladvies en over de inhoud van het onderwijskundig rapport dat ze van de basisschool ontvangen. Ze zijn er ook ontevreden over dat een aantal leraren in het 
basisonderwijs onvoldoende wordt gefaciliteerd om de mentoren in het voortgezet onderwijs te ontmoeten voor een gesprek of voor feedback.

Het schooladvies is niet altijd puur gebaseerd op de mogelijkheden van de kinderen. Sommige scholen geven een te hoog advies omdat de eisen van het voortgezet onderwijs onbekend zijn of omdat ze het jammer (zielig voor het kind) vinden wanneer een kind op een lager niveau instroomt. Ouders bemoeien zich er soms ook mee. Ze komen tussenbeide, omdat ze denken dat hun kind een kans verdient om onderwijs op een hoger niveau -dan geadviseerd werd- te volgen. De ouders kunnen, om dit te bereiken, erop staan dat belangrijke informatie over hun kind wordt achtergehouden. Het is volgens de Europese privacywetgeving verboden voor scholen om informatie over kinderen te verstrekken zonder de toestemming van de ouders.

De geïnterviewde mentoren betwijfelen of de leerkrachten van groep 8 in het primair onderwijs voldoende op de hoogte zijn van de onderwijspraktijken in het voortgezet onderwijs. Ze vragen zich af of leraren in het basisonderwijs zich bij hun voorbereiding bewust zijn van de eisen van het voortgezet onderwijs en of zij de kinderen adequaat ondersteunen bij het ontwikkelen van voldoende onafhankelijkheid en zelfstandigheid om aan die eisen te voldoen. Ondanks het feit dat kinderen assertiever zijn, merken mentoren op dat ze ook steeds meer afhankelijk zijn van hulp bij het oplossen van hun sociale emotionele problemen die ontstaan door een gebrek aan sociale vaardigheden. De mentoren merken op dat ouders ook een rol zouden moeten spelen in het ondersteunen van hun kinderen bij het ontwikkelen van sociale en emotionele vaardigheden. Dit moet niet alleen een taak voor school zijn, maar voor alle opvoeders, inclusief ouders.

Om bovengenoemde problemen aan te pakken, is het nodig dat alle belanghebbenden nog beter samenwerken en dat ouders en kinderen een rol als gelijkwaardige partners in het overgangsproces gaan spelen. Een dergelijke samenwerking kan aanzienlijk worden verbeterd als ouders en kinderen als gelijkwaardige partners aan het overgangsproces deel kunnen nemen.

\section{Conclusies}

De belangrijkste conclusies uit de literatuurstudie en de empirische studies hebben geleid tot de formulering van vijf stellingen, die hieronder kort worden samengevat.

De overgang is een school overschrijdend fenomeen; het is een continu proces dat begint op de basisschool en doorgaat totdat de kinderen gewend raken aan hun middelbare school en zich 'op hun plaats voelen' in het voortgezet onderwijs. Het basisonderwijs sluit meestal niet naadloos aan op het voortgezet onderwijs. De kinderen moeten leren hoe ze de verschillen 
tussen de basisschool en de middelbare school kunnen overbruggen, hoe ze zich moeten aanpassen aan de nieuwe regels, manieren en gewoonten van het voortgezet onderwijs, hoe ze zich moeten gedragen en wat ze wel of niet moeten doen.

Vanwege het school overschrijdende karakter moeten leerkrachten aan beide zijden van de overgang samenwerken om een soepele overgang en continuïteit in de ontwikkeling van de kinderen te waarborgen (Anderson et al., 2000). In de praktijk is die samenwerking meestal beperkt tot het uitwisselen van informatie over het curriculum, in plaats het uitwisselen van informatie over individuele kinderen (Topping, 2011).

De voorwaarde voor een succesvolle overgang is een goede voorbereiding op de basisschool, die voldoet aan de verwachtingen van de middelbare school. Mentoren verwachten dat kinderen die naar het voortgezet onderwijs gaan, een zekere mate van onafhankelijkheid hebben verworven. Helaas staat dit haaks op de dagelijkse praktijk, omdat de kinderen vooral in de sociale context afhankelijk lijken te zijn van hulp en begeleiding van hun leraren in het voortgezet onderwijs. Leerkrachten in het basisonderwijs lijken zich de hoge eisen die het voortgezet onderwijs stelt aan de autonomie en de sociale vaardigheden van kinderen niet te realiseren. Daarom besteden ze er onvoldoende aandacht aan tijdens de voorbereiding.

We hebben geconstateerd dat kinderen, behalve door een slechte voorbereiding ook om andere redenen een minder succesvolle transitie kunnen ervaren. Persoonlijke en gezinskenmerken, een schooladvies wat niet past bij de mogelijkheden van een kind, weinig ouderbetrokkenheid, zich niet betrokken voelen bij de middelbare school en de beperkte mogelijkheden om het overgangsproces te evalueren en aan te passen kunnen er de oorzaak van zijn dat een soepele transitie wordt belemmerd.

De verwachtingen, ervaringen en perspectieven van kinderen en leerkrachten hoeven niet overeen te komen. Daarom kan de inbreng van kinderen, -over hoe zij hun schoolleven ervaren en wat belangrijk voor hen is-, er een waardevolle aan bijdrage leveren om begrip bij hun mentoren te bewerkstelligen (Mason \& Danby, 2011). Als mentoren kinderen betrekken bij zaken die hen aangaan en die zaken samen met de kinderen bespreken, kunnen de mentoren misschien een manier vinden om kinderen te helpen om minder afhankelijk en meer verantwoordelijk/ zelfstandig te worden. Kinderparticipatie kan bovendien een positieve invloed hebben op het welzijn van kinderen, op hun ontwikkeling en hun mentale gezondheid (Bru, Stornes, Munthe \& Thuen, 2010; Chung et al., 1998; Lundqvist, 2014; Waters et al., 2012), en kan daardoor bijdragen aan een soepele overgang.

Leraren in het voortgezet onderwijs twijfelen erover of het beter is om, voordat kinderen de overstap maken, goed geïnformeerd te zijn of om juist heel weinig over de kinderen te weten om ze een frisse start te geven (McGee, Ward, Gibbons \& Harlow, 2004). De geïnterviewde 
mentoren wilden kinderen de kans geven op een nieuwe start, zij het onder bepaalde voorwaarden: ze wilden geïnformeerd worden over ernstige problemen, zoals de behoefte aan speciale zorg of begeleiding, een pestverleden of een moeilijke thuissituatie. Hoewel sommige ouders misschien terughoudend zijn om dergelijke informatie te delen, kan het achterhouden ervan ertoe leiden dat kinderen een valse start maken op hun nieuwe school. Die kinderen zullen dan in het voortgezet onderwijs instromen met een hoger schooladvies dan ze aankunnen, zonder dat hun mentor hiervan op de hoogte is. Wanneer kinderen door gebrek aan essentiële voorinformatie niet de begeleiding krijgen die ze mogen verwachten, dan is het onwaarschijnlijk dat ze succes zullen ervaren bij de overgang van basisschool naar middelbare school, wat kan leiden tot een valse start. 
Curriculum Vitae 


\section{Curriculum Vitae}

Marlau van Rens was born in 1954 in Meijel, the Netherlands. She graduated in 1975 with a teacher diploma from the Pedagogische Academie dr. Van Gils in Roermond, and in 1980 she obtained a second-degree teacher qualification in visual arts from the Gelderse Leergangen in Nijmegen.

Before graduating from the Gelderse Leergangen, Marlau van Rens obtained a job as a drawing teacher at HNO Sint Anna in Venlo (later called Onderwijsgemeenschap Venlo). She offered drawing lessons in both vocational (individual) education (VMBO and IHNO) and secondary vocational education (K) MBO.

In 1992, Marlau van Rens was appointed as coordinating teacher at the kindergarten Peuterspeelzaal ut Debberke in Meijel. In 1998, she combined this job with a part-time position at the practical school Praktijkschool Het Nieuwveld in Helmond (now called Praktijkschool Helmond). The working time factor at the practical school was then expanded. In 2000, Marlau van Rens bid goodbye to the kindergarten.

At the practical school, Marlau van Rens taught theoretical subjects (arithmetic, Dutch language, training in social skills) and a practical subject (drawing). She also became the grade seven mentor for the first time. In addition to her job, Marlau van Rens started studying pedagogy at the Fontys University of Applied Sciences in Sittard. She was awarded a Bachelor of Education (B.Ed.) in 2004, and a Master of Education (M.Ed.) in 2006.

In 2006, Marlau van Rens was appointed to het Seminarum voor Orthopedagogiek at Utrecht University of Applied Sciences as a part-time teacher for the Masters of Special Educational Needs (SEN) in Valkenburg. In 2007, she made the transition from the practical school to the ambulatory service of Stichting Speciaal Onderwijs Noord en Midden Limburg (SSONML, currently Onderwijsgroep Buitengewoon) in Venlo, where Marlau van Rens worked as an ambulatory counsellor and educational advisor in primary education, secondary education and secondary vocational education until 2019. Since 2016, Marlau van Rens has also worked for the Teachers Development Fund (LerarenOntwikkelFonds/ LOF), where she coaches fellow teachers from primary and secondary education in the province of Noord-Brabant, who have received a grant to implement an innovative idea in their daily practice.

In addition to her work in the education sector, Marlau van Rens started another masters level study in 2011: a Master in Evidence-Based Innovation in Teaching (MEBIT) at the Top Institute for Evidence-Based Education Research (TIER) at Maastricht University. In 2013, Marlau van 
Rens was awarded a Master of Science degree. Her graduation research provided Marlau van Rens with the stimulus to embark on her latest challenge, $\mathrm{PhD}$ research into the transition from primary to secondary education from the perspective of the children and the teachers. 


\section{Dankwoord}

Het proefschrift is af, mijn promotietraject afgerond. Ik ben blij dat het werk erop zit. Het was leuk, een uitdaging die ik meestal met veel plezier -en soms met frisse tegenzin- ben aangegaan. We hebben het samen gefikst. Sommige vragen zijn beantwoord, andere moeten nog onderzocht worden. Het is nu tijd om iedereen te bedanken die mij heeft geholpen om zover te komen.

Mijn ouders zorgden voor een goede basis. In een tijd waarin het voor velen nog niet vanzelfsprekend was dat een meisje ging studeren, zeker niet wanneer zij de oudste was van een groot gezin, gaven zij mij de kans en de ruimte om te doen wat ik leuk vond, waar ik goed in was en waar ik verder mee kon. Ze leerden mij onder andere om de minder leuke dingen niet uit de weg te gaan, af te maken waaraan je begint en niet af te gaan op wat men vindt maar een eigen oordeel te vormen. Daar ben ik hen dankbaar voor.

Eigenlijk kwam het nooit in me op om te promoveren. Wim Groot, heeft me gestimuleerd om deze uitdaging aan te gaan. Als een vreemde eend in de bijt kwam ik, na het afronden van de Master-studie MEBIT, via Wim, terecht bij TIER. Een buitenpromovendus, niet bekend met en onwetend over de gebruiken en de gewoonten binnen de academische wereld, een exoot. Wim beloofde dat ik het traject niet in mijn eentje hoefde af te leggen. Hij hield woord en introduceerde Henriëtte Maassen van den Brink en later ook Carla Haelermans.

Wim, je hebt me altijd geholpen wanneer dat nodig was. Je liet me zelf de oplossingen zoeken -en vinden- voor de problemen die ik tegenkwam. Wanneer die oplossingen anders uitvielen dan jij wellicht had verwacht dan hielp je me om mijn spoor te volgen en mocht het 'niet sporen' dan gaf je dat duidelijk aan. Dank je wel, dat je altijd -en snel- reageert op mijn vragen, positief bent ingesteld en meeleeft wanneer er iets te vragen, te vieren of te mopperen valt! Henriëtte, jouw frisse kijk op het onderzoek heeft me scherper gemaakt. Jij en Wim zijn het vaak met elkaar eens, vaak ook niet. Dat maakte dat ik me nog meer bewust werd van het belang van het maken van beredeneerde en beargumenteerde keuzes. Hartelijk dank daarvoor. Carla, dank je wel voor je hulp en je nauwgezetheid. Jij vond vaak net dat allerlaatste foutje in mijn paper. Je hebt me meermaals gewaarschuwd voor de beren die een onderzoeker op haar weg tegenkomt. Zelf maakte ik me weinig zorgen. Mijn werk en mijn onderzoek vonden buiten de universiteit plaats, op de scholen.

De hoofdpersonen in mijn onderzoek zijn de schoolverlaters van groep acht en hun mentoren in de brugklas, in het bijzonder de mentoren die hebben deelgenomen aan de focus interviews. Hen en hun afdelingsleiders wil ik speciaal bedanken omdat ik nooit tevergeefs een beroep op hen deed. Jullie maakten tijd voor mij en hebben me aan alle informatie geholpen die ik nodig had om antwoorden te vinden op mijn onderzoeksvragen. 
Verder wil ik iedereen bedanken die een bijdrage leverde aan mijn onderzoek en aan het tot stand komen van mijn thesis: Lynne Kocen voor haar hulp als editor en de leden van de leescommissie voor hun kritische commentaar en feedback. Theo Dersjant, die me beter heeft leren interviewen, Peter Beelen voor het digitaliseren van de vragenlijsten en Leo Tittulaer voor zijn hulp bij de opmaak van mijn thesis.

Tot slot bedank ik mijn familie voor hun mentale steun, Birgitte voor haar oprechte belangstelling en tips en mijn man en kinderen voor hun nuchtere commentaren. Twan, dank je wel voor je hulp als ik weer eens in gevecht was met de computer, Juul en Luuk, hartelijk bedankt voor jullie vertrouwen in mijn kunnen, Jan bedankt voor het laatste duwtje in mijn rug. 


\section{TIER Research Series}

I. C. Haelermans (2012). On the productivity and efficiency of education. The role of innovations in Dutch secondary education.

II. L. van Welie (2013). They will get there! Studies on educational performance of immigrant youth in the Netherlands.

III. S. Cabus (2013). An economic perspective on school dropout prevention using microeconometric techniques.

IV. I. Cornelisz (2013). School choice, competition and achievement: Dutch compulsory education.

V. M. Heers (2014). The effectiveness of community schools: Evidence from the Netherlands.

VI. N. Ruijs (2014). Empirical studies in the economics of education.

VII. D. Bartelet (2015). Basic mathematics skills development in children: An evaluative study on cognitive and educational factors.

VIII. I. Rud (2015). The relationship between youth crime and education.

IX. J. Coenen (2016). Teacher characteristics and student performance.

X. D. Hidalgo Saá (2017). Essays in Economics of education and training.

XI. E. Sneyers (2017). What works to improve student success: The effects of academic dismissal policies, student grants, and institutional mergers on student outcomes.

XII. R. Ariës (2018). An evidence-based approach to working-memory-based training in secondary education to improve reasoning test achievements.

XIII. F. H. G. Haan (2018). In pursuit of excellence: Four (natural) experiments in the economics of education.

XIV. M. A. Somers (2020). Human Capital Mismatch in the Labour Market.

$X V$. M. van Rens (2020). The transition from primary to secondary education: A study of the voices of children and teachers in the Netherlands. 